University of Louisville

ThinkIR: The University of Louisville's Institutional Repository

$5-2008$

\title{
Job satisfaction levels of juvenile detention education faculties and the implementation of best teaching practices compared to overall program efficacy.
}

Rebecca Minton Painter 1958-

University of Louisville

Follow this and additional works at: https://ir.library.louisville.edu/etd

\section{Recommended Citation}

Painter, Rebecca Minton 1958-, "Job satisfaction levels of juvenile detention education faculties and the implementation of best teaching practices compared to overall program efficacy." (2008). Electronic Theses and Dissertations. Paper 1090.

https://doi.org/10.18297/etd/1090

This Doctoral Dissertation is brought to you for free and open access by ThinkIR: The University of Louisville's Institutional Repository. It has been accepted for inclusion in Electronic Theses and Dissertations by an authorized administrator of ThinkIR: The University of Louisville's Institutional Repository. This title appears here courtesy of the author, who has retained all other copyrights. For more information, please contact thinkir@louisville.edu. 


\title{
JOB SATISFACTION LEVELS OF JUVENILE DETENTION EDUCATION
}

\section{FACULTIES AND THE IMPLEMENTATION OF BEST TEACHING PRACTICES}

COMPARED TO OVERALL PROGRAM EFFICACY

\author{
By \\ Rebecca Minton Painter \\ B.S., Western Kentucky University, 1980 \\ M.A.E., Western Kentucky University, 1987

\begin{abstract}
A Dissertation
Submitted to the Faculty of the Graduate School of the University of Louisville in Partial Fulfillment of the Requirements

For the Degree of
\end{abstract}

Doctor of Philosophy

Department of Leadership, Foundations and Human Resources Education University of Louisville

Louisville, Kentucky

in cooperation with

Department of Educational Administration, Leadership, and Research

Western Kentucky University

Bowling Green, Kentucky

May, 2008 
Copyright 2008 by Rebecca M. Painter

All rights reserved 
JOB SATISFACTION LEVELS OF JUVENILE DETENTION EDUCATION FACULTIES AND THE IMPLEMENTATION OF BEST TEACHING PRACTICES COMPARED TO OVERALL PROGRAM EFFICACY

\author{
By \\ Rebecca Minton Painter \\ B.S., Western Kentucky University, 1980 \\ M.A.E., Western Kentucky University, 1987 \\ Rank I, Western Kentucky University, 1998 \\ A Dissertation Approved on
}

March 31, 2008

By the following Dissertation Committee:

Dissertation Director 


\section{DEDICATION}

This work is dedicated to a host of individuals who have empowered me throughout the adventure of creating a dissertation. First, I would like to dedicate this work to the memory of my late husband, Kenneth Painter. Kenny always told me he wanted to be married to a doctor. Even though our marriage has moved into another realm, I am confident that he is aware of my finally completing this educational milestone. Second, I dedicate this work to my parents, Hobert and Irene Minton. They were children of the depression and were determined to give their children an education. Third, I dedicate this work to my children, Rheanna, Charles, and Caden. It is really hard to deal with a mother, mother-in-law, and Granna who is still going to school at this point in her life! Fourth, I dedicate this work to my friends who have provided research assistance, advice, legal interpretations, editing, and a sympathetic ear, Sandra, Olivia, and Don. Fifth, I dedicate this work to my advisor, Dr. Christopher R. Wagner. He and I have had a long academic journey from Master's work in 1987, with Dr. H. Dwight Cline, through 1998 with Rank I work in Educational Administration, and in 2008 with a Doctorate of Philosophy program. 


\section{ACKNOWLEDGEMENTS}

Special thanks go to Dr. Christopher R. Wagner, who chaired the dissertation committee. He provided professional guidance through the hazy environs of the collaborative WKU/UofL doctorate program of study for Educational Administration and leadership. He has been a staunch supporter of all of my academic endeavors since our 1985 introduction by Dr. H. Dwight Cline. I value our professional relationship and appreciate the friendship these challenges have forged.

In addition to the chair, I have been fortunate to work with a very strong professional team of committee members. Dr. Jeanne R. Fiene, Dr. Edward W. Bohlander, Jr., Dr. Joseph M. Petrosko, and Dr. Thaddeus Dumas have each played an important role in the dissertation process. Dr. Fiene provided a strong professional example, Dr. Bohlander provided an informed juvenile justice connection, Dr. Petrosko provided valuable $\mathrm{U}$ of $\mathrm{L}$ authentication and statistical analysis expertise, and Dr. Dumas stepped in to fill a vacancy left by a departing $U$ of $L$ committee member. Furthermore, $I$ appreciate the contributions and statistical support of Dr. John R. Bruni who provided me with invaluable statistical analysis and interpretation. His assistance was priceless in completing Chapter Four of this study.

Last, but not least, I have to thank my students. They provided the real-life connection for this work and reinforced my determination to complete the project in order to improve their lot. Our facility motto is, Yesterday is history. Tomorrow is a 
mystery. Today is a gift. Unfortunately, the only gift I can give them (my Happy Hamsters) is hope through education.

\section{Happy Hamsters}

Constantly running yet sadly going nowhere,

Stopping only to eat, drink, and sleep,

Large faces stare, poke and prod, they do not care.

If only they knew, I lie in my bed and weep.

When they reach in and give me a squeeze,

I bite fearfully and give a defiant squeak.

How I wish to leave this plastic prison and feel a breeze.

I try to escape yet I'm always foiled.

I suppose I'm just weak.

Mr. A.

(Warren Regional Juvenile Detention Center Resident)

"Verily I say unto you, inasmuch as ye have done it unto one of the least of these my brethren, ye have done it unto me." Matthew 25: 40. 


\section{ABSTRACT \\ JOB SATISFACTION LEVELS OF JUVENILE DETENTION EDUCATION \\ FACULTIES AND THE IMPLEMENTATION OF BEST TEACHING PRACTICES COMPARED TO OVERALL PROGRAM EFFICACY

\author{
Rebecca Minton Painter \\ May $9 \& 10,2008$
}

Federal legislation in 1992, entitled the Juvenile Justice Delinquency Prevention Act, reordered many of the previous methods employed in the detention of juvenile offenders. Among the reform measures required by the act, there was a mandate to separate adult and juvenile offenders, provide educational opportunities, and establish a process for ensuring juvenile rights. The shift in emphasis from simply incarcerating young offenders to providing educationally sound programs, including both academic and life skills, continues to be a challenging concept. Even though the legislation was passed in 1992, not all juvenile detention facilities have adopted every reform measure. One of the purposes of this study is to examine the possible relationship between job satisfaction levels of juvenile detention faculties and their use of best teaching practices.

Juvenile arrests for violent crimes ranged from an all time high of over 500 per 100,000 juveniles in 1994 to approximately 300 per 100,000 in the year 2000 . In 1997 , there were over 100, 000 juveniles in custody in the United States in one type of facility or another. A study conducted by associates from the Office of Juvenile Justice and Delinquency Prevention found that more than seventy-five percent of the confined population was being housed in facilities that were not adequately staffed and 
violated at least one regulation relating to living space and/or failure to provide educational opportunities. A large percentage of juveniles in detention also have alcohol, drug, and mental health disorders which, if left untreated, will likely lead to their continued participation in the juvenile and later adult justice systems. With the Juvenile Justice Delinquency Prevention Act (JJDPA) of 1992, the issue of over population was addressed, but the specifics of education were open to interpretation.

This study expands the present knowledge base for developing a successful educational program at Juvenile Detention Centers in Kentucky. Job Satisfaction and Best Teaching Practices were significantly related with strong correlations among facility and teaching practices. This finding suggested the need for administration of facilities and faculties to be united in their programming efforts. One disappointment from the findings revealed that Kentucky Educational Collaborative for State Agency Children (KECSAC) employs a state evaluation tool, which is not sufficient to evaluate program efficacy.

It is a commonly accepted fact that without effective evaluation, there can be no accountability. According to Quint Studer (2004), founder and CEO of the Studer Groups, "The most satisfied employees work in organizations that have systems and processes in place that are designed to sustain service and operational excellence." While KECSAC attempts to evaluate programs, their instrument has not been tested for validity or reliability, and the researcher was unable to find a correlations among it and the other two explored factors, job satisfaction and/or the implementation of best practices. 


\section{TABLE OF CONTENTS}

PAGE

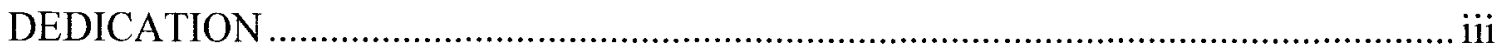

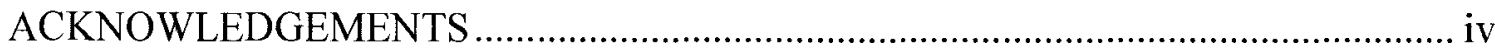

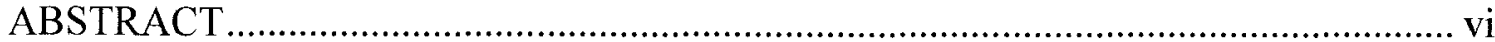

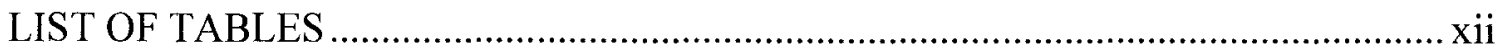

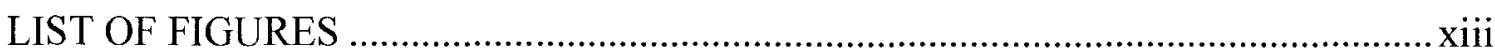

CHAPTER

I. INTRODUCTION

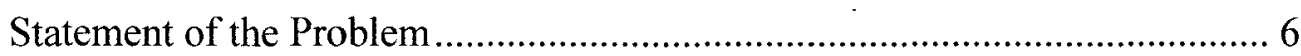

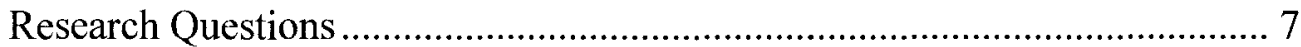

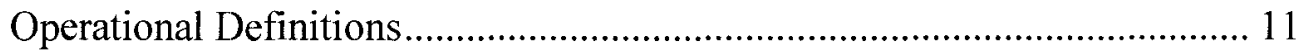

Purpose and Significance of the Study ..................................................... 12

National Historical Summary ………………………............................... 14

The Ideal Juvenile Justice System .............................................................. 21

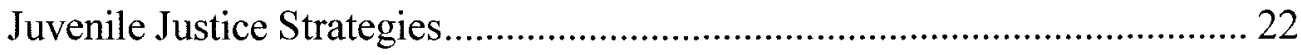

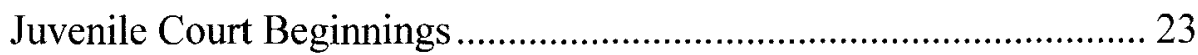

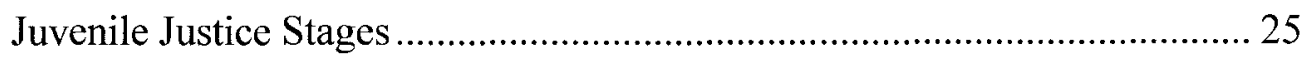

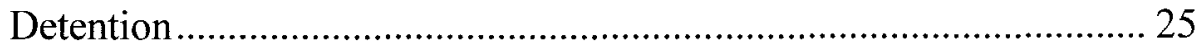

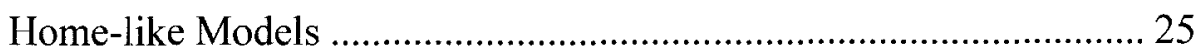

Hospital Architectural Persona ............................................................ 25

Beginning Juvenile Detention Facilities .............................................. 26

Kentucky Historical Summary .................................................................... 27 


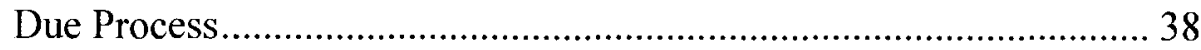

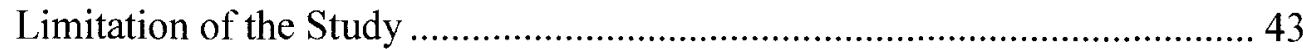

Definitions Used in the Study .......................................................................... 45

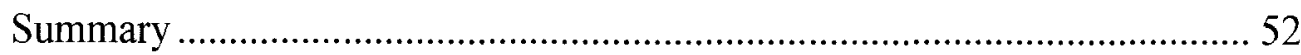

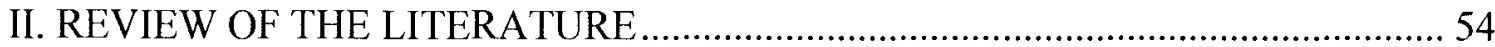

Definition of At-Risk, Juvenile Delinquents.................................................... 57

Essential Needs Factors .................................................................... 57

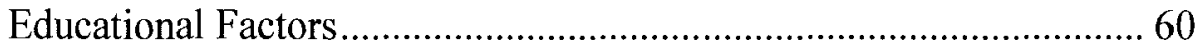

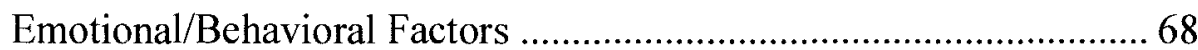

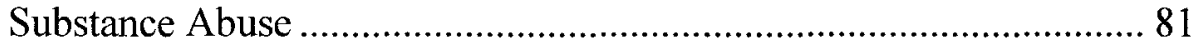

Educating At-Risk Juvenile Delinquents .................................................... 87

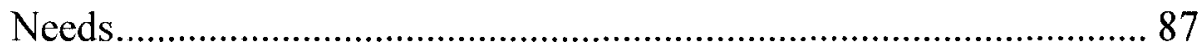

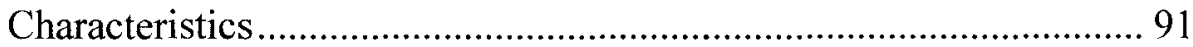

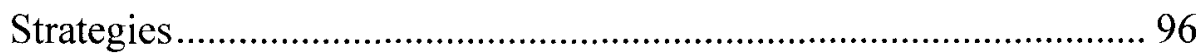

Developing the Self Concept of At-Risk/Juvenile Delinquents................... 135

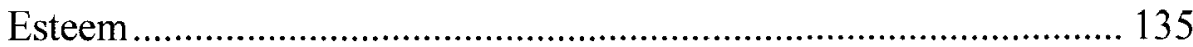

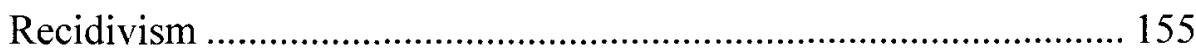

Essential Attributes of the Effective Detention Center Educator ................. 178

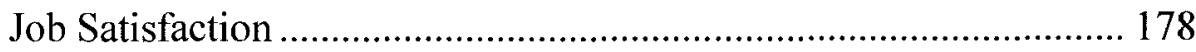

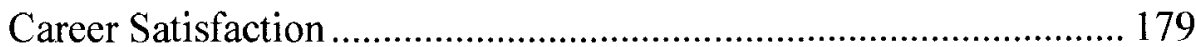

Teacher Autonomy and Stress ....................................................... 181

Teacher Self Esteem and Performance ............................................ 183 


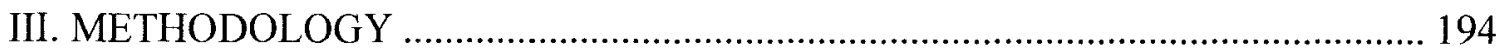

Research Questions and Study Design ....................................................... 196

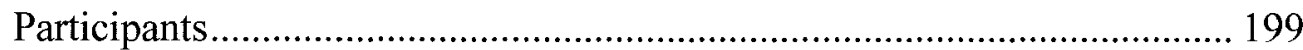

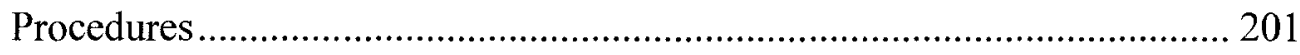

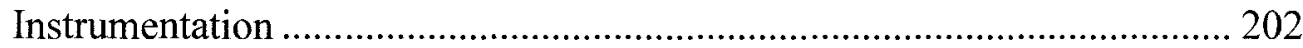

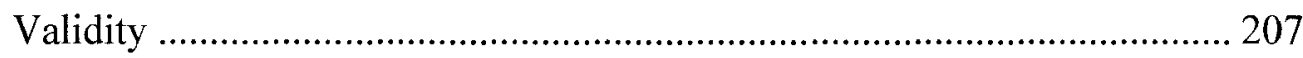

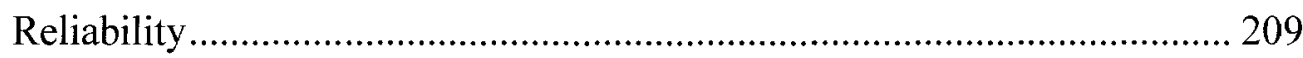

Data Analysis ....................................................................................... 210

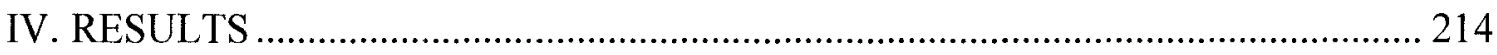

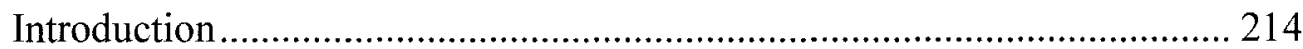

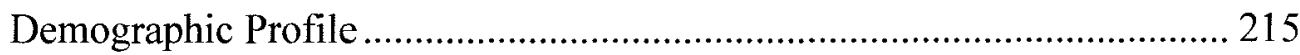

Minnesota Satisfaction Questionnaire Data Summary ............................... 215

Best Practices Survey Data Summary ...................................................... 218

KECSAC Program Improvement Tool Data Summary ............................... 221

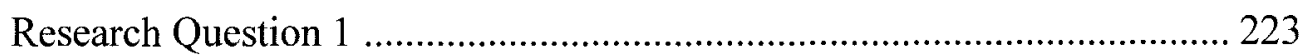

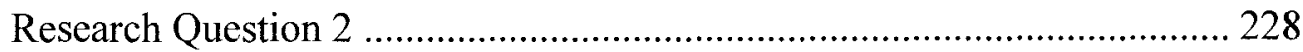

Research Question 3 ...................................................................... 230

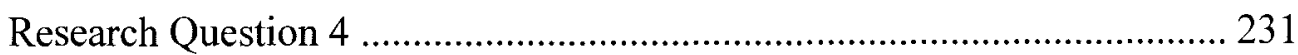

V. DISCUSSIONS, CONCLUSIONS, AND RECOMMENDATIONS........................ 234

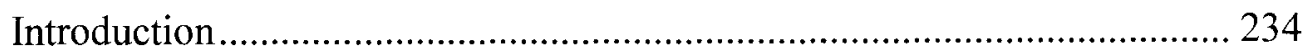

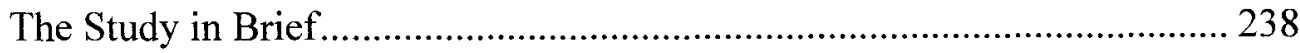


Kentucky Educational Collaborative for State Agency Children ...... 240

Summary 242

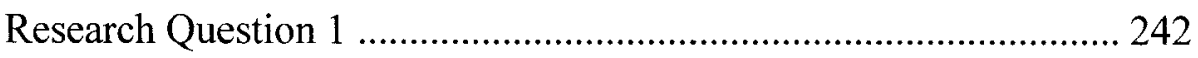

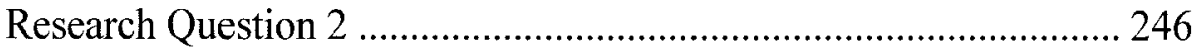

Research Question 3 ................................................................ 247

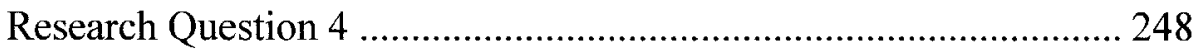

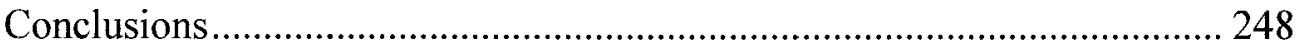

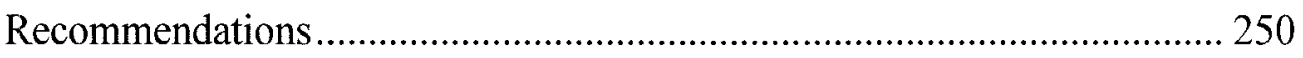

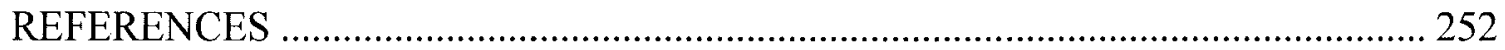

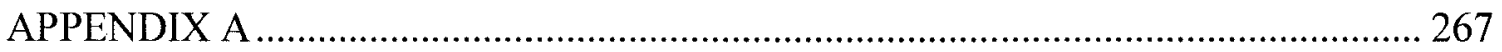

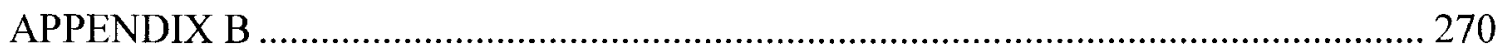

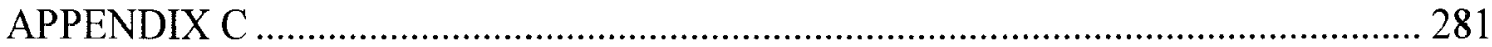

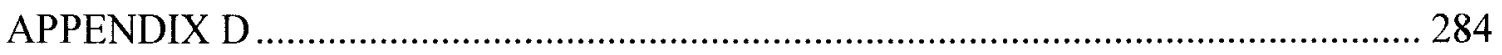

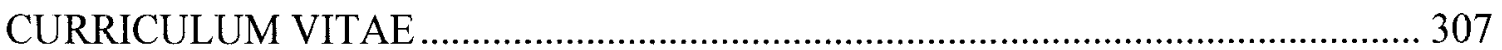




\section{LIST OF TABLES}

TABLE

PAGE

1. Detention Center and Pilot Study MSQ Statistics ............................................. 216

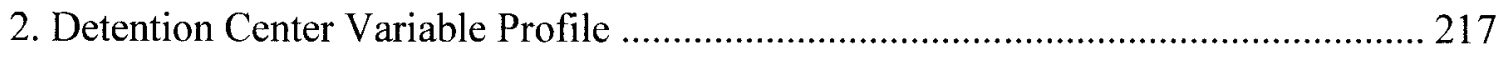

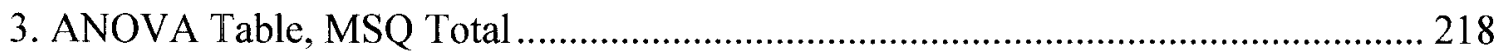

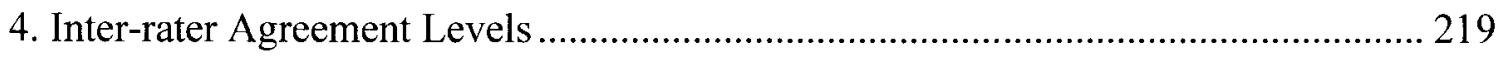

5. Best Practices Survey, Facility and Education Indices ............................................. 221

6. KECSAC Point Totals and Percentages by Centers …………………………........... 223

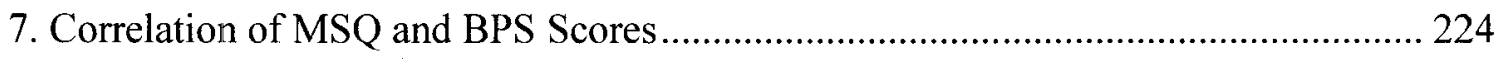

8. Descriptive Statistics for MSQ and Best Practices Education and Facility …............. 225

9. (ANOVA) for Best Practice Survey and Minnesota Satisfaction Questionnaire........ 226

10. Descriptive Statistics for BPS Indices per Center................................................. 229

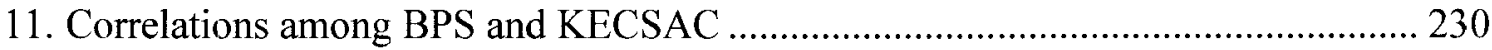

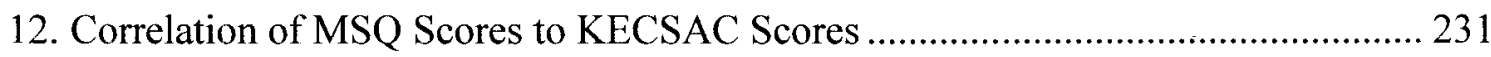

13. Individual Correlation of MSQ, BPS-E, BPS-F, and KECSAC ........................... 232 


\section{LIST OF FIGURES}

FIGURE

PAGE

1. Block Diagram of Study Correlations/Relationships.......................................... 8

2. Flow Diagram of Study Correlations/Relationships .......................................... 9

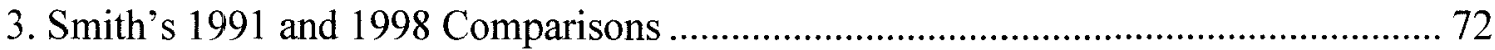

4. Tattooed Adolescent's Characteristics.......................................................... 75

5. Dembo and Williams: Delinquent Behavior Surveys ...................................... 84 


\section{CHAPTER I \\ INTRODUCTION}

The purpose of this study is to research juvenile detention center educational programming and validate variables which may cause a reduction in the recidivism of juvenile delinquents. According to published statistics, 18, 006 juvenile cases were opened and referred to the Kentucky Department of Juvenile Justice in the 2004 fiscal year with an average cost of $\$ 228.14$ per case (Lewis, 2004, p. 3). The quantity and associated costs, short and long term, are of major concern, but the most pertinent question lies in why and how these children become juvenile delinquents and the best way to rehabilitate this at-risk population.

These questions can best be evaluated by looking at juvenile detention programs located across the state of Kentucky - Warren Regional Juvenile Detention Center (WRJDC), Lincoln Village, Boyd, Fayette, McCracken, Breathitt, Adair, and Campbell. Most of these programs supply structure, which is the common missing factor in the delinquent's families and in programs with which they have previously been involved. The juvenile delinquents served in Kentucky's detention centers desperately need a structured/regimented environment developed by individuals with a high level of job satisfaction who willingly implement best practices that result in high performing programs. The biggest challenge faced by all these educators is a commonality found in present day teaching challenges. The teacher must be taken off the pedestal. 
Teachers must no longer be "cast in the familiar role of information dispenser, fountain of wisdom, or the all knowing expert/presenter/lecturer" (Zemelman, Daniel, \& Hyde, 1993, p. 156). They become "moderator, facilitator, coach, scribe, designer, observer, model - everything but the standard, normal, stereotypical, conception of the teacher" (Zemelman, Daniel, \& Hyde, p. 156). As the need to be omnipotent, omnipresent, and all-knowing fades, teacher job satisfaction increases. Pressure to be the ALL moves out and freedom to step outside of the traditional box grants these individuals the desire to try new strategies without fear of retribution, such as not lecturing the entire class period.

All juvenile detention facilities require structure; it is unfortunate that the level of consistency and structure necessary for safety requires educational opportunities to be restricted in order to fall within the required facility parameters. "Teachers who use Best Practice structures don't need Assertive Discipline - their classrooms already have order, discipline, and productivity which arise out of children's engagement in work, not their fear of humiliation and punishment" (Zemelman, Daniel, \& Hyde, p. 204). This statement is very true of detention center classrooms. While facility programming must adapt to a center's regimented environment, teachers have a professional obligation to supply these at-risk students with educational, emotional, and social training necessary for success. As best practices are implemented, teachers witness student success which shades their perception of personal achievement and satisfaction in a job well done. These teachers are motivated to provide concrete tools, which will endow their at-risk students with educational successes that empower them to positively embrace today's world. Welltrained and motivated educators are the key to rehabilitation for juvenile delinquents. The 
identification of best practices, job satisfaction levels, and program success will lead to an identification of attributes necessary to save this growing population. "Providing every child, regardless of race, income or ethnicity, with a quality education is a basic right that our public schools and policy makers must deliver. To make this happen, we must provide all students with the tools to fulfill their limitless potential" (Weaver, 2007, p. 4).

The value of this study can be found in the increasing population of at-risk youth incarcerated in detention centers. Nationally, the arrest rate of at-risk youth as "calculated by dividing the number of arrests of persons ages $10-17$ by the number of persons ages $10-17$ in the population" yielded a rate of $77 \%$ while the Kentucky rate was $25 \%$ (FBI, 2006). One Kentucky Juvenile Detention example is the WRJDC, which is assigned 1, 200 residents a year. This facility has served approximately 7, 200 at-risk children during its 6 years of operation. National statistics state "between 2000 and 2004, the number of judicially waived delinquency cases increased $21 \%$ while the number of cases waived for person offense increased 27\%" (Stahl et al., 2007, p.38). "The number of delinquency cases involving detention increased $42 \%$ between 1985 and 2004, from 232, 400 to 341 , 300. The largest relative increase was for person offense cases (131\%), followed by drug offense cases (117\%) and public order cases (103\%)" (Stahl et al., p. 30). Recidivism rates, on a national average, are $50 \%$ to $80 \%$. These averages are produced by "weighting to produce national estimates .... The Archive employs an elaborate multivariate procedure that assigns a weight to each record in the national case-level data base that, when used in analysis, yields national estimates of juvenile court activity"( Stahl et al., p. 95). 
In contrast, WRJDC documents a recidivism rate of $30 \%$ based on the informal record keeping of the Detention Alternative Coordinator (DAC). The confidentiality issue associated with juveniles makes it very difficult to tabulate specific, documented percentages. The law guarantees that these children have a right to remain anonymous and the tabulating of firm data is a challenge. It is illegal to mark and track these residents. However, these informal statistics make the identification of the successful attributes in Kentucky Juvenile Detention programs imperative since they may assist with the further reduction of this rate for WRJDC and the other facilities. Furthermore, the study will add to the existing knowledge base concerning the education of this at-risk population by researching job satisfaction, best teaching practices, and program efficacy. These correlational findings should be of benefit to other programs across the nation as efforts are made to improve services to juvenile delinquents.

This study attempted to identify attributes of a successful juvenile detention educational program. Literature related to educating at-risk students identifies a number of best practice strategies, which assisted in the development of a researcher generated survey, the Best Practice Survey (BPS). The Minnesota Satisfaction Questionnaire (MSQ) was utilized to examine detention center faculties' job satisfaction, and the Kentucky Educational Collaborative for State Agency Children (KECSAC) program improvement tool evaluated program efficacy. State and national experts in the field of juvenile justice have advocated promotion of a new management system for Juvenile Detention facilities. According to presentations at the National Juvenile Delinquency Prevention Association held annually in Indianapolis, Indiana by the National Juvenile Detention Association (NJDA), there should be a focus on education rather than 
punishment (Roush, October, 1996). Kentucky leadership has taken steps to revamp several of their facilities. These new leaders resorted to a ground up management style in order to facilitate restructuring efforts. Innovative regional directors recruited former employees and teachers to assist new superintendents with line employee training and educational programming. Their goal was to turn punitive establishments into facilities with a focus on education. Efforts were validated by invitations to be presenters at national conferences that advocated their aggressive stance for revamping antiquated programs. These leaders presented at several conferences, three times for NJDA in Indianapolis, Indiana and once for NJDA in Hot Springs, Arkansas, eight times for Kentucky Educational Collaborative for State Agency Children, multiple times for Title I workshops and local school systems. They have not produced published materials but their message was validated by requests to speak to professional organizations looking for ways to serve at-risk populations.

Unfortunately, personality clashes and state budgeting issues forced some of these groundbreakers into early retirement while others silenced their message due to disillusionment with the system. Once again, good programming took a back seat to technicalities and finances. Their leaving and/or abandonment of the mission made this study all the more important. These lone voices were silenced by early retirement, and a written documentation of effective educational practices and strategies became imperative if the movement toward better programming in juvenile detention facilities were to continue. Therefore, weight was added to this research project with a very reallife application and need to document programming strategies, teacher contentment and innovativeness, and 
the resulting proactive curriculum which would produce an effective detention program.

The development of this study was based on the theory that an emphasis on educational programming, including the use of best practices in educational delivery and in the job satisfaction of detention center educators will result in the reduction of recidivism rates. A literature review of best practices for juvenile detention education provided an assortment of authenticated essential attributes and practices for curriculum development and instructional delivery. A survey was developed to identify presence and importance of each trait within Kentucky Juvenile Detention facilities. The Minnesota Satisfaction Questionnaire (MSQ) was administered to explore and measure job satisfaction levels using detention center teachers as the sample. The Kentucky Educational Collaborative for State Agency Children (KECSAC) evaluation tool measures programs based on 9 Standards with a total of 80 Standards, Indicators, Descriptors, and Evidence (SIDE). This study reviewed programming at the eight juvenile detention centers in Kentucky. The goal was to provide documentation that explained the correlations among best practices, job satisfaction, and program efficacy.

\section{Statement of the Problem}

The increasing number of juvenile delinquents society was forced to incarcerate substantiated the relevance of this problem; thus, juvenile services must provide better care and more intense motivational education in order to curb this trend. The 18, 006 juvenile cases opened in the 2004 fiscal year (Lewis, 2004) and referred to the Kentucky Department of Juvenile Justice substantiated the need for better programming. The magnitude of associated costs is of major concern to taxpayers who pay the bills, 
legislators who develop the budgetary allotments, the clients (juveniles) themselves, and society in general.

Nationally, one-fourth of the overall at-risk juvenile population is assigned to detention settings. This subgroup of delinquents represents a valuable resource to society and must not be allowed to slip through the cracks inherent in ill-conceived programs lacking educational opportunities. In addition, the national recidivism rate of one-half to three-fourths proves that present programs are merely revolving doors of failure (FBI, 2006). In contrast, recidivism rates for the eight detention centers across Kentucky range from a low of $30 \%$ in the best case to a high of $80 \%$ in the worst case (Lewis, 2004). The best-case scenario is that the centers are doing something right. The worse case scenario is that the centers are exacerbating the problem.

In summary, the problem facing society is how to best meet the needs of a growing number of juvenile delinquents being incarcerated in detention centers. For economical and moral reasons, society must demand that practitioners and those who manage and lead develop better programming that will serve to rehabilitate these children. This study addressed three areas supported by the literature as being intricate components of successful programming. Investigating and documenting the possible correlations among the three components of satisfaction, practices, and performance may provide additional strategies to those striving to reclaim this wasted resource.

\section{Research Questions}

As the extent of the number of juvenile delinquents housed in Kentucky's juvenile detention centers was contemplated, the urgency of the situation became apparent. The Office of Juvenile Justice and Delinquency Prevention (OJJDP) provides current reports 
on research findings, statistics, and programs that work. Some documented facts state "the prevalence of serious juvenile delinquency could be reduced significantly by identifying and treating the 8 percent of juveniles who are at-risk of becoming chronic offenders when they first come into contact with the juvenile justice system" (Flores, 2003, p. 12). Second, OJJDP looks for "ways to enhance current reentry programs and to build on innovative ideas to combat recidivism and, thus, reduce violent and serious crime" (Flores, 2003, p. 14). Third, OJJDP acknowledges the links among education, employment, and success. The Promising and Effective Practices Network's (Flores, 2003, p. 21) "efforts to help youth involved in the juvenile justice system prepare for economic self-sufficiency and productive citizenship by identifying and promoting effective youth development and employment programs" is one type of best practice strategy that effective detention center educators may employ.

These three nationally highlighted areas were embedded in this study and serve as a basis for the research questions. Based on the study of the correlations among job satisfaction (MSQ), implementation of best practice teaching strategies (BPS), and program efficacy as determined by KECSAC, important programming components were highlighted and explored. The research questions supplied enlightening correlations among significant components of effective programs. Theoretical relationships among the dependent variables, MSQ, BPS, and KECSAC, and the independent variables, eight detention centers in Kentucky are shown in Figure 1 and Figure 2.

\begin{tabular}{|l|l|l|l|l|}
\hline $1 . \mathrm{MSQ}$ & $\rightarrow$ & BPS & & \\
\hline $2 . \mathrm{BPS}$ & $\rightarrow$ & KECSAC & & \\
\hline 3. MSQ & $\rightarrow$ & KECSAC & & \\
\hline 4. MSQ & $\&$ & BPS & $\rightarrow$ & KECSAC \\
\hline
\end{tabular}

Figure 1. Dependent Variable Correlations. 
The relationships among Minnesota Satisfaction Questionnaire Scores, Best Practices Survey Education and Facility Scores, and the audit tool for Kentucky Educational Collaborative for State Agency Children Scores was illustrated in the following example.

Independent Variables, Eight Juvenile Detention Centers in Kentucky, Warren, Adair, Boyd, McCracken, Lincoln Village, Fayette, Breathitt, and Campbell.

Dependent Variables, MSQ, BPS, and KECSAC

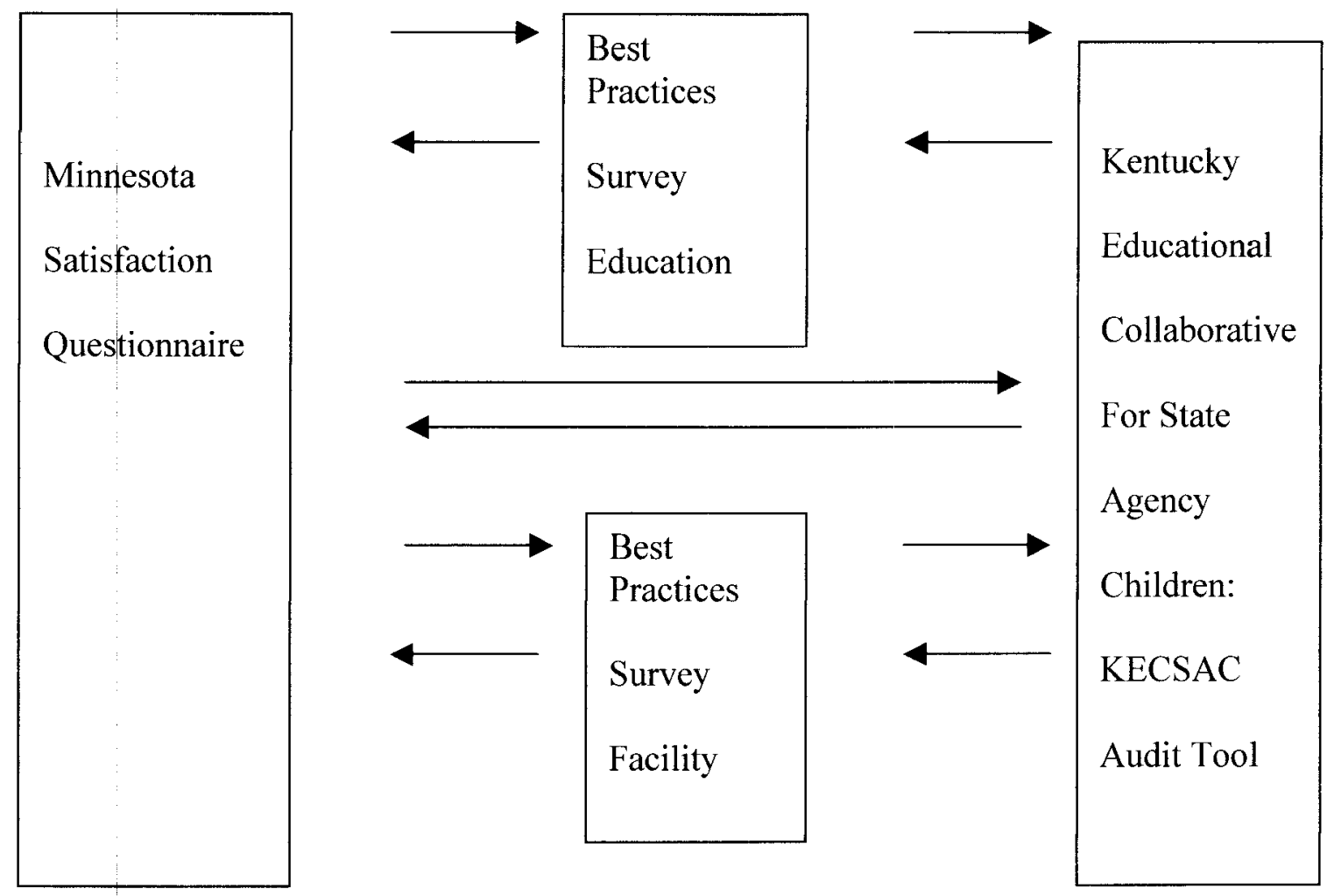

Figure 2. Flow chart of Correlations among Dependent Variables. 
1. Is there a significant relationship between MSQ scores and BPS scores?

2. Is there a significant relationship between BPS scores and KECSAC scores?

3. Is there a significant relationship between MSQ scores and KECSAC scores?

4. Does a significant relationship exist between the KECSAC scores and the combined effect of BPS and MSQ scores?

As the job satisfaction level of educators was measured, there were 20 significant areas explored. Satisfaction scores were based on the following measures, Ability utilization, Achievement, Activity, Advancement, Authority, Policies and Practices, Compensation, Co-workers, Creativity, Independence, Moral Values, Recognition, Responsibility, Security, Social Service, Social Status, Human Relations, Technical Supervision, Variety, and Working Conditions. When the researcher decided to explore the implementation of best practices, 25 components were highlighted. In order to better manage the data, these areas were divided into two sections, strategies relevant to the facility component and strategies relevant to the education component. Areas explored at the facility level were, Structure, Safety, Security, Fairness, Consistency, Community Involvement, Physical Training, Conflict Resolution, Nutrition, Treats/Rewards, Management Involvement, Counseling, and Health Services. Areas explored at the education level were, Education Curriculum, Reading and Math Levels, Career Majors, Learning Styles, Life Skills, Computer Skills, Teachers, Accelerated Reader Program, Special Events, Drug/Sex Education, Violence Prevention, and Career Planning. The KECSAC tool looks at 9 Standards and provides indicators, descriptors, and evidence for each item being evaluated, Curriculum, Evaluation and Assessment, Research-based Practices, Performance 
Excellence, Removal of Barriers, Professional Development, leadership Capacity, Utilization of Resources, Action Plan, and Education Focus rather than Punishment. Operational Definitions

The terms listed below had the following operational definitions for this study:

1. Juvenile Detention Centers are secure facilities that house retained juveniles who are in various stages of being adjudicated.

2. Juvenile Delinquents are individuals from age 10 up to age 18 who are classified as status offenders or youthful offenders by the judicial system.

3. The Department of Juvenile Justice (DJJ) is the branch of state government charged with providing due process for juvenile delinquents.

4. Teachers are certified educational professionals employed by school districts and housed at DJJ secure Juvenile Detention Center facilities.

5. Facilities are the physical DJJ buildings and operational procedures that provide structured and secure housing for residents involved with the juvenile judicial process.

6. Kentucky Educational Collaborative for State Agency Children (KECSAC) is a monitoring group established to coordinate the implementation of DJJ and the Kentucky Department of Education (KDE) policies geared toward educating this atrisk population.

7. The Best Practices Survey (BPS) is a researcher generated survey that measures the presence and importance of literature-based best practices for educating juvenile delinquents. 
8. The Minnesota Satisfaction Questionnaire (MSQ) was purchased from the University of Minnesota as a tool to measure the degree of satisfaction present in educational professionals.

9. The Standards, Indicators, Descriptors, and Evidence (SIDE) document is a monitoring tool utilized by KECSAC to evaluate the performance of DJJ Juvenile Detention Centers, facilities and teachers.

\section{Purpose and Significance of the Study}

The purpose of this exploratory study was to investigate levels of job satisfaction among the teaching staff, teaching strategies, and program efficacy at each of the eight juvenile detention centers in the Commonwealth of Kentucky and to examine the correlations among the factors. The Minnesota Satisfaction Questionnaire (MSQ) was used to evaluate the level of job satisfaction among the professional teaching staff; the Best Practices Survey (BPS) focused on best teaching practices and was authenticated by an exploration of best teaching strategies for at-risk populations. Last, the results of the questionnaire and survey were correlated with the annual KECSAC SIDE audit scores.

The significance of the study was legitimized by adding to existing knowledge bases and the resulting correlations among the three explored areas. "Freedom of conscience is matched by an internal and personally executed flexibility that prevents individuals or groups from tearing the organizations apart" (Cusick, 1992, p. 216). "Tolerance rests on the fact that everyone knows, learning is ultimately a personal and personalized endeavor, the power of the organization is limited, and that the matter of learning comes down to what parents encourage, teachers teach, and students will do" (Cusick, p. 216). In the detention setting, parents are nonentities while resident choices 
are very controlled; however, the human spirit cannot be controlled and the resulting acquisition of knowledge continues to be a personal action. "Freedom of conscience and choice are the system's source of energy and renewal" (Cusick, p. 216). In detention centers, educators provide this energy and renewal. "Individuals, acting on their own and for their own reasons add the passion, energy, and commitment that make education happen" ( Cusick, p. 216). Teachers are the catalysts that make rehabilitation work in detention settings. If offenders were rehabilitated, the recidivism rate would decrease and Juvenile Justice would be a nonentity. "Effort and quality may vary, but in working life, compliance is not problematic" ( Cusick, p. 44). This statement summarized the detention center educators. They followed the rules. Their effectiveness was found in their ability to make those rules work for the betterment of their students. As educator characteristics were explored through identifying the presence of best practice strategies and job satisfaction levels, correlations were established showing their impact on the efficacy of the program as determined by the KECSAC ratings. Identification of implementation of best practices and levels of job satisfaction provided a basis for overall program effectiveness. In summary, the researcher's goal was to provide an identification of teaching components, job satisfaction, and efficacy of existing educational programs. Through a study of the relationships among these measurements, an explanation was provided for the performance of current Kentucky juvenile detention centers' educational programs. Therefore, the purpose and significance of this study, which was grounded in the necessity for juvenile detention reform and society's acceptance of the need to address and redirect the paths of childhood criminals, has been partially fulfilled. 


\section{National Historical Summary}

As is true of every American legal institution, the juvenile justice system finds its roots in Europe. England and France greatly influenced American philosophy concerning childhood and discipline. The consensus was that "childhood, prolonged into an adolescence from which it was barely distinguished, was characterized by deliberate humiliation" (Aries, 1962, p. 262). Humiliation was considered to be the most effective tool of discipline. Fortunately, this ideology evolved into a more collectively, conscientious model of respect. The change in methods reflected a "new orientation of the concept of childhood, which was no longer associated with the need for its humiliation" (Aries, p. 264).

Further changes in juvenile discipline procedures came about through the intervention of a group of Quakers in New York City. In 1796, legislation was passed that nullified the usual practice of whipping and death for many crimes and replaced it with imprisonment. In 1823, the Society for the Prevention of Pauperism looked at the atrisk population of juveniles and suggested the construction of a "House of Refuge." This facility was an alternative to prisons where children were housed with mature criminals (Fox, 1970). In 1826, Pennsylvania opened the Philadelphia House of Refuge that accepted children convicted of crimes or who were vagrants (Roush, October, 1996). It is important to note that there was "a discriminating nature of the reform; only "proper objects' were to be sent to the House, not every vagrant and criminal child" only those judged to be worthy were accepted (Fox, 1970, p. 1190). Sadly, the mandate called for a judgment by officials concerning the feasibility of "who could still be rescued" (Fox, 1970, p. 1190). The goal was to redeem juveniles who were not yet hardened delinquents; 
"This concept of pre-delinquency was one of the central concepts of juvenile justice for well over a century" (Fox, p. 1191).

In 1835 , the trend continued as Pennsylvania legislation added incorrigibility as a reason for confinement. The litigation mentality of the time caused this law to be challenged by juvenile delinquent advocates (PA 1839: Ex Parte Crouse, Wharton Reports). The court concluded that the House of Refuge was a school of reform, not a prison for punishment. Therefore, when a parent had lost control, the parens patriae, or the community, can step in to facilitate the reformation of the juvenile (Pennsylvania Juvenile Justice Task Force, 1991). Once again, Europe -- namely Britain -- provided the U.S. with the stepping stone necessary to build our juvenile justice foundation. Parens patriae was a doctrine that viewed the king as a parent. It was grounded in the theory that the king, or state in our case, can step in and provide protection/correction for persons who were not of full legal capacity (Roush, October, 1996).

According to Murray, 2001, professionals of the 1800 s began to hold strategy meetings to discover ways for the state/king to address the needs of juvenile delinquents. In 1846, the famous writer Charles Dickens discussed juvenile penal issues with Alexander Maconochie at a meeting of juvenile correctional educators. From this encounter, Dickens was impressed enough to incorporate "Maconchie's mark [reformatory] system into the running of Urania Cottage, the 'Home for Homeless Women'." This organization was located in Lime Grove, Shepherd's Bush, England. Dickens explained, "I do not know of any plan, so well conceived, or so firmly grounded in the knowledge of human nature ... as what is called Captain Maconochie's .... The girl's are to be tempted to virtue, not dragged, driven or frightened," but motivated to 
improve (Murray, 2001, p. 256 - 259). This goal was achieved by every girl keeping a copy of her itemized behavioral record. If successful, some moral reformation would occur through their desire to see documented progress.

During the same time frame, America followed England's lead and experienced an educational and religious reformation that addressed the issue of troubled children. Up to this time, children were viewed as miniature adults, as documented by Western Kentucky University's Kentucky Library and Museum's permanent display of the Victorian Era. Fortunately, our country was quick to embrace the theology that children have unique characteristics and needs. Ultimately, the Puritan influences led America to develop a system of boarding schools and strict curriculum designed to address the mental and moral deficiencies of at-risk children (Aries, 1962).

In the true American tradition, the United States took the premise that the courts are the common guardians and expanded upon it. From education and religion/strict discipline and useful labor, America progressed to reform schools in the 1800s. In 1847, the Lyman School for Boys in Westboro, Massachusetts, opened. In 1855, a girls' reform school opened in Lancaster. In 1857, the State Reform Farm opened its doors in Ohio (Cole, 1989). With the entrance of facilities such as these, America began a journey of neglect and abuse that was typical of the times.

Throughout American history, there has been a documented tendency for the weak to be down-trodden and abused. Unfortunately, the weak in our early history happened to be the at-risk juvenile population. The Child Labor Public Education Project sponsored by the University of Iowa in 2000 provides statistical evidence that needy children were viewed as replaceable commodities in urban areas; they came cheap and 
could supply extra income for immigrant families or displaced agrarian oriented families. While this is a sad statement about our country, it is one that must be taken into consideration without bias. The formidable strength of our country can find a foundation in the early labor force that consisted of many children. This foundation is what makes our country what it is today. It is easy to look back and condemn actions. It is more difficult to control situations and make appropriate choices during times of hunger, war, and social unrest (Child Labor Public Education Project, University of Iowa, 2000). Industrialization and immigration were key factors in the development of a more humane society that stepped up to address the issue of juvenile delinquents. Family farms were dissolved when members left for the city and lucrative employment. Many immigrants flooded these same areas and created an influx of children that were often unsupervised, uneducated, orphaned, and hungry (Child Labor Public Education Project, University of Iowa, 2000). Factories were able to employ this population for minimal funds. However, as social reform became stronger and regulated the employment of juveniles, these jobs were lost. The children who were depending on a pay check were back on the street -hungry, tired, and angry. Such were the roots of juvenile courts in the United States (Child Labor Public Education Project, University of Iowa, 2000).

Eventually, the Progressive Reform movement converged upon the scene of America's juvenile justice system and addressed the public outcry of abuse and neglect prevalent in the models of the aforementioned institutions.

During the Victorian and Progressive era (1830 to 1920) millions of middle-class homemakers took part in grassroots political action through affiliation in women's voluntary organizations. Rather than challenging the status quo of male 
dominance, reform-minded clubwomen exploited the cultural ideology of their day - an idealization of womanhood that granted women moral superiority and absolute authority in all matter related to the health and welfare of the family - to achieve their political goals" (Tucker, 2004).

As the $20^{\text {th }}$ century rolled around, "the combination of moral empowerment, feminine mastery and collective identity was a potent mix for conceptualizing a broader political role for middle-class mothers at a time when women and children from less fortunate families were suffering from the devastating consequences of urban poverty" (Tucker, 2004). These women organized to promote many progressive social reforms with juvenile justice being significantly represented by such leaders as Julia Lathrop and the Settlement House movement. These precursors to youth development centers were "residential centers established and staffed by educated, middle-class men and women to provide outreach and social services to the urban poor" (Tucker, 2004) and were the beginnings of juvenile justice reform.

It took a long time for juvenile justice to acknowledge the juvenile's right to due process. However in 1967, Gerald Gault and an obscene phone call, which he orchestrated, finally led the way for the first major judicial challenge to the parens patriae system and that philosophy of juvenile justice. In this case, a delinquent was denied due process in the court systems. Under the parens patriae system, the judge acted as the omnipotent authority and sentenced the juvenile troublemaker to 6 years in a secure juvenile facility. As a result of this landmark court case which challenged the absence of due process for juvenile delinquents and served as a catalyst for reform, Justice Abe Fortas overturned Gault's 6-year sentence to the Arizona Children's 
Detention Home because , "Under our Constitution, the condition of being a boy does not justify a kangaroo court. If Gault had been an adult, he would have faced fines ranging from $\$ 5.00$ to $\$ 50.00 "$ (Cole, 1989 , p. 433 ) rather than spending 6 years in a secure facility. "The search for justice is an age-old quest; from our origins as a colonial people to the present day, our entire history can be fairly characterized as a search for justice" (Newman, 1975, p. 411). With this summary statement, justification for the current study was established because it attempted to document factors necessary for fair and effective programming that would lead to fair and effective juvenile delinquents programming.

Kopecky (1989) summarized the juvenile justice problem with the theory that courts were the common guardian of the community. Systems that were rooted in this philosophy viewed the juvenile court as a substitute for family. Through services, the courts would survey communities looking for children who lacked academic or social services and referred those individuals to the courts. Procedural due process was considered unnecessary because the court's "motivation was perceived as beneficial rather than punitive"... "The difficulty with this activist approach is that it conflicts with due process values. It conflicts with procedural due process because the Juvenile Court judge is not a neutral decision maker but, rather, remains actively involved in the provision of social services" (p. 7).

Court cases such as Gault, and reports such as Kopecky, built upon the previously discussed Progressive Era social movement that had looked at environmental factors' influence on behavior with a goal of providing treatment instead of punishment while staying within due process. The "brutality of the conditions under which children were incarcerated" (Cole, 1989, p. 434) fueled this urban area movement. It was headed by 
prominent women citizens who became known for their advocacy for at-risk juveniles. These women were movers and shakers and members of such organizations as General Federation of Women's Clubs, The Women's Christian Temperance Union and the National Consumer's League and were at the forefront of Progressive Era reform movements. They addressed child labor practices, neglect and dependency, poor processing of immigrant children, runaways, orphans, and delinquents (Newman, 1986). With their endeavors, they were able to push society toward the current level of juvenile justice and alternative practices. Cases such as Gault and reports from advocates such as Kopecky, allowed the focus in juvenile delinquency to remain on "the necessity for societal modifications if long-range crime prevention is to occur" (p. 410).

Embracing the Progressive Era, the philosophy of the Pennsylvania Juvenile Justice Department evolved away from the original House of Refuge philosophy, a Quaker-led movement in 1800 New York, and moved beyond the parens patriae theory. Their goal progressed to the preservation of the family unit, whenever possible, if public safety were not compromised. The Philadelphia House of Refuge was established in 1826 and was second to New York's House of Refuge. These houses were established to provide housing for juvenile delinquents and end the contamination of children who were locked up with mature criminals (Fox, 1970). From these beginnings, Pennsylvania continued their juvenile justice reform as they focused on the "least restrictive alternative placement that meets the needs of the juvenile" (Pennsylvania Juvenile Justice Task Force, 1991, p. 24). After 170 years of effort and programming modification, Pennsylvania developed the following list of Guiding Principles. 


\section{THE IDEAL JUVENILE JUSTICE SYSTEM:}

1) Ensures that every decision made and every service provided is designed to meet the needs of the youth and the community.

2) Is based on fixed accountability/responsibility for each youth and for each component of the system.

3) Includes clear criteria for entry to the juvenile justice system and its various components.

4) Includes needs assessments to open access to other systems (such as children and youth services, mental health/mental retardation, drug and alcohol, and education).

5) Includes case managers who have the responsibility and authority to acquire needed services.

6) Takes into account how decisions affect various parts of the system.

7) Is guided by the least restrictive alternative consistent with the needs of the youth and the safety of the community.

8) Emphasizes community responsibility, involvement and awareness.

9) Keeps youth involved in education/training and provides year round access to school.

10) Involves youth and family.

11) Stresses services in the community.

11) Reassesses individual needs at every stage.

12) Addresses the needs of the victim.

13) Ensures that the facilities to which youth are committed are geographically close to their families.

14) Encourages components of the system to relate in a rational, coordinated way.

15) Promotes flexibility in the access to and use of resources.

16) Provides adequate compensation and training for employees of the system. 
17) Requires local and state planning that actively involves all components of the system.

19) Develops a funding system that is consistent with the philosophy of the service delivery system.

20) Includes evaluation, data collection/management (MIS), and planning and research capabilities. (Pennsylvania Juvenile Justice Task Force, 1991, p. 5)

Unfortunately, the juvenile justice system continuously fails to meet such grandiose plans. By reaching too far and trying to solve a host of moral and social problems, juvenile delinquency groups tend to lose their focus; the needs of the organizations begin to outweigh the needs of the children. According to Hunter's $\underline{\text { Culture }}$ Wars, 1991, America has "intellectuals and progressivists that are struggling to interpret our past and future and push through their own personal interest" (p. 63). After years of revamping and evaluations, the juvenile justice system is no exception to this tendency for personal needs and ideologies to color perceptions. Across the nation, ideas and assumptions held by governing individuals continue to require surveillance and monitoring by the federal government. Cases such as Gerald Gault vs. the State of Arizona highlight the inconsistency and unethical practices prevalent in juvenile justice (Cole, 1989) and validate the need for a continuous auditing of the juvenile process, i.e., KECSAC and the SIDE document.

Juvenile Justice Strategies

\section{Alternative Placement Beginnings}

Alternative practices first gained attention in the form of John Augustus, a cobbler who was destined to make a difference in the lives of many juvenile delinquents. In 1841, Boston, Massachusetts embraced the concept of English common law and the conditional 
suspension of punishment (Moreland, 1941 as cited in Roush, October, 1996). The courts cooperated with Augustus by allowing the posting of bail; thus, the grounds were laid for probation -- a key alternative practice today. These initial endeavors led to him being credited with developing the forerunner for today's probation system. In 1869, the Massachusetts legislature appointed an agent to the Board of State Charities (Shultz, 1973). This individual facilitated a program of probation that produced legislation authorizing the mayor of Boston to employ paid probations officers as court officials (Pennsylvania Juvenile Justice Task Force, 1991).

These historical efforts provided the origins of today's juvenile court system. According to the Center for Legal Studies at the University of Illinois, Governor John Altgeld was one of the founding fathers of the movement (Kopecky, 1989). He immediately tapped his resources and appointed Julia Lathrop to evaluate the facilities in his state. Ms. Lathrop followed in the footsteps of renowned social workers Jane Addams, Lucy Flowers, and Elvina Stevens. In addition, she had the momentum of the Chicago Bar Association's influence from such individuals as Judge Richard Tuthill, Judge Harvey B. Hurd, Ephriam Banning, John W. Ela, Edwin B. Smith, and Clarence Darrow. With this backing, she evaluated the programs and found them to be sadly lacking. Indeed, she was horrified by the handling of juvenile offenses and demanded reform legislation. The result of her investigation was "The Juvenile Court Act" (Roush, October, 1996).

\section{Juvenile Court Beginnings}

In Chicago, the first juvenile court was established by an Illinois law entitled "An act to regulate the treatment and control of dependent, neglected and delinquent children" 
(Sussman \& Baum, 1969, p. 14). Although Chicago is routinely credited with the innovation of holding children's trials independently from adults, they were not alone in their efforts. Many other areas were initiating the same practice, 1870 -- Suffolk County, Massachusetts; 1892 -- New York, Indiana, and Rhode Island (Sussman \& Baum, 1969, p. 15). Interestingly, the Illinois legislature of 1899 passed a Juvenile Court Act that was the first document to be lauded as an exemplary sample for other areas within the United States (Platt, 1969).

Prior to this legislation, Pennsylvania had experimented with Juvenile Justice. Initially, the Pennsylvania legislature stated that children under 16 could not be incarcerated with adults and that their cases had to be listed on separate dockets and tried in separate courts. Unfortunately, for the children, the Pennsylvania Superior Court declared the new statute unconstitutional (Pennsylvania Juvenile Justice Task Force, 1991).

Fortunately, another state jumped on the bandwagon in 1899. The Illinois Juvenile Court Act designated three distinctions of the juvenile court movement, (1) a separate court of justice was created for children; (2) the rehabilitation/treatment of children was emphasized by the idea that juvenile court is not a criminal but civil court; (3) a system of probation was developed (Lathrop, 1917 as cited in Roush, October, 1996). In 1903, the Pennsylvania General Assembly readdressed the issue of juvenile court. This time, the statute was upheld because of the parens patriae doctrine. As the practice spread, a national trend was established in the juvenile court statutes arena by the 1920s (Roush, October, 1996). 


\section{Juvenile Justice Stages}

\section{Detention}

Throughout the course of history, three distinct stages of juvenile detention development can be documented. Currently, we are in a phase of Detention. Sadly, there has been an increase in abusive criminal acts by juveniles, which is finding its foundation in the breakdown of family and community structure. As home, school, and society are failing in controlling this at-risk population, the state is being forced to supply structured environments that can house these youngsters safely and securely. Thus, the number of juvenile detention centers is escalating at a fearsome rate (Roush, April, 1996) and testify to the fact that our nation is in a juvenile delinquency crisis.

\section{Home-like Models}

Prior to World War II, money constraints due to the depression mandated a utilization of existing facilities to handle juvenile offenders. These facilities were small home-like models, or adult jails. Status offenders, minor offenders, and dependentneglected children were often housed in large state homes that were not secure. They were the forerunners of today's group homes. Serious offenses were channeled to local jails or state training schools and reformatories. In rural areas, extended families provided relief for state coffers by providing alternative placement for troubled youth (Norman, 1957).

\section{Hospital Architectural Persona}

After WWII, urban areas began a construction period that modeled a "hospital architectural persona" (Norman, 1957, p. 395). At this point, jails or municipal lockups 
were still home to the serious offenders. Twenty-seven percent of all detained youth ended up incarcerated in a county jail or police lockup in 1945. There were three reasons for this trend, unavailability of a judge, strain existing between child and parent, and to secure the community against danger from a child (Tappan, 1949). During that time frame, periods of detention were viewed to have a "therapeutic value in shocking, coercing, or threatening the child into 'behaving himself' (p. 388). As the fatality rate for juveniles increased in direct correlation with this practice, society finally began to voice concern (Tappan, 1949; Norman, 1957).

\section{Beginning Juvenile Detention Facilities}

The governmental construction boom after the depression continued to accelerate in juvenile justice. By 1962, 242 secure facilities could be found in the United States (Cavan, 1969). By 1971, 303 juvenile detention facilities were on record in our country (Pappenfort \& Young, 1980). The year 1989 saw the quantity rise to 492 (Allen-Hagen, 1991). Continued construction was the trend through the 1990s, even though the financial drain from adult prisons and jails often led to the closing of juvenile facilities. As is often the case, our nation continuously adhered to the philosophy of punishment as opposed to prevention. The surety of adult criminals outweighed the potential threat of juvenile delinquents. A quick fix was to lock the adults up and ignore the juvenile offenders who would grow to be said criminals. An ounce of prevention is worth a pound of cure! was not in the national vocabulary.

There is some debate over who can claim to be the "first" juvenile detention facility in the United States. Cook County Juvenile Court opened the Arthur J. Audey Home around 1906 (Tappan, 1949). This facility had several floors and was located in 
downtown Chicago (Jordan, 1968). In 1923, an updated center was opened and, in 1970, the executive branch opened the 500-bed Cook County Temporary Juvenile Detention Center. The Los Angeles County Juvenile Hall competes with Cook County for the dubious honor of being the first center. Both are credited with opening in 1906 (Cavan, 1969). The significant factor is not who came first but the regretful detail that there was such a need for juvenile detention centers.

\section{Kentucky Historical Summary}

Kentucky's current Juvenile Justice Department was founded on an extensive study launched in 1992. The Annie E. Casey Foundation initiated the Juvenile Detention Alternatives Initiative (JDAI), which spanned several years and examined diverse sites to address the intense national concern relevant to the rising trend of juvenile delinquency. The study looked at the trend from 1985 to 1995 when detention facilities were in serious trouble due to overcrowding, which produced dangerous settings with detrimental, unsanitary, and harmful practices. Because of public concern, this organization evaluated the situation and came up with four objectives for juvenile detention. They were (a) elimination of inappropriate or unnecessary use of secure confinement, (b) minimization of failures to appear in court and reduction of delinquent behavior, (c) redirection of funding from building to alternative strategies, and (d) improvement of conditions in secure detention facilities (Steinhart, 2000).

Key strategies were identified as ways to accomplish these objectives. The first was collaboration. The goal was to bring together all stakeholders in an effort to establish policy that would promote accountability (Steinhart, 2000). From this collaboration, the 
JDAI project produced a twelve-volume publication, Pathways to Juvenile Detention Reform.

Overview, The JDAI Story, Building a Better Juvenile Detention System

1. Planning for Juvenile Detention Reforms, A Structured Approach

2. Collaboration and leadership in Juvenile Detention Reform

3. Controlling the Front Gates, Effective Admissions Policies and Practices

4. Consider the Alternatives, Planning and Implementing Detention Alternatives

5. Reducing Unnecessary Delay, Innovations in Case Processing

6. Improving Conditions of Confinement in Secure Juvenile Detention Centers

7. By the Numbers, The Role of Data and Information in Detention Reform

8. Ideas and Ideals to Reduce Disproportionate Detention of Minority Youth

9. Special Detention Cases, Strategies for Handling Difficult Populations

10. Changing Roles and Relationships in Detention Reform

11. Promoting and Sustaining Detention Reforms

12. Replicating Detention Reform, Lessons from the Florida Detention Initiative (Steinhart, 2000, p. 71).

Kentucky utilized these key elements of JDAI's documented effective detention systems (e.g., planning, collaboration, admissions, alternatives, timeliness, secure programming, data collection, minority representation, management strategies, changing roles, sustaining reforms, and replicating programs) and developed today's Department of Juvenile Justice. One intricate element of this process has been the development of $\underline{A}$ Practitioner's Guide to Juvenile Detention in Kentucky by The Children's Law Center. 
"The compilation of this manual involved a multi-disciplinary group of professionals dedicated to juvenile justice.... This project was supported by the Office of Juvenile Justice and Delinquency Prevention, Office of Justice Programs through the Kentucky Department of Juvenile Justice. The opinions, findings and conclusions or recommendations expressed in this publication are those of the authors and do not necessarily reflect the views of the US Department of Justice or Kentucky Department of Juvenile Justice" (Brooks et al., March, 2001, Foreward).

However, it is interesting to note that this document continues to be referenced as the "Bible" of juvenile detention centers. When Detention Alternative Coordinators (DAC) were interviewed to discuss the origin of detention in Kentucky, this document was referenced with reverence. Facility superintendents and assistant superintendents pointed in this direction when questioned about details. Therefore, it is safe to conclude that this document should be viewed as the basis for juvenile detention in Kentucky, since these programs are governed by the standards and procedures mandated in the document.

In 1996, the Kentucky General Assembly enacted legislation to reform Kentucky's Juvenile Justice System. The Department of Juvenile Justice (DJJ) was formed and began operations in December 1996. Ralph E. Kelly, Ed. D., was appointed as the first commissioner of juvenile justice. His first challenge was to address a federal mandate that ordered Kentucky to revamp the juvenile justice system.

While the Commonwealth was a long time participant in the Juvenile Justice and Delinquency Prevention Act (JJDPA) formula grant program, years of noncompliance eventually resulted in the state's removal from this formula grant program. The state's non- compliance included significant numbers of juveniles being housed in adult jail facilities, and high numbers of status offenders being detained in violation of the Act. As such, the state lost millions of dollars in JJDPA funding form 1992-1996 (Brooks, et al., Forward). 
The loss of funding provided a strong impetus to correct the situation. Two highlighted factors needing immediate attention were, (1) Too many juveniles being housed in adult jails, and (2) Kentucky's law permitting the secure detention of status offenders (Brooks et al., March, 2001).

Kentucky was given a grace period for the years 1997 and 1998. The Office of Juvenile Justice and Delinquency Prevention (OJJDP) held their funds and gave them a chance to get in compliance. In November 1998, Kentucky filed a plan with OJJDP to overhaul their juvenile programming and meet federal guidelines within a 3 year period. Since they were in compliance with three of the four core components by the end of their allotted time, they were granted the funds in February 1999. The four core modifications that brought Kentucky back in the federal graces were

(a) To eliminate the inappropriate or unnecessary use of secure detention;

(b) To minimize failures to appear and the incidence of delinquent behavior;

(c) To redirect public finances from building new facility capacity to responsible alternative strategies; and

(d) To improve conditions in secure detention facilities. (Steinhart, 2000, p. 6)

Kentucky did not comply with the "jail removal core requirement primarily because juveniles were being detained in Kentucky's intermittent holding facilities beyond the time permitted by federal law" (Brooks et al., March, 2001, p. II-5).

Kentucky received Title II formula grants to assist with the creation of alternatives to secure detention. In 1999, \$847, 000 from 1997 funds was used to establish alternative detention programs. As of January 2001, all but four of the original thirteen intermittent holding facilities in Kentucky had closed. DJJ continued construction of regional secure detention facilities and was able to report full compliance 
with JJDPA in its 1998 update to their 3 year improvement plan. They were awarded $100 \%$ of the available funds. The primary problem Kentucky faced with JJDPA was that statutes allowed the secure detention of status offenders for up to 43 days prior to disposition. In an effort to bring Kentucky in line with federal mandates, JJAC proposed HB 296 to the 2000 General Assembly (Brooks et al., March, 2001). The introduction of this bill served as a reminder of the state's commitment to providing juvenile offenders with the highest level of security, professionalism, and protection of rights. This emphasis evolved from the national trends of ignoring rights and operating under the European concept of the king/state (parens patriae) having jurisdiction over parental rights. Kentucky continues their effort to provide for the security of society and protect the rights of juveniles.

In 1988, Congress added the Disproportionate Minority Confinement (DMC) mandate to juvenile justice. Defined, this means "Disproportionality exists when the percentage of incarcerated minority juveniles exceeds the percentage of minority juveniles in the general population" (Brooks et al., March, 2001, p. II-6). Thomas (2000) noted the following:

In 1997, minorities made up about one-third of the juvenile population nationwide but accounted for nearly two-thirds of the detained and committed population in secure juvenile facilities. For black juveniles, the disparities were more evident. While black juveniles age 10 to 17 made up about $15 \%$ of the juvenile population, they accounted for $26 \%$ of juveniles arrested and $45 \%$ of delinquency cases involving detention. About one-third of adjudicated cases involved black juveniles, yet $40 \%$ of juveniles in secure residential placements were black. (p. 24)

Kentucky's Department of Juvenile Justice continues to be dedicated to monitoring the minority census. These statistics are proof of the need to keep a close watch on juvenile systems and their efforts to stop this waste of youth, hope, and promise. 
OJJDP's 1999 report, And Justice for Some, reiterates the need for a continued commitment to reducing minority representation in juvenile justice. Kentucky's minority population was $10 \%$ in 1999 with a rate for minorities in juvenile detention of $41 \%$. This rate was four times over Kentucky's population percentage with black males being the most over represented group. Furthermore, $56 \%$ of these minority juveniles were transferred to adult criminal facilities (Thomas, 2000).

In an effort to address the concerns these statistics ignited, Kentucky chose to follow intervention activities found in the Disproportionate Minority Confinement (DMC) Technical Assistance Manual, direct services, training and education, and system change (Thomas, 2000). Kentucky has focused on collecting data in a comprehensive and consistent manner. They created the Subcommittee on Equity and Justice for All Youth (SEJAY), with the goal of providing a "hands-on approach to pinpoint critical stages in the juvenile justice system where overrepresentation is present" (Brooks et al., March, 2001, p. II-13). The collection of these data will validate the need for programming change and will provide a direction for initiatives aimed at reducing minority representation in juvenile justice.

\section{Overview of Kentucky's Juvenile Detention System}

Historically, juvenile detention in Kentucky consisted of a county program that theoretically housed juveniles in separate sections of adult facilities. The criteria were that the juveniles should remain isolated by sight and sound and that the facilities be monitored by the Department of Corrections. In the 1990s, Kentucky counties saw an unprecedented increase in juvenile detention budget requirements. This escalation came about due to an increase in the demand for juvenile detention which, in turn, produced a 
shortage of facilities equipped to handle juveniles. The court system struggled to place juveniles appropriately and often had to transport a juvenile for extravagant distances (Brooks et al., March, 2001).

In addition to geographic location and travel, the state also experienced a multitude of other detention problems such as health care and educational providers, adequate housing, community services, and programming resources. These problems gave rise to "a rash of class action lawsuits, including lawsuits against the facilities in Kenton, Daviess, and Franklin Counties" (Brooks et al., March, 2001, p. III-I). Juvenile conditions were questioned concerning "improper supervision, poor environmental conditions, lack of educational resources, and other programming, along with inadequately trained staff”' (Brooks et al., March, 2001, p. III-I). Kentucky's juvenile crisis exploded in the political arena when funding from the Juvenile Justice and Delinquency Prevention Act (JJDPA) formula grant program was lost. Non-compliance with requirements (i.e., housing juveniles in adult facilities and detaining juveniles in violation of JJDPA) for multiple years led to placement on non-participating state status and resulted in the loss of millions of JJDPA funds from 1992 to 1996 (Brooks et al., March, 2001).

When finances became an issue, Kentucky's 1996 General Assembly appropriated funds for the establishment of the Department of Juvenile Justice. The goal was to instigate a statewide juvenile system that would meet JJDPA requirements and would relieve counties of "fiscal and operational responsibilities for the detention of juveniles" (Brooks et al., March, 2001 p. III-2). Ironically, in 1980, the Kentucky Unified Juvenile Code had been developed but was tabled until July 1, 1987, due to a lack of 
funds. At that time, its function was to revamp the entire Juvenile Justice system "to make Kentucky laws concerning juveniles comprehensive, predictable, consistent, systematic, logical, balanced, and fair" (Kentucky Youth Advocates, 1987, p. 4 - 6). In theory, the code was to align juvenile laws and place authority for adjudication in juvenile sessions of district court. If funding had been available, Kentucky would have avoided the federal mandate in 1996, which drove the state to juvenile justice reform. County jail systems would not have experienced the abrupt cut in funding by the establishment of centralized juvenile detention centers, and the at-risk population might have been rehabilitated; thus, a reduction in the adult prison population would have been forthcoming. It is a documented fact that juvenile delinquents have a higher rate of adult imprisonment due to the establishment of criminal patterns of behavior established during adolescence (Sabol, Minton, \& Harrison, 2007).

An important initiative created by the Kentucky Unified Juvenile Code is the Court Designated Worker (CDW) program. These individuals provide intake and diversions services and process public and status complaints on juveniles outside the formal court system in an effort to provide the best placement for these at-risk children (Williamson, 2000). If the youth is not subject to trial as an adult and it is only a status offense (an offense that is a crime because the individual committing the act is under 18), the CDW determines placement and avoids court involvement. Placement options are varied. Juveniles may be released to parents or a legal guardian or placed in an alternate holding facility. This early intervention clears the court dockets and allows for at-risk children to receive personalized attention from legal professions without the red tape of a court hearing and/or judgment (Williamson, 2000). 
"In 1980, the Kentucky General Assembly passed a comprehensive, unified juvenile justice system; however, due to state revenue shortfall, actual implementation was delayed for four years .... In July $1984, \$ 363,100$ was appropriated to the Administrative Office of the Courts for the preparation and implementation of a statewide Court Designated Worker (CDW) Program" which would protect the juvenile and society from violence and the violation of personal rights (Williamson, 2000 p. 20). This program was the beginning of a newer, more proactive juvenile justice organization designed with the needs of the juvenile and society in mind. The goal was to provide the least restrictive environment that would guarantee the safety and security of both entities.

Slowly, Kentucky moved toward excellence in juvenile justice as the department revamped its detention facilities. The operation and oversight of these units has moved from county catastrophes to well-oiled, state-run operations. Under Kentucky law, there were three types of secure facilities prior to 1997, a secure juvenile detention facility; a juvenile holding facility (separate location attached to an adult facility); and an intermittent holding facility (a secure setting in an adult facility with a limited detaining period not to exceed 24 hours) (KRS 600.020, 2001). The goal was for statewide detention to become the full responsibility of the state by 2003. By 2007, eight of the originally proposed ten facilities have been opened. Kentucky juvenile services continue to follow educational federal guidelines, Title I, by striving to provide the least restrictive environment possible while maintaining the safety and security of juveniles and of society.

The facilitator for the current DJJ policy is the Detention Alternatives Coordinator (DAC). This position is commissioned to screen at-risk youth admitted to a facility. An 
objective assessment is administered to determine the risk factor attached to the juvenile. Placement is based upon the results of these assessments and what is considered to be the least restrictive detention placement. Placement considerations are influenced by the juvenile's potential of danger to self and society, probability of appearing for a hearing, seriousness of the crime, re-offense risk, gang affiliation, drug use, family history, and court history (Brooks et al., March, 2001). The DAC has several options for placement. At times, emergency shelters are the optimal choice. When juveniles need to be detained, youth alternative centers, group homes, foster homes, and non-secure juvenile facilities might be an option. Finally, when there are serious concerns, secure centers are the method chosen (KRS600.020, 2001).

Serious concerns are defined in KRS Chapters 600 to 645 , which are traditionally referred to as the Unified Juvenile Code in Kentucky.

“"Abused or neglected child' means a child whose health or welfare is harmed or threatened with harm when his parent, guardian, or other person exercising custodial control or supervision of the child inflicts or allows the infliction of physical, sexual, or emotional injury by creating a high risk environment, engages in dangerous conduct, fails to provide essential protection and care, abandons the child, or exploits the child in anyway" (KRS 600, p. 621).

The current juvenile management system in Kentucky has evolved from a dismal county administered failure, which forced Kentucky to follow the national evolution of juvenile justice. However, as state budgeting becomes tighter, successful state juvenile facilities are facing some tough county opposition. For example, Daviess County has suffered severe revenue loss because of the new initiative. Problems began in 2001, when 
state officials transferred all juvenile inmates housed in Daviess County to a facility in Bowling Green, Kentucky. As a result, the county lost $\$ 90.00$ a day for every inmate housed in the 58-bed juvenile facility. The facility housing the juveniles was described by the following: "In 1998, the U.S. Department of Justice's Civil Rights Division alleged the downtown jail [that housed the juveniles] was overcrowded. Investigators also said the facility was 'dirty and unhealthy' and that inmates were abused and denied medical care" (Mayse, 2005).

Currently, this county is petitioning the state legislature to allow them to open a county run juvenile facility. When money comes into play, members of society step back and tend to take the least expensive route. Unfortunately, this inexpensive strategy has the potential of being a very costly mistake for the future. The U. S. Department of Justice released statistics projecting that 1 in every 15 people will serve time for a criminal act. In 2006, the number of state and county inmates reached 2, 245, 189, producing a staggering proportion of 497 prisoners per 100, 000 U.S. residents. The vastness of these numbers triggered an exploration of the characteristics of adult prisoners and produced an alarming statistic, $12 \%$ of the adult prison population reported having experienced some form of foster care or juvenile justice intervention. With this point in mind, society should be concerned when the overall number of juveniles delinquents increased by $26 \%$ (Sabol, Minton, \& Harrison, 2007). Thus, in the long run, cost savings on the front end will produce a greater deficit in finances and human potential as juvenile delinquents enter adulthood poorly prepared to become productive citizens. 


\section{Due Process}

The previous example is only one of many ways that politics become involved when state funding comes under scrutiny. Groups considered liabilities rather than assets frequently experience the first wave in budgetary reductions of services. Juvenile delinquents have historically been the losers in such political manipulations, i.e., parens patriae. It was much cheaper to defer to the dispensation of the court rather than to provide due process. Thankfully, the juvenile process rights are protected under the $6^{\text {th }}$ Amendment and the Due Process Clause of the $14^{\text {th }}$ Amendment of the United States Constitution along with Sections 2, 10, and 11 of the Kentucky Constitution (Brooks et al., 2001). Juvenile opportunity for representation is critical and has long been accepted by Kentucky's courts. This belief is supported by the finding in Sizemore $v$. Commonwealth, Ky., 450S.W. 2d 494, 497 (1970), "a waiver of counsel . . may not be permitted unless it appears that the waiver was intelligent, competently, understandingly, and voluntarily made by the defendant .... In all criminal prosecutions the accused shall enjoy the right to have the Assistance of Counsel for his defense" (Sizemore v.

Commonwealth, Ky., 450S.W. 2d 494, 497 (1970), p. 499). The final significance of the case was the establishment of financial responsibility for this right to counsel. "If courts have the inherent power to direct a lawyer to defend an indigent criminal, then those same courts have the inherent power to direct the state treasurer to pay the lawyer. If furnishing of counsel is the obligation of the state, then it is the obligation of all the people collectively and should be paid out of the common treasury" ((Sizemore $v$. Commonwealth, Ky., 450S.W. 2d 494, 497 (1970), p. 501). With the issue of payment settled, the appointment of counsel became law without controversy. 
The Kentucky Unified Juvenile Code of 1986 aligned the long-standing principles documented by the U.S. Supreme Court in re Gault, 287 U.S. 1 (1967) relevant to juvenile representation. "The court shall, when the child is brought before the court: (1) Explain to the child and his parents ... their respective rights to counsel and, if the child and his parents ... are unable to obtain counsel, shall appoint counsel for the child ..." (KRS 610.060, p. 648 [1] [a] ). The right against self-incrimination shall be explained by stating that the child, parents, relatives, guardians, or custodians may remain silent if their input is harmful to the case (p. 648 [1] [b]). Under this section of the law, the child also has the right to confront his accuser, appeal from a determination of the court, and, finally, "Advise the child that these rights belong to him and may not be waived by his parents, guardian, or person exercising custodial control" (KRS 610.060, p. 648 [1] [c] [d] \& [e]). Furthermore, "A child shall have a right to counsel at his detention hearing determining his right to freedom pending the disposition of his case ..." (KRS 610.290 [1]).

The U.S. Supreme Court in Schall v. Martin ruled on freedom from institutional restraint (Schall v. Martin, 467 U.S. 253, 1994). A juvenile's liberty interest is narrower than adults because, due to age, a juvenile is always in someone else's custody. A juvenile's right to liberty can be over-shadowed by the state's parens patriae in an effort to promote the welfare of the juvenile. However, the courts determined that due process had to be followed once the youth is detained.

According to the Schall case, (Schall v. Martin, 467 U.S. 253, 1994, p. 265) due process includes

(a) An expeditious probable cause hearing; 
(b) Findings regarding the need for detention once probable cause is established;

(c) Expedited fact-finding hearings;

(d) Conditions of confinement, which do not amount to punishment.

One of the references in the Schall v. Martin case of 1994 validates the need for

dedicated educators in juvenile detention centers:

Our society recognizes that juveniles in general are in the earlier stages of their emotional growth, that their intellectual development is incomplete, that they have had only limited practical experience, and that their value systems have not yet been clearly identified or firmly adopted .... For the same reasons that our society does not hold juveniles to an adult standard of responsibility for their conduct, our society may also conclude that there is a greater likelihood that a juvenile charged with delinquency, if released, will commit another criminal act more so than that an adult charged with a crime. To the extent that self-restraint may be expected to constrain adults, it may not be expected to operate with equal force as to juveniles. Because of the possibility of juvenile delinquency treatment and the absence of second-offender sentencing, there will not be the deterrent for the juvenile which confronts the adult. Perhaps more significant is the fact that in consequence of lack of experience and comprehension the juvenile does not view the commission of what are criminal acts in the same perspective as an adult .... There is the element of gamesmanship and the excitement of 'getting away' with something and the powerful inducement of peer pressures. All of these commonly acknowledged factors make the commission of criminal conduct on the part of juveniles in general more likely than in the case of adults (People ex rel. Wayburn $v$. Schupf, 39 N. Y. 2d, p. $687-688,350$ N. E. 2d, 1976 p. 908-909).

Central to the purpose of the current study was the examination of specialized educational programming intended to rehabilitate and educate incarcerated juveniles and reduce recidivism among those benefiting from these programs. The level of job satisfaction among professionals responsible for aligning this curriculum to core content was considered to be a major factor for best practices to be implemented. Furthermore, programs that were geared toward the rehabilitation of these at-risk children tended to score higher on state evaluation tools, and facilities were able to project a recidivism rate 
lower than the state average. Thus, the educational component of juvenile detention centers was documented as a intricate part of the rehabilitation process.

Society's current view of juvenile delinquents makes it imperative for providers of delinquent care to tap every resource in order to treat this epidemic of wasted youth. "In the past, many of the juveniles in the system were not considered hardened criminals, but simply wayward youngsters who had strayed from the right path. Today, buzzwords such as 'super predator' are used increasingly in the press and by politicians to describe the new type of youthful offender - ruthless young men and women who see crime as a rite of passage and who are unconcerned about the consequences of their actions" (Gluck, 1997, p. 62). In the 1970s, juvenile delinquent programming in the United States focused on treating the child as a whole person. In 1974, the United States Department of Justice issued the Juvenile Justice Delinquency Prevention Act (JJDPA) and established the Office of Juvenile Justice and Delinquency Prevention (OJJDP). The function of this entity was to share information so practitioners, researchers, policymakers, and the public would have ready access to reports on research findings, statistics, and programs that work for juvenile delinquency prevention and rehabilitation (Roush, October, 1996). Before the establishment of this act and office, schooling was the main component of the detention center; however, Roush's research suggested that other aspects of practical living should be addressed as well. One such component added was counseling. This area provided an enriched curriculum with an emphasis on instilling juvenile value and ethics as well as decision-making skills.

In the 1980s, a growth in adult corrections led to a reduction in juvenile services. "Facilities incorporated the best of the old programs into newer, more cost-effective 
ones" (Gluck, 1997, p. 66). Special education programs were developed, and federal funds were utilized in an educational setting to supplement funding cuts. The results found that the "best programs involved all the staff - teachers, doctors, counselors, youth workers - working together to deal with the whole kid" (Gluck, p. 66). In some locations, staff hours were manipulated so that programming could go on throughout the waking hours. "Traditional school hours were extended to ensure that everyone had an opportunity to attend class" (Gluck, 1997 p. 66). This is a testimonial to the need for informed, motivated, and accountable teachers.

In 1998, Kentucky opened its third juvenile detention facility. Governor Paul Patton stated, "Our goal is to make sure they don't move from here to there," (Schroeder, 1998) as he gestured toward the nearby Campbell County Jail. Then Commissioner Kelly stated, "These kids won't be sleeping in late, or watching TV all day" (Schroeder, 1998). He said the center would offer counseling, schoolwork, exercise, and other activities.

In contrast, on September 15, 2005, the Senate passed its fiscal year 2006 appropriation bill for Commerce, Justice, and Science, which included funding for juvenile justice programs. The Delinquency Prevention Block Grant Program was appropriated zero funds in FY05. There was a proposal for $\$ 43.1$ million for FY06. The House approved ZERO funds, and the Senate approved $\$ 5$ million (Blankenship, 2005). When funding cuts occur, programming suffers. Innovative efforts undergo drastic reductions because all energies surge to the vital organs, maintaining the status quo for survival. Without the dedication of motivated and innovative educators, juvenile detention centers will revert back to the ideology of locking them up rather than on treatment with the term "punishment" re-surfacing in many juvenile codes (Gluck, 1997). 


\section{Limitations of the Study}

According to the Office of Juvenile Justice and Delinquency Prevention, their mission is to "provide national leadership, coordination, and resources to prevent and respond to juvenile delinquency and victimization" (Silver, 1996). OJJDP supports states and communities in their efforts to develop and implement effective and coordinated prevention and intervention programs and to improve the juvenile justice system so that it protects public safety, holds offenders accountable, and provides treatment and rehabilitative services tailored to the needs of juveniles and their families (Silver, 1996).

One of the major initiatives promoted by OJJDP is research to develop knowledge about specific problems, monitor trends, and to analyze practices of juvenile justice systems. The goal is to conduct national quantitative research to assess the problem of delinquency and determine how the juvenile system can respond most effectively at local, state, and national levels. "The challenges presented by juveniles in crisis require coordination and information exchange among Federal agencies, State and local governments, professional organizations, researchers, and other juvenile justice professionals" (Silver, 1996).

The current study, Job Satisfaction levels of Juvenile Detention Education Faculties and the Implementation of Best Teaching Practices Compared to Overall Program Efficacy, was the researcher's effort to add to the knowledge base of Kentucky's educational practices in the eight juvenile detention centers located across the Commonwealth. It attempted to demonstrate the correlations among job satisfaction, best practice implementation, and program effectiveness, thereby, validating the necessity of 
the first two components to produce the third. In order to best utilize the information presented, the following limitations should be noted:

1. The primary sources of data collection were two questionnaires and the KECSAC SIDE document. The Minnesota Satisfaction Questionnaire was a purchased tool that had been extensively researched for validity and reliability. The Best Practices Survey was a researcher-developed tool based on an extensive literature review of best teaching practices for juvenile delinquent programming. The third piece used for data collection was the state developed program assessment tool - KECSAC which has not undergone reliability and validity checks. The two questionnaire tools have potential problems, getting an adequate number of responses, consistent responder understanding, and conscientious efforts to supply truthful answers. The SIDE document has the problem of reliability and validity.

2. This study was reflective of Kentucky Juvenile Detention Centers and covered a specific window of time; therefore, the generalizability of the results was limited to the specific study locations during the data collection time. Furthermore, the small number of centers $(n=8)$ caused concern when statistical procedures were used to make sense of collected data.

3. The Best Practice Survey was researcher generated. The pilot study yielded some reliability and validity; however, the survey needs to be administered again to get a sense of the true value of the data.

4. The KECSAC document provides overall institutional scores not individual quantities. Whereas, the MSQ and the BPS were completed by individuals 
teaching at these institutions.

5. Before the implementation of documented Best Practices at Detention Centers can occur, Professional Development and facility buy-in must occur to maintain safety and security at the facilities.

By keeping these limitations in mind, this study can best serve the purpose of supplying additional information to the present knowledge base for establishing effective programming for adjudicated youth, the value of which is supported by the Office of Juvenile Justice Delinquency Prevention.

\section{Definitions used in the Study}

Juvenile detention and education have a language specific to the area. In an effort to process the findings of this study, the following terms are briefly defined for accuracy and efficiency. Kentucky Revised Statue Chapters 600 to 645 provides these definitions (KRS 600.00-645.00). KRS 600.010 (1) states "KRS Chapters 600 to 645 shall be known as the Kentucky Unified Juvenile Code."

Abused or neglected child means a child whose health or welfare is harmed or threatened with harm when his parent, guardian, or other person exercising custodial control or supervision of the child:

(a) Inflicts or allow to be inflicted upon the child physical or emotional injury as defined in this section by other than accidental means;

(b) Creates or allows to be created a risk of physical or emotional injury as defined in this section to the child by other than accidental means;

(c) Engages in a pattern or conduct that renders the parent incapable of caring for the immediate and ongoing needs of the child including, but not limited to, 
parental incapacity due to alcohol and other drug abuse as defined in KRS 222.005;

(d) Continuously or repeatedly fails or refuses to provide essential parental care and protection for the child, considering the age of the child;

(e) Commits or allows to be committed an act of sexual abuse, sexual exploitation, or prostitution upon the child;

(f) Creates or allows to be created a risk that an act of sexual abuse, sexual exploitation, or prostitution will be committed upon the child;

(g) Abandons or exploits the child;

(h) Does not provide the child with adequate care, supervision, food, clothing, shelter, and education or medical care necessary for the child's well being. A parent or other person exercising custodial control or supervision of the child legitimately practicing the person's religious beliefs shall not be considered a negligent parent solely because of failure to provide specified medical treatment for a child for that reason alone. This exception shall not preclude a court from ordering necessary medical services for a child; or

(i) Fails to make sufficient progress toward identified goals as set forth in the court-approved case plan to allow for the safe return of the child to the parent that results in the child remaining committed to the cabinet and remaining to foster care for fifteen (15) of the most recent twenty-two (22) months.

Child means any person who has not reached his $18^{\text {th }}$ birthday, unless otherwise provided. 
Commitment means an order of the court which places a child under the custodial control or supervision of the Cabinet for Health and Family Services, Department of Juvenile Justice, or another facility or agency until the child attains the age of eighteen (18) unless the commitment is discharged under KRS Chapter 605 or the committing court terminates or extends the order.

Court means the juvenile session of District Court unless a statute specifies the adult session of District Court or the Circuit Court.

Court-designated worker means that organization or individual delegated by the Administrative Office of the Courts for the purposes of placing children in alternative placements prior to arraignment, conducting preliminary investigations, and formulating, entering into, and supervising diversion agreements and performing such other functions as authorized by law or court order.

Department means the Department for Community Based Services. In Kentucky it means the Department of Juvenile Justice (DJJ).

Dependent child means any child, other than an abused or neglected child, who is under improper care, custody, control, or guardianship that is not due to an intentional act of the parent, guardian, or person exercising custodial control or supervision of the child. Detention means the safe and temporary custody of a juvenile who is accused of conduct subject to the jurisdiction of the court who requires a restricted environment for his or her own or the community's protection.

Detention hearing means a hearing held by a judge or trial commissioner within twenty-four (24) hours, exclusive of weekends and holidays, of the start of any period of detention prior to adjudication. 
Emergency shelter is a group home, private residence, foster home, or similar home-like facility which provides temporary or emergency care of children and adequate staff and services consistent with the needs of each child.

Emotional injury means an injury to the mental or psychological capacity or emotional stability of a child as evidenced by a substantial and observable impairment in the child's ability to function within a normal range of performance and behavior with due regard to his age, development, culture, and environment as testified to by a qualified mental health professional.

Habitual runaway means any child who has been found by the court to have been absent from his place of lawful residence without the permission of his custodian for at least three (3) days during a one (1) year period.

Habitual truant means any child who has been found by the court to have been reported as a truant as defined in KRS 159.150 one (1), two (2), or more times during a one (1) year period.

Intermittent holding facility means a physically secure setting which is entirely separated from sight and sound from all other portions of a jail containing adult prisoners, in which a child accused of a public offense may be detained for a period not to exceed twenty-four (24) hours, exclusive of weekends and holidays prior to a detention hearing as provided for in KRS 610.265, and in which children are supervised and observed on a regular basis by certified juvenile facility staff.

Juvenile holding facility means a physically secure facility, approved by the Department of Juvenile Justice, which is an entirely separate portion or wing of a building containing an adult jail, which provides total sight and sound separation between 
juvenile and adult facility spatial areas and which is staffed by sufficient certified juvenile facility staff to provide twenty-four (24) hours per day supervision.

Least restrictive alternative means, except for purposes of KRS Chapter 645, that the program developed on the child's behalf is no more harsh, hazardous, or intrusive than necessary; or involves no restrictions on physical movements nor requirements for residential care except as reasonably necessary for the protection of the child from physical injury; or protection of the community, and is conducted at the suitable available facility closest to the child's place of residence.

Needs of the child means providing necessary food, clothing, health, shelter, and education.

Non-secure facility means a facility which provides its residents access to the surrounding community and which does not rely primarily on the use of physically restricting construction and hardware to restrict freedom.

Parent means the biological or adoptive mother or father of a child.

Person exercising custodial control or supervision means a person or agency that has assumed the role and responsibility of a parent or guardian for the child, but does not necessarily have legal custody of the child.

Physical injury means substantial physical pain or any impairment of physical condition.

Physical secure facility means a facility that relies primarily on the use of construction and hardware such as locks, bars, and fences to restrict freedom.

Public offense action means an action, excluding contempt, brought in the interest of a child who is accused of committing an offense under KRS Chapter 527 or a public 
offense which, if committed by an adult, would be a crime, whether the same is a felony, misdemeanor, or violation, other than an action alleging that a child sixteen (16) years of age or older has committed a motor vehicle offense.

School personnel mean those certified persons under the supervision of the local public or private education agency.

Secure juvenile detention facility means any physically secure facility used for the secure detention of children other than any facility in which adult prisoners are confined.

Serious physical injury means physical injury which creates a substantial risk of death or which causes serious prolonged disfigurement, prolonged impairment of health, or prolonged loss or impairment of the function of any bodily member or organ.

Sexual abuse includes, but is not necessarily limited to, any contacts or interactions in which the parent, guardian, or other person having custodial control or supervision of the child or responsibility for his welfare, uses or allows, permits, or encourages the use of the child for the purposes of the sexual stimulation of the perpetrator or another person.

Sexual exploitation includes, but is not limited to, a situation in which a parent, guardian, or other person having custodial control or supervision of a child or responsible for his welfare allows, permits, or encourages the child to engage in an act which constitutes prostitution under Kentucky law; or a parent, guardian, or other person having custodial control or supervision of a child or responsible for his welfare allows, permits, or encourages the child to engage in an act of obscene or pornographic photographing, filming, or depicting of a child as provided for under Kentucky law. 
Social service worker means any employee of the cabinet or any private agency designated as such by the secretary of the cabinet or a social worker employed by a county or city who has been approved by the cabinet to provide, under its supervision, services to families and children.

State secure facility for residential treatment means any setting, which assures that all entrances and exits are under the exclusive control of the facility staff, and in which a child may reside for the purpose of receiving treatment.

Status offense action is any action brought in the interest of a child who is accused of committing acts, which if committed by an adult, would not be a crime. Such behavior shall not be considered criminal or delinquent and such children shall be termed status offenders. Status offenses shall not include violations of state or local ordinances which may apply to children, such as a violation of curfew or possession of alcoholic beverages.

Take into custody means the procedure by which a peace officer or other authorized person initially assumes custody of a child. A child may be taken into custody for a period of time not to exceed two (2) hours.

Valid court order means a court order issued by a judge to a child alleged or found to be a status offender:

(a) Who was brought before the court and made subject to the order;

(b) Whose future conduct was regulated by the order;

(c) Who was given written and verbal warning of the consequences of the violation of the order at the time the order was issued and whose attorney or parent or legal guardian was also provided with a written notice of the 
consequences of violation of the order, which notification is reflected in the record of the court proceedings; and

(d) Who received, before the issuance of the order, the full due process rights guaranteed by the Constitution of the United States.

Violation means any offense, other than a traffic infraction, for which a sentence of a fine only can be imposed.

Youthful offender means any person regardless of age, transferred to Circuit Court under the provisions of KRS Chapter 635 or 640 and who is subsequently convicted in Circuit Court.

This extensive list of definitions serves as validation of the technicalities, rights, obligations, and legal ramifications contained in the juvenile justice legal system. The guardians of this legal system have attempted to define and align all aspects of legal proceedings that involve juvenile delinquents. The laws, rights, and proceedings that govern the handling of at-risk children are consistent and protective. They are the result of many law suits, advocacy groups' audits and watch-dog tactics, and compassionate politicians who were striving to provide a rehabilitative educational system that would rescue the growing number of children getting involved in destructive, illegal activity.

\section{Summary}

In 1996, Kentucky's legislature implemented a comprehensive reform of the juvenile justice department as the result of a federal mandate stating that funding would be withdrawn unless specific issues were resolved. By 1999, concerns had been addressed and funding was restored to the department. With this restoration, Kentucky's Juvenile Justice Department became a nationally recognized leader in juvenile reform. 
The Quality Assurance Branch monitors educational programming to assure that the impetus of this mandate continues.

The researcher shares this concern for excellence and has explored ways to determine the quality of educational offerings to a challenging yet deserving at-risk juvenile population. There is very little research available that focuses on the correlation of the three components explored; therefore, this non-experimental, quantitative study was conducted to add to the knowledge base of strategies and conditions that have proven effective for working with this group. By measuring job satisfaction, evaluating the implementation of best teaching practices, and coordinating those measurements with overall program efficacy, this study will show the relationship among these variables and highlight the importance of satisfied teachers who are motivated to utilize the most proficient instructional strategies in order to have a successful program that addresses the needs of this volatile population. 


\section{CHAPTER II}

\section{REVIEW OF THE LITERATURE}

This literature review was divided into five sections. Each section has subsections that serve to provide a clearer picture of the divisions. The first part of the literature review described the at-risk population incarcerated in juvenile detention centers and profiled the students of challenged educators. In order to explain this research, there was a need to explain the participants. This explanation involved three sub-sections that defined juvenile delinquents. The first section, Definition of At-Risk Juvenile Delinquents, contained a definition of the at-risk population that required the services which unsuspecting educators were expected to deliver with professional, yet compassionate, expertise. It provided a historical connection for the development of the term at-risk and empirical research that facilitated a rich and meaningful description. The first section ended with a summary of the literature review that substantiated this definition of at-risk.

As the foundation developed, the needs, characteristics, and strategies that are unique to this population were explored. The second section of the review, Teaching Juvenile Delinquents, attempted to summarize the findings discovered. It looked at the suggested strategies and was used to describe the teacher best qualified for a juvenile detention setting. From the tactics, a picture was framed of the type of educator needed to work with these residents. Troubled adults cannot effectively work with troubled children. These empirical data were taken from a purposeful random sampling of the 
populations and are subjected to statistical processes to provide tabulation and correlation and to confirm validity and reliability. The research was summarized and will provide validation for the study.

The third section addressed Self Concept. There is an essential need for selfesteem, in this population. These juvenile delinquents stumble through Maslow's Hierarchy of Needs (Maslow, 1954) and are struggling to meet the requirements of the self-esteem level. The section summarized resources that provided prolonged studies with statistical analyses; triangulation; peer reviews; negative case analysis; clarification of biases; member review; rich, thick data; and to a limited degree, external audits. From an examination of the children, a checklist for the teachers was developed. The resulting evaluation tool, BPS, served as a measure of successful juvenile detention centers and facility educators. A summary provided a synopsis of self-concept and its presence in the juvenile delinquent populations at detention centers; thereby, a snapshot of the requirements for a detention center educator was developed.

The fourth section moved the focus away from the student and explored the teacher's Job Satisfaction level. The significance of high job satisfaction was highlighted by the unique characteristics and abilities that juvenile detention center educators must possess. In order to meet the unique demands of their placement, "Detention education must be geared to the diverse academic, cultural, social, emotional, and developmental needs of the youth in detention" and these educators must have a strong knowledge base and a firm dedication to their task (Roush, October, 1996, p. 123). Dissatisfaction with job placement was hypothesized to be one of the main factors for the absence of best practices in facility programming. Empirical research showed this belief was not 
necessarily accurate; however, the findings were inconclusive and the researcher decided to use personal observation as the deciding factor for making a strong argument that Job Satisfaction levels were tied to program efficacy.

Prior to conducting the research, a pilot study was undertaken. The purpose was to refine the data gathering instruments, to define the population, and to streamline data analysis. The fifth section, Pilot Study Findings, highlighted the unique characteristics of juvenile justice personnel as opposed to juvenile detention center educators. This section explained the need for the proper definition of teacher and highlighted the distinctive nature of the detention setting, "Juvenile detention is the temporary and safe custody of juveniles who are accused of conduct subject to the jurisdiction of the court and who require a restricted environment for their own or the community's protection while pending legal action" (Roush, April, 1996, p. 4). The study also served as a guide for sorting data and for justification of limiting correlation explorations.

As previously stated, the chapter comprises five sections: Definition, Teaching, Self Concept, Job Satisfaction, and Pilot Study Findings. Empirical studies were synthesized in each category. To facilitate the development of a concise, informative review, each section was divided into subsets. Definition of At-Risk, had four components: Essential Needs Factors, Educational Factors, Emotional/Behavior Factors, and Substance Abuse Factors. Teaching Juvenile Delinquents had three components: Needs, Characteristics, and Strategies. Self Concept had two components: Self-Esteem and Recidivism. The fourth section of this literature review focused on the type of educator needed for this at-risk population and supported the connection between job satisfaction and job performance, to a limited degree. Theoretically, if one is satisfied, 
one will perform better. Better performance will occur because of an implementation of higher quality educational skills. With both of these factors present, the program should score higher on state evaluations based on research. When this chapter was completed, the literature review provided a research basis for a study of Job Satisfaction Levels of Juvenile Detention Education Faculties and the Implementation of Best Teaching Practices Compared to Overall Program Efficacy.

Definition of At-Risk: Juvenile Delinquents

\section{Essential Needs Factors}

Working with juvenile delinquents requires the consideration of several factors. One necessary element is the ability to define the at-risk behavior present in the children. This definition is rooted in a long tradition of analyzing juveniles and pinpointing needs prevalent in the population at-risk of falling behind their peers. The at-risk status can be due to many reasons. Children born with physical handicaps are automatically placed in the at-risk slot along with children born with mental deficits. A third bracket for the atrisk definition deals with economic issues, and the fourth area deals with social challenges for a socio-economic division. These four factors are viewed as the major causes of children falling behind their peers and will be discussed further in the chapter.

In 1954, Maslow's Hierarchy of Needs was developed. This theory said that there were five levels of needs present in a child's life. The first level of need was the requirement for physical gratification. Included in this level was the need for food, water, clothes, and shelter. The second level of need was labeled safety. This area included a requirement for security and protection. Third, children had a need for social gratification. The need to feel that they belonged and were accepted by a group was 
essential for their sense of self. Fourth, there was a need for esteem. Individuals needed to respect themselves and others in their world. Last, when individuals reached the highest level of Maslow's Hierarchy, self-actualization, they reached the maximum portal of development. It was the area where self-fulfillment became the focus and the need for validation moved from peer approval to self-acknowledgement (Maslow, 1954)

In 1994, Human Resources, Webb, Montello, and Norton discussed a new version of Maslow's Hierarchy of needs. They explained a technique which Alderfer developed, the ERG (Existence, Relatedness, and Growth) theory. This theory contends that individuals can move in between levels without having all the requirements of each division met to move up and there is an overlapping of levels that allows one to advance in given circumstances. The Existence level includes the physiological and safety levels of Maslow's Hierarchy. Relatedness includes safety, social, and esteem. The Growth level includes the esteem and actualization level. According to Webb, Montello, and Norton, 1994, motivation is present in all three levels. The motivation depends on the seriousness of the need. Individuals may seek needs at higher levels even though some lower level needs have not been met. This happens when there is not a pressing need for the components of the level. For instance, in detention, residents may jump to the Esteem level because the lower needs of safety and social are not relevant. The WRJDC detention program is aligned to provide a universal fulfillment of these needs without considering individual requirements.

Juvenile delinquents in detention centers suffer from the consequences of this need for peer approval. Society has documented proof that succumbing to peer pressure could lead to serious and long-term consequences (e.g., note the number of juvenile 
delinquents processed by juvenile justice on a yearly basis). Koerner (2000) contended that juveniles became delinquents by choice. Responsibility for actions was avoided and there was a deceptive act of boredom utilized that drove others away. Adolescents had learned that trying new skills could lead to failure. Therefore, their feelings of omnipotence were damaged. To survive, these students stopped trying because they feared failure, which would cause them to acknowledge that they were not all powerful. Gang/clique acceptance was a blessing and a curse. These groups gave a sense of belonging, but they could also turn on the member, if it became profitable to sacrifice the individual. These students loved to find weaknesses in others; however, they feared exposure of their "real" self. When they did not like something, they responded with anger and violence. Their mentality was that no one, not even the great "me, and I'm in charge" could change things. Their actions were rooted in the hopelessness they felt which permeated their existence and which destroyed their connectedness and fostered alienation.

In 2003, Heward authored Exceptional Children. In his work, at-risk refers to children considered to have a greater than usual chance of developing a disability. This definition is often applied to infants and pre-school children because of birth conditions or home environment. It also refers to students with learning problems that put them atrisk of school failure. Disability is any restriction or lack of ability to perform an activity in the manner or within range considered normal for a human. At-risk children are more like other children than they are different. Documented risk factors include biological and environment concerns. There are developmental delay factors, which include items such as delayed speech. There are established risk conditions, which mean conditions such as 
Down syndrome and biological risk conditions such as premature births. Finally, there are environmental risk such as extreme poverty, parental drug/alcohol abuse, homelessness, abuse/neglect, and low parental mentality. All of these factors are present at the beginning of a child's life. It is unfair for these circumstances, over which they have no control, to repress the development of their potential intelligences and, therefore, handicap them in today's competitive society.

As a summary of juvenile delinquency and at-risk, 2003 saw the advent of a book by Rubin called Juvenile Justice Policies, Practices, and Programs. He defined at-risk in terms of juvenile justice jurisdiction. He used terms such as abused - physical, sexual, and emotional; neglected - absence of proper care provided by parents (i.e., food, shelter, safety, education, medical); and dependency - absence of care through no fault of the parents because there are no parents or they have no funds. Status Offenders refers to children who have conduct illegal only because of their age. For instance, they are run a ways, they are truants, or they are beyond parental control. Youthful Offenders refers to children who are being charged as adults due to the seriousness of their crimes. Juvenile justice looks more closely at the specific areas of at-risk behavior in order to provide focused interventions. In Juvenile Justice, at-risk is defined as a juvenile who has committed an offense at an early age, and/or exhibits a multiple problem profile that includes significant problems within the family, at school, with drugs, with alcohol, gang involvement, running away, and stealing.

\section{Educational Factors}

Bonny, Britto, Klostermann, Hornung, and Slap (2000) explored school connectedness or the feeling of closeness to school personnel and the school 
environment. This quantitative study defined "at-risk" in terms of inter-personal relationships. The researchers hypothesized this connection in the school environment decreased the likelihood of health risking behaviors during adolescence. They hoped to target the factors that differentiated between those who felt connected and those who felt alienated and to provide interventions to improve the conditions of at-risk students.

The population of the study consisted of all students attending the $7^{\text {th }}$ through $12^{\text {th }}$ grades of eight public schools. The students completed a modified version of the inschool survey designed for the National Longitudinal Study of Adolescent Health (Add Health). The school connectedness score (SCS) was the summation of five survey items. Bi-variate analyses were used to evaluate the association between SCS and twelve self reported dependent variables. The SCS had a mean of 15.7 and a range of 5 to 25 . Of the twelve variables associated with connectedness, seven (gender, race, extracurricular involvement, cigarette use, health status, school nurse visits, and school area) were examined in the linear regression model utilized to identify a set of factors best predicting connectedness. All, but gender, were significant in predicting students with SCS $>1$ standard deviation below the mean.

Of the 3,491 students receiving surveys, $56 \%$ (1, 959 students) submitted usable surveys. The sample was $47 \%$ white and $38 \%$ black. Median age was 15 and median grade was ninth. The findings of the study showed that decreasing school connectedness was associated with four potential factors, declining health status, increasing school nurse visits, cigarette use, and lack of extracurricular involvement. Black race, female gender, and urban schools were also associated with lower school connectedness scores. These 
factors should be signals for school personnel to point out potential at-risk students and allow for proactive intervention instead of reactive treatment.

One program that could be implemented to restore school connectedness proactively came in the work of Leone and Malmgren (2000) who examined the academic achievement of incarcerated youth that participated in an intensive summer reading program. The intervention combined direct instruction and whole language activities over a 6 week summer program. The study design was a quantitative study, which looked at pre-and post-test data. Paired $t$ test of pre-and post-test showed significant improvement.

The method was an intensive auxiliary reading program for juvenile delinquents housed at a detention facility serving a large urban area on the east coast. The intervention combined approximately three hours of direct instruction and whole language reading activities per day. Pre- and post-test reading skills were assessed via the Gray Oral Reading Test, third edition (GORT-3). Paired $t$ tests of pre- and post-test standardized scores demonstrated significant improvements on three of four reading subtests.

The focus of the study was on the effect of a short intensive reading program on the reading abilities of low-achieving incarcerated youth. Pre-tests were conducted in June and July, 1998 with Form A of the GORT-3. Assessors were trained in utilization of the device and included the test author and four graduate students from the fields of special education and criminal justice. All pre- and post-tests were administered on a oneon-one basis at the detention facility.

The intervention procedure consisted of the administration of a corrective reading 
placement test to all participants. Students were grouped for instruction on the basis of their performance. Reading instruction consisted of (a) Corrective reading curriculum, (b) whole language reading instruction comprising reciprocal peer tutoring with an emphasis on student summarization and prediction, and (c) oral reading. Components of the approach addressed standards of both code and meaning emphasis approaches to reading instruction. Intervention activities for a 6 week period were 45 minutes of corrective reading comprehension instruction; 60 minutes of whole language/peer tutoring activities; and 20 minutes of teachers reading aloud. Over the 6 week period, each intervention classroom was visited several times. The level of treatment integrity was calculated by dividing the number of occurrences by the total number of observations. Treatment integrity was high with $100 \%$ fidelity of implementation of key components. Youngsters who participated in this study were selected from a larger sample of 103 juveniles adjudicated at the detention facility in early July, 1998. One hundred participated in the pre-test: 98 males and 2 females with 3 non-participants. Fifty-one of this initial testing remained at the center for the duration of the study. Two participants turned 19 before the post-test so the sample size was $(n=49)$. Only participants whose pre-test scores were at least $2 / 3$ of a standard deviation below the mean on an overall composite score of reading were included $(n=45)$. The average age of the 45 males was 17.07 (minimum 13.92 and maximum 18.75). All 45 were African-American. Criminal charges made up $77.8 \%$ of the reasons for commitment. Detained juveniles made up the remaining $22.2 \%$. There were $44.4 \%$ who received special services $([n=10]$ for emotional; $[n=7]$ for learning disabilities, $[n=3]$ for mental retardation).

The study did not identify the independent variable; however, it appeared to be 
reading instruction. The dependent measures were the GORT-3 scores. These tests were constructed to have a mean Oral Reading Quotient (ORQ) of 100 and a standard deviation of 15 . At pre-test, the median ORQ for the selected sample was 58, which was below the first percentile. A mean ORQ could not be computed because of the large number of participants who scored below the floor of 52 . Over $73 \%(n=33)$ of the participants scored pre-test ORQ's at or below the first percentile. Standardized scores on the four GORT-3 sub-tests (i.e., Rate, Accuracy, Passage, and Comprehension) were utilized as dependent variables.

Analyses were conducted utilizing $t$ tests for paired observations with participants' pre- and post-test scores. Using an alpha level of .05, pre- and post-test differences on the sub-tests rates were found to be statistically significant with $t(.44)=$ $2.81, p=.007$. Pre- and post-tests differences on accuracy were significant with $t(44)=$ $3.13, \mathrm{p}=.003$. Passage was significant $t(44)=2.42, p=.020$, but Comprehension did not reach statistical significance $t(44)=1.53, p=.133$. At post-test, $66.7 \%$ of the samples $(n$ $=30)$ still recorded ORQ scores at or below the first percentile, while $8.8 \%(n=4)$ scored within $2 / 3$ of a standard deviation of the mean.

The results of the present study demonstrated that it was possible to improve reading skills for low-achieving juveniles with a relatively brief intervention. The 45 juveniles in the study showed overall gains in each of the four sub-tests as measured by the GORT-3. Gains on the Comprehension test were not statistically significant and suggested that these skills were more resistant to change or that the program design was not as powerful with regard to Comprehension as it was for fluency.

Over all scores for ORQ's at the pre-test stage was $61.2 \%(n=30)$ of the portion 
who remained at the facility for the whole study. At the post-test, a large number still scored below the first percentile and added emphasis to concerns that a large percentage of incarcerated youth possesses inadequate reading skills that led to recidivism.

One limitation of the study was the fact that simultaneous activities made it impossible to pinpoint particular components which were responsible for the improvements reported. Another limitation was the lack of formal fidelity of treatment implementation measures. This study demonstrated that short-term, intensive educational services can have a positive impact on the reading performance of incarcerated youth, reduce the recidivism rate, and remove one of the main causes of the at-risk label, "educationally challenged."

The educational focus was continued as Beebe \& Mueller (1993) conducted an investigation to relate juvenile offenders' categories of offense with their achievement status. The study reviewed case records and documented the relationship between achievement and juvenile offense. Research design and methods were based on a qualitative case study approach that utilized historical documents. The case file for every resident during a 1-year span was reviewed and coded as to demographics (age, sex, and grade placement, nature of offense, intelligence/reading, and math achievement test data). The study was historical and descriptive in nature.

All youthful offenders in the review were placed in a regional juvenile detention center under court order. The regional detention center (RDC) was a state operated facility licensed by the Department of Social Services in the state of Michigan. The RDC was a secure setting for male and female youthful offenders. The youth represented 63 different counties. There were 12 sixth graders; 158 tenth graders; 96 ninth graders and 
57 twelfth graders. The sample $(n=583)$ consisted of 486 males and 97 females. The study did not identify independent and dependent variables.

The categories of offense were Category 1-Aggressive Felonies, Category IIProperty Felonies, Category III-Misdemeanor, and Category IV-Status Offenses. The residents were characterized by the offense for which the youth was charged. After this placement was determined based on court records, the residents were evaluated based on different achievement procedures. Test results utilized were accumulated from Peabody Individual Achievement Test, Wide Range Achievement Test, Woodcock Johnson Psycho-Educational Battery, Basic Achievement Skills Individual Screener, Woodcock Reading Mastery, and Durrel Analysis of Reading Difficulties.

The data were mostly associated with the Wide Range Achievement Test. No differentiation was made regarding sex and achievement level. The demographic data, category of offense, and achievement grade level were surveyed. The results revealed in this sample showed that the majority, $95 \%$ were functioning below grade level in Reading and $98 \%$ were below grade level in Math. The means and standard deviations of the Reading and Math standard scores showed that although the Reading scores were below average, they were still higher than Math. A $t$ test was utilized to determine if a significant difference between Reading and Math scores by category was noted. A significant score was found in each category with Reading skills being stronger than Math skills. The data were further analyzed to see if differences existed among the various categories on the Reading dimensions. The researchers did $t$ test comparisons by categories. These results indicate that those offenders with aggressive felonies had more 
severe Reading and Math deficiencies than the other categories. No difference was noted in Reading and Math skills in the other categories.

Of the 583 subjects, 271 had intelligence test results included in their file. The Wechsler Intelligence Scale for Children was the most frequently used procedure. This sample attained a mean intelligence quotient of 89.7 on those subjects having Reading and IQ test results. The mean achievement standard score was 87.38 . The mean intelligence quotient of Math scores was 81.66. The difficulty in the academic realm appeared less dramatic when related to expectation levels as opposed to their grade replacement.

The summary of this study showed that adjudicated youth had problems conceptualizing and processing information with basic reading skills and with mathematical computations. The study hypothesized that youths with learning difficulties were more likely to be delinquent if they (a) were ADHD and displayed aggressive behavior, (b) had a relatively low IQ, abrasive social skills, and language social perception difficulties, (c) were significantly frustrated over school achievement, (d) had a history of both early conduct problems and a parent, particularly a father, who was criminal and/or alcoholic, and (e) were part of a family system in which there was significant difficulty in setting and enforcing rules. Juvenile delinquent youth at the RDC exhibited intellectual and academic skill deficits regardless of offense category through the more severe achievement deficits related to more severe charges; this finding supports the definition of at-risk youth, which is under development. Low educational attainment tends to be directly tied to juvenile delinquent tendencies. 
Payne (1998) generated some understandings of these phenomena in her work.

She stated that there are two types of poverty. They are generational poverty which has to do with a family having been in poverty for at least two generations and situational poverty that has to do with the lack of resources due to a particular event (i.e., death, illness, or divorce). Generational poverty has its own culture, rules and beliefs. A key indicator of the two is that in generational poverty there is a mentality of society owing one a living and in situational poverty there is one of pride and a refusal to accept charity. Poverty is a major force in at-risk youth. Characteristics evident in youths in a poverty setting are disorganization, excuses, no homework, physical aggressiveness, need to entertain, only seeing "parts" of the situation, inability to monitor behavior and motivate self, laughing when disciplined, only working if they like the teacher, disliking authority, unawareness of common courtesies, and the need to talk back. Being in poverty is rarely about lack of intelligence or ability; it is contingent upon situations in which a youth finds himself or herself. Poverty males tend to fight and flee as coping strategies while poverty females take care of their man and downplay his faults. Both populations are doomed to failure. To escape, students must (1) realize there is a choice, (2) be taught the hidden rules of society, and (3) be provided with the necessary education to advance.

\section{Emotional/Behavioral Factors}

The definition develops and emotional/behavior factors are highlighted as significant areas of concern in explaining juvenile delinquents. Prior, Smart, Sanson, \& Oberklaid (2001) conducted a review of longitudinal data, from infancy onward, as a prospective study of the temperament and development of a large and representative sample $(n=2443)$ in Victoria, Australia. They were examined to identify predictors of 
psychological disorder at 11-12 years of age. Subjects contacted were evaluated on an 18month cycle from the first year of life. At the time of this article, 1, 724 of the original participants were still available to provide information. Epidemiological data indicated that $15-20 \%$ of school-age children suffered relatively serious behavioral and emotional problems, which significantly compromised their everyday functioning in multiple domains.

Children scoring in the at-risk range for psychological disorder, according to parents, teachers, and self-reports using the Child Behavior Questionnaire, were selected at 11-12 years of age for an in-depth assessment and comparison with a group of children with no history of adjustment problems. Analysis of group differences using longitudinal data gathered from infancy to 12 years focused on parent and teacher reports on child temperament and behavior, various facets of home, and school adjustments. Authors developed a child report form to be utilized with the Rutter Child Behavior Questionnaires to evaluate outcome measures of adjustment for the 12-year-old students. Sub-scores, as well as a total behavior problem scores, were provided. When ratings fell in the clinically needy range, tabulation occurred to show the stability of behavior problems. Furthermore, data showed $80 \%$ of the ratings had been in the delinquent range at least once. In the comparison group, only $10 \%$ fell into the at-risk range.

To detect emerging differences related to the development of problems, a series of MANOVA analyses were conducted to examine the data year by year and by source of report. In the process, a number of statistical analyses were performed to guard against Type I errors. Following a significant MANOVA result, unvaried $F$ tests were computed 
to assess the contribution of the individual variables. In the analysis of variance tests, an effect size of 0.10 was defined as small, 0.25 as medium, and 0.40 as a large effect.

The strongest predictors of adjustment at 12 years were previous behavior problems along with some specific temperament factors involving self-regulation capacities and mother's overall rating of child difficulty. Results based on parallel teacher data, including peer adjustment and social and academic competence measures, were consistent with parent data. Overall, the research confirmed the persistence of early appearing behavior problems in a community sample and the longitudinal influence of temperament factors in childhood. The study supported the need for a focus on early intervention and prevention strategies in the child mental health field. The preceding case study highlighted the need for state institutions to be proactive in their dealings with atrisk youth as they develop a preventative stance instead of a treatment mentality. This preventative stance required a look at juvenile detention.

Smith (1998) conducted a survey with youths incarcerated at a juvenile detention center to explore emotional and behavioral characteristics. The study was focused on recent changes in health care options that have resulted in longer stays in detention centers for children who might previously have been given alternative residential treatment.

Sixty-one residents were interviewed from December 1997 through March 1998. Ages ranged from 11 to 18 years. The ethnic makeup of the sample was $67 \%$ Hispanic, $18 \%$ Anglo, $8 \%$ African American 5\% Native American, and 1\% Asian. The sample contained $77 \%$ males and $23 \%$ females. Almost half of the students were in special 
education. The average number of times arrested by self-report was eight. There were no independent or dependent variables identified in the study.

The research design was a qualitative self-report assessment of behavioral and emotional functioning. Questions were worded in a manner which aided in making diagnosis using criteria from the Diagnostic and Statistical Manual of Mental Disorders (DSM-IV). For the purpose of this survey, when a participant answered in a manner consistent with a DSM - IV diagnosis, it was considered sufficient to suggest a problem area.

Residents were approached and asked if they would be willing to participate in an interview. Questions from the inventory were read to the resident who marked yes or no on an answer sheet. This procedure was necessary because of the large number of residents with poor reading skills. This study compared a 1991 study to the current study in the table below. 


\begin{tabular}{lll}
\hline Inventory Question & 1998 & 1991 \\
\hline Parents not married & $82 \%$ & $78 \%$ \\
Family members in trouble w/ the law & $77 \%$ & $35 \%$ \\
Alcohol Use & $33 \%$ & $56 \%$ \\
Marijuana Use & $53 \%$ & $37 \%$ \\
Inhalant & $57 \%$ & $28 \%$ \\
Cocaine & $51 \%$ & $26 \%$ \\
ADHD & $79 \%$ & $50 \%$ \\
More Violent Conduct Disorder & $90 \%$ & $79 \%$ \\
Depression Rates & $54 \%$ & $46 \%$ \\
Manic Depression & $39 \%$ & $20 \%$ \\
Anxiety Disorder & $54 \%$ & $25 \%$ \\
Post Traumatic Stress Disorder & $26 \%$ & $40 \%$ \\
Suicide Attempt & $32 \%$ & $25 \%$ \\
\hline
\end{tabular}

Figure 3. Smith's 1991 and 1998 Comparisons.

Results suggested that the residents had more emotional and behavioral difficulties than those who were detained seven years ago. Suicide rates were found to be twice as high for detained adolescents with internalizing problems of depression and anxiety. Little formal research had been conducted on rates of mental illness among adolescents and this study simply reported the facts without any statistical manipulation. The value of the study was the additional awareness of suicide as a component of the atrisk definition. 
In keeping with the purpose of this section to define at-risk, this article was selected because the authors, Roberts and Ryan (2002), conducted a study that sought to determine the prevalence and socio-demographic characteristics of tattooed adolescents in a nationally representative sample and to evaluate the association between tattooing and several high-risk behaviors.

This was a quantitative study that used data collected by the National Longitudinal Study of Adolescent Health (Add Health). For this survey, adolescents were randomly selected from a representative sample of junior and senior high schools and invited to complete two waves of in-home surveys, 1 year apart. The schools were stratified by size, ethnic composition, region, and neighborhood type. Individual adolescents were stratified by gender and grade. Other groups were intentionally oversampled to supplement the nationally representative core sample group. An initial group of $(n=72,118)$ adolescents completed the first wave. Only the core sample group was used for this study $(n=6,072)$.

After the exclusion of $12^{\text {th }}$ graders and respondents who did not complete wave two, the sample size was $(n=4595)$. The independent variable was listed in the study as a predictor variable. It was the possession of a permanent tattoo. Socio-demographic factors used as predictor variables included gender, age, ethnicity, neighborhood type, number of parents in the home, parental educational level, and family income.

The dependent variables were listed as outcome variables. They were selected from four major areas of high-risk behavior: sexual involvement, substance use, violent behavior, and school problems. Sexual involvement was measured with a single item: sexual intercourse. Substance use was evaluated using three separate items that measured 
any in the last month, smoking in the last month, any marijuana use in the last month, and any binge drinking during the last year. Violent behavior was evaluated using three separate items that tested for any report of involvement in a serious physical fight, inflicting serious injury, or joining a named gang in the last year. School problems were measured using two items that tested any episode of truancy and school failure (D or less in content areas) during the past year. All variables were scored dichotomously as involvement versus no involvement.

Descriptive analyses were used to determine the prevalence of tattooing in the sample and the incidence of new tattoo acquisition between waves one and two. Bivariate associations between demographic variables and responses to the honesty question reported tattooing and outcome risk behaviors as well as the association between tattooing and risk behavior were examined using two analyses. The relationship between tattooing and peer substance use was examined using an independent sample $t$ test to compare the mean peer substance use score.

Logistics regression models were used to determine association between tattooing and risk behaviors with socio-demographic and peer substance use variables controlled. All of the demographic variables that were significantly associated at a level of $p>.05$ with any of the risk behaviors were retained in the final models. Before development of the final models, each of the components was tested for multiple colinearity; no correlations high enough to present problems with multi-colinearity were found. The descriptive analyses, $2 \times 2$ analysis, independent sample $t$ test, and logistic regressions were performed using a statistical computer program. The level of significance for all tests was set at $p<.01$. 
The summary of important research findings showed the average age of tattoo acquisition was 16.8 years with a standard deviation of 1.4. The demographic factors of tattooing showed older adolescents were significantly more likely to be tattooed $(.05 \%$ vs $7.6 \%, p<.001)$, single-parent adolescents were twice as likely to be tattooed $(6.4 \%$ vs $32 \%, p<.001)$, lowest income quartile were most likely to be tattooed $(6.8 \%, p<.001)$, and highest income quartile were least likely to be tattooed $(3.2 \%, p<.001)$. High parental education levels caused a fall in tattooing: high school or less $(7.0 \%$ and $5.7 \%$, $p<.01)$ and college or more $(2.4 \%, p<.001)$. Gender ethnicity and the neighborhood type were not significantly associated with tattooing.

Tattooing was significantly associated with higher levels of peer substance use. In the survey, $3.5 \%$ of non-tattooed and $11.6 \%$ of tattooed adolescents reported that all of their three best friends were daily smokers and had used alcohol and marijuana in the last month.

In bi-variant analysis, significant associations were found between tattooing and all of the high-risk behaviors:

\begin{tabular}{lcc}
\hline Behavior & Tattooed & Non-tattooed \\
\hline Sexual Activity & $83 \%$ & $36 \%$ \\
Substance Use & $63 \%$ & $26 \%$ \\
Physical Fights & $54 \%$ & $32 \%$ \\
School Problems & $60 \%$ & $26 \%$ \\
\hline
\end{tabular}

Figure 4. Tattooed Adolescents' Characteristics 
In logistic regression analyses adjusting for socio-demographic variables and peer substance use, tattooed adolescents were significantly more likely to report high rates of involvement in all of the at-risk behaviors examined. This study demonstrated that tattooing was a common behavior among adolescence and was strongly related to a wide variety of behaviors that put adolescents at-risk for morbidity and mortality. Tattooed adolescents reported greater involvement in sexual intercourse, higher levels of substance use by their peers and themselves, significantly higher levels of violence perpetration, and more frequent school problems than their non-tattooed peers. Given the strong links between tattooing and high-risk behavior found, tattooing in an adolescent can serve as a useful, easily visible, clinical marker that may identify adolescents who are at a higher risk for engaging in delinquent behavior. Therein lies the importance of this study for this research.

One of the most threatening behaviors of delinquents is bullying. Joronen, Graham, and Schuster (2003) conducted à study that analyzed data from a community sample of $(n=1985)$ mostly Latino and black sixth graders. They researched multiple data sources to better understand the psychological and social problems exhibited by bullies, victims, and bully/victims. Their goal was to document and utilize the unique problems of bullies and their victims to develop school-wide, anti-bullying programs.

The study consisted of sixth grade students in eleven public schools in the metropolitan area of Los Angeles. All of the schools were in low-income communities and qualified for Title I funds. Free lunch statistics ranged from $47 \%$ to $87 \%$. Three schools were primarily black, three were mostly Latino, and five had no majority group. The study did not include special education, limited English proficiency, or gifted- 
students. Permission forms were sent home in English and Spanish with a return rate of $78 \%$. Of those forms returned, $90 \%$ granted permission. The final sample consisted of $(n=1985) 45 \%$ Latino, 26\% black, $11 \%$ Asian, $10 \%$ white, and $8 \%$ other. Mean age was 11.5 years with no independent variables identified in the qualitative study.

This was a comparative case study that utilized surveys with nominal and ordinal scales. Data were collected from eleven schools in four school districts split over the Fall of 2000 and the Fall of 2001. Research team members conducted the data collection. Self-administered student surveys took approximately 1 hour to complete. Teachers rated students 'social behavior and peers provided reports of classmates' observed/perceived behavior.

The study supplied three perspectives: self, peer, and teacher reports. A labor intense peer nomination methodology was utilized. Each student provided confidential reports on bullies and victims. Individual nominations were combined to determine the strength of reputations. Peer nomination reliability was stated but the source was not given. Validation for the study was given by the fact that it was the largest investigation on bullying and victimization among ethnically diverse urban adolescents, to date.

Youth involved in bullying were classified in categories developed in prior studies. Peer nominations were utilized whereby students listed up to four classmates from a class roster who fit specific descriptions for bullying: starts fights and pushes others around; puts down and makes fun of others; and spreads nasty rumors. The victim description included the following: gets pushed around; is put down and made fun of; and about whom nasty rumors are spread. The three bully nominations received were correlated (Cronback's [alpha] $=0.90$ ) and summed for each student. The procedure was 
repeated for the victimization nominations $([$ alpha $]=0.87)$.

Cutoff values that were established from previous studies were utilized. Sixteen students fell 0.5 standard deviations above the sample mean on bully nominations and below the sample mean on victim nominations and were classified as bullies; students with victim nominations who were 0.5 standard deviations above the sample mean and whose bully nominations fell below the mean were classified as victims; and students whose peer nominations for bullying and victimization were both 0.5 standard deviations above the mean were identified as bully/victims. Non-aggressive, non-victimized youth who were identified as falling below the sample mean on both bully and victim nominations and the rest of the sample were classified as borderline.

Self reported psychological distress was evaluated using three indicators. Depression was measured with the 10-item Children's Depression Inventory Short Form. Respondents were asked to choose an option that best described how they had been feeling during the past 2 weeks. Bi-weekly item scores were summed (range: 0-2) and $([\mathrm{alpha}]=0.80)$. The Social Anxiety Scale from adolescents was administered. Each of the 12 items was rated on a 5-point scale. Scores were averaged and ([alpha] $=0.85)$. Peer Reports of adjustment were gathered by peer nominations, which were used to assess social adaptations within the peer group. Respondents nominated up to four classmates considered to be the "coolest" and four they did not hang out with "uncoolest". Social status or rank, avoidance, and peer rejection were evaluated. Nominations were summed for each student and standardized within the classroom.

Teacher-rated adjustments were obtained when teachers rated student behavior on eleven interpersonal competence items with a 7-point scale with item specific anchors. 
Three sub-scales were yielded: internalized problems $([$ alpha $]=0.61)$, conduct problems $([$ alpha $]=0.89)$, and popularity $([$ alpha $]=0.79)$. Teachers also rated school engagement with six items from the Teacher Report of Engagement questionnaire. Ratings were on a 4-point scale with scores averaged and $([$ alpha $]=0.89)$. For analysis, this measure was reverse coded to indicate problems similar to the other variables and relabeled as disengagement from school.

Statistical methods addressed differences among the bully/victim groups regarding psychological distress, social adjustment, and school engagement utilizing analysis of variance. Statistically significant group differences $(p<0.01)$ were followed up with pair-wise comparisons (Tukey test, significant difference $[p<0.05]$ ). All variables were converted into standard scores with a mean of zero and standard deviation of one. Values of zero were at the 50th percentile, positive scores were above the 50th percentile, and negative scores were below the 50th percentile.

The summary of important research findings consisted of an evaluation of each of the areas mentioned above. The students were classified as: bullies (7\%), bully/victims $(6 \%)$, victims $(9 \%)$, borderline (22\%), and uninvolved (56\%). Boys were twice as likely as girls to be classified as bullies ( $10 \%$ vs $5 \%$ ), three times as likely to be bully victims ( $10 \%$ vs $3 \%)$, and almost twice as likely to be victims ( $12 \%$ vs $7 \%)$. Conclusion, boys are at-risk in the bully arena. The race/ethnicity aspect showed black and other youth were most likely and Asian least likely to be classified as bullies $(11 \%, 10 \%$, and $3 \%$, respectively). Other and white were most likely and Latino least likely to be victims $(13 \%, 12 \%, 7 \%$, respectively). Black youth were most likely to be classified as bully/victims (10\%). 
Significant differences appeared on all psychological adjustment indicators with bullies reporting the lowest and victims the highest levels of depression, social anxiety, and loneliness. Bully/victims fell in between with elevated levels of depression and loneliness but average levels of social anxiety. Peer-rated adjustment showed bullies were regarded as the highest and victims the lowest in social status with classmates avoiding both.

Teacher-rated School Engagement and Social Adjustment showed marked differences. Teachers' ratings of popularity and peer nominations of social status had a Pearson correlation $(r=0.37, p<0.001)$. Teachers rated bullies as more popular and victims as least popular. Victims displayed more internalizing of problems than bullies or bully-victims, but not more than uninvolved according to the teachers. They ranked bully-victims as manifesting the most and uninvolved students the fewest conduct problems. All three groups were rated as disengaged in school.

Multi-variance analyses of covariance on each of the measures showed the same results as the bi-variate analyses. Sensitivity analyses showed the pattern of difference across the five groups was the same for all analyses with no evidence of the findings being dependent on specific criterion.

This study expands the definition of at-risk to include youth involved in bullying in a community sample of ethnically diverse middle school students. Bullies manifest the fewest number of adjustment problems because they are psychologically stronger than non-bully classmates. They enjoy high social status but are avoided. Victims suffer emotional distress and are avoided. Bully-victims (those who both bully and get bullied) are especially troubled. They are socially ostracized, display conduct problems, are least 
engaged in school, and most likely to report elevated levels of depression and loneliness. The favorable social ranking of bullies is the noteworthy result of this study. Comprehensive school-wide anti-bullying programs need to focus on changing the awareness of how bystanders contribute to the bully problem, and reduce the at-risk status for bullies and their victims. Bullying is one of the most anti-social acts that permeate the world of juvenile delinquents.

Lynam (1996) explained the child studied in the previous work. The author discussed the fact that-risk factors include biological, social, and ecological situations. Long term exposure to these risk factors result in a cumulative culture that reflects specific factors such as family dysfunction, school adjustment problems, and association with deviant peers. These different risk factors tend to predict similar outcomes and often overlap in at-risk characteristics present in juvenile delinquents. These characteristics result in anti-social behavior that is bred in the soil of poverty, ineffective parenting, family and personal inadequate schooling and drug/alcohol abuse, peer rejection, and association with deviant individuals and groups. The resulting culture that arises from these factors gives rise to the growing number of children who find themselves caught up in the Juvenile Justice System. At this point, their family is removed from the picture and they are left to answer for actions that were the consequences of their "soil."

\section{Substance Abuse}

Unfortunately, no definition of juvenile delinquents would be complete without a look at substance abuse. Dembo and Williams (1994) conducted an investigation that reported on the development and validation of a classification scheme using longitudinal 
data on a cohort of high-risk juveniles who entered a detention center in Tampa, Florida in 1986.

The study participants were a random sample of detainees that was drawn from consecutive entries to the Hillsborough Regional Juvenile Detention Center in Tampa, Florida between December, 1986 and April, 1987. The youths were re-interviewed 10 to 15 months following their initial interviews. The study spread over a three and one half year time frame with 399 unduplicated Florida resident detainees admitted to the Tampa Bay Center. All female detainees and a random sample of half the boys were invited to participate. The mean age was 15 years. The youngsters were admitted either for a new arrest $(62 \%)$ or on a pick up order for failure to appear in court or another judicial reason (38\%). The voluntary interviews took place within 48 hours of admission. Each detainee was paid $\$ 10.00$ for the 1 hour and 15 -minute interview. Ninety-eight percent of the eligible youths participated.

Follow-up interviews were completed with 305 youth (236 males and 69 females) for an overall completion rate of $76.4 \%$. The computed overall success rate for reinterviews was $88.9 \%$. The study did not provide a demographic breakdown for the first round. However, the second round of interviews consisted of 297 youths. Eight were excluded because they were institutionalized since the date of their initial interview. Of the group re-interviewing, $77 \%$ were male, $42 \%$ were black, and $20 \%$ Anglo. They averaged 17 years of age. Discriminate analysis indicated the follow-up group was not statistically different from the initial group (Chi-square test of Wilks' lamba $=47.22$, $([d f=35, p>0.05])$. For the second interview, $55 \%$ was interviewed in the community, 
$30 \%$ in a criminal justice facility, $14 \%$ in a detention center, and $2 \%$ in psychiatric hospitals or foster home facilities.

The study did not state independent and dependent variables or subsequent methods of measurement. The study was a social science longitudinal study that used a structured pre- and post-interview form. Cluster analysis, which used a set of multivariate statistical procedures to create classification from empirically formed clusters was applied to substance use and delinquency data collected. The longitudinal study of juvenile detainees empirically derived five groups of youths from information gathered at initial interviews: alcohol/marijuana-hashish users, low-level delinquents, alcohol/marijuana-hashish and cocaine using non-delinquents, high delinquency cocaine users, and heavy cocaine using non-delinquents. Validity of the typology was supported by a variety of other initial interviews, alcohol/other drug use and delinquency data, and by recidivism information. The study goal was to develop and validate a classification scheme for juvenile delinquents.

The research was based on self-reports of marijuana/hashish and cocaine use prior to the initial interview together with the results of urine test that checked for authenticity. It also included self-reported criminal actions against persons, theft crimes, and drug sales in the year prior to the initial interviews. One of the instruments utilized was the National Institute on Drug Abuse Household Survey. The first set of data were $(r=0.47$, $n=297, p<0.001)$ and the second set of data were $(r=0.45, n=297, p<0.001)$. Urinalysis tests to determine recent use of nine drugs were utilized. At first, $40 \%$ of the 297 youths were positive on at least one drug. With cocaine at $10 \%$ on the second test, $32 \%$ of the initial study was not available, so findings were not included. Of noteworthy 
interest, however, was cocaine usage was at 19\%. Drug usage among today's youth provides one of the most challenging employment factors for educators in a detention setting. Youth without drugs present a "normal" adolescent challenge. Delinquents with drug issues present an unknown work situation with a constantly changing culture that requires professional flexibility and compassionate consistency.

Self-reported delinquent behaviors looked at twenty-three delinquent behaviors. The areas were general theft, drug sales, crimes against persons, index crimes, and total delinquency.

\begin{tabular}{lcc}
\hline Behavior & $1^{\text {st }}$ Survey & $2^{\text {nd }}$ Survey \\
\hline Crimes against people & $78 \%$ & $57 \%$ \\
General theft & $80 \%$ & $60 \%$ \\
Drug sales & $32 \%$ & $35 \%$ \\
Index crimes & $73 \%$ & $54 \%$ \\
Total delinquency & $95 \%$ & $84 \%$ \\
\hline
\end{tabular}

Figure 5. Dembo and Williams: Delinquent Behavior Surveys.

Recidivism, agency contacts/placement, and at-risk time following initial interviews were documented through official records.

The results of the study looked at patterns of substance abuse and delinquent behavior. Based on analysis of the general population, sample factors that emerged were related. Three principle components with values greater than one explained $65 \%$ of the variance and were rotated to oblique criteria. There were low correlations among the three factors (range 0.152 to 0.296 ). 
Typology development involved a cluster analysis of the youths' alcohol/other drug use and delinquency. Agglomerative hierarchical cluster analysis used Euclidean distance as the similarity measure and average linkage between groups as the merging criterion. In hierarchical agglomerative clustering, clusters were formed by grouping cases into larger and larger clusters until all cases were members of a single cluster. The Euclidean distance measure was processed and applied to oblique factor scores that formed clusters that distinguish between correlated factors.

Demographic Comparison of the five clusters of youth, found three significant differences. The heavy cocaine-using, non-delinquent group was predominately female, whereas most of the youths in the other four clusters of youths were male. No statistically significant socioeconomic differences existed across the five clusters of youths.

Delinquency referral history, in general, reflected these results as expected differences across the cluster groups. The high rates of drug felony and drug misdemeanor referrals for the alcohol/marijuana-hashish and cocaine-using nondelinquent group tended to reflect possession charges for alcohol and marijuana, not cocaine.

Mental Health Abuse and Family Problem factors pointed out that high delinquency cocaine users reported the highest rate of physical abuse while low-level delinquents claimed the least involvement in the use of drugs. Cocaine users were more involved in delinquency, participated more in crime, and were placed at a high risk of continued engagement in troubled activities.

The groups differed significantly in regard to the percentage placed in judicial proceedings and those placed in programs. Drug usage signaled a high rate of 
involvement with juvenile delinquent programs. Statistically significant differences were found in the rates of referral/arrest for drug felonies.

The classification scheme reflected a profile of different detainee types that had different degrees of risk for the pursuit of troubled behavior, over time. As such, it showed preliminary promise as a conceptual tool to practitioners in making intervention/ treatment decisions involving juvenile detainees in an effort to reduce their likelihood of moving unto more serious involvement in substance use and delinquency/crime over time. Results were consistent and found that delinquent behavior increased following involvement in illicit drug use and that arrest for drug offenses and property offenses decline with decreasing frequency of drug use.

The report added to the definition of at-risk by pointing out there is an urgent need to recognize the juvenile delinquent potential and redirect the lives of troubled youth. These children must be seen in holistic terms. Their substance use and delinquency/crime are not only related to one another, but to a variety of mental health issues which need to be considered in understanding them and responding to their needs. Unfortunately, under the present circumstances, the juvenile justice system is a conveyor belt into the adult correction system for many youths.

The definition of at-risk/juvenile delinquent encompassed physical, socioeconomical, and educational realms. At-risk was used to label youth who were at-risk of falling behind their peers in development. This delay could be the product of a physical deficiency such as a birth defect, an injury, or abuse. Socio-economic factors reflected the financial, educational, and developmental level of the family into which the child was born. The educational level focused on the child's ability to stay abreast of the academic 
program in public education. Academic deprivation is a key factor in the juvenile delinquent's at-risk status. The most noteworthy tool in correcting this deprived state of being is found in the attributes of a mature and stable "teacher."

\section{Educating At-Risk Juvenile Delinquents}

\section{Needs}

Learning temperaments are essential areas to be explored in order to educate atrisk students' needs, Nunn and Miller (2000) examined the learning temperaments and needs differences between at-risk students receiving psychosocial and academic interventions with an average-performing comparison group. Studies of learning have long emphasized the role temperamental characteristics, perception of needs, and accommodating for these differences could play in facilitating successful responses to the learning environment.

The participants were students attending a large mid-west high school in grades 10 through $12(n=701)$. This was a random sample of students who voluntarily participated in the study. In all, 293 males and 408 females, consisting of 472 at-risk students, and 229 comparison students were surveyed. Students were primarily Caucasian and from middle to lower-middle income backgrounds. The Nunn Assessment of Learning Temperament (NALT) was utilized with a Likert-type scale consisting of 110 items representing seven oblique factors that have demonstrated satisfactory statistical validity and reliability.

A two-way analysis of variance was employed to examine the effects of gender and at-risk status upon NALT factors. The Achievement Orientation (AO) had a main effect for at-risk of $F(1,518)=42.81, p<.001)$, with at-risk students being significantly achievement orientated $(M=27.55)$ than were the comparison group $(M=20.79)$. Main 
effects for gender and interaction were non-significant. Anxiety in Performance

Situations (APS) revealed a significant effect for gender, $F(1,518)=39.22, p<.001$, while females demonstrated higher scores $(M=33.83)$ than males $(M=28.38)$.

Conceptual Level Concrete (CLC) variance was $F(1,513)=4.45, p<.03$. The at-risk students had a lesser need for concreteness in learning experiences $(M=11.02)$ compared to the comparison group $(M=11.82)$. The Informal Learning Style (ILS) showed at-risk students had a greater desire $(M=20.05)$ compared to the comparison group with $(M=$ 17.34). Kinesthetic Style (KS) showed males had $(M=22.79)$ while females had $(M=$ 20.42). Self Concept as a Learner ( $\mathrm{SCL}$ ) had a main effect for gender $F(1,518)=16.03$, $p<.0001$, with males $(M=22.35)$ and females $(M=20.38)$. Overall, at-risk students had a mean score of $(M=19.69)$ compared to the comparison group $(M=23.81)$ and perceived themselves less favorably as learner.

Results of the study revealed at-risk students had learning temperaments, which indicated fewer tendencies for achievement orientation and self-initiative. Their scholastic dispositions signify a preference for broader conceptual schemas, less fact based approaches, and greater emphasis on underlying ideas and relevancy of subject. Atrisk students valued the informality and comfort of the learning environment and described their temperaments as needing more physical sensation, movement, and handson activities. Finally, these at-risk students viewed themselves as experiencing chronic failure; therefore, they looked upon the school as a difficult experience and they perceived themselves as less academically competent than their peers. These issues combined to explain why self-motivation and self-directed acting were nonentities for this population. These missing ingredients - motivation and direction - led to great stress 
for at-risk children because, according to Maslow's Hierarchy of Needs, they are missing essential components. One of the best ways to supply these missing parts is in modeling. Teachers who are highly motivated and explicit, who lead by example, and who provide supplemental nurturing that will serve as a blueprint for these delinquents are the most effective deterrents to failure for this group.

While looking for ways to work with adolescent offenders more successfully, Moroz (2000) documented the use of use of progressive relaxation to help an incarcerated young offender deal with stress. This was a single case study that triangulated data from observations and interviews. Credibility, transferability, dependability, and confirm ability were addressed by the accumulation of rich, thick data.

The client was a juvenile entering a Young Offenders Center (YOC) because of an irresponsible act. He was experiencing stress-induced stomach attacks according to a doctor's diagnosis. Stress was described as the result of a perceived inability to handle the demands one encountered. Initially, the sample was $(n=4)$ because the researcher wanted to keep the client from being singled out. He purposively selected three other residents to join the group counseling.

The intervention, Progressive Relaxation, was explored by a case study research design method that was a treatment program that incorporated out-of-treatment homework, group interventions, and session-by-session summaries. Tables of selfmonitored indices of relaxation were provided for each session. Variables observed were scheduling, client time constraints, physical evidence gathered from relaxation, and facility protocol. 
After dissolving the initial group and doing one-on-one discussions, there was some success. The student bought into the program and did his homework, which reflected his desire to reduce his stress-related symptoms. Suggested changes were to slow down the process, to forget groups, and to realize there is no hierarchy of stress provoking events.

Continuing the quest to help educate at-risk youthful offenders, Howard (2001) presented a case study of the use of Art Therapy in the treatment of a juvenile delinquent. The client was David, a 15-year-old, who was committed to the hospital of the Children's Medical Center by the Juvenile Court. He had committed several low class burglaries before he was placed. He was the youngest son of a prominent attorney and was brought up in a good neighborhood where his parents were respected citizens.

The method was a twice-weekly, one-on-one session with an art therapist. The strategy was to encourage David to take out turbulent feelings on paper. He drew and explained his art. This was a 4-month treatment plan. The goal was to lead the juvenile to insights into his behavior through his pictures.

Influences evaluated were home environment, economic status, stress level, and intelligence level. Coping strategies that arose out of the Art Therapy by interpreting the pictures and taking out the turbulent feelings on paper were tabulated and triangulated. Data were collected through interviews with David and historical documents on file.

The data were not analyzed. However, the findings were summarized and it was determined that David developed some coping strategies through picture interpretation. He concluded that he inherited the worst qualities of both parents. He expressed his opinion of a dowdy, neglectful older mother and an overshadowing, successful, and 
vigorously outgoing father. The economic state of his family allowed him to receive individual psychoanalytical Art Therapy. His unusual intelligence and artistic ability helped him learn about himself and provided a way to cope with his emotional problems.

\section{Characteristics}

Researchers Kamps, Willis, Greenwood, Thorne, Lazo, Crockett, Akers, and Swaggart (2003) conducted a study that applied an early screening approach to determine the risk status of children in five urban schools and monitored their patterns of reading growth over 3 years.

Student population sizes were $291,151,262,574$, and $312(n=1590)$. Of the 730 students in kindergarten through second grade, 383 students participated and represented $52 \%$ of the students $(n=383)$. There were 213 boys and 170 girls. Demographics included 154 African-Americans, 130 European-Americans, 30 Hispanic, 25 African immigrants, 26 Asian, and 18 other. One hundred and forty-six students participated as typical peers (i.e., did not meet screening criteria for behavior or academic problems) and 237 students were determined to be at-risk. Forty were at-risk for behavior problems. A total of 137 exhibited academic delay, and 60 were determined to have both behavior and academic problems.

The research design was a longitudinal grade-cohort style that was used for 3 years. At the start of the study, Cohort One students $(n=237)$ were in kindergarten or first or second grade and were followed for the next 2 to 3 years. Cohort Two students ( $n$ $=146$ ) began the study a year later and were followed for 2 years. Students in the study were assessed twice in year 1, four times in year 2, and three times in year 3. In all, 2615 assessments were collected. 
The Dynamics Indicators of Basic Literacy Skills (DIBELS) and the Systematic Screening for Behavior Disorders (SSBD) were the two measurements used. The DIBELS data were used to determine the characteristics and effectiveness of reading curriculum reforms. The SSBD evaluated the behavioral risk.

Description statistics in the form of cross tabulations, means, and standard deviations were used to explore the frequency and magnitude of specific variables of interest. Pearson product-moment correlation was used to examine the linkages between the three DIBELS measures at common points in time with respect to a single trajectory of progress toward more proficient reading. Hierarchical linear modeling (HLM) was used to address research questions related to the pattern at growth in early literacy skills and oral reading fluency.

The methods used to process data collected in the study showed that 197 of the students showed academic risk on the DIBELS. One hundred thirty-seven were academically at-risk and 60 were academic and behavioral. Based on the behavioral screening, 100 were determined to be at-risk; 40 exhibited behavioral risk alone, and 60 showed both behavioral and academic.

It was possible to evaluate the strength of concurrent relationships among DIBELS skills because of the measurement of the individual students at common points in time. If large and consistent, correlations reflected a common progress spike toward increased reading proficiency. Overall, these correlations were large and statistically significant.

Pearson product-moment correlations among adjacent skills were 0.79 for letter naming and nonsense word fluency $(n=362, p<0.0001)$ and 0.78 between nonsense 
word fluency and oral reading fluency $(n=1087, p<0.0001)$. These were only slightly larger than the correlations among the more distant skills of letter naming and oral reading fluency $(r=0.79, n=253, p=0.0001)$.

Overlapping DIBELS skills accounted for a substantial range of variance in each other on the order of $55 \%$ and $62 \%$. These strong relationships among earlier and later DIBELS skills that reflected an improved spiral toward learning to read were unique to the issue of early identification of students at-risk for reading problems.

HLM results indicated that growth in letter naming, nonsense word fluency, and oral reading fluency were a result of the reading curriculum. Overall results indicated accelerated growth patterns. The main effect for curriculum type significantly influenced growth patterns of slope and acceleration, and led to significant differences in mean performance at the end of first, second, and third grades. Skills in each area were positively affected by Reading Mastery, Success for All, and literature-based curricula, in that order. (This piece of information was noteworthy for this research due to its strategy implication.)

The effects of both risk and curriculum were examined in an HLM analysis that included effects and their interaction. Main effects were significant for both risk (slope, $t[377]=-1.922, p=0.05)$ and curriculum (intercept, $t[377]=3.607, p=0.001)$; and effects (acceleration, $t[377]=3.800, p=0.0001$ ), but the interaction effect was not significant.

Students with academic risks, behaviors risks, or both made less progress than students with no risks. Students using Reading Mastery made the most. Growth curves showed faster initial growth with slow deceleration for the no-risk group, whereas the 
at-risk group showed slow growth that accelerated into the third grade. Even with this unexpected spurt, the at-risk group still fell below their no-risk peers. When a high-risk student managed to outscore a low-risk peer, it was because of the Reading Mastery curriculum.

In summary, the Reading Mastery curriculum produced better growth in reading fluency than Success for All or literature-based curriculum. Students with a single risk factor progressed more slowly than the general population. Students with behavioral risk, however, made better progress and became more fluent readers than students with academic risk. Students with both academic and behavioral risk made the least progress; thus, the juvenile delinquent emerged.

Not only are academic issues of concern for at-risk students, but violent behaviors are unsettling characteristics arising from this population. Sprague, Walker, Stieber, Simonsen, Nishioka, \& Wagner (2001) focused on the growing concern about violent and destructive behaviors of youth that require intervention by juvenile justice and youth serving agencies. The purpose of this study was to provide a clear understanding of the nature and range of behaviors that result in juvenile crime so that the issues could be addressed in a practical, proactive manner instead of reactive.

The study identified a purposeful random sample of 44 high-risk fifth grade participants by collecting information from a number of sources. A multiple gating approach was utilized that applied multiple assessment gates or screens that were sequential in nature and linked to each other to accomplish an assessment task. Students passed through multiple levels of analysis with a goal of detecting those students most in need of intervention. Nominations and observations were utilized, along with existing 
school records. Parents completed the Achenbach Child Behavior Checklist and the teacher completed the Walker McConnell Social Skills Assessment Tool. Finally, information on eligibility for free or reduced lunches and special education status was obtained.

The study design was based on the correlations among frequency of Department of Youth Services (DYS) contact and frequency of school discipline referrals for the sixteen participants who had at least one contact. The correlation based on this gross comparison was low $(p=.10)$. The correlations among the highest delinquency severity score and frequency of discipline referrals was calculated and a moderate $(r=.54)$ correlation was found. In the full sample $(n=44)$, the relationship between severity score and referral frequency was in the moderate rate $(r=.53)$. The overall relationship between frequency of DYS contact and referrals was negligible $(r=0.014)$.

A numeric score was derived to calculate descriptive and correlation statistics regarding gender, age, special education status, free and reduced lunch eligibility, and frequency of school discipline referrals. Juvenile crime data included frequency of court worker contact and severity scores. Frequency of court contact and frequency of school discipline referrals were correlated and found to be nominal. However, nominated students were found to have a number of commonly recognized risk factors including low-income status, academic problems (special education), school and community discipline problems, and high negative ratings on standardized behavioral assessments. Adding the delinquency information to school-based information provided a broader basis for the consideration of intervention options and encouraged educators to expand the scope of intervention efforts. Implications of the study were that an informed 
public or professional group would have a greater potential of developing an extensive, expansive, and encompassing plan, if they had all the facts that were available and a leadership that was capable of consensus building. Developing adequate programs will facilitate the education of at-risk juveniles and allow educators to implement promising programming that will address the unique requirements of the Juvenile Delinquent.

Koerner (2000) stated that juveniles become delinquent by choice. They deny responsibility for actions and act bored to drive others away. These students have learned that trying new skills can lead to failure and that damages their feelings of omnipotence. To survive, these students stop trying in case they fail and have to acknowledge that they are not all powerful. Gang/clique acceptance is a blessing and curse. These groups give a sense of belonging but can also turn on the member if it becomes profitable to sacrifice that individual. These students love to find a weakness in others while they fear exposure of their "real" self. When they don't like something, they respond with anger and violence. Their mentality is that no one, not even the great me (and I'm in charge) can change things. Their actions are rooted in the hopelessness that they feel which permeates their existence and explains their need to bully others.

\section{Strategies}

Moody (1997) researched the effectiveness of pair counseling on incarcerated juvenile offenders who had various emotional problems. He looked at the difficulty of stimulating moral reasoning in pair counseling and the impact the program had on recidivism. The design of the study was a treatment and control study aimed at increasing moral reasoning, improving interpersonal relationships, and reducing recidivism. The 
researcher was the facility psychologist. He saw the students in 20 sessions over a 10week period.

The sample consisted of 28 young male students incarcerated at a North Carolina training school. The treatment group consisted of 14 student volunteers (mean age 14 years and 2 months) who were having problems at the facility. In the purposeful sample, $71 \%$ were African Americans, $21 \%$ were Caucasian, $7 \%$ were Native American and the IQ range was 52 to 102 with a grade point average (GPA) of 4.8 reading level. The control group consisted of fourteen males-mean age 14 years and 4 months-who were chosen because they were similar to the treatment group and representative of the school population. This group was $100 \%$ African American with an IQ range of 68 to 94 and a GPA in reading of 5.2.

Data collection consisted of a pre-testing of the participants that took place 1 to 2 weeks before the beginning of the 10 -week intervention. Post-testing took place the week after completion of the intervention. A Defining Issues Test (DIT) was given which was based on Kohlberg's moral reasoning theory. The DIT was an objective paper and pencil measure with three dilemmas, each of which was followed by a list of twelve issues for the respondents to consider in deciding how to resolve the dilemmas. It provided a $P$ score, which was the percentage of stage five and six reasoning used by the respondent. The corrective facility's behavior point system was used to evaluate behavior before and after the interventions to compare the treatment group and the control group. Qualitative data were collected through journal entries, information from staff members, and audiotapes of sessions. 
Qualitative data included students' responses in their journals, information obtained from staff members, and audiotapes of the sessions. Journals were completed at the end of each session and remained in each student's personal folder in the pair counseling room. The information provided the basis for observations about lessons the students learned about peer relationships. It was hypothesized that the treatment group would learn more appropriate means of interacting with peers as a result of this intervention. Examining the interaction of the pairs throughout the intervention assessed this hypothesis. The researcher listened to tapes of the sessions to see if the students were able to generate more appropriate alternatives and more sophisticated strategies as the intervention progressed. The students' journals were also examined to assess their thoughts about how their interactions with their partner and other peers progressed.

Although the treatment group was perceived by treatment providers as having more significant problems than the control group, chi-square tests did not indicate significant differences between the two groups on the background data. The treatment group was more assaultive, but the difference was not significant. Because the students were not randomly selected, pre- and post-test scores on training school points and the DIT were analyzed with an analysis of covariance (ANCOVA). The pre-test scores on the DIT and training school points were used as the covariate for both post-test variables. There were no significant differences between the treatment and the control group on the DIT, $F(1,23)=1.97, p>.17$. Results also indicated no interaction effects for the DIT, $F(1,23)=0.264, p>.61$. There were no significant differences between the treatment group and the control group in relationships among recorded training school points, $F(1,25)=0.674, p>42$. Results also indicated no interaction effects for training school 
points, $F(1,25)=0.253, p>.62$. Recidivism results were that $50 \%$ of the pair-counseling students had been recommitted to training school and $50 \%$ of the control group had been recommitted after 18 months. Chi square tests did not indicate significant differences in the two groups. Analysis of covariance (ANCOVA) between the two groups on pre- and post-test showed no significant difference in immoral reasoning between the two groups. He concluded that group work was not effective and that the time frame was an essential item to be considered for the future success of a pair-counseling program.

Overall, the comparison between the treatment group and the control group showed that pair counseling did not stimulate moral reasoning for the majority of the students. It did not have an impact on recidivism. The null hypothesis, that pair counseling would not improve peer relationships, was not rejected. Given the fact that pair-counseling was so demanding and time consuming and that it was not clearly effective, it was impractical to implement the program on a large scale. Therefore, pair counseling was limited as to its usage in juvenile justice systems.

Pair counseling is only one technique that might be utilized. Moral reasoning education is fast becoming a core subject. Dieruf (2004) designed a study to determine the impact of educational programs on moral reasoning of the students as measured by the Defining Issues Test (DIT). The relevancy of this paper lies in the moral reasoning concept. At-risk students must be taught moral reasoning to counteract their delinquent tendencies.

This study $(n=94)$ was conducted at the University of New Mexico. It involved 58 Physical Therapy (PT) and 36 Occupational Therapy (OT) students. The overall mean $P$ score (DIT) for this sample was between 45 and 46, which was in range for college 
students. There was no significant difference between PT and OT students or for the entering or exiting scores for either group. There was a significant difference between age and the $P$ score of the DIT.

Each participant completed a demographic survey that included age, educational level, marital status, and number of children; however, the information was not reported in the study. The sample consisted of entry-level bachelor's degree students with approximately half of the students returning to school for a second degree. The study was a qualitative longitudinal design that followed two consecutive classes in each program from entry until graduation approximately 2 years later. A factorial analysis of covariance was used to determine the effects of a professional degree program and time after the adjustment for the effects of age. There were no independent or dependent variables.

The Defining Issue Test was administered on the first day of class as a pre-test and sometime in the final semester as a post-test. It was a structured objective test composed of six hypothetical stories, and each presented a moral dilemma. It has had rigorous reliability and validity testing. Test-retest reliabilities for the $P$ score are in the high 0.70 's or 0.80 's and internal consistency is in the high 0.70 's.

The General Linear Model (GLM) procedure within SPSS, a factorial analysis of covariance, was used to examine the effects of a professional degree program PROF (PT \& OT) and TIME (Entry and Exit) after adjusting for the effects of age. The betweensubject factors, PROF and TIME, used estimated marginal means for the comparisons. Type III sum of squares was used to test the model with main effects of PROFESSION and TIME and the interaction of PROFESSION with TIME, controlling for the covariate of AGE. AGE was covaried from the analysis because it was known to have a positive 
effect on ethical thinking and should be related positively to $P$ scores. By removing its effect, the influences of PROF and TIME were seen clearly. Two consecutive classes $(n=108)$ were followed to graduation. Fourteen subjects were eliminated due to inconsistency for a sample of $(n=94)$.

When the results were discussed, AGE was found to be significant at 0.003 . As stated before, the professional students scored in the expected $P$ score range, 45 to 46 and that there was a significant relationship between age and $P$ score. There was no significant difference in entry level and exiting $P$ scores or in students with or without previous degrees. These were unexpected findings because continuing education was supposed to be one of the best predictors of $P$ score increase. Based on these results, it seemed that the educational program at UNM was not enhancing the moral development of the students. Herein lies the significance for at-risk students; if moral development is not taught before continuing education, then it will not be taught. Juveniles will remain delinquent and proceed to the adult prison system.

Every aspect of the development of at-risk children has been explored. It seems as though social deficiencies are major obstacles for them. Griffin and Smith (2002) conducted a pilot study to examine the effects of an intervention program on the conversational skills of incarcerated juveniles. Their findings supported the contention that aggressive adolescents with learning disabilities would benefit from interventions designed to improve conversational skills. Often times, the structure and security of detention centers are such that the only people left to model safe and acceptable conversational skills are the educators. This is an area that requires "thinking outside of the box" from teachers as they strive to provide normal communication in a structured 
environment. Only a dedicated, satisfied individual will explore innovative ways to provide for the unique needs of this population.

This study consisted of eight incarcerated residents at the Youth Diagnostic Development Center in Albuquerque, New Mexico. All participants were males between 15 and 18 years old. All had been sentenced to terms between 1 and 2 years. They were previously diagnosed with learning disabilities in oral language skills. Each participant had a significant discrepancy $(S D=1.5)$ between intelligence and oral language ability. Participants were randomly assigned to a treatment group $(n=4)$ or a control group $(n=$ $4)$.

The study had two hypotheses. One was that students who received direct instruction in how to engage in conversation would show improvement in identified conversational skills. The second one was that direct instruction would result in more improvement than simply allowing participants the opportunity to have conversations.

Factors explored were the intelligence level as measured by an IQ test and oral language ability as measured by a standardized test. The independent variable was communication effectiveness and the dependent variable was conversational skills, which were measured by conversation questionnaire and conversation observation forms. The research design and methods for data analysis were quantitative. The pilot study had two hypotheses previously stated and a treatment and control group. A questionnaire assessed the boys' conversational skills on a 5-point Likert-type scale. Items rated were the following: talks in group effectively, keeps conversations going congenially, changes topic appropriately, and accepts different points of view. The ratings, (1) rarely, (3) sometimes, (5) usually, were recorded. A conversation observation form targeted four 
conversation skills, eye contact, head nodding, questions, and empathy or perspective talking.

Each group met for six sessions of 45 minutes during a 3-week period. Independent judges rated the conversational skills during a 5-minute portion of a participant driven discussion. During the next four sessions, participants in the treatment group were given specific lessons on conversation skills. The control group was given directions to conduct a conversation about anything and received no instruction on conversation skills. At the sixth and last session, the judges again rated the participants using the conversation questionnaire and observation forms.

The results were presented in tables. Means and standard deviations for conversation skills scores, treatment and control groups, pre- and post-instruction were as follows: Pre-treatment group $(M=57.75, S D=23.80)$, Post-treatment group $(M=63.50$, $S D=25.21)$, Pre-control group $(M=69.33, S D=4.16)$, Post-control group $(M=49.33$, $S D=24.09$ ). Total pre- and post-instruction scores averaged across raters were as follows: Pre-instruction was 117 for the treatment group and 104 for the control group. Post-instruction was 127 for the treatment group and 71 for the control group.

Both hypotheses were supported. It appeared that the participants who received conversational skills training showed improvement in the identified skills. Treatment group participants improved their skills while the control group seemed to have declined.

The results of this small experiment showed that aggressive adolescents with learning disabilities would benefit from language training. Such training would divert their tendency to misinterpret language and conversational cues as hostile. This is a behavior that may predispose them to become violent, as indicated by previous research. 
The importance of this study lies in its addition of information to the at-risk paradigm being developed. Communication problems seem to be an established component for at-risk students, and as such, require innovative strategies.

From social skills to academic deficiencies, authorities are scrambling to meet the diverse needs of juvenile delinquents. Their main interventions lie within the educational arena. If they can employee well grounded teachers, they have accomplished a humongous feat. Often times, detention centers are faced with educational personnel who are on the downside of retirement. These individuals are placed in detention centers to allow them to complete their time in the least challenging setting. Studies such as Beech and Platt (1994) which conducted a field-test to evaluate the effectiveness of learning strategies for decoding words, paraphrasing text, taking test, and setting goals serve as a reminder of the challenge that faces detention educators. It provides a marked reminder that these students require personnel that are ready to step up to the plate, not a group that will retire to the dugout without a battle.

The participants enrolled in this learning strategy course consisted of 32 correctional educators, 16 men and 16 women. All participants were working with offenders under the age of 21 , with 25 teaching in academic settings and seven teaching in vocational settings. At the conclusion of the course, 27 correctional educators had completed all requirements.

The methodology for this consisted of teaching an instructional strategy that had emerged as an alternative to the traditional skills and content approach. It had been operationalized through the Strategies Intervention Model, which included what to teach (curriculum), how to teach (instructional techniques), and how the environment could be 
arranged to facilitate the acquisition, maintenance, and generalization of strategies (environment). Students were given pre-tests (performance on grade level materials prior to instruction in the strategy), practice tests (performance on reading level materials after instruction in the strategy), and post-performance tests (performance on grade level materials after instruction in the strategy). Scores were produced in word recognition with $99 \%$ required for mastery and comprehension and $65 \%$ required for mastery. Each inmate was asked to read a 100-word passage aloud and answer five questions about the passage. The performance was compared to the criteria for mastery. Teachers conducted maintenance probes with students by following up periodically after the post-test to see if students were still applying the strategies. Data were recorded on line plot graphs to show pre-test and post-test results. No statistical analysis was performed on the data.

The field-test had an overall consensus among participants that the paraphrasing (comprehension) and word identification (decoding) strategies were extremely effective, while the education planning strategy was not effective due to its perceived lack of applicability to the youthful offender. The word identification strategy appeared to be extremely successful with juvenile offenders by offering them a quick and effective way to decode unknown words. These strategies would be very useful in addressing the learning needs of at-risk juveniles.

From decoding to literacy, educators explore various strategies to facilitate learning. Drakeford (2002) conducted an investigation to evaluate the effectiveness of an intensive literacy program aimed at increasing the literacy skills of youth confined to juvenile corrections. In this investigation, a multiple baseline design across participants was used to evaluate the effectiveness of the literacy program. 
Participants in the study were six students at Oak Hill Youth Center in Laurel, Maryland. The mean age was 17 years with a commitment timeframe of 6 months. All participants were African American males with reading scores at or below the 25th percentile according to the Wide Range Achievement Test and Corrective Reading Placement Test taken from their academic files. Each student had a history of educational disabilities and/or had received special education services.

The study did not contain dependent and independent variables. However, the research design and methods used were a multiple baseline design that included Science Research Associates (SRA) Corrective Reading, an oral reading measurement, and the Rhode-Secondary Reading Attitude Assessment (RARA). There were three research questions in the study:

(1) What effect will an intensive literacy program have on the oral reading fluency of incarcerated youth?

(2) What effect will an intensive literacy program have on the grade placement levels of incarcerated youth?

(3) What effect will an intensive literacy program have on the attitude toward reading of incarcerated youth?

Procedures followed in the study included obtaining a baseline. First, a singlesubject multiple baseline research design was used to assess reading fluency of participants and to answer research question number one. This approach avoided the use of averages often found in group designs and allowed for evaluation of individual participants. Each subject was compared to himself while intervention was replicated with the other five. Words read correctly were used to answer research question one. 
Second, participants' attitude toward reading literacy was measured by the RARA. This 25 item questionnaire had 0.84 re-test reliability. The scale was used for the pre- and post-assessment to determine changes of attitude toward reading. Third, the Corrective Reading Placement Test was administered to determine pre- and post-test grade placement level of each participant. The SRA reading program was utilized to provide enhanced reading instruction for students at-risk. Fourth, the oral reading measurement was assessed five times during the study with reliability checks that were calculated by dividing the low number of words read correctly and dividing by 100 . The mean reliability during baseline and intervention for Group One was 83.3 and 85.4 respectively. The mean reliability for Group Two during baseline and intervention was 82.4 and 84.1 respectively.

Analysis in the study was shown in a line graph. For question one, changes were demonstrated from baseline scores to intervention scores. During baseline, student performance remained stable with respect to level and trend. Once intervention was applied, the graph increased. For question two, descriptive analysis was used to demonstrate grade placement changes of each participant. For question three, the median and mode of the RARA were compared and contrasted to gauge changes in attitude toward reading as a pre- and post-intervention assessment.

In summary, this study demonstrated that reading skills of youth in corrections could improve given the opportunity to learn in a structured environment and provided that the faculty were motivated and willing to provide instruction in that structured environment. This reading literacy program not only increased reading skills of the youth in corrections, it also provided encouragement for the participants to become productive 
members of society which should be the ultimate goal of all programming that involves this at-risk population.

With literacy at stake, researchers have explored prerequisites for rehabilitation and determined that reading and spelling skills should be strategic elements. Svensson, Lundberg and Jacobson (2001) conducted a study to estimate the prevalence of reading and writing disabilities in juvenile institutions. These disabilities seem to be related to the socio-economic factors of environmental, educational, and emotional origin.

The study was quasi-experimental and had three hypotheses: There is a prevalence of reading disability in juvenile delinquents, a gender difference would be clear, and immigrants would show a different relationship between decoding and comprehension than native Swedes. The hypotheses were clearly stated and supported by the use of frequency distributions and measurements of central tendencies.

The sample included 163 pupils from 22 institutions - pure diagnostic centers, schools, and treatment facilities. The purposeful sample consisted of 114 boys and 49 girls. A large proportion of the sample had an immigrant background.

The independent variable was not stated but most likely was reading instruction. The dependent variable would, therefore, have been the decoding and comprehension ability levels. Statistical descriptions were provided by the use of frequency distributions displayed on histograms. The frequency distributions were an organized tabulation of the number of individuals located in each category on the scale of measurement for each test. The frequency distributions took the disorganized set of scores and placed them in order from highest to lowest, grouping together all individuals who had the same score. The frequency distribution allowed the researchers to see "at a glance" the entire set of scores. 
It showed whether the scores were generally high or low, whether they were concentrated in one area or spread out across the entire scale, and provided an organized picture of the data. It also allowed the researchers to see the location of individual scores relative to all of the other scores in the set.

A correlation $(r=0.69)$ was shown with spelling scores plotted against word chain scores for the total sample $(n=152)$. This statistical technique measured and described the relationship between these two variables and critical limits for low performance were specified (spelling $<26$, word chains $<36$ ). These two variables were observed, as they existed in the environment. There was no attempt to control or manipulate them. A scatter plot was utilized with the $X$ values placed on the horizontal axis of the graph and the $Y$ values were placed on the vertical axis. This method allowed researchers to see patterns and trends that existed in the data (i.e., the lower left quadrant included cases with serious literacy problems).

Measurements of central tendency were the statistical measure used to determine a single score that defined the center of the distribution of test scores on each evaluation. The goal was to find the single score that was most typical and most representative of the entire group of test scores. Means were provided for each test when the sums of the scores were divided by the number of entries. Standard deviations were supplied to describe the typical distance of scores from the mean. The manipulation of these statistical data provided a frame of reference to determine the norms for this population. When the norms were established, they were utilized to support the hypotheses of the study. The findings were tabulated through frequency distributions, means, standard 
deviations, and correlation. There was a table that showed age, gender, and backgrounds. The mean age was 15.5 years.

Word decoding results were illustrated on a histogram. The sample $(n=163)$ had the age groups collapsed because it was obvious that the pupils' age interval investigated reached the same average regardless of age group. The developmental curve for word chains reached a plateau at the age of $16-18$ years. The results came close to a normal distribution. It was not possible to discern any distinct signs of bimodality. No subgroups arose from the statistical analysis. Instead, a continuous variation of reading ability was measured with the word chains test.

In a word chain norm group, grade four had $M=36$ and grade 7 - 9 had $M=62$. The overall mean for this group was 52.3, and the standard deviation was $15.3(p=0.01)$. The scores for pupils in this study were significantly lower than the normal population. Approximately $28 \%$ of the pupils reached or exceeded the normal average. The gender difference in word decoding among juvenile delinquents in this study was at least as large as in the normal population. The mean for the boys was 49.8 with $S D=14.9,(n=114)$. The mean for the girls was 58 with $S D=14.9,(n=49)$.

The spelling test had 36 items. The test was standardized for ages $10-12$ years. The skewed distribution with a strong accumulation of scores near the ceiling level was expected. The norm group, grade four, had $M=25.7$ and grade six had $M=32$. The results of the research had $M=28.5$ and $S D=8.3,(n=152)$. The average score was below the mean value for 12-year-olds (28.5 vs 32.0 ). Boys' was 26.7 and girls' was 32.6 for a significant difference $(p<0.01)$. The gender gap was wider on this test than in the normal population ( 5.9 vs 2.8 points). 
Reading comprehension was shown on a histogram with the genders separated.

The following statistics were recorded: Boys ( $n=114), M=14.9, S D=2.9$ and girls ( $n=$ 49), $M=15.1, S D=2.8$. Sixteen percent $(n=17)$ of the boys did not reach the average level (11.4 points) for grade three. Only $8 \%(n=4)$ of the girls showed low achievement (there was no significant difference between boys and girls in reading comprehension in the whole group). Nearly half of the boys (47\%) and girls (49\%) had a reading comprehension score above the average grade eight (16.4 points). The reading comprehension test items were divided into nine items related to prose reading and nine items related to document reading. There was a significant difference between native Swedes and immigrants in terms of prose reading in the whole group and the boys' group. There was no significant difference in document reading. For girls, there was no significant difference in prose or document reading.

Forty-two matched pairs of Swedish and immigrants boys were matched on age and word chain scores. These pupils were then compared in terms of reading comprehension. Word identification skill was equal but there was a significant difference in prose reading. Native Swedes outperformed the immigrant boys on the reading task: $M$ $=15.1, S D=2.81$ for the Swedes and $M=13.49, S D=4.26$ for the immigrants.

A scatter plot of the results of the word chains and spelling was developed. The correlations among word reading and spelling was high $(r=0.69)$. The critical limit of poor performance on the two tests was word chains $<36$ points and spelling $<26$ points. The lower left quadrant included cases with serious literacy problems. Seventeen (11\%) were located in this area, of which only two were girls. 
This imbalance between the sexes among very poor readers and spellers was greater than found in other investigations. The over-representation of immigrants among pupils at institutions for juvenile delinquency might have contributed to the large share of pupils with serious difficulties. Eighteen percent of all immigrants were in the lower achievement region compared with $7 \%$ of the Swedish pupils.

This international research showed that the aspects focused on were central components in reading ability and showed high association with more advanced aspects of reading. The educational implication was that the process of constructing meaning and the raising of cultural competence are more important than word identification.

Progressing from reading and spelling, Hamilton, Seibert, Gardner, and TalbertJohnson (2000), examined the effects of guided notes on the academic performance of seven students with learning and behavior problems who were in a medium-security juvenile detention center to evaluate the effectiveness of guided practice.

The research design was a single subject $\mathrm{ABAB}$ reversal design across experimental conditions. The baseline condition was the students' own notes which they recorded prior to training. The study covered 22 individual sessions divided as follows: 6 days in the first baseline phase (ON1), 8 days in the first treatment phase (GN1), 5 days in the second baseline phase (ON2), and 3 days in the second treatment phase (GN2). The format for each session was as follows, (a) a 10-minute quiz on the previous day's lecture; (b) immediate feedback on the correct quiz responses; (c) a 15-minute lecture on new information, during which students took notes ( $\mathrm{ON}$ or $\mathrm{GN})$; (d) a 5-minute review of the information just presented; and (e) a 15-minute study period for the next day's quiz. Participants were not allowed to take notes to the facility's living quarters. This control 
was instituted to reduce the possibility of differences across students due to different study habits during the evening.

The participants in the study were seven adolescent males ranging in age from 13 to 18 years. Six were identified as LD and one was in the basic education program. The IQ scores ranged from 81 to 119. Six were white and one was African American. All students were residents in a detention center for juvenile offenders.

The case study looked at the students' ability levels as expressed by IQ scores, the setting for the class - a detention center, and the fact that the same teacher presented all of the lessons. Data collected were accuracy of notes and daily quiz scores (academic performance).

The summary of the study confirmed previous research findings. There was a documented improvement in academic performance when guided notes were used. All participants improved their quiz performances during the GN conditions, with one exception. It appeared that guided notes provided students with a more accurate set of notes to study. This supplied them with the tools necessary to level the playing field and assisted them with becoming active learners.

No educational program is complete without homework. Cancio, West and Young (2004) conducted a study that examined the effects of self-management and parent participation on homework completion, homework accuracy, academic achievement, and teacher/parent ratings of perceived homework problems of students with emotional and behavioral disorders (EBD). They were interested in looking at students who were educated in integrated settings and evaluated the success/failure rate of at-risk students. These students were considered to be at-risk for school failure because of their inability 
to remain attentive, complete tasks and assignments, and accomplish homework. They were characterized by their failure to manage school and social behavior.

The participants in this study were classified as EBD students. Six males, ages 11 to 15 years, and their parents participated. The students were in grades six through eight and were classified as EBD by special education rules and regulations by Utah and school district criteria.

The independent variables were parent training, student training, and performance records. Parent training consisted of familiarizing parents with the procedures of the program and exploring the research, which drove the program. Student training was conducted during one 30-minute to 45-minute training session and presented training on how to conduct the homework program's self-management and matching procedures. The performance rewards for homework were major components of the intervention and provided positive reinforcement in the home and school setting. These independent variables were monitored by a parental homework checklist, performance log, and a homework points account book.

The dependent variables were percentage of homework assignments completed, accuracy of homework, academic achievement, homework problem checklist (HPC), and matching sheets. The principal collector who daily utilized established criteria checked off homework completion. Accuracy was determined by the use of answer keys and achievement evaluated by the administration of the Kaufman Test of Educational Achievement (KTEA), which was administered twice by a test administrator unacquainted with the study objectives. It was give prior to baseline and after completion of the intervention condition. The (HPC) included 20 potential problems and participants 
were asked to estimate the frequency of occurrence. Finally, the matching sheets were a student and parental tool, which contained self-monitoring procedures to be evaluated by each parent and child.

The research design was a quantitative study that assessed interrater reliability in two ways. Parent/Staff scores on the math assignment were checked on a daily basis to compute a point-by-point correspondence of accuracy on the assignments. A reliability coefficient was derived based on the number of agreements plus disagreements and multiplied by 100 . Each of the 24 problems was scored as agreement if staff and parent scored it correctly or a disagreement if they scored it incorrectly. Inter-observer reliability was $99.0 \%$.

Treatment fidelity in the intervention condition was monitored by the observer filling out a Reliability/Treatment Verification Worksheet and Parent Homework Checklist to verify the quality and completeness of parents' delivery of treatment. The treatment fidelity data indicated that parents administered intervention procedures with $96 \%$ accuracy.

Social validity was established by questionnaires investigating both parent and student attitudes toward homework. Student interviews were conducted individually at school; parent interviews were conducted in the home.

Prior to intervention, the homework completion rate had an overall average baseline of $2 \%$ for all students. The overall completion rate for the intervention condition was $92 \%$. Median scores were reported because of the wide range of completion. All students had median scores of $100 \%$ for homework during the intervention phase. Homework accuracy baselines were stable and low at $2 \%$. During the intervention, 
performance reflected high averages of assignment accuracy. The range was $80 \%$ to $96 \%$ with an overall accuracy average of $89 \%$.

Academic achievement was established with the KTEA mathematics pre-test (5.3, range $=4.1-6.3)$ and post-test $(6.3$, range $=4.5-7.6)$. This reflects an average score increase of 1 year per participant. The mean ratings for the teacher HPC had an average baseline rating of 48 with range from 28 to 57 out of a possible 60 points. The average post-intervention rate was 30 with the average change in HPC score at approximately 18 points (range $=-8$ to 34$)$.

The parent version of the HPC scores had an average baseline score of 40 with a range of 17 to 59 . The average post intervention rating was 16 with a range of 6 to 36 . The average drop in HPC scores was -24 points (range $=-11$ to -50 ). Social Validation had both parents and students rating the program favorably.

In summary, all students demonstrated immediate improvement in homework completion and accuracy after the self-management and parent participation intervention was introduced. Completion and accuracy rates increased along with academic achievement. It appeared that the development of an appropriately designed homework program can strengthen math instruction and achievement; thus, another tool to be used in the battle to save at-risk juveniles has been documented.

Since the goal of education is employability, strategies must include a vocational component. Boxler (2004) examined ways criticalities were fostered, forms they took, and pedagogies that reflected classroom practices. In addition, some of the problems and contradictions of teaching for criticality in this context were examined.

The sample for this study consisted of eight female students, seven white and one 
African American. The age range was nineteen to seventy. Socioeconomic factors ranged from divorced to unwed mother. All students were experiencing an economic crisis due to being laid-off from factory employment.

There were no independent or dependent variables. The author used an interpretive ethnographic method to study criticality in the classroom within a job reeducation program designed to prepare laid-off factory workers for employment in clerical positions. The theoretical framework introduced the idea of multiple criticalities in contexts examined at the intersection of biography and culture. This intersection occurred when individual needs and social issues were viewed simultaneously. Interpretive ethnography was a form of research that interrogated moments or periods of interaction and attempted to construct a mutual understanding of self and others. It viewed culture not as a structure but as a creative, complex, emergent process and served as an explanation of the intersection.

Interpretive ethnology worked to understand how the participants constructed and lived meaningful lives. It was auto-ethnographic in that it began with the researcher and went beyond acknowledgement to inclusion. It used personal narrative to connect the personal with the cultural.

The study was intended to move away from didactive discussions and explore manifestations of criticalities [real-life connections] in job-related skills classes. Data were collected from three main sources. Informal interviews of an institutional personnel member were utilized to provide a broader institutional context. Interviews were conducted via telephone and in person. The second data source was notes taken during and after the course. The third source was personal, reflective journals written during the 
course and after the course during the researcher's graduate studies.

The perspective the research adopted looked at critical thinking as it was underwritten by critical theory in terms of philosophy strategies for action, and as a method for analysis. The individual was acknowledged but individualism was denied. The basis was that it was in the consciously examined company of others that one would most effectively reflect, learn, survive, and transcend. The goal was to tell stories of the people's lives and then establish those same stories in relationship to the larger social pictures.

For this study, criticality was found in the daily work of average adult educators in various programs. It was based on deducting what justice and democracy meant for each of the participants and actively worked toward processes that met those standards in daily teaching. The study concluded that criticality was not monolithic, it was multiple, dynamic, complex, and contradictory. This was not surprising since it was a qualitative study. The contribution of this study to the strategies, needs, and characteristics section of the review lies in the emphasis on the vocational and relevant aspects of education. Juveniles who have jobs are less likely to commit delinquent acts or to become repeat offenders once they are employed.

Most of the identified at-risk juveniles fall under the federal guidelines for Special Education Services. Leone (1994) conducted a case study that examined programs for students with disabilities in a midwestern state department of juvenile services undergoing some litigation. The purpose was to evaluate the offerings and document the implementation of Special Education services. Research was collected as part of the discovery phase of a lawsuit brought against a state system of juvenile services. 
The design was an exploratory investigation focused on a contemporary phenomenon (special education services) within its real-life context (a detention facility). It focused on aspects of special education and specific practices. Structure of the program, timeliness of obtaining records, commitment to providing services, and the disproportionate amount of time these students spent in confinement were items researched. This study utilized interpretive or naturalistic inquiry to guide the investigation of a state-level juvenile corrections educational system and services for students with disabilities.

Multiple sources of information were utilized: interviews with teachers and superintendents, observations including informal visits to all classrooms, and a file review of 64 special education students, 63 non-special education students, and 27 potential placements were employed to gather data. Specific questions were used during the initial interviews and a theoretical framework was developed which was guided by previous observation and evaluations of special education programs in both juvenile and adult correctional facilities. In addition, there was a review of the characteristics of special education placement and related services, a survey of the Individualized Education Programs (IEP's), and a documentation of institutional practices that interfered with access to special education services. The litigation status provided the researcher with unrestricted access to all aspects of the programs and subjects.

A random sample of 64 special education and 63 non-special education juvenile justice files were reviewed. In addition, a purposive sample of 27 youth with potential mental health and /or mental retardation who were not enrolled in special education was considered. 
The principal investigator developed a data collection sheet for file review. Also included in the examination were the state plan, relevant regulations, documents describing the operations and purpose of the behavior management area in the facility, and staff memorandums that described the school program. Data analysis consisted of reviewing field notes from interviews and observations, examining aggregated file review data, and notes taken from document reviews. The process of triangulation was used to confirm or disconfirm preliminary findings.

Unfortunately for the state, a number of specific problems were identified. According to Leone (1994), the following substantive and procedural aspects of IDEA were not being met:

(1) The Department of Juvenile Justice facility was not recognized as an agency participating in the state's special education identification program.

(2) Services were only provided to youth previously identified before incarceration.

(3) There was a backlog of 4 months before pending placement in the facility.

(4) The transfer of records between facilities was in violation of federal timelines.

(5) Individual Education Plans were not written correctly.

(6) Parental representation was ignored and surrogate parents rarely attended the meetings.

(7) Inclusion was embraced.

(8) Related services were minimal. ( Leone, p. 57)

For Special Education to be legally and correctly implemented, there must be some systematic change made in the way this juvenile justice system operated. The 
findings were documented and processed to relate back to the general population to provide authenticity and relativity to the general concern over special education implementation, which will be a component in the current research.

These special education students require extensive services. Hellriegel and Yates (1999) studied the relationship between a correctional and public school system by comparing and contrasting the offered services. She attempted to develop an understanding of the relationship between an educational and a human service agency.

The case study was a qualitative design that was naturalistic due to the inability to manipulate change or control the research setting. Data were collected through unstructured and semi-structured interviews. A pilot study helped develop the themes to be addressed on the open-ended questionnaire. Resident files and educational records were also used.

Study participants were a purposeful random selection from 12 school districts and 10 correctional facilities. Anonymity was assured because of the sensitive nature of the content. A principal and two to three teachers at each school were interviewed along with care staffs that were selected by the supervisors from the facilities.

Researchers employed a constant, comparative method of analysis for the examination of the data from public school systems and correctional facilities that provide services to juvenile offenders. The interview guide categories were used for the analysis of data, patterns and themes of the content were developed from interview data as well as data found in educational and treatment records. Cross-case analysis methodology facilitated the grouping of answers from different interviewees to common questions and allowed the analysis of different perceptions held on central issues. The 
answers to each question were analyzed and categorized using descriptions and direct quotes from the participants. Seven categories emerged; interagency collaboration, interagency communication, transition plans, parental involvement, correctional facility education program development and implementation, cross-agency knowledge, and special education and related services.

The concluding remarks stated that there was a consensus concerning the need for increasing the levels of trust, communication, and collaboration between the two organizations. Findings concluded there needed to be an understanding of missions, policies, programs, and services with an open door communication system to facilitate the sharing of information and understanding between the public schools and correctional facilities.

Society attempts intervention strategies for at-risk students by forcing them to become involved with community based treatment programs that should assist with educational, emotional and social needs. Wilgus and Epstein (1978) presented a comparative case study of two community-based treatment programs for adolescents. One program survived, and the other program did not. The research explained why one program was successful and why the state department closed one down. The purpose was to describe organizational dynamics of their survival and demise and to highlight best practices for the management of treatment facilities for at-risk juveniles. Providing quality programming that targets the needs of troubled children is one of the most effective strategies available for the treatment of this population. Consistency and structure are documented requirements for success. Treatment facilities cannot survive 
without a motivated, educated, and professional approach. Neither can teachers survive in detention settings without the same characteristics.

This study was a qualitative, five-point comparison of a professional home for adolescents and a family home for youth: (a) control/governance body, (b) formal organizational/structural differences, (c) degree of professionalism, (d) clientele served, and (e) community relations. Variables were the setting, policies, procedures, perceptions of community leaders, and alienation caused by hostility. There were no data analyses in the study. The findings were tabulated and reported by Wilgus and Epstein (1978) as precautions for managers of comparable programs.

(1) The family homes for youth had no local board of directors.

(2) They had an undifferentiated organizational structure.

(3) They depended on paraprofessionals for staffing.

(4) The program took all referrals from across the state.

(5) Administrators exhibited an adversary relationship with local agencies and incurred the hostility and distrust of influential community members. (Wilgus \& Epstein, p. 490.)

Due to the negative connotations attached to these findings, this facility was closed even though it was successfully serving its clientele. Significant conclusions were the following:

(1) Successful treatment is not always the most relevant issue in survival.

(2) Community-based treatment strongly suggests that attention be paid to both the professional and residential communities. Failure to establish links erodes community support. 
(3) The inability to assess the power and influence of community leaders can impact funding of a program.

(4) Even though an agency successfully serves all residents [even ones others will not accept], the administrators must remember the agency is dependent upon the local community for its existence.

(5) A state-supported agency cannot maintain a pure advocacy approach and survive. (Wilgus \& Epstein, p. 491)

This case study is dated but serves to emphasize the lack of research that has gone into the development of programming for this population of at-risk students. The settings these children inhabited were very restrictive due to the need to preserve safety and security; therefore, the strategies that could be utilized were restricted because policy and procedure drove the programming. It was one thing to talk about group work, peer tutoring, hands-on, field trips, and real-life experiences; it was quite another thing to attempt to implement these strategies in a maximum security setting. Group work could develop into an up-rising; peer tutoring could transform into a brawl. "Hands-on" took on a whole new connotation when it was a threat to other students. Field trips meant shackles and chains. Real-life experiences consist of rape, murder, robbery, etc.

Glasser (1990) geared his work toward focusing education on classroom management strategies. He contended that if schools stopped pushing students to excel on meaningless state assessments and started teaching students according to interest inventories and learning styles, then discipline issues would disappear. The way teachers manage must be changed and the way materials are presented must be revamped. Effective teaching is being able to convince all students to do quality work. If coercion is 
removed and students are evaluated on what they do in school, the move to quality will be well on its way. A quality school will not accept low-quality work. Quality work is taught; it is the goal. According to Glasser, young people who are involved in quality education will not engage in self-destructive activities because they have seen real-life connections between education and success. They have an innate desire to succeed; therefore, they will not knowingly compromise their endeavors.

Rief (1992) suggested that we look for ways to allow students to respond to their world in ways other than "writing." It was proposed that educators utilize visual and performing arts as mediums to facilitate academic endeavors. Children need to be empowered to foster all levels of intelligences at each promising stages of development. Educators need to celebrate these multi-literacies and provide varied activities to access diverse ability levels. Trusting and respecting our students may be the best models we provide for them in creating culturally healthy environments that accelerate the learning power of an at-risk population.

Zemelman, Daniels, and Hyde (1993) provided educators with a concise teaching guide. Their focus was to blend a positive view of children with commitment to certain curriculum and to develop an improved understanding of how learning works. They suggested that there be less time spent on traditional methods of instruction such as, lecture, passivity, silence, worksheets, reading textbooks, exposure, memorization, grades, tracking, pull out, and standardized test. They advocated more hands-on experiments, active learning, high-order thinking, deep study of limited subjects, real non-fiction reading, and responsibility for one's own learning. Furthermore, they suggested democracy in the classroom, attention to affective needs and learning styles, 
and cooperative/collaborative learning. Finally, they pointed out that heterogeneous grouping, collaborative teaching, and qualitative/anecdotal grading/records were the most effective ways to educate at-risk students. They advocated a resurgence of Dewey's educational model that highlighted instruction that was child centered, experimental, reflective, authentic, holistic, social, collaborative, democratic, developmental, constructivist, psycholinguistic, and challenging.

Ornstein and Hunkins (1993) attempted to assist educators in developing pedagogy that could be utilized to meet the needs of this challenging population. The Saylor and Alexander Model is a planning process and systematic approach to curriculum development.

1. Goals, objectives, and domains. Start with goals and objectives from the four domains, personal development, human relations, continued learning skills, and specialization.

2. Curriculum design. Content, organization, and learning opportunities should be noted.

3. Curriculum implementation. Teachers select teaching tools/strategies and materials necessary to present the material.

4. Curriculum evaluation. This will focus on the plan, the quality of instruction, and the learning behaviors of the students. (Ornstein \& Hunkins, 1993, p. 269) If goals and objectives were met, then the material could justifiably be added to the scope and sequence of the program.

In 1995, the federal government published Teachers \& Goals 2000. This publication addressed at-risk needs by suggesting the utilization of Title I funds to 
supplement programs at the educational institutes attempting to serve these children. Some strategies include extended school day programs, extended summer school options, and tutoring for the reinforcement of basic skills. In addition, the elementary schools have been encouraged to provide transitioning efforts for pre-school students to primary school. The ultimate goal of these activities is to increase parental involvement in the educational process of these children. This involvement should result in the improved academic performance of these students. The percentage of these at-risk youths in a school system is so extensive in some areas that they qualify for a school-wide Title I program that allows the services to be provided to all students. These Title I schools utilize the arts (i.e., dance, music, theatre, and the visual arts) to address the learning styles of their at-risk population. Furthermore, they engage in teaching life skills classes that expose children to manners and other culturally accepted standards of behavior.

The end of the 1990s saw a focus on professional development for teachers working with at-risk youth. Holcomb (1996) advocated the RPTIM Professional Development strategy. The steps include readiness where the problems are identified. Second, there is a planning stage where the problems are evaluated. Third, training is provided to develop a plan of action to attack the problem. Fourth, the implementation stage provides resources to activate the plan and finally a maintenance stage is provided where monitoring occurs to insure that the new plan is implemented as agreed upon by the faculty. Without monitoring, there is no way to guarantee the implementation and continuation of a program. For the needs of at-risk students to be addressed, the professional development of their teachers must be addressed. 
Payne (1998) addressed the need for at-risk students to build a learning structure inside their heads. Payne contended that many students from poverty do not have the learning structures sufficiently in place to do well on standardized assessments. Areas in which students are deficient include four structures. The first structure has to do with having an organization mechanism for data acquisition. The second structure deals with the availability of cognitive strategies that process data. The third structure deals with the conceptual framework strand that stores and retrieves data. Finally, the fourth structure is sorting the data by utilizing graphic organizers. The focus of this treatise was to expound upon the fact that educational institutions must be in the business of teaching thought processes. Schools must address the needs of their diverse populations by supplying strategies, which "normal" students take for granted (i.e., learning structures).

Slocumb and Payne (2000) contended that at-risk students from poverty bring unique gifts to the educational setting. Some prerequisites for tapping these gifts include the ability of educators to shed stereotypical middle class images. The lack of resources and opportunities, along with hidden rules, creates a complex and forbidding mask that children of poverty are forced to wear. Teachers must accept the fact that home environment cannot be changed; it must be accepted, understood, and moved beyond. To survive in poverty requires great strength. Overcoming the abuse, drugs, alcohol, abandonment, handicaps, poverty, etc. requires strength to triumph over these adversities. Equitable treatment is essential if these students, as adults, are to have equal economic opportunities. Education is a key component to breaking the poverty cycle and it behooves educational professionals to share this key with the children of our institutions. 
Arends (2000) discussed teaching strategies that scrutinized the presentation of cognitive strategies to juveniles. These strategies included four areas of development. Number one is the area of rehearsal. This is a time when students are committing materials to memory by repeating the data out loud to address the auditory learning style. If the learners are tactile, they can do this with play dough in their hands to provide tactile stimulation and if they are kinesthetic, they can walk around as they are speaking. If they need visual stimulation, they can look at a poster, as they are talking to their imaginary public. The second area addressed is elaboration. Here, the student is involved in adding details to new information and creating association clues to enhance retention. Thirdly, the student will enter the organizational area of cognitive strategies. At this point, he or she will reorganize or pick out main ideas from a large body of information and mentally highlight it as being important. Fourthly, meta-cognition must occur. The student must actively think about thinking and monitor the cognitive process on a conscious level. Atrisk students require pointed, goal driven instruction of cognitive strategies for knowledge acquisition. These processing skills must be taught to challenged students while "normal" students acquire these strategies in other situations (i.e., at home observing their professional parents in action and during family planning sessions).

Phillips and Gibbons (2000) compiled a set of writings which were part of the National School Improvement Institute's Program. The thesis for their work was that teachers who model learning and continuous improvement as valuable and joyful will have students who value continuous improvement and find achievement rewarding rather than just doing assignments or working for a grade. They based this idea on some previous opinions, which they have gathered throughout their careers. One thought was 
"Hurt people, hurt people. . . Healed people, heal people" (Phillips \& Gibbons, 2000, p. 15). At-risk students do not respond to linear logic such as reward/punishment, so this statement requires a focused approach. No healing can occur in a blame frame. Strategies must be aimed at restoring the spirit. This restoration requires access to adults that can provide rich and varied life experiences and instill hope. Healing teachers borrow new ideas or invent a new strategy or practice. When it doesn't work, they expand options and view children and adolescents as a journey. Healing teachers see the healing before it happens and treat students as if they are improving. This future frame becomes selffulfilling. Failure is a choice. It may not be a conscious choice but it is a repeating of behaviors that led to destruction. A good activity to use to combat this is to have students list 10 things they can do to fail and have them list 10 things the teacher can do to help them fail. According to Phillips and Gibbons, the majority of our students - 97\% - can succeed academically, if we vary the time and instructional methodology; therefore, it is incumbent upon educators to supply these simple modifications for success. Brain research emphasizes the need for creating imagery within the mind related to the content being presented (visual imagery) and that tie into real-life experiences. A teacher should model the attitudes and learning strategies she desires of students. Additionally, she should locate other adult mentors to assist with this modeling which is a subtle way of altering a climate or changing an attitude. Humor is invaluable as a discipline strategy to be utilized by these adult mentors.

Wolfgang (2001) discussed multiple strategies for discipline. Public education teachers have to select the strategy that works for them and implement it for an effective behavior management program. School wide programs do not work consistently because 
different teachers have different styles. People need to pick and choose appropriate components for their customized plan. When public educators fail to control their educational facility, juvenile justice facilities bear the consequences of these deficits. The strategy that is most beneficial to the juvenile delinquent is Glasser's Reality Therapy and Control Theory. A summary for this model was presented in this text:

(1) A rational approach

(2) Responsibility for learning moral and acceptable boundaries of living within society.

(3) Student must learn to satisfy personal needs without infringing upon other's rights.

(4) Each person has basic needs of belonging, freedom, power, and fun.

(5) Students need to acknowledge their own behavior and commit themselves to a more logical and productive form of behavior.

Teaching strategies are simple yet explicit. First, confront the misbehaving student and tell them to stop (Naming and Commanding). Second, ask "what" questions to lead students to an explanation. Third, press for a plan of action (Commanding). Fourth, agree on some natural consequences of the plan (Reinforcement). Fifth, failure to follow the plan leads to different stages of isolation. The plan consists of observing the student in the situation, assessing what you the teacher are doing, starting fresh with each plan, and making educational changes by making the school/classroom relevant and eliminating failure. According to Wolfgang, Glasser sees the establishment of care and warmth as a necessary human prerequisite for an individual who hopes to begin to come to grips with the awesome responsibility of being a planner, manager, and executor of 
one's own actions. At-risk students must be helped to acknowledge their behavior as being irresponsible and to take action to make it more logical and productive. We must live together, we must bear the consequences of our actions, and we must make a commitment to act in a responsible manner toward others. If public educators were able to impart these societal norms to their at-risk students, then the need for juvenile detention centers would be greatly reduced. Therefore, the first steps of rehabilitation for childhood criminals should be their classroom teachers rather than court designated workers (CDW's) and guards.

Blomberg and Waldo (2001) advocated small facilities and low student-teacher ratios. Certified teachers and professionals should be employed and students should be accurately placed by grade level test. Individual Educational Plans (IEP's) should be utilized in curriculum planning. The school should have an effective and appropriate curriculum that meets the needs of the population. Appropriate transitioning should be provided for students as they move between placements and a system of aftercare aimed at effective community reintegration should be available. Lastly, the school should adopt a comprehensive instructional and technological delivery system that is supported by ongoing professional development for the teaching staff.

Mazano, Pickering, and Pollock (2001) contended that successful strategies depend on specific types of students in specific situations, with specific subject matters. Effective Pedagogy depends on instructional strategies, management techniques, and curriculum design. Teaching strategies that have positive effects on student learning are those that teach students how to

- Identify similarities and differences 
- Summarize and take notes

- Reinforce effort and provide recognition

- Practice skills and complete homework

- Form non-linguistic representations

- Engage in cooperative learning

- Set objectives and process feedback

- Generate and test hypothesis

Currently superintendents of public schools and school principals observe classrooms, supervise teachers, and provide feedback based on their observations of teaching strategies. Better supervision and evaluation techniques have promoted a resurgence of best practices within the walls of both public schools and juvenile detention centers.

Klopovic, Vasu, and Yearwood (2003) listed 14 points to be considered in the development of an educational facility for juvenile delinquents.

1. Locate the school in a separate facility.

2. Maintain low teacher/student ratio.

3. Maintain a safe, positive, and nurturing environment.

4. Maintain autonomy with tactful oversight.

5. Encourage vigorous community involvement.

6. Manage by teams.

7. Establish and require challenging expectations and standards.

8. Maintain an active flow of information.

9. Vary instruction, address learning styles, make real-life connections, and practice non-traditional methods. 
10. Recruit, hire, and retain quality teachers.

11. Encourage and nurture the residents and teachers.

12. Provide on-going professional development for teachers and support staff.

13. Utilize records, IEP's, parents, community, and facility staff.

14. Evaluate students and program daily with feedback and rewards.

(Klopovic, Vasu, \& Yearwood, 2003, pp. 13-2-13-10)

Rubin (2003) offered additional suggestions for effective detention centers. Many of the components overlap with the previous source.

1. Utilize major community resources.

2. Implement a broad range of programming.

3. Provide vocational training.

4. Address learning styles.

5. Establish an interpersonal skills training program.

6. Supply individual counseling for behavior problems.

7. Supplement the educational program with multiple services.

8. Develop a restitution agenda for juvenile offenders.

9. Embrace Balanced and Restorative Justice by highlighting restitution, service to victims, and decentralization of probation services, community service, and victim participation in all Juvenile Justice Proceedings, victim-offender mediation, and accountability boards. (Rubin, 2003, pp. P4-1-P4-14)

Balanced and Restorative Justice (BARJ) is the most productive strategy to emerge since the 1990's. Its application encompasses a multidimensional approach that overlaps and intertwines throughout the listed services. 
Implementing the previous documented strategies required a creative teacher, a concerned citizen's group, an open-minded facility superintendent, strong (physically and mentally) supervisors, teamwork, safety, security, and the dedication and concern necessary to think "outside of the box." This ability to "think outside of the box" is what empowers professionals and allows them to address the needs, define the characteristics, and implement the strategies necessary to teach juvenile delinquents.

The education of an at-risk juvenile delinquent requires a look at the unique needs, characteristics and strategies necessary for a successful program. Juvenile delinquents need an informal, global environment that addresses all four learning styles with emphasis on tactile and kinesthetic. Auditory is an essential component for females and Visual is essential for males. A successful program requires that each child's preferred learning style be addressed. Kinesthetic and tactile traits should be embraced and capitalized upon rather than condemned to suspension halls. In order for a facility to meet the educational challenges of their residents, they must have an educational staff that is knowledgeable, creative, and empowered to meet the unique demands placed upon them by this unorthodox "student."

Developing the Self Concept of At-Risk/Juvenile Delinquents

\section{Esteem}

Eitzen (1976) looked at self-concept issues with boys adjudicated for delinquent behavior and living in a setting guided by behavior modification principles. The purpose was to evaluate Cohen's thesis that delinquent gang membership permits working class boys to recoup self-esteem lost through defeat in middle class institutions.

The research setting was a community based group home where six to eight delinquent boys resided with a trained foster parent couple. A purposeful random sample 
$(n=16)$, generated over a year's time, completed a questionnaire, which included a semantic differential scale devised by Schwartz and Tangri. The respondents were asked to rate themselves on each of ten sets of bipolar adjectives. It was also administered to see how the student thought significant others viewed him. The questionnaire was administered to each boy at the beginning at his stay, at four months, nine months, and at the completion of his stay.

The design of the study was not stated. However, for comparison, all eighth grade boys from a junior high school in the community were given the same questionnaire ( $n=$ 82). Initially, the self-esteem of the delinquents had a negative mean score $(p<.01)$ when compared to the control group. Mean scores showed that the higher the mean score, the lower the self-concept or the more unfavorable the perception of others' evaluations. The treatment group explored factors such as setting, age, race, gender, socio-economic status, and behavior modification principles. The independent variable was behavior modification and the dependent variable was self-esteem scores after that behavior modification.

Additional findings showed that the greater the length of stay, the more positive the self-esteem scores became. The control group set the baseline scores from "normal" juveniles/students. A second research question, how others viewed him, influenced the student's own self-esteem and actions. If he perceived a positive opinion, then he portrayed a more positive image.

To summarize, initially scores were more negative for the treatment group than the control group on the pre-test but were more favorable than the control group on the posttest. Self-concept means of the experimental group were congruent with their 
perceptions of how their family/friends evaluated them. Implications showed that the treatment group left with an improved self-image that was significantly better than the average for the control group and that the probability of a lasting effect was high based on how the boys perceived their significant others regarded them.

Unfortunately, behavior modification leads to labeling. Chassin, Presson, Young, and Light (1981) investigated labeling effects in a group of institutionalized adolescents. A common core of various labeling theories contends that clients play a sick role attempting to accommodate a self-fulfilling prophecy.

Subjects were 119 students from two public high schools $(M=17.4$ years $), 111$ male adolescent delinquents from a state correctional facility $(M=16.4$ years $)$ and 33 male and female adolescents from three psychiatric hospitals ( $M=16.3$ years). All three groups were predominately white (the control group had one black subject and the in patient group had two black subjects). Four of the six participating agencies were located in the same mid western city, with one high school and one hospital located in smaller nearby communities.

Independent variables were physical settings and labels. Dependent variables were self-concept and acceptance or rejection of the label. The questionnaire about perceived roles was group administered. A multivariate analysis revealed that the three groups of subjects did not agree on a single definition for a given role. A semantic differential technique and discriminate analysis were used to compare profiles of selfratings to profiles of role ratings. Two separate analyses were performed: one compared self ratings with the control group's stereotypes, and the other compared self-ratings with 
a subject's own group stereotypes. Significance of findings was evaluated by looking at $\mathrm{z} / \mathrm{t}$ scores for validity $(p<.001)$.

In conclusion, the findings suggested that an adolescent might choose one of several responses to a socially assigned label. Possible responses included accepting or rejecting the label as well as misperceiving the content of the role. Implications for selfconcept measurement and for labeling theories seem to correlate. Labeling effects on self-concept are complex:

(1) Incarceration impacts self-concept more than being hospitalized in a psychiatric institution.

(2) Adolescents do not necessarily accept deviant labels.

(3) Adolescents tend to distort stereotypic meaning of labels.

Eyo (1981) compared British male delinquents $(n=90)$ with their non-delinquent counterparts $(n=121)$ in terms of scores on seven socialization related domains of selfconcept. Since the acquisition of a deviant concept of self, there has been a long standing hypothesis that self concept can insulate or increase vulnerability to delinquency.

The sample $(n=211)$ British males consisted of 27 boys aged 14 to 16 from a Remand home within London, 24 boys aged 14 to 16 from a Community home in a suburb of London, 39 boys aged 17 to 21 from a closed "Bortal" outside London, 62 boys aged 14 to 18 from a central London grammar school, 25 boys aged 16 to 18 from a north London comprehensive school, 24 boys aged 17 to 20 from an East London technical college, and 10 boys aged 16 to 18 from a University in London. They were chosen through purposeful random selection. 
The Counseling and Research Form, Tennessee Self Concept Scale (TSCS) was administered to non-delinquents within group classroom situations and to delinquents in small groups of seven to ten within institutional classrooms. The 100 item (TSCS) provides a separate measure for each domain. The one-way analysis of variance (ANOVA) for unequal sample sizes and with weighted means was used to analyze the data for each domain of the self-concept.

The Total Self-Concept exhibited the expected trend of mean scores showing nondelinquents to be higher in overall self-esteem than the delinquent groups. This manifested itself in the highly significant ANOVA result, $F=19.22, d f=3 / 207, p<.001$. Thus, the hypothesis that the delinquents would manifest poorer overall self-concept was strongly supported. A significant factor was that sentenced juveniles had higher selfesteem than those awaiting sentencing. This supports the need for a speedy trial for Juveniles.

Once caught up in the system, delinquents must be speedily placed as many times as necessary for rehabilitation. Byrd, O’Connor, Thackrey, and Sacks (1992) administered a Role Construct Repertory Grid and the Self-Consciousness Scale to determine whether frequent offenders could be differentiated from infrequent offenders on the basis of these instruments. The hypothesis was that frequent offenders would have more "delinquent" self-concepts than the infrequent offenders.

There were 40 subjects in this study. The home addresses of approximately 170 male offenders institutionalized in the United States were retrieved from their case records. Request for permission to examine each juvenile were then forwarded to the parent(s) with stamped envelopes for the return of the signed permission forms. The 
researchers examined all youths who had permission to be included in the study, except for those who were released before they could be seen, and two others who refused to participate.

They were divided into two groups based on frequency of their offenses. The infrequent offenders ( $n=22$; mean age 16 years and 1 month) had two or fewer prior arrests. The frequent offenders ( $n=18$; mean age 15 years and 9 months) had been arrested three or more times.

Each subject was seen individually. The Self Consciousness Scale (SCS) was administered first, and the Role Construct Repertory Grid (RCRG) was administered second. A two-way analysis of covariance was performed on the two groups with the number of days that a youth had been incarcerated used as the covariate to account for any effect of the length of incarceration (LI) on the delinquency of the subjects' selfconcept (DSC). The independent factors in the analysis were the frequency of offenses (FO) and private self-consciousness (PSC).

The results were based on a raw regression coefficient between the covariate and delinquency self-concept, which was -.03. There were no significant effects at $p<.05$ for (FO), $F(1,35)=1.97$, (PSC), $F(1,35)=.001$, or their interaction, $F(1,35)=.288$. This data reflected no effect between length of incarceration and self-concept. The major hypothesis, that a direct relationship existed between self-concept and delinquent behavior where frequent offenders had lower self-concepts than the infrequent offenders, was not supported. In fact, there was a cell mean that indicated that those youth who offended less frequently displayed a more delinquent self-concept. 
These results suggest that many youths who identify with juvenile delinquents were somewhat less prone toward delinquent behavior. This interesting phenomenon could have skewed the results and might be explained by the fact that the delinquents could have been unwilling to face their own delinquency and were more than likely in denial.

In an effort to rehabilitate the repeat offenders it is essential to have insight into their psychological makeup. Baker (1999) conducted a study where delinquent and nondelinquent youth were investigated in regards to the use of four types of cognitive distortions and their overall global self-esteem. Cognitive distortions were defined as inaccurate or rationalizing attitudes, thoughts, or beliefs concerning one's own or other's social behavior. They were used to justify socially unacceptable actions as acceptable. Therefore, the purpose of this study was to compare the differences between juvenile delinquents and non-delinquents in regards to cognitive distortions and global selfesteem.

The participants $(n=20)$ consisted of 10 male delinquents and 10 nondelinquents. The delinquents were residents of Riverbend Treatment Center, a division of youth services and a maximum-security facility located in St. Joseph, Missouri. The nondelinquents were high school students attending Chillicothe High School in Chillicothe, Missouri. Both groups ranged from 14 to 18 years old with the average age of 15.8 for the delinquents and 16.0 for the non-delinquents.

The design was a quantitative study that used independent $t$ tests to determine the relationship between the delinquents and non-delinquents and the use of four connective distortions: self-centered, blaming others, minimizing/mislabeling, and assuming the 
worst. The method was to administer three questionnaires. The "How I Think" questionnaire was used to measure the four different types of cognitive distortions. The self-reported delinquency scale was used to verify the types of crimes committed by the juvenile and the "What I Am Like" scale was used to measure global self-esteem.

The subjects were purposely assigned to delinquents or non-delinquents based on court-ordered placement and enrollment at Chilliothe High School. Both scales were administered to the students during a 1-week timeframe and at approximately the same time of day. Completion time averaged 30 minutes. After the questionnaires were completed, they were scored and compared/contrasted.

Independent $t$ tests were calculated. The means for the self-centered cognitive distortion were $2.80(S D=0.74)$ for the non-delinquents and $3.50^{\circ}(S D=0.85)$ for the delinquents. No significant differences were found $t(18)=-.964, p>.05$. The means for blaming others were $2.60(S D=.59)$ for the non-delinquents and $3.56(S D=.73)$ for the delinquents. Significant results were found, $t(18)=-3.215, p<.05$. The means for minimizing/mislabeling were $2.7(S D=.60)$ for non-delinquents and $3.92(S D=.99)$ for the delinquents. Significant results were found $t(18)=-3.302, p<.05$. The means for assuming the worst were $2.67(S D=.75)$ for the non-delinquents and $3.76(S D=.78)$ for the delinquents. Once again, significant results were found, $t(18)=-2.09, p<.05$.

These findings showed that overall delinquent youth use more cognitive distortions than non-delinquent youth and non-delinquents have a higher global selfesteem than delinquents. Delinquents use cognitive distortions to justify their unacceptable actions. This attitude allows the juvenile delinquent to function with a high 
level of self-esteem even though society is telling them they are wrong. This sense of omnipotence is a key ingredient of the juvenile delinquent definition.

Once again the vocational component must be addressed for the long-term success of the juvenile. Munson and Strauss (1993) investigated self-esteem and career salience of institutionalized juvenile delinquents in the context of Super's Lifespan Career Development Theory. They looked at participation, commitment, and value expectations in home-family roles and their implications for career counseling.

The participants were 185 male adolescents who represented adolescent offenders $(n=60)$ and adolescent non-offenders $(n=125)$. The average age was 17 years. The adolescent offenders were randomly selected from a maximum security institute in Ohio. The sample consisted of 55\% Caucasian, $43 \%$ African American and less that $1 \%$ other. A non-matched sample of male high school students was used as a comparison group. They were randomly selected from junior classes at four high schools. Thirty were chosen from each school $(n=120)$. The composition was $94 \%$ Caucasian, $5 \%$ African American, and 2\% Hispanic.

A Self-Esteem Inventory (SEI) that took approximately 10 minutes to complete was the instrument utilized. There was one total score based on 25 items. Split-half reliability was reported to be .90 . The Salience Inventory (SI) measured the relative importance of five primary life career roles. It yielded a total of 15 scores. A multiple analysis of variance (MANOVA) was used to test differences between adolescent offenders and adolescent non-offenders. When MANOVA proved significant, a discriminate function analysis was computed to determine the characteristics of this difference. 
In summary, the mean and standard deviations for Career Salience variables indicated offenders scored higher than non-offenders on 8 of the 15 measures. A major finding of this study was that participation, commitment, and values expectations in homefamily roles contributed significantly to self-esteem in adolescent offenders. The multivariate analysis yielded a significant main effect, $F(15,169)=4.15, p<.001$. The percent of variance was $2.4 \%$. The differences between adolescent offenders and adolescent non-offenders were attributed to participation, commitment, and values expectations in home-family and work variables, as indicated by the discrimination function analysis.

An implications was that Career Counseling appeared to be a positive strategy to utilize in the rehabilitation of Juvenile Delinquents. This at-risk population needed a reallife focus to buy into the program of life. Career Counselors needed to assist the youth with various career roles that would enhance productive and lawful efforts toward career saliency.

Realistically, educators/caregivers must recognize that vocational concerns are not of major importance to juveniles. Peer pressure and belonging are the driving force behind many at-risk youth. Cheng (1997) explored this area of juvenile delinquent concern. The author looked at self-esteem and fear of negative evaluation (peer pressure) found in 77 fan club members from two clubs located in urban Hong Kong. The club members were age 16 and below. This purposeful random sample was compared with a random sample of 128 age-equivalent secondary school students who had never joined a fan club. 
The study design was a case study that utilized observation, interviews, and historical records. A logistic regression analysis showed that being a fan club member was associated with poor self-esteem and a strong fear of negative evaluation (peer pressure). Areas evaluated were age, race, gender, socio-economical status, fan club membership, poor self-esteem, fear of negative evaluation (peer pressure), and oblivion as to the desire to be a member of a fan club. Through triangulation of data, findings showed that most fan club members were females with poor self-esteem.

The study methodology was weak. However, implications for the adolescent who was searching for a sense of identity were that identification with an idol and sharing a common purpose with a fan club could be important sources of values, meanings, and fulfillment. Idolatrous activities took up a large amount of the adolescent's time and resources. If the idol was positive, then good consequences arose. If the idol was negative, juvenile delinquency tendencies tended to surface.

Levy has done much work on self-concept and delinquency in Australian adolescents. His three studies add emphasis to the need for institutions to actively address self-esteem issues. Levy (June, 1997) began his extensive research with a study that contended that self-concept was an integral part of identity development for adolescents. This study was designed to test Australian adolescents' utilizing self-evaluations regarding delinquent behaviors.

The sample includes 365 adolescents (199 boys and 166 girls) from state high schools, Catholic high schools, and state delinquent institutions. Whole classes of grades nine to twelve were included and diverse ranges of socioeconomic and ethical factors were present. Randomness of the sample was assumed because of the multiple same 
grade classes available. This was a quantitative study that hypothesized that the state of the adolescent's self-concept, particularly if it was very negative, was likely to be a significant propellant into delinquent behavior.

The first measure used was the Self-Report Delinquency Scale (SRDS). The participants were administered the SRDS, which was used to classify them into nondelinquent and non-institutionalized delinquent categories. The institutionalized delinquents also completed this questionnaire. It was used to confirm the degree of delinquent behavior compared with non-delinquent and non-institutionalized delinquent groups. The second measure was labeled the Personal Descriptive Scale (PDS). The researcher developed this scale to explore self-perception of esteem. It consisted of 12 pairs of self-descriptor items; higher scores indicated a more positive self-concept.

The SRDS indicated higher delinquency scores for boys than girls on all items except public drinking. The alignment of this factor with masculinity could explain why it was not viewed as negative. The mean scores were tabulated on this instrument. The range on total scale was minimum $=12$, maximum $=60$. Since adolescents are so diverse, self descriptors were divided into adult state and peer state.

In adult state, the mean of 24.52 for the non-delinquent group was higher than the delinquent groups. The female group mean was highest, $F(2,362)=59.37, p=.0005$. The direction of the means of the delinquent groups supported the hypothesis. In the peer state, the three means were non-delinquent $(M=20.08)$, non-institutionalized delinquent $(M=20.54)$, and institutionalized $(M=19.46), F(2,362)=2.80, p=.06$. The means for the males followed the same directional pattern but the females ascended from institutionalized, to non-institutionalized and then to non-delinquents. 
The $t$ test for differences in self-concept indicated a significant difference between the non-institutionalized delinquents and the institutionalized delinquents which was shown by $F(2,362)=2.06, p=.04$. The non-delinquent group was not significantly differentiated.

On the PDS, the hypothesis was supported. Both boys and girls followed the same pattern, $F(2,362)=33.02, p=.0005$. Further $t$ tests were used to determine the difference in total self-concept scores among the three groups. The non-delinquent group was significantly different from the non-institutionalized delinquent group $t(309)=4.17$, and from the institutionalized delinquent group $t(220)=7.00, p=.0005$. The noninstitutionalized delinquent group was significantly different than the institutionalized delinquent group $t(195)=4.19, p=.0005$. A gender comparison yielded no significant difference.

Research summaries reported there appeared to be an inverse relationship between self-concept states and delinquency. More positive self-concept (adult state) corresponded with a lower level of delinquency, and a more negative self-concept (peer state) corresponded with a higher level of delinquency. The way respondents perceived themselves was reflected in their behavior. The analysis of the items in the SRDS indicated higher delinquency scores for boys than girls on most items. The interrelationships of the factor utilized to develop the dimensions of self-concept added future importance to this study.

Levy (Fall, 1997) continued his look at self-concept and found only a paucity of empirical work in the literature on the relationship between self-concept and delinquency done between mid 1970 and early 1990. This research area has long been a difficult place 
to explore. The main reason for the difficulty is because of the juvenile status of the population and the confidentiality issues involved with children.

The random sample for this study consisted of 230 adolescents (131 males and 99 females) with signed consent. The children were in grades 9 to 12 from a number of coeducational public and Catholic high schools. The schools were located in Queensland, Australia with students coming from a diverse range of socioeconomic groups and ethnic backgrounds. Of that number, 54 adolescents ( 49 boys and 5 girls) were from juvenile delinquent institutions. All adolescents participated voluntarily and anonymously. Data were collected from three groups, non-delinquent males $(n=32)$, females $(n=60)$; noninstitutionalized delinquent males $(n=40)$, females $(n=34)$; and institutionalized delinquent males $(n=49)$, females $(n=5)$.

The method used was the Tennessee Self-Concept Scale (TSCS). It was comprised of 90 scale items and 10 self-criticism items. The design of the response sheet was a matrix format. Three classifications were determined by using Mak's Self-Report Delinquency Scale, non-delinquent, non-institutionalized delinquent, and institutionalized delinquent. Analysis of variance (ANOVA) and $t$ tests were used to assess the overall effects of the independent variables (identity, behavior, personal, and family morals/ethics) on self-concept. Computerized analysis was conducted using Statistical Package for the Social Sciences (SPSS). Mean scores, ANOVA, and $t$ test comparisons revealed significant differences in self-concept between the groups.

Implications were that TSCS highlighted the importance of self-concept as a way to differentiate groups of adolescents based on delinquency. The hypothesis of negative self-concept leading to greater incidences of delinquency was strongly supported by the 
total scores. The results of this research lent support to the importance of the relationship between self-concept and delinquency. The expected relationship between positive levels of self-concept and low levels of delinquent behavior was supported.

In a third study by Levy (2001) information was provided on a study that examined the attitudes toward institutional authority and self-concept among nondelinquents, non-institutionalized delinquents, and institutionalized delinquents. Participants included 365 adolescents (199 males and 166 females) from a number of large, coeducational Australian state high schools and Catholic high schools. They were randomly drawn from entire classes of grades 9 to 12 . Once again, he was working in Queensland, Australia where he encountered a diverse range of socio-economic levels and ethnic backgrounds. Also included in the study, were 54 institutionalized delinquents. This was all the information provided by the researchers concerning the subjects.

A Self Report Delinquency Scale was used. It contains 34 yes/no items that canvassed behaviors that ranged from less serious to very serious delinquent acts. The scale was culture specific to Australian adolescents. Satisfactory reliability and validity was documented. Next, he used an Attitude toward Institutional Authority scale. The 30item scale measured attitudes toward institutional authority. Responses were made on a 5- point Lickert-type scale. The Tennessee Self-Concept Scale was used to evaluate selfconcept. Analysis of variance yielded an $F$ ratio of 73.49 , which was significant beyond the .0005 level. 
The Attitude towards Institutional Authority Scale was a 30 item measure that looked at attitudes. Responses were made on a 5-point Lickert-type scale. Four subscales, two for formal and two for informal authority, were developed.

The Tennessee Self-Concept Scale (TSCS) measured the self-concept of individuals who were at least 12 years old. It provided a global score with several subscales, Identity, Self-Satisfaction, Behavior, Physical Self, Moral Ethical Self, Personal Self, Family Self, and Social Self.

The data were compiled into five tables. Table one provided inter-correlations for the Attitude towards Institutional Authority Scale. There was a high degree of intercorrelation for the total and subscale scores, which supported previous studies. The scale was found to have acceptable reliability and scores correlated well with other sources.

The study provided mean scores on the Attitude towards Institutional Authority Scale and the Tennessee Self-concept Scale. The mean score for the non-delinquent group ( $M=116.8)$ was considerably higher than the mean scores for the delinquent groups: $(M=96.84)$ for the non-institutionalized delinquents and $(M=92.44)$ for the institutionalized delinquents. Analysis of variance yielded an $F$ ratio of 73.49 , which was significant beyond the .0005 level.

The study also tabulated $t$ tests comparisons by delinquency groups, nondelinquent vs. non-institutionalized delinquent; non-delinquent vs institutionalized delinquent; non-institutionalized delinquent vs institutionalized delinquent. There was no significant difference in attitude between the delinquent groups. On the other hand, comparison of the non-delinquent group with the non-institutionalized delinquent group and with the institutionalized delinquent group revealed significant differences. 
In addition, the study summarized $t$ tests comparisons by gender and delinquency group, male/female non-delinquents; male/female non-institutionalized delinquents; male/female institutionalized delinquents. There was no significant difference on the basis of gender for any of the groups.

Finally, the study documented an analysis of variance. It yielded an $F$ ratio of 115.22 and was significant at the .0005 level. It also provided degrees of freedom, sum of squares, and mean squares for Attitude towards Institutional Authority Scale and Tennessee Self-Concept Scale.

This study found a trend in self-concept and attitude towards authority scores. It suggested that self-concept was a key indicator in differentiating delinquents from nondelinquents. It identified significant correlations among attitude towards authority and each of the TSCS sub-scales, with behavior, morals, and ethics being the most powerful indicators. The hypothesized findings were substantiated by the research. The nondelinquents scored highest, institutionalized delinquents scored lowest, and noninstitutionalized delinquents fell in the middle.

A natural progression from Levy's work on self-concept was an investigation of Queensland youths who failed to enter the workforce or the continuing education arena. Why didn't they enroll in a tertiary course [college] or get a job? Whiteley (2001) conducted a study that focused on exploring Queensland youths' continuing education or work ethics. She looked at four groups: those enrolled in college, those employed, those undertaking another form of continuing education, those who were unemployed or not in the labor force. For her purposes, at-risk was defined as those young people who were at- 
risk of never being able to take advantage of a range of employment or educational opportunities.

Study participants were pulled from a population of 33, 259 students who completed year 12 in Queensland and were sent a four-page survey. Of that number $(n=$ $33,259), 12,915$ students returned the survey. Five percent (571) indicated they were not employed or studying. For comparison purposes, three matched samples were randomly drawn from the main data set $(n=12,915)$. The three groups were: college students, employed respondents, and an additional group who was involved in various continuing education efforts. These samples were matched to the type of undergraduate school attended: $82 \%$ (471) of the unemployed group had attended a government school, $10 \%$ (57) attended Catholic schools, $8 \%(43)$ attended independent schools, $(n=571)$. There were $242(42 \%)$ fewer males than females who indicated they were unemployed or not in the work force.

One measure used to evaluate survey information included the Department of Education, Training and Youth Affairs tool (DEYTA). This provided definitions of socioeconomic status, geographic location, and identified respondents in regional and poor areas. Geographic location did not appear to be a factor in employment. Employed respondents were likely to be from a rural or isolated area. At-risk youth tended to reside in urban areas. Therefore, it was concluded that geography was not a negative factor.

Further exploration revealed that the at-risk youth followed a pattern relating to the educational achievement of parents. At-risk youth were found to rarely have a father who had completed college courses. This fact reflected their lower socioeconomic status 
and emphasized that this group suffered from a lack of exposure to further education within their family environment.

Other areas evaluated in the study included questions concerning applications to college, reasons for not continuing studies, information provided for continuing studies by undergraduate sources, and information at-risk youth wished they had received. Results included the following:

(1) The majority of the at-risk youth did not prepare for the college experience and did not apply for admission.

(2) It was suggested that failure to secure employment, lack of interest in future study, and the failure to attend college characterized the current situation of youth at-risk. It was important to note that at-risk graduates intended to enter the work force or attend college; however, they were unsuccessful when they attempted to pursue their preferred option.

(3) There was a significant difference between at-risk and continuing education groups in relation to information provided by institutions. Youth at-risk were significantly less likely to have solicited information.

(4) Approximately $40 \%$ of those not in future study or employment provided written comments regarding the type of information they would have liked to receive about post secondary options.

This was a qualitative study that did not utilize any statistical procedures to analyze the collected data. The study suggested features that characterize youth at-risk and indicated reasons for not engaging in full-time work or study after leaving school. At-risk youth did not share many similarities with those working or studying. The 
majority of the at-risk youth indicated that they were not interested in further study. This was not surprising given that many displayed low levels of achievement at school and became involved with juvenile justice at an early age.

Bullis, Sprague, and Walker (2001) supported the supposition that anti-social behavior breeds in the soil of poverty, ineffective parenting practices, drug use, inadequate schooling and academic failure, peer rejection, and association with deviants. Inadequate social skills transcend economical barriers for at-risk youth. A suggested strategy that addresses the lack of these skills is called Structured Social Skills TrainingSSST. There is no documented cure for this problem; however, this program tends to help but unless consistently applied with stringent guidelines, there is little documented proof of improvement. There are two types of SST programs. One is a universal intervention that uses a wide range to address a large population's needs. This is a cost-effective method that has been proven weak but better than nothing. Number two is a targeted intervention program for use with a specific at-risk group or individual targeted needs. This is expensive but very effective.

The desirable situation is to use a targeted intervention program that is long term, delivered in a key targeted setting, has periodic boosters, and is an integrated study with the home and or school. The learning process embraces problem recognition which is a situational analysis, role playing, and empathy producing procedure. Next, the individual develops a generation of alternatives to the documented behavior. Third, the individual makes a decision about the best alternative to be utilized as a replacement strategy. Fourth, there needs to be a mental rehearsal of the skill that covers two areas: social skills mechanics-body language and social content-what to say. Examples of this type of Social 
Skills Training are First Step for pre-schoolers, CLASS for acting out students, RECESS for aggressive students, and PEERS for socially withdrawn students.

Brooks, Brown, Lester, Soler, Watson, and Williamson (2001) focused on the state's mandates for the Department of Juvenile Justice facilities. The attempted to align the necessary components for juvenile detention centers in Kentucky. The state's focus has been to address the Individual's with Disabilities Education Act (IDEA). Federal legislation provides all eligible juveniles, including those incarcerated, to be provided with educational services tailored to their specific academic needs. This process includes providing the least restrictive environment, meaning that the "special" student is educated in classes with non-disabled students. The identification, referral, and evaluation process is followed for placement of children. Individual Educational Plans are written and implemented for identified students. Special education and related services are provided with due process protection that enforces the child's rights under IDEA. When juvenile delinquents are placed in the justice system, their educational plans must be implemented as written. Incarcerated youth are still entitled to all special education services noted on their IEP. Furthermore, there is a documented correlation between education and recidivism; therefore, it is imperative for education to continue at an uninterrupted pace to stop the revolving door effect at juvenile justice facilities.

\section{Recidivism}

Finally, we reach the most challenging component of the juvenile delinquent atrisk phenomena: Recidivism. Waldie and Spreen (1993) organized a research project that explored recidivism of delinquency in juveniles with learning disabilities (LD). Data from a longitudinal study initiated in 1978 were examined. Subsequent data were 
examined from the same group at the median age of 18 years and 25 years. Through a discriminate analysis, personality characteristics of youth with learning disabilities were documented.

A total of 203 students were first assessed between the ages of 8 and 12 years from 1966 to 1972 . The students had been referred to the University of Victoria Neuropsychological Laboratory because of learning problems. There was a low racial minority population and only moderate representation of socio-economic deprivation. The average full scale IQ was $92.46(S D=15.1)$. During the first follow-up, the sample ( $n=65)$ reported contact with the police. During the second follow-up, the sample size was divided: $(n=25)$ no further police contact and $(n=40)$ persistent police contact. Of the $(n=65)$ sample, there were 47 males and 18 females.

This was a qualitative study that utilized detailed, structured personal interviews of approximately 2 hours. The initial sample $(n=203)$ provided the first group data. The sample was developed through a review of historical documents - records from the laboratory. Phase 1 interviewed the $(n=203)$ sample and pulled a second sample $(n=65)$ with police contact. Phase 2 looked at this group again and made two subgroups: $(n=25)$ no further contact and $(n=40)$ persisting contact.

Phase 1 included a 163-item interview covering a wide range such as family characteristics and relationships, school experiences and attitudes, employment history, health and behavior problems, social relationships, and involvements with the police. Parents completed the interview, too, plus a behavior rating scale consisting of 30 sixpoint ratings on major bipolar adjectives describing the participant. Next, the subjects 
completed a personal adjustment inventory. Both scales had reliability and validity with split-half reliability for the Bell scale between .83 and .88 .

In Phase 2, all subjects $(n=65)$ were given a structured 2-hour interview covering Phase 1 criteria. In addition, a neurological examination covered 22 hard and soft signs and a series of 14 standardized psychological tests. Dividing the group into persisting contact and no further contact with police developed the sub-groups. Data analysis included a discriminate function analysis of data from the Behavior Rating Scale and the Adjustment Inventory.

The variables were explored extensively with the final combined analyses pinpointing six: judgment, temper tantrums, cruel or mean, destructive, active and lively, impulsive. These were labeled as six contributing variables defining susceptibility theory:

(1) Judgment had $F(6)=5.47$ with significance $.03, p<.05$

(2) Temper tantrums, $F(6)=1.45$ with significance $.23, p<.05$

(3) Cruel or mean, $F(6)=.70$ with significance $.41, p<.05$

(4) Destructive, $F(6)=2.23$ with significance $.14, p<.05$

(5) Active and lively, $F(6)=1.80$ with significance $.19, p<.05$

(6) Impulsive, $F(6)=4.44$ with significance $.04, p<.05$

From this summary, indicated results were that two items discriminated between non-persisting and persisting: recidivist youth with LD showed poorer judgment in most matters and were more impulsive. Significant characteristics that made at-risk youth more susceptible were: lack of impulse control, inability to anticipate consequences, and lack of reasonable judgment. 
This study supported the Susceptibility Theory: LD was linked to certain underdeveloped personality skills (i.e., impulsiveness and poor judgment). Deficiencies in these areas led to delinquent behavior through unwise social choices. In conclusion, the researchers projected that some of the factors that restrained a normal child from committing a delinquent act were not present in the LD child because of the learning disability. The problem was not callousness or street toughness on the child's part but rather a lack of knowledge of acceptable behavior.

Restitution as a determent was explored when Roy (1995) conducted a study to examine the impact of restitution on juveniles' recidivism after their successful exit from a victim restitution program in Lake County, Indiana. The study looked at reconviction and offenses committed after successful exit from the program. It compared restitution and probation only groups and explored factors related to recidivism.

The subjects in the restitution group included 113 juveniles who were successful in the program from January 1989 to December 1990 . The probation only group consisted of 148 youths who were successfully discharged from probation during the same time frame as the restitution group. In both groups, the majority of the subjects were white $-74.3 \%$ restitution and $61.5 \%$ probation only. About $87 \%$ in the restitution group and $73.3 \%$ in the probation group were males with the average age at 15.5 years for the first group and 15.8 years for the second group. Participants had histories of substance abuse, prior arrest records, and a history of diversion. The average age for first offense was 15.8 for the restitution group and 14.4 years for the probation group.

The independent variables included individual characteristics (i.e., race, gender, and disposition age), case characteristics (i.e., substance abuse history, prior offense 
history, prior diversion and detention, and age at first offense), and a program characteristic (i.e., number of days in program supervision) respectively. Disposition age, days in supervision, and first offense age were intentionally scaled and the other independent variables were coded dichotomously.

The dependent variable, recidivism, was measured in terms of number and types of subsequent offenses as well as reconviction of successful subjects during fellowship. Types of offenses were dichotomously coded as felony and non-felony. Reconviction was also coded dichotomously.

Since the dependent variable was given dichotomous coding, discriminate function analysis was computed to calculate whether the effects of a collection of independent variables make any significant difference between the two groups. These linear combinations of the independent variables that best measure between-group (restitution/probation) differences were found through discriminate analysis. Logistic regression was computed for a within-group analysis for the restitution group. This computation estimated the chances of an event occurring (reconviction, coded1) made in reference to another event (no reconviction, coded 0 ).

This was a quantitative study that used dichotomous coding and logistic regression to evaluate the dependent and independent variables. The hypothesis tested in the analysis was that there was no significant difference in recidivism between the two groups. The study used a discriminate function analysis to calculate the effects of the independent variables and insight into the difference was gained by examining Wilk's lamba. 
Summary of the research findings found recidivism differences among the subjects of the two groups were statistically significant $(F=68.87, p<.0005)$. Wilk's lamba provided insight into the difference. As the value of lamba approached 0 , variance was attributed to between-group difference. Substance abuse and days in the program were the most significant predictors of recidivism. Significance of each was 0.000 ( $p<$ $.0005)$. Wilk's lamba for the discriminate function (.864) suggested that the variance was found in each program. The findings from the discriminate function analysis did not support the hypothesis tested in the analysis.

Logistic regression coefficients, standard errors, and odds of recidivating were looked at for a within-group analysis. Age at disposition was the only variable with a statistically significant coefficient $(p=1.842, p<.001)$. A look at case characteristics showed statistically significant results for substance abuse history $(b=3.590, p<.05)$, prior offense history $(b=3.590, \mathrm{p}<.01)$. Prior diversion $(b=-2.669, p<.05)$ and age at first offense $(b=-1.657, p<.01)$ had statistically significant negative relationships to the probability of recidivism.

Overall, the between-group analysis indicated the gender, substance abuse history, prior offense history, prior detention history, age at first offense, and number of days in the program were significant variables to make a statistically significant difference between the groups in terms of recidivism. The study demonstrated that $25 \%$ of the firsttime offenders and $50 \%$ of the repeat offenders committed recidivist offenses. The issue that arose from the study was who should pay the restitution, the juveniles or the parents. To address the at-risk factor of social responsibility, this study supported the need for juveniles to pay the restitution so they would be held accountable. 
While traditional educators were addressing learning needs outside of facilities, sentencing and recidivism was researched by Manski and Nagin (1998). They compared the impact of the two main sentencing options available to judges, confinement in residential treatment facilities and diversion to non-residential treatment, on recidivism.

The research design and methods used for data analysis was an empirical study where treatment selection was randomly distributed and recidivism probabilities followed a parametric model. It was a classical randomized experiment with a nonparametric analysis. The study sought to examine what could be learned about the treatment effects under alternative models. The researchers obtained bounds under weak nonparametric modes of analysis that clarified the source of common disagreements about the magnitudes and signs of treatment effects.

There was a random treatment selection that identified classical treatment effects (CTE). CTE difference between recidivism probabilities that would occur under mandatory residential treatment and mandatory non-residential treatment was documented. The status quo treatment effect (STE), that documented the difference between recidivism probability under mandatory residential treatment and under the actual sentencing rules used by judges, was recorded.

The sample $(n=13,197)$ consisted of male offenders born from $1970-1974$ and adjudicated by the Utah Juvenile Justice System. The National Juvenile Court Data Archive organized these records into files, which recorded all delinquency, status offense, and abuse and neglect cases referred for court intake. The data for each case included the dates of referral and disposition and the reasons for and disposition of the referral. The independent variables were age, race, sex, and number of prior referrals by the judicial 
primary purpose of this study was to test one measure of dynamic factors in terms of its ability to predict recidivism. Data on a number of stable factors were collected to serve as a comparison.

All participants were drawn from the Van Horn Youth Center (VHYC), a juvenile rehabilitation group home during the time periods July 1, 1996 to June 30, 1997. The study included only juveniles for whom CAFAS scores were available $(n=41)$. The sample was composed of 21 Latinos (60\%), eight whites (23\%) five African Americans (14\%), and seven Chinese youth (3\%). There were 19 males (54\%) and 16 females (46\%). Seven participants were 14 , nine were 15 , fourteen were 16 , and five were 17 years old.

The study did not identify independent and dependent variables; however, it did discuss two types of predictors-stable and dynamic. The stable predictors included ethnicity, age at discharge, sex, and number of sustained offenses prior to program participation. The dynamic predictors were the CAFAS 8-scale and 5-scale. The 8-scale subscales were schoolwork, home, community, behavior, moods/emotions, self-harm, substance abuse, and thinking. The 5-scale subscales were role performance, behavior, moods/self harm, substance use, and thinking.

This was a quantitative study that hypothesized that a focus on individuals' recidivism would be advantageous for juvenile justice policy makers. Based on this hypothesis, the CAFAS was empirically tested to determine the degree to which it predicted recidivism in a sample of juvenile offenders.

A chi-square test of independence was conducted for each of the categorical variables (ethnicity, sex, and age at discharge). Kendall's tau was computed for sex and 
age at discharge and Pearson's correlation coefficient was computed for the number of prior offenses, age of discharge, the CAFAS 5-scale total, and the CAFAS 8-scale total.

The only stable predictor with a significant $(p<.05)$ relationship with recidivism was sex: males were more likely to re-offend than were females. The CAFAS had a significant relationship with recidivism: the CAFAS 5-scale total was significant at the $(p<.05)$ level and the CAFAS 8-scale total was significant at the $(p<.01)$ level.

When CAFAS scores were presented by recidivism, the groupings provided practical significance for policy makers and practitioners. A Pearson chi-square test demonstrated that CAFAS scores, non-recidivist, and recidivist were significantly different from one another, chi $2(2, n=35)=9.29, p<.01$.

The study looked at the average number of offenses committed by two groups: minimal risk and at-risk/exceptional risk. The second grouping had $73 \%$ more felonies, $30 \%$ more misdemeanors, and $64 \%$ more probation violations.

Pearson's correlation coefficient was computed for each variable. The results for recidivism, as a continuous variable, were similar to those for recidivism as a dichotomous variable: sex was the only significant $(p<.05)$ stable factor. Both the CAFAS 5-scale total $(p<.05)$ and the CAFAS 8-scale total $(p<.01)$ were significantly related to recidivism.

In summary, the primary hypothesis was true: There was a significant relationship between the CAFAS and juvenile recidivism. Worse scores on the CAFAS predicted future offenses. Only one of the stable factors (sex) demonstrated a significant relationship with recidivism. The findings had three implications: 
(1) The CAFAS should be used to determine which juveniles are at-risk for future offenses, and resources should be allocated accordingly.

(2) Future research should emphasize the assessment of dynamic factors in juvenile recidivism.

(3) The methodological issue of whether recidivism should be treated as a dichotomous or a continuous variable was resolved because both sets of analyses reached the same conclusions. Therefore, the skewed distribution of the offense count did not distort the results.

This research suggested that mental health assessment techniques were useful in targeting at-risk juveniles. Cooperation and the sharing of information would result in more accurate decisions regarding the needs of juvenile offenders and eventually recidivism would be reduced to extension.

By understanding the limitations of current data collecting tools, practitioners are hoping to improve their evaluation process. Katsiyannis, Zhang, Barrett, and Flaska (2004) conducted an investigation to research the limitations of existing prediction models regarding recidivism among juvenile offenders. Psychosocial variables were added to background variables to investigate the contributions of these factors to the prediction of recidivism. The goal was to encourage continues efforts to improve the validity of prediction models.

Participants were 299 adolescent boys incarcerated at the Youth Rehabilitation and Treatment Center (YRTC) in Kearney, Nebraska from July, 1998 to July, 1999. The age range was 12 to 18 with the sample mean of 16.2 years. Of the sample, $(n=253)$, $84.6 \%$ were non-recidivists, $46(15.4 \%)$ were recidivists, 48 (16\%) were parole violators, 
and $22(7 \%)$ were both recidivists and parole violators. The ethnic/racial composition was 169 (56.5\%) Euro-Americans, 37 (12.4\%) African Americans, 47 (15.7\%) Hispanic Americans, 11 (3.7\%) Asian American, and 6 (2\%) Native Americans. Eighty-nine participants (30\%) reported receiving special education. Special Education labels included learning disability, $39(13 \%)$ and emotional disability, 18 (6\%). Fifty-nine participants (20\%) reported gang affiliation. The sample $(n=299)$ average IQ (Wechsler Intelligence Scale for Children [WISC-R]) for reading achievement, math achievement, and writing achievement scores were $96.49,94.58,94.09$, and 82.30 , respectively.

The study was quantitative and used four psychosocial measures, The Adolescent Drinking Index (ADI), the Reynolds Adolescent Depression Scale (RADS), the Inventory of Parent and Peer Attachment (IPPA), and the Personality Research Form (PRF). Follow-up data on recidivists were collected in 1999-2000, 2000-2001, and 2001-2002 and cross-referenced with people admitted to the facility in 1998-1999 to determine which individuals became recidivists.

Chi-square tests for difference between recidivists and non-recidivists on demographic variables were conducted. A hierarchal regression analysis was conducted to examine the successive and independent contributions, age of incarceration, academic functioning, current psychopathology/adjustments, and personality variables to the prediction of recidivism. Age of incarcerations was entered as the first predictor. Next, three measures of academic functioning- WISC-R full scale IQ, Woodcock-Johnson reading achievements, and inclusion versus non-inclusion in special education- were entered at Step Two. Third, scored on the RADS depression index, IPPA attachment to parent total, and ADI total drinking were entered into the equation. Finally, two 
personality measures identified in preliminary uni-variate analyses as discriminators of recidivism were forced into the equation, PRF- Succorance and PRF- Cognitive Structure.

A negative relationship between PRF-Cognitive Structure and recidivism was expected. Increases in $\mathrm{R}^{2}$ associated with entry of each of the four sets of predictors were calculated and tested for significance. To reduce the experiment alpha level to .05 , the alpha level was set at .0125 for each of the four sets and at .005 for each of the nine tests at Step Four.

The results showed that recidivists and non-recidivists did not differ with regard to special education history, gang involvement, or race. There was a group difference in parole violation. Forty-seven percent by recidivists were parole violators, compared with $9 \%$ of the non-recidivists. Results of the hierarchal regression analysis include the following:

(1) Age of commitment significantly increased, $\mathrm{R}^{2}, F(1,96)=11.17, p<.001$.

(2) At Step 4, the inclusion of PRF-Succorance and PRF-Cognitive Structure significantly increased, $\mathrm{R}^{2}, F(2,188)=6.70, p<.005$.

(3) The four step model accounted for $16 \%$ of the variation in recidivism, $F(9,188)=$ $3.95, p<.001$.

(4) At Step Four, two achieved regression coefficients were significant at $p<.001$. These were age of commitment $t(188)=-3.55, p<.001$, and PRF-Succorance $t(188)=-2.73, p<.001$. 
(5) The final regression coefficient for PRF-Cognitive Structure did not reach significance, $t(188)=-1.80, p<.000$ and the RADS depression score had a significant value of $t(188)=-2.58, p<.011$.

The uni-variate relationships were summarized. RADS depression, PRFSuccorance, PRF-Cognitive Structure, and age of commitment show negative correlations with recidivism; however, only age of first offense met the .005 significance level.

These findings suggested that individual difference in educational achievement were not predictive of recidivism. Depression was identified as a related variable but the directional relationship was inconsistent with expectations. Interpretation of the relationship between cognitive structure and recidivism could be projected but with caution. The final regression coefficient was only marginally significant $(p<.08)$ and was the result of self-reporting. In succorance, recidivists reported a lower need for approval and support by others indicating a lower need for approval; thus, poorer relationships resulted.

Finally, the results suggested that information about personality traits succorance and cognitive structure - could be used in predicting and understanding recidivism. Age of first commitment was found to be the single most important predictor of recidivism.

The development of a healthy self-concept that portrayed a personal photograph that allowed for pride and self-esteem was a challenge the research pursued. The studies supplied a summary of tactics that could be utilized to improve a juvenile's self-image and would eventually result in an improved opinion of himself or herself. This 
improvement would empower the at-risk youth and a natural reduction in recidivism would occur. By breaking the cycle, society could be provided with another contributing member rather than a draining adult statistic.

To offer a better understanding of Juvenile Delinquent self-esteem and recidivism rates, The Special Needs of Youth in the Juvenile Justice System, A Project of Children's Law Center in Covington, KY was published in June, 2001. This document states that education is critical to the prevention of delinquency and the reduction of recidivism. It shows that government and culture is attempting to reach consensus on how to rehabilitate this at-risk population. Higher levels of literacy are associated with lower rates of Juvenile delinquency, re-arrest, and recidivism. Individual Education Plans (IEP's) are being viewed as one tool in addressing the unique and varied needs of these children. Culture demands that individual needs be acknowledged and government states that, if institutions fail to implement IEP's, they are violating state and federal statues and regulations for special education services. Accountability is attached by the removal of federal funding if these plans are not implemented. In view of the seriousness of this charge and subsequent loss of funding, effective programs should implement IEP's and focus on literacy, life skills training, and an extensive diagnosis system that includes educational, vocational, social, emotional, and continuous behavioral assessment of youth. The main goal of the Juvenile Justice System is to provide these short term residents with some authentic educational success that carry over into their future placement, school efforts, and/or home environment. Thus, government and culture have arrived at an uneasy but necessary consensus on how to provide treatment for juvenile delinquents. 
Additional support for a bonding of government and culture can be seen in a 2003 dissertation by Day entitled, Each Child, Every Child. This material addressed the fact that property poor districts and the school children they serve were irrationally trapped in a system which made the scope and quality of education depend on property values and the limited taxing powers. Kentucky school children have a substantial, fundamental interest in and right to adequate educational opportunity. Any legislation placing a discrete class of children at a disadvantage in their ability to obtain a meaningful public education should be subjected to the strictest constitutional scrutiny. The final decision backed up the opinions of the educators and districts that initiated the law suit that triggered KERA. Judge Ray Corns decided, "It is a duty of the General Assembly to provide an adequate educational opportunity for our children in need ... not only does it have to be adequate, but there has to be equity. A child cannot be penalized educationally because of geography" (Day, 2003).

Based on Judge Corns's summary, it may be concluded that juvenile delinquency is the result of culture driven, in part, by government. Sadly, no one is able to avoid the responsibility of the development and the need to handle the issue of these at-risk children. They are a population that is growing and refusing to go quietly into the night of our ignorance.

A theoretical validation of Judge Corns summary was found imbedded within Osborne and Gaebler's Reinventing Government and Hunter's Culture Wars. These works highlighted strategies that address an underlying paradigm of this study, Juvenile Delinquency is a national problem that requires a commitment from all corners of society. Culturally, family units and their resulting values must be evaluated and 
rejuvenated. Governmentally, social reforms must be supported and financed. The following discussion will supply a connection between these two major players in the juvenile delinquent's world, Culture and Government. In addition, an understanding of the repetition of offenses or recidivism might be explained by a look at the complicated system that is attempting to replace the home environment of the child. Parens patriae is alive and well in today's legal system; however, the proceedings become complicated by the intricacies of our political system. When an at-risk child crosses the line and becomes a ward of the court, family is replaced by the state. Unfortunately, goals become clouded when viewed through different theories and practices, and today's world necessitates different management tactics for juvenile delinquents. Childhood criminals have long been a concern for society as supported by the historical development of juvenile detentions. Families were not able to correct the problems that society was introducing to troubled children. In view of these complications, an argument developed that is certainly stimulating in terms of academia but does not supply an answer to the issue of the increasing delinquency rate in America. However, before we can find a cure, we have to research the causations and determine the guilty parties. In order to focus our effort and implement successful strategies, we have to develop a common goal.

In an effort to better understand program development, the idea of Government versus Culture was explored. The definition of government is the act of governing, specifically, the control and administration of public policy in state agencies. The definition for culture is socially transferred behavior patterns, arts, beliefs, institutions, and all products of human work and thought that are passed down through generations 
and families. In view of these definitions, one can compare the ideology of the books based on how decisions are driven, how the public sector is viewed, practice, competition, and providers as described in each book. With these comparisons in mind, a blue print for detention center programming can be developed that will align the governmental issues of policy and procedures with the cultural issues of rehabilitation by replacing or establishing acceptable behavior norms.

Reinventing Government deals with the running of institutions (i.e. detention center education). In this book, there is an intense depth of concern for the character of life and moral commitments. Sincere observations are expressed about various communities struggling with historically submerged cultural conflict. Furthermore, there is a definite ideology of smaller is better. Education should be downsized and held accountable for its products. The general public is better educated and will not continue to pay for inferior services and goods; furthermore, the fact that tax payers demand a fair return for their financial investments is a motivating factor for evaluating existing detention center educational programs. A clear grading system of our mission arises wherein a need to provide services and/or resources for an informed, demanding public and quality is determined not only by the customers but society as a whole. The goal is to provide "a simple clear outline of a new way of conducting the public business" which happens to be educating our juvenile delinquent youth (Osborne \& Gaebler, 1993, p. xvii).

From an educational perspective, decisions have traditionally been based on input. Today, however, we see the public forcing education to evaluate output. Citizens refuse to pay higher taxes while quality declines. Present day technology allows output to be 
measured and education produces an informed and questioning population, which has deep cultural ramifications. As culture changes, it drives education to change (Osborne \& Gaebler, 1993). Specifically, the education of this at-risk population holds an obscure yet grim position in tax payers' minds. With their numbers increasing, attention is focused on DJJ efforts to salvage this population.

In Culture Wars, the public culture (legal and political) drives private culture by setting boundaries of personal behavior and thought. Personal interest and aspirations rooted in private culture becomes expressed as political claims in the public realm, thus, uniting government, education, and culture as decisions are derived in today's political arena. The nation's public culture encircles the combination of myths surrounding its history and future promise (Hunter, 1991). In America, one has to label these "myths" with titles such as the following examples, Thomas Jefferson's Declaration of Independence and Patrick Henry's "Give me Liberty or Give me Death!" Here one sees prime examples of how public culture or government drives and/or derives from our population's private culture. "At stake is how we as Americans will order our lives together" (Hunter, 1991, p. 34).

The Educational institutions of America have long been credited as being the source of our cultural indoctrination. Culture Wars deals with this culture of the people, for the people, not institutions. In summary, public to Culture War entails human works and thoughts while Reinventing Government's public entails an institution's processes and acts - one a noun and the other a verb. In the Juvenile Detention realm, the state assumes the role of both culture and government. Cultural manipulation occurs through state mandated policies and procedures. For the changes to occur and to be beneficial, an 
understanding and awareness of governmental issues and cultural highlights must be acknowledged, respected, and reconciled to produce the common goal of rehabilitation.

Through comparisons, I have concluded that, Reinventing Government expounds upon the fact that the public will no longer stand for dead weight, and will demand a fair product for a fair price. Juvenile detention centers can no longer be considered homes for teachers who are considered to be dead weight in their districts. Culture War says that education is, in large part, the weaver that manipulates, propagates, and formulates the fabric of our culture (Hunter, 1991) and that "the struggle for power is in large part a struggle between competing truths ..." (Hunter, 1991, p. 58). Therefore, it would be reasonable to suggest that juvenile detention centers are areas where school districts should place their most highly skilled educators. Since Reinventing Government deals with a product and Culture Wars deals with an ideal, the detention center educator can use these philosophies and gain insight into how to function within structured set parameters of policy to rehabilitate a juvenile delinquent that will conform to societal norms and become a self-sufficient member of society.

Therein lies the justification for this correlation - OUTPUT. No matter how you look at your world and the processes running it - culturally, politically, or educationally the final product, the output, must be the driving concern for our evolving juvenile justice system. No longer is America a land of plenty where human potential can be ignored. The at-risk population in Juvenile Detention Centers is an untapped resource that must be reclaimed. These children have been stripped of their childhood, dreams, self-esteem, and survival tools. 
To this point, this literature review has provided a research base for the development of Job Satisfaction Levels of Juvenile Detention Education Faculties and the Implementation of Best Teaching Practices Compared to Overall Program Efficacy. The first section, Defining At-Risk, explored the Essential Needs Factors, Educational Factors, Emotional/Behavior Factors, and Substance Abuse Factors. The second section, Teaching Juvenile Delinquents, dealt with Needs, Characteristics, and Strategies. The third section, Developing Self-Concept analyzed Esteem and Recidivism. When these three sections were placed together, a framework was developed that would provide valuable insight into a challenge that has continuously bombarded society. The fourth section looked at the necessary characteristics for a productive Juvenile Detention Educator. These people are the last hope for many of these at-risk children. They will succeed in renewing and rejuvenating hope or they will provide the final extinguishing of the childish enthusiasm and optimism which all children embrace unconditionally at birth. The fifth section provided insight into the type of research necessary to document the correlations significant to this study so valuable data could be added to the small amount of published research concerning juvenile detention centers.

Initially, Defining At-Risk, looked at Maslow's Hierarchy of Needs and Koerner's Definition of a Juvenile Delinquent. The two concepts overlapped and provided the basis of the definition. At-risk and juvenile delinquent are not synonymous. All juvenile delinquents are at-risk but not all at-risk children are juvenile delinquents. Physical needs, safety, social, self-esteem, and self-actualization were described as basic components necessary for at-risk individuals. Koener's definition of juvenile delinquents 
added the component of choice to the equation. In order to protect their omnipotence, they succumbed to the hopelessness that permeated their existence.

Next, the definition was further developed by the addition of Educational Factors and Emotional/Behavioral Factors connected to at-risk. School connectedness and tattoos signaled trouble. Reading instruction, status categories and achievement, and bullies each provided components of the at-risk status. Predictors of disorders and mental health care options rounded out the educational realm.

Finally, Substance Abuse Factors were briefly explored by the research that described a classification scheme for juveniles. A cluster analysis of substance abuse variables was utilized. The contribution of the study was that delinquency status increased with substance abuse and decreased with the termination or reduction of use.

The second component of the review was Teaching At-Risk/Juvenile Delinquents. There were three subsections, Needs, Characteristics, and Strategies. Needs compared the psychosocial area and the academic arena. Characteristics described early reading fluency and violent destructive behavior. Strategies surveyed pair counseling, moral reasoning, and conversational cues. Academic concerns were decoding words, literacy programs, guided notes, reading/spelling, and math homework. Vocational strategies were explored along with Special Education rights, school programs, and community agencies. When these three subsections were compressed, they provided significant insight into the Teaching At-risk/ Juvenile Delinquent section.

The third section generated a synopsis of Developing the Self-Concept of AtRisk/Juvenile Delinquents. It contained two subsections, Self-Esteem and Recidivism. The self-concept component had to do with how a juvenile viewed him or herself. The 
self-esteem subsection looked at various studies that dealt with how the juveniles feel about their "snapshot" concept. Behavior modification, labeling, delinquent occurrence, cognitive distortions, career salience, fan clubs, and Australian research provided a look at juvenile delinquent self esteem issues.

Recidivism was a force fit under the self-concept section. The rational for the category was based on academic and psychosocial variables. Learning disabilities, restitution, sentencing, and predictors of recidivism were evaluated in this section. The fact that a juvenile delinquent repeated self-destructive actions (in many cases multiple examples were cited) made a strong statement about their feelings of self worth (i.e., selfconcept and self-esteem). Until this personal catastrophe was corrected, little headway could be expected.

Teacher job satisfaction proved to be an unsubstantiated belief held by the researcher. Empirical studies tended to prove that satisfaction is not related to the implementation of best practices. Time in a position tended to be a stronger factor. This phenomenon was explained by the professional's implementation of mandated professional development procedures. The length of time in a position was directly related to the implementation of mandated strategies, which were documented to be best practices. In summary, if a teacher stayed in a program, best practices were implemented through a simple adherence to policy and procedure.

Pilot study findings, served as a way to customize the study and actually address the pertinent question of how to provide a better educational program for adjudicated youth in Kentucky. While the study was geographically and chronologically restricted, it 
was successful in pinpointing relationships among the three researched factors, Satisfaction, Best Practices, and Efficacy.

In summary, by the focus on definition, education, and self-actualization the review attempted to summarize the unique requirements facing professionals that deal with this at-risk population. It strove to illustrate the essential attributes of a juvenile detention facility educator and showed the relationship between satisfaction, practices, and performance. A significant area of this research explored the need for high levels of job satisfaction to be present in educational professionals stationed at detention centers. Theoretically, this attitude should be the impetus necessary for a successful program but this study left that theory hanging.

\section{Essential Attributes of the Effective Detention Center Educator}

\section{Job Satisfaction}

Researchers Ma and MacMillan (1999) conducted a study to examine how teacher professional satisfaction is related to background characteristics and workplace conditions measured through teaching competence, administrative control, and organizational culture.

The research design was of a quasi-experimental design that consisted of a self analysis where teachers used descriptors for job satisfaction. Perceptions of teachers are often based on affective or subjective judgments of the degree to which they have successfully taught instructional objectives. The instruments were sixth grade student achievement test scores and questionnaires plus teacher questionnaires.

A Likert-type scale rated teacher's job satisfaction. Composite variables were used to measure workplace conditions with a multiple regression approach to analyze the 
data. Four models were tested, teacher backgrounds, workplace conditions, interactions between gender and work place conditions, and interactions between gender, workplace conditions, and years as a teacher. Correlation coefficients were used to show how the four constructs were distinct. There was little influence from co-linearity among variables in the regression analysis.

The participants in the study were a population that consisted of an entire group of New Brunswick teachers $(n=2,202)$ with approximately $75 \%$ being women and $25 \%$ men. Demographic information included gender, age, aboriginal status, minority status, handicap status, and education. Aboriginal status, minority status, handicap status, and education were so skewed that only gender and age were utilized.

In summary, one of the most important findings of this study was the role administrators played in promoting teachers' job satisfaction. A positive perception of interactive relationships with school administration narrows the satisfaction gap among teachers with varying teaching experience and promotes a feeling of accomplishment and satisfaction. This sense of value and teamwork helps them feel at ease with their teaching and merges into all aspects of academia. A higher level of professional satisfaction arises and performance automatically increases.

\section{Career Satisfaction}

Chapman and Lowther (1982) conducted a study that proposed a conceptual scheme of influence affecting teachers' career satisfaction and reported a study using that scheme to investigate the relationship between selected abilities, values, and accomplishments and teachers' career satisfaction. 
The general premise was that career satisfaction depended on the congruence between abilities, values, and accomplishments that should characterize a teacher. Individual teachers who rated themselves on skills, abilities, values, and professional accomplishments exhibited these attributes. High scores reflected more satisfaction while low scores suggested professional dissatisfaction.

Career satisfaction was measured on a self-rating Likert-type scale with career satisfaction being defined as the mean response on a satisfaction scale composed of two items, current employment satisfaction and satisfaction with progresses made in professional career. A 4-point scale was utilized on a questionnaire that provided data for a multiple regression using a direct-within-set-wise entry procedure used to analyze the relationship of abilities, values, and accomplishments.

The overall analysis yielded a multivariate $F$ of 14.69 , significant at the .01 level. Furthermore, $36 \%$ of the variance in teacher career satisfaction was explained by identified predictor variables. An examination of Beta weights indicated that women reported greater satisfaction than men. By a systematic removal of variance factors, it was determined that career satisfaction was significantly related to self-rated skills and abilities and the importance assigned to different indicators of professional success.

The population began with 5, 764 University of Michigan 1980 teaching graduates. The sample consisted of 400 randomly selected teachers between 1946 and 1976. The 2, 933 returns made a $51 \%$ response rate. After a review of credentials and response styles, a sample of 542 remained. They had taught continuously and were currently full-time public school teachers. 
The independent variables were developed from a review of literature of earlier studies. They were, personal demographics, skills and abilities, values and accomplishments. The dependent variable, career satisfaction, was to be defined and measured. Satisfaction was measured in this quasi-experimental research study by respondents' self-ratings and Likert-type scales asking about overall experiences.

In summary, this study proposed a conceptual scheme to explain the influence affecting teacher career satisfaction and second, used that scheme to investigate the relationship between selected skills, abilities, and accomplishments and their career satisfaction. Results supported a conceptual scheme, women were more satisfied than men; skills and abilities explained a small amount of variance; achieving difficult activities was of little importance; actual accomplishments had a strong positive relationship to satisfaction; and lastly, relationship of administration's recognition and teacher satisfaction was discussed and found to have a positive correlation.

\section{Teacher Autonomy and Stress}

Pearson and Moomaw (2005) conducted a study to examine the relationship between teacher autonomy and on-the-job stress, work satisfaction, empowerment, and professionalism. It was hypothesized that autonomous teachers would demonstrate less on-the-job stress, greater work satisfaction, perceived empowerment, and a high degree of professionalism. The target population consisted of 300 teachers who worked in three neighboring school districts/counties in Florida ( $n=67,52$, and 52). Two elementary, two middle and high schools were utilized. Of the 300 teachers sampled, complete data were obtained from 171 for a response rate of $57 \%, 37(21 \%)$ were elementary, $88(52 \%)$ were middle and 46 (27\%) were high school. The mean years of experience were 14. 
The research design and method revolved around the use of a Teaching Autonomy Scale (TAS). The tool used a 4-point Likert type scale. A confirmatory factor analysis yielded a stable factor structure with improved internal consistency reliability $(r$ $=.83)$. Reliability of each scale was determined using the Cronback alpha internal consistency coefficient. Relationships were examined using the Pearson product-moment correlation coefficient.

This quasi-experimental study had an independent variable teaching level which a multivariate analysis of variance and effect sizes were determined using $\dot{\eta}^{2}$ (the strength of the association between teaching level variable and the scores). The dependent variables were less on-the-job stress, greater work satisfaction, perceived empowerment, and a high degree of professionalism.

Internal consistency reliability was determined on the variables general teaching autonomy, curriculum autonomy, stress satisfaction, empowerment, and professionalism $(r=+.80, .80, .72, .34, .91, .61 ;$ respectively $)$. All of the correlations among the variables were significantly different from zero $(p<.05)$. The highest correlation was between perceived empowerment and professionalism. Teachers who felt empowered perceived a higher degree of professionalism.

The results of multivariate analysis of variance using a curriculum and general autonomy, stress, satisfaction, empowerment, and professionalism as correlated dependent variables and teaching level as the independent variable yielded significant differences between the three teaching levels on the omnibus multivariate test with $[F(12,322)=2.72, p<.001]$. Follow up uni-variate $F$ tests revealed that significant teaching level differences were found on the variables curriculum autonomy with 
$[F(12,16)=7.95, p<.001]$, general teaching autonomy $[F(2,166)=5.87, p<.001]$, and professionalism $[F(2,166)=3.39, p<.05]$. Tukey post hoc comparisons were performed between the mean scores of the teaching levels on the three significant variables detected $(p<.05)$, and although significant differences were found, the effect sizes were weak $\left(\dot{\eta}^{2}=.09, .07, .04\right)$ for curriculum autonomy, general teaching autonomy, and professionalism.

In summary, it was found that as curriculum autonomy increased, on the job stress decreased. There was little association between curriculum autonomy and job satisfaction. Furthermore, it was demonstrated that as general teacher autonomy increased, so did empowerment and professionalism. As job satisfaction, perceived empowerment, and professionalism increased on-the-job stress decreased, and greater job satisfaction was associated with a high degree of professionalism and empowerment. The study also indicated that autonomy does not differ across teaching level.

\section{Teacher Self Esteem and Performance}

Baumeister, Campbell, Krueger, and Vohs (2005) conducted a review study that had surprising results. Their research argues that efforts to boost people's self-esteem are of little value in fostering academic achievement or preventing undesirable behavior. However, the study found that people with high self-esteem were significantly happier than others. Thus, there is a correlation between the two, self esteem and happiness, but causation was not established.

The traditional method used to measure self-esteem tends to be self reporting. Studies are qualitative and depend on self-reporting surveys. This method is worrisome because similar self-ratings of other attributes often prove to be way off base. 
Baumeister, Campbell, Krueger, and Vohs reviewed studies which explored correlations among various qualities and found clear positive links between self-esteem and multiple attributes.

They reviewed one study which looked at physical attractiveness. It found that self-reports were not consistent with others' opinions. The correlations with self esteem were negligible, $r=+.01$ for males and $r=-.04$ for females. A parallel phenomenon affects those with low self-esteem who are prone to floccinaucinihilipilificatiori, "the action or habit of estimating as worthless." People with low self-esteem are not merely down on themselves; they are negative about everything.

The study review researchers set up their work to emphasize objective measures wherever possible. This requirement reduced the relevant studies from 15, 000 subjective/objective to 200 objectives. The researchers were also mindful to avoid the assumption that a correlation among self-esteem and some desired behavior establishes causality. They conducted a 2-year effort to sort out the issue by reviewing studies relating self-esteem to academic performance.

They reviewed studies of possible links between workers' self regard and job performance echoed what had been found with schoolwork, the simple search for correlations yielded some suggestive results but did not show whether a good self image led to occupational success or vice-versa. The first two studies summarized looked at a total of 23, 542 high school students in the mid western states of Iowa and Nebraska during the years 1986 and 1995.

Other methodologically sound studies which they researched established that these results are the same for adults. Five interpersonal skills were surveyed. The only 
one that remained statistically significant was with the subjects' ability to initiate new social contact and friendships. This population was among 1980's Texas college students.

A 2002 study found in this review study, found that adults in New York produced results that showed people low in self-esteem tend to distrust their partner's expressions of love and support. In 1987, Kentucky adults showed that those who think highly of themselves respond to problems by severing relations and seeking other partners rather than staying in negative situations through fear of being alone.

Various studies across the country were used and looked at sex, drug use, alcohol use, etc. The overall result was that no categorical statement could be made. The few positive findings unearthed reflected nothing more than self-report biases. Specifics of the studies were not given. Research design and methods were not listed. Furthermore, the qualitative nature of these studies did not allow for independent or dependent variables; therefore, based on our literature scheme, the findings were not significant.

The importance of this review lies in the significance of self-esteem and job performance to professional satisfaction and job performance. The review established that correlation does exist but causation cannot be established. The utilization of this review of studies ties into the current research. By looking at correlations among best practices, job satisfaction, and performance evaluations, the current research hopes to pinpoint some causation for that elusive and mysterious satisfied employee.

\section{Factors for Teacher Retention}

Inman and Marlow (2004) conducted a study to explore teacher professional dedication. The goal was to conceptualize current satisfactions levels of new teachers to identify positive aspects of teaching to be utilized as factors for teacher retention. The 
large number of beginning teachers who continue to leave the profession within the first few years of entering validates the importance of the work.

The study sample was derived from a population for an on-going study that surveyed teachers across the United States. This sample was taken from Georgia's public school directory using Gay's Table of Random Numbers to identify 50 counties. Next, the procedure was repeated to identify five schools per county. Finally, principals supplied information from five teachers $(n=1,250)$.

The Recruitment and Retention Project of 2002 discussed by Inman and Marlow (2004) identified three major areas as factors that influenced teacher retention, which was noted as the dependent variable. The independent variables were the areas highlighted as causing the defection of educators. They were identified as external factors, employment factors, and personal factors.

A 10-item survey instrument consisting of 21 characteristics drawn from these areas was sent to teachers in participating schools. Of the 500 returned instruments, $40 \%$ were classified as beginning teachers. Specific research design and method was not explained. However, it appears that an analysis of factors influencing teacher retention occurred. The survey explored three main factors with subdivisions under each. An objective review of practices assisted with a casual examination that pinpointed significant trouble spots. Factors that accounted for two thirds of all educators' evaluations were as follows: the need to schedule all breaks; the requirements of signing in and out; limited access to work areas; mandatory bus, playground, hall, and lunchroom duty, lack of private offices and locations for personal phone calls; and the absence of time to confer with colleagues. 
The summary of the research findings is explained in the following. The teacher most likely to leave was identified as the secondary male teacher with fewer than 5 years. The teacher would be in an environment with a principal that stifles creativity and with a faculty that was at odds with his ideology. The final factor would be the absence of the professional prestige that was expected to accompany the job. The teacher most likely to stay would be an early childhood or elementary female whose employment factors were perceived as supportive and whose professional prestige was viewed as positive.

As administrators explore ways to retain satisfied educators, they have to take a more in-depth look at assignments. In 2005, Brunetti, Courtney, and Marston, conducted a study to look at similarities and differences between elementary and high school teachers by exploring their job satisfaction, goals, responsibilities, importance of subject areas, work relationships, and perceived balance of home and professional lives. The goal of the study was to be helpful in planning career development that would lead to the retention of beginning and experienced teachers at elementary and high school levels.

The study participants consisted of a sample size $(n=426)$ of high school teachers in Northern California. They taught in a predominately middle class area with a wide range of socio-economical challenges. There was a return rate of $40 \%$ with 169 being returned. The elementary teachers interviewed were from the same school district with the same district characteristics. Several hundred surveys were handed out to 26 schools but only 49 were returned. Twenty-one teachers were interviewed.

Since the elementary response was so poor, the researchers looked at another district. A sample of teachers from Pennsylvania was utilized. These teachers taught in a lower middle class population with predominately Caucasian students. The descriptive 
statistics for this district consisted of $n=80$ for distributed surveys with 51 being returned and 30 teachers being interviewed. The total study sample was $(n=506)$ for the surveys and $(n=51)$ for the interviews.

The study was quantitative and qualitative for a qusai-experimental model. The surveys were a quantitative effort to gather data from a population that framed the independent factor of elementary and high school teachers employed in public school districts. The economic characteristics were similar. However, the geographic features of California and Pennsylvania provided some cultural diversity that might have flavored the results.

The dependent factors that were in the study included job satisfaction among this sample. In addition, the factors studied were goals of the teachers and perceived job responsibilities. Given the range of assignments, the importance of subject areas was explored. The final dependent factors were professional relationships and balance of professional and personal lives.

This study used a dual research design. The quantitative survey material was treated to $t$ tests used to determine the "significance of differences in item mean scores between high school teachers and elementary teachers, as well as between the two groups of elementary teachers" (Brunetti, Courtney, \& Marston, 2005, p. 480). The qualitative interview tool was processed by triangulation of the data. A multiple-reviewer approach was utilized. Each researcher "read, re-read, and drew themes from the interview transcriptions and narrative summaries for the interview he or she had conducted" and then they read and analyzed their fellow researcher's work (Brunetti, Courtney, \& Marston, p. 485). 
In summary, the results were based on a sample of high school and elementary teachers from northern California and elementary teachers from eastern Pennsylvania. Overall, there was a high degree of satisfaction with jobs. Core professional values were motivators for staying. As expected, California teachers valued freedom and flexibility while Pennsylvania teachers valued salary, tenure, and a family-friendly teaching schedule. The fact that high school and elementary teachers differ on subject importance was also substantiated by this study. Both groups framed their teaching goals to focus on academic and social success for their students with California teachers highlighting the need to be role models to the students and Pennsylvania teachers pinpointing an obligation to parents and families. Both groups crossed over geographical barriers to summarize "how time-consuming teaching was in their lives and how challenging it was for their families" (Brunetti, Courtney, \& Marston, p. 494).

In order to summarize the debate of job satisfaction leading to job performance, the researcher utilized a review by Cropanzano and Wright (2001). The review looked at literature in an attempt to draw a connection between satisfaction and performance. According to the authors, "organizational scientist and practitioners have been fascinated by the happy-productive worker thesis" (Cropanzano \& Wright, 2001, p. 183). Supposedly, there is a positive correlation among research that measures happiness in employees and productive performance in their job situation. Unfortunately, years of study into this matter have not substantiated the myth. "The thesis remains equivocal.... The explanation of this phenomenon lies in the ambiguous definition of happiness and in the various ways of operationalizing the term" (Cropanzano \& Wright, 2001, p. 197.) 
Instead of remaining focused on job satisfaction and performance, researchers have diversified into defining the measurement as presence and absence of positive/negative affect, lack of emotional exhaustion, and as psychological well-being. Sometimes there is an "appreciable association with job performance and other times, there is not" (Cropanzano \& Wright, p. 183). Interestingly enough, the authors' state, "Despite this caveat, our general conclusion is an optimistic one for management scholars and practitioners alike, Happiness promotes higher job performance" ( Cropanzano \& Wright, p. 183).

Their conclusion was based on a historical convention, which drives "the happyproductive worker thesis to be operationalized as the relation between job satisfaction and job performance" (Cropanzano \& Wright, p. 185). However, this straightforward assumption becomes derailed when you venture into the realm of causality. The authors found these casual relations between job satisfaction and performance: "Job satisfaction may cause job performance; Job performance may cause job satisfaction: Both performance and satisfaction may be caused by a variety of third variables" (Cropanzano \& Wright, p. 185). The relationship remains cloaked in the ambiguous quirks of human nature.

In conclusion, the authors determined that "happy-productive worker thesis" continues to challenge researchers. Contextual definitions of happiness continue to blur the findings with multiple factors personal and environmental, clouding the outcomes. However, "it seems evident to us that promoting happiness-related issues is an intrinsic good for which all should work" (Ruack, 1999). The authors contend that focusing on 
what is right for people will lead to better performance and as such, the never ending quest for contentment remains desirable for its own worth.

This final summary statement supports the need for the present study: $J_{o b}$ Satisfaction Levels of Juvenile Detention Faculties and the Implementation of Best Teaching Practices Compared to Overall Program Efficacy. Whether the research shows a correlation or not, the thesis itself continues to be a viable item of interest and the human connection provides the justification.

\section{Pilot Study Findings}

The pilot study for this research provided some helpful and insight into the limitations of this study. The pilot was conducted with a national group of juvenile delinquency professionals who met at an educational forum in Annapolis, Maryland $(n=16)$. These individuals were from all areas of juvenile services. They were teachers, Court Designated Workers (CDW), counselors, administrators, central office personnel, facility supervisors, medical personnel, etc. Analysis of the pilot data quickly pointed out the need to streamline the components of the study. In an effort to make the work more meaningful for the researcher and for juvenile justice administration, the following changes were made.

1. Only educators' data would be processed. People outside of the educational field would not recognize best practices and could not determine presence and importance. They tended to think in terms of their position.

2. Educators would be defined as teachers in the facilities. This eliminated administrators since they are usually housed at district board offices. They would skew the data since they are not on location. 
3. It was determined that the importance factor would be held for future research. The number of relationships among presence and importance to be researched was too numerous for this setting.

4. It was determined that the presence factor on the BPS would be compressed into two categories, Education and Facility. This allowed for a clearer correlation picture.

5. Since the KECSAC/SIDE tool provides an overall program score, the MSQ and the BPS scores will need to be facility scores rather than individual.

6. The BPS scores will be reported as indexes rather than means.

When these six factors were addressed, the study presented an accurate view into the correlation of job satisfaction levels, implementation of best teaching practices, and overall program efficacy. Replication of the study should be possible since the centers studied are designed to reflect national standards endorsed by the U. S. Department of Juvenile Justice, the U. S. Department of Education, and the Office of Juvenile Justice Delinquency Prevention Act. However, the researcher understands that this is a localized study that may be meaningful only to those facilities that were surveyed.

With the conclusion of Chapter two, a review of purpose seemed needful. "A guiding principle of juvenile detention reform is that it must be grounded in good data. A quantitative analysis of current detention is therefore an essential part of detention reform planning" (Steinhart, 2000, p. 20). The goal of this research study was to show the correlations among Job Satisfaction levels of Juvenile Detention Education Faculties and the Implementation of Best Teaching Practices compared to Overall Program Efficacy. By the establishment of these relationships, the researcher hoped to highlight the 
importance of these individual factors. While aggregate data were easy to compile from system-wide records, the individualized exploration (of which this work was comprised) tended to be more challenging. After a literature review into each component area and a tabulation of pilot study findings, the researcher was able to explore the variables more accurately and productively.

Chapter III will discuss the Methodology utilized to expedite this study, Chapter IV will explain and tabulate the findings, and Chapter V will summarize the work.

Eventually, the researcher hopes to offer these findings to the Office of Juvenile Justice Delinquency Prevention to be utilized in the Research and Program Development Division, which "pursues a comprehensive research agenda, develops knowledge about specific problems, monitors trends, and analyzes the practices of the juvenile justice system" (Silver, 1996).

Locally, the researcher hopes to provide a better understanding of how to produce an effective educational component to detention.

Detention education is a core program component in juvenile detention facilities because of the following, most youth have a history of poor academic performance, the period of crisis can serve as a catalyst for change, state and federal laws mandate education, facilitates a return to school when discharged, enhances chances of employment following release, academic success enhance self-esteem and improve problem-solving abilities, and provides youth not enrolled in school continuing education options (Roush, April, 1996, p. 123). 


\section{CHAPTER III}

\section{METHODOLOGY}

Negative national attention on juvenile justice issues in 1992 led to a gradual movement of state efforts geared toward addressing juvenile justice. The focus on education in the detention setting evolved from a federal consent decree that was issued to the state of Kentucky in 1996. In response, the General Assembly passed House Bill 117 to establish the Department of Juvenile Justice (DJJ). Prior to the creation of DJJ, Kentucky was not in compliance with the Juvenile Justice Delinquency Prevention Act (JJDPA). This federal legislation required certain provisions as it pertained to the detention of juveniles. The two main factors that were trouble spots in the old system were the housing of juveniles in adult facilities and the failure to provide adequate educational programming.

The need for educational reform in detention centers was highlighted to the researcher by a real-life connection. Part of my training to become an educator in a juvenile detention center required visits to detention facilities throughout the Commonwealth of Kentucky. What I encountered triggered a concern for developing programming that would meet the needs of juvenile detention students. This quantitative research examined the job satisfaction levels of juvenile detention education faculties and the implementation of best teaching practices compared to overall program efficacy. The study received Human Studies approval from the University of Louisville as \#400.06 and Western Kentucky University as \#HS07-021. 
The purpose of this study was to examine the perceptions and levels of job satisfaction among the teaching staff at each of the eight Juvenile Detention Centers in the Commonwealth of Kentucky. An attempt was made to discover if there were correlations among job satisfaction, best practices, and program performance. Thus, the study examined four possible relationships.

1. Did job satisfaction have any influence on the presence of best teaching practices?

2. Was the lack of best teaching strategies detrimental to scores on the KECSAC monitoring tool?

3. Did job satisfactions have any effect on KECSAC scores?

4. Did job satisfaction and best teaching practices have a significant relationship with KECSAC scores?

Research suggested there was a significant relationship between each of these items. Theoretically, a teacher who found a high level of satisfaction in his/her job could be expected to be a professional who explored and implemented proven teaching strategies. With this exploration and implementation, a strong educational program should be developed that addressed the state standards for detention centers housing atrisk state agency children. As these standards were implemented, the rating of the program should have systematically increased; therefore, the quality of educational services would become evident to lay-persons (i.e., facility administration, youth workers, and support staff) who were collaborating with the faculty. 


\section{Research Questions}

The four questions, which guided the research in this study, were as follows:

1. Is there a significant relationship between the Minnesota Satisfaction Questionnaire (MSQ) and the Best Practice Survey (BPS)?

2. Is there a significant relationship between BPS and Kentucky Educational Collaborative for State Agency Children (KECSAC)?

3. Is there a significant relationship between MSQ and KECSAC?

4. Does a significant relationship exist between the KECSAC scores and the combined effect of BPS and MSQ scores?

\section{Study Design}

The study design was quantitative, with statistical analysis being utilized to validate the behavioral sciences. The study was a non-experimental study in which descriptive data were collected through the use of surveys with numerical scores given to explain the degree to which the standards/characteristics were implemented and/or present. This descriptive, statistical information was used as a method to organize, summarize, and interpret the data. The goal of the correlational method was to look for interrelationships among variables but the study could not determine the cause and effect of these variables. Data were recorded on a qualitative thematic coding analysis or on assigned numerical values (which were utilized in this study). This mixed method research provided this area of research with a better method of correctly analyzing data. All qualitative data were quantitatively coded into multiple statistical manipulations (Trochim, 2006). 
The study used all data taken from the surveys and assigned a quantitative value to each. This information produced new findings focusing on relationships among the three key components, job satisfaction, best teaching practices, program efficacy, using a quasi-independent variable consisting of certified teachers as participants to provide education in eight Kentucky juvenile detention centers. The dependent variables explored were job satisfaction, best practices implementation and performance and suggested the following hypothesis; stronger job satisfaction leads to greater best practices implementation resulting in higher KECSAC scores. The discrete variable consisted of the number of participating certified teachers and their locations. The continuous variables were the MSQ scores, the BPS scores, and the KECSAC scores. The higher and lower scores on each survey established real limits. Nominal scales were developed by the assignment of numerical values to descriptive characteristics on each survey. Quantitative scores were formulated for X (MSQ), Y (BPS), and Z (KECSAC) (Patten, 2005).

Participants in this research came from a non-random control group with similar demographics, certified educators of core content areas at juvenile detention centers in Kentucky. Demographics played an important role in the pilot study when comparing hierarchical education positions; surveyed data determined that supervisors and administrators looked at the questions differently and skewed the results. Therefore, the study was modified to look at only educators/teachers at juvenile detention centers to provide more realistic correlations among the research areas (Patten, 2005).

The study is a non-experimental type in which questionnaires were utilized to provide data in the form of numerical scales to measure feelings. In this study design, the 
researcher looked at the teacher's job satisfaction and best practices in order to explain the current condition (KECSAC scores) (Patten, 2005).

This type of non-experimental research was used in the survey/questionnaires instruments (i.e., MSQ and BPS). These tools measured the attitudes, beliefs, and behaviors of the population to look at what facilitated the present structure. Pearson correlation was used to determine the degree of relationship among two or more variables that were bracketed and defined the situation under study.

As the correlation efforts began in the pilot study, it was deducted that using the MSQs intrinsic, extrinsic, and general categorical alignment of the dimensions was not a viable option. The pilot study suggested a different exploration. The correlations among three tools with three categorical divisions would have provided too many pieces of data to be explored in one study. In an effort to provide a more meaningful work, the researcher decided to utilize three tools, MSQ, KECSAC, and BPS. Within these tools, it was determined that breaking the BPS into two divisions of education and facility would provide a clearer picture of the relationships among satisfaction, performance, and practices at the school level and the facility level.

With these parameters in mind, deductive processing of the surveys began. The MSQ and the BPS used a Likert-type scale ranging from very dissatisfied to very satisfied, never to almost always, and not at all important to highly important. The KECSAC instrument provided a numerical score that evaluated the program based on state standards. These scores were assigned based on observations by trained state evaluators. The scoring rubric was a standardized document that was implemented across 
the department of juvenile justice. Components were evaluated to allow for a correlation coefficient that should support or disprove the null hypothesis.

To summarize, this study consisted of an exploration of the literature that provided an informed analysis of the essential attributes of a successful detention center. After the attributes were identified, a survey (BPS) was constructed to measure presence and importance of these factors. The MSQ survey was used to determine job satisfaction levels, and the KECSAC audit scores were employed to evaluate effectiveness/performance of state programs.

A comparison of statistics provided a clear picture of centers and their success rate based on these three areas. As the study progressed, it was determined that Pearson's correlation could be used to establish the relationships among these three components and validate the worth of the effort. With a clear understanding of these three factors, administrators in detention centers have new tools to utilize as they attempt to reach this at-risk population and reclaim some of the wasted human resources flowing from this incarcerated group.

\section{Participants}

The population for the pilot study was a group of educational professionals gathered for a national convention in Annapolis, Maryland. The range of state representation was Maryland, Indiana, Texas, New York, Michigan, Ohio, and Nebraska. Demographics played an important role in the pilot study. Upon review, it was immediately obvious that educational professionals produced a random sample that was too diverse and resulted in skewed results due to differing job responsibilities. The pilot study consisted of all types of workers connected with juvenile detention centers. In 
evaluating the data, it was determined that supervisors and administrators brought a different mentality to the board and should be researched separately.

Based on this fact, the researcher decided to consider teachers only. First, educational administrators in Kentucky's detention centers are not housed in the facility. They maintain offices at the central office level and are not involved in the daily operations of the facility. Second, facility administration looks at structure and punitive rehabilitation, not education. Third, counselors focus on treatment, which cannot occur in detention centers because residents have not been sentenced. Teachers are the only personnel who look at academic performance as a method of rehabilitation, with their common outlook focused on KERA goals and objectives. Therefore, the pilot results led to the conclusion that the sample definition needed to be more restrictive, i.e., participants needed to be certified teachers in Kentucky Juvenile Detention Centers. Thus, the study was modified to provide a more realistic correlations among the research areas. Furthermore, it was determined that the KECSAC audits needed to be completed by an unbiased/neutral observer outside the facilities rather than the subjects of the research.

Based on the deductive approach used in this research, the actual study sample was defined as certified teachers in Kentucky's eight juvenile detention centers. There were 31 teachers in the facilities. Of this number, 31 completed surveys, for a return rate of $100 \%$. Since Babbie (1990) recommends that a survey rate of $60 \%$ is required to validate a study, the researcher feels a $100 \%$ return rate should add authenticity to the study. The sample $(n=31)$ was purposefully selected to cover the entire teaching staff at juvenile detention centers in Kentucky. According to Blunt and Dickinson (2005), 
descriptive surveys tend to use small samples, measures of central tendency, and percentage distributions of the variables studied to produce meaningful results. This summary reflected the research findings of the current work.

Participants were identified and selected on their role as teachers/educators and by facility, and were surveyed to provide data for levels of job satisfaction, best teaching practices implementation, and program performance/efficacy as measured by the KECSAC tool. Data were compiled to produce overall facility results in order to compute the Pearson correlations among BPS (interrater results), MSQ (averages), and the facility score of the KECSAC tool. The correlations among these areas validated the focus of the study and provided needed insight into the education of detention center populations.

\section{Procedures}

According to Marshall and Rossman in 1995, the use of descriptive surveys was an appropriate investigative tactic for this work. Furthermore, Cresswell (1994) theorized that these tools were highly recommended for researching attitude variables relevant to job satisfaction and best practices. Since this research is concerned with a study of current situations at detention centers, Fowler's (1993) work served as a validation of the effort to look at the present and tabulate the current relationships among the variables being investigated.

With these three research recommendations in mind, the Minnesota Satisfaction Questionnaire (MSQ) was selected first. The MSQ project began in 1957 and has been highly successful in measuring job satisfaction. Secondly, the Best Practice Survey was developed by the researcher in 2005 and is based on a review of the literature with a main focus on Marzano, Pickering, and Pollock's (2001) work. The third survey was an audit 
tool used by the Kentucky Educational Collaborative for State Agency Children. This instrument was developed under the direction of Leon Swartz of the Kentucky Department of Education to evaluate juvenile justice programs. These tools were authentic to the area they were measuring.

As the study began, a packet of material was delivered with individual instructions for the MSQ and the BPS survey. A cover letter contained a synopsis of the study with an explanation of how the material would be published. Participants were assured of their anonymous status with identifying marks being used by the researcher only to ensure complete coverage of the sample group. Filling out and returning the surveys constituted informed consent and willingness to participate in the research study. A letter of approval for the study was obtained from Mr. Mike Dossett, Deputy Commissioner of Kentucky's Department of Juvenile Justice, and gave the researcher access to the KECSAC scores.

\section{Instrumentation}

Questionnaires/surveys are major tools used by the behavioral sciences to evaluate program performance, practices, and levels of satisfaction. "Seasoned researchers employ surveys that are easy to complete, gather data consistently and accurately, and produce results that answer specific research questions" (Dobbie, Parchman, Passmore, \& Tysinger, 2002, p. 281). Descriptive surveys (BPS and MSQ) were used to collect knowledge, behaviors, and attitudes with a systematic approach that assisted this novice researcher. Fortunately, the study did not encounter some of the traditional limitations of surveys (i.e., cultural drawbacks, taboo subjects, or unknown terminology). Finally, these surveys used the traditional Likert scale, "with a statement as 
a stem (which focuses on only one variable) followed by responses ranging from strongly disagree to strongly agree" (Dobbie et al., p. 284).

This research investigated detention center teachers' motivation to perform. One of the instruments used was the Best Practices Survey (BPS). It follows the systematic approach modeled by the Minnesota Satisfaction Questionnaire. The survey was constructed by defining the data or constructs to be measured. In essence, the Delphi technique was employed in a modified form as "an iterative process in which items are nominated and rated by a group of experts until consensus was reached" (Dobbie et al., p. 282-283).

The theoretical framework underpinning the development of the BPS survey was derived from the results of observations, interviews, professional development, and a review of the literature relevant to juvenile delinquent education. The categories of best practices were transformed into two-part statements (indicating to what degree present and to what degree important). Detention center educators were required to respond on a five-point Likert scale from strongly agree to strongly disagree for presence and importance. The categories of best teaching practices questions were designed to measure the perceived level of presence and the relative importance of each practice.

In addition, the Best Practices Survey (BPS) was designed to measure the use or non-use of meaningful instructional practices in juvenile detention educational programs. This survey was developed to reflect the suggestions found in the Desktop Guide to Good Juvenile Detention Practice, a research report compiled in 1996 by Dr. David W. Roush of the National Juvenile Detention Association Center for Research and Professional Development at Michigan State University. The four areas addressed were physical, 
intellectual, social, and emotional. Erikson's psychosocial stages of development were addressed along with the developmental areas of activity, competence, identity, social skills, structure, and involvement (Heward, 2003). After a review of the literature, 25 areas were explored on this survey. Broad areas addressed were structure, safety, security, fairness, consistency, education, community involvement, careers/vocational planning, learning styles, physical training, life skills, computer skills, nutrition, celebrations, and facility involvement.

The Best Practices Survey also reflected the best practices strategies documented in the renowned publication Best Practice, New Standards for Teaching and Learning in America's Schools by S. Zemelman, H. Daniels, and A. Hyde in 1993. Their goal was to compile a national consensus about "best educational practice." Over a 15-year period, a group of professionals worked in a Best Practice Network and in the Illinois Writing Project to perfect their suggestions. This book was the result of extensive research and involvement that identified 13 interlocking principles, assumptions, or theories.

According to their research, educational programs should be child-centered, experiential, reflective, authentic, holistic, social, collaborative, democratic, cognitive, developmental, constructivist, psycholinguistic, and challenging.

The Minnesota Satisfaction Questionnaire, short form, was administered to 31 teachers in the eight Kentucky Detention Centers. It consisted of 20 items, each referring to a reinforcer in the work environment. The respondent indicated how satisfied he/she was with the reinforcer on his/her present job. Five response alternatives were presented for each item, "very dissatisfied, dissatisfied, neither (dissatisfied nor satisfied), satisfied, very satisfied." This tool was developed as a result of the Work Adjustment Project 
(Minnesota Studies in Vocational Rehabilitation supported in part by a Research Grant RD-1613-G from the Vocational Rehabilitation Administration; Department of Health, Education, and Welfare; Washington, DC, 20201) to measure job satisfaction with several specific aspects of work and work environments.

"The Minnesota Satisfaction Survey is a result of the Minnesota Studies in Vocational Rehabilitation, better known as the Work Adjustment Project, and is a continuing series of research studies being conducted on the general problem of adjustment to work" (Weiss, Dawis, England, \& Lofquist, 1967, p. v). The study looked at work adjustment problems that related to vocational rehabilitation. The research began in 1957 with two objectives: cross-reference the probability of rehabilitating displaced workers and the evaluation of their work adjustment potential. These goals are reflected in the Theory of Work Adjustment a conceptual framework for research that explores the relationship between "work personality" and the work place. The theory states, "Vocational abilities and vocational needs are the significant aspects of the work personality, while ability requirements and reinforcer systems are the significant aspects of the work environment" (Weiss et al., 1967, p. v). In summary, the project studies how well a worker's abilities mesh with the job requirements.

The MSQ is defined as a "measure of one of the primary indicators of work adjustment". ... Specifically, it "measures satisfaction with several specific aspects of work and work environments" (Weiss et al., 1967, p. v). The questions provide a personal summary of the workers' level of satisfaction with their job requirements, production, and environment. By having a complete picture of these issues, an effective plan can be custom designed to assist vocational clients. 
The third tool used was the KECSAC program improvement tool - Standards, Indicators, Descriptors, and Evidence (SIDE). The Oregon School Study Council developed this audit tool under pressure to produce a tool to be used for program evaluation. Their work provided a summary of research-based alternative education strategies and highlighted the following areas, low ratio of students to teachers; structured classrooms with behavioral management; positive rather than punitive emphasis; adult mentors; and individualized behavioral interventions based on functional behavioral assessment, social skills instruction, and high-quality academic instruction.

The KECSAC program improvement tool consists of standards, indicators, descriptors, and evidence (SIDE). There are a total of nine standards with a varying number of indicators to be used for evaluation. Each indicator has descriptors that explain/represent the standard being evaluated along with an evidence column containing proof it was met or missed and to what degree.

- Standard One evaluates Curriculum. It states, "The program develops and implements a curriculum that is rigorous, intentional, and aligned to state and local standards." There are nine indicators with a descriptor of each, along with a column to record the evidence that reflects a high or low score in that area.

- Standard Two evaluates Assessment with eleven indicators. The focus is, "The program uses multiple evaluation and assessment strategies to continuously monitor and modify instruction to meet student needs and support proficient student work."

- Standard Three evaluates Instruction with eleven indicators - "The instructional program actively engages all students by using effective, varied, and researchbased practices to improve student academic performance."

- Standard Four evaluates Culture with nine indicators - "The district, schools, and program function as an effective learning community and support a climate conducive to performance excellence."

- Standard Five looks at Support - "The district, schools, and program work with families and community groups to remove barriers to learning in an effort to meet 
the intellectual, social, career, and developmental needs of students and has six indicators."

- Standard Six looks at Professional Development - "The district, schools, and program provide research-based, results-driven professional development opportunities for staff and implement performance evaluation procedures in order to improve teaching and learning," with nine indicators.

- Standard Seven examines leadership - "District, school, and program instructional decisions focus on support for teaching and learning, organizational direction, high performance expectations, creating a learning culture and developing leadership capacity," with eight indicators.

- Standard Eight surveys Resources/Organization - "The program is organized to maximize the use of all available resources to support high student and staff performance," with ten indicators.

- Standard Nine looks at Planning - "The district, schools, and program develop, implement, and evaluate a comprehensive and effective plan that communicates a clear purpose, direction, and action plan focused on teaching and learning," with sixteen indicators.

\section{Validity}

The first survey administered to the population was the Best Practices Survey constructed by the researcher. This tool was a Likert-type rating scale measure of best practices (presence and importance) which incorporated Best Practices from Marzano's, Pickering's, and Pollock's Classroom Instruction That Works theory along with real-life programming strategies validated by a low-critical incident history developed to explore practices in detention. The systematic theoretical framework of a juvenile detention center was reflected and evaluated by a student-generated survey tool (BPS) that attempted to measure the existence and degree status of identified strategies proven to be effective with at-risk students. This survey was validated by a literature review that explored the definition of juvenile delinquents. Furthermore, it documented best teaching 
practices, characteristics, needs, and physical deficits of these children and considered the past, present, and future for a solution for salvaging their wasted potential.

The second instrument, the MSQ, "makes it possible to measure one aspect of vocational rehabilitation" (Weiss, Dawis, England, \& Lofquist, 1967, p. vi). The survey met the accepted standards for reliability and showed evidence of validity and included a 30-page bibliography, which provided reliability, and validity documentation that accompanied the purchased survey. The researcher purchased the tool from Vocational Psychology Research, N657 Elliott Hall, University of Minnesota, Minneapolis, MN 55455-0344. Construct validity was "derived mainly from its performing according to theoretical expectations." The evidence supporting the MSQ was found in the Theory of Work Adjustment and the Minnesota Importance Questionnaire (MIQ) (p. 16). "The reinforcer system of the work environment held constant; satisfaction /MSQ becomes a linear function of the linear composite of needs/MIQ. The results of these studies indicated that the MSQ measured satisfaction in accordance with expectations from the Theory of Work Adjustment" (p. 18-19).

This KECSAC audit instrument was developed under the direction of Leon Swartz of the Kentucky Department of Education for the use of the Department of Juvenile Justice. Research that supported the document was collaborated by the Alternative Education Programs for At-Risk Youth, Issues, Best Practice, and Recommendations by T. Tobin and J. Sprague, 1999, of the Institute on Violence and Destructive Behavior, College of Education, University of Oregon. This paper was developed with support from the United States Department of Justice and Office of Juvenile Justice and Delinquency Prevention at the University of Oregon. 


\section{Reliability}

The reliability for the Best Practice Survey (BPS) was established across the 25 dimensions with a Pearson correlation of .567. The survey did not appear to inflate the relationships among the dimensions. In order to work with the data, an index was calculated for the education (BPS) and the facility (BPS) at each center. After the indices were developed, an internal consistency correlation of .78 was calculated. Content reliability was addressed by using indices instead of mean scores. In order to justify these indices, the interrater agreement range was tabulated. The use of the interrater agreement empirically justified the aggregation of data and proved that the data were homogenous within that group (Harvey \& Hollander, 2004). The study goal was to show the degree to which people agree on what they see. An acceptable agreement was .7. The expected variance for a flat distribution of random answers on the BPS was 8.25 .

The Minnesota Satisfaction Questionnaire/MSQ reliability was established with internal consistency. The Hoyt reliability coefficients for each norm group were high. The range for intrinsic was .84 to .91 and .77 to .82 for extrinsic. The general satisfaction ranged from .87 to .92 . Median reliability coefficients ranged from .80 to .90 . There are no data available for the short-form MSQ; however, the organization has a 2-year test/retest study in progress, and the long-term reliability infers that the co-efficient will continue on the same trends for the short-term (Weiss, Dawis, England, \& Lofquist, 1967). The reliability for MSQ had a coefficient Alpha of .94. The variance for the pilot was .5 , and the variance for the study was .4 .

The reliability for the KECSAC tool has not been statistically calculated. According to the Kentucky Educational Collaborative for State Agency Children Annual 
Report for 2003 and 2004, this was the first year KECSAC evaluated programs using Kentucky Department of Education Standards. Per the report, "Data obtained at the end of the 2003-2004 year may be used to establish the reliability and validity of the evaluation tool and whether or not a standards evaluation system can be used to improve program proficiency." In a conversation with the director of KECSAC, Dr. Norman W. Powell, the following was revealed, there are no formal statistics for reliability and validity [for the KECSAC instrument]; it is based on program performance. "This instrument has not undergone formal reliability testing," (N. Powell, personal communication, August 14, 2007). "The tool was developed using state core content and the indicators criteria. Also, the ACA standards were used as sectional headings." In summary, the "2003-2004 data used to establish reliability and validity was an in-depth look at overall program improvement/performance based on scores not a statistical analysis." To date, the KECSAC instrument continues to be used as an evaluation tool.

\section{Data Analysis}

The collected data were disaggregated with Pearson correlation to determine the relationship among satisfaction, practices at educational and facility levels, and performance. The population/sample was very cooperative, and returned materials were completed with a good faith effort to provide complete feedback. The MSQ data were calculated as cumulative means for each of the eight centers. The BPS data were calculated as indices for educational and facility practices at the same eight centers, and the KECSAC scores were reported as point totals converted to percentages.

In this research, a quasi-independent variable, which is a non-manipulated, nonrandom variable or factor, was used to designate the research group. The factor 
identifying this group was the population being composed of the juvenile detention center teachers in Kentucky. The dependent variables, treatments, or conditions being evaluated were job satisfaction, best practices implemented, and job performance. None of these treatments/conditions were manipulated. Teachers employed at the detention facilities answered Survey/Questionnaire items. The audit tool was a measurement of performance as perceived by an outside auditor.

The researcher employed a repeated measures design. Testing the same group with three different tools gathered data concerning the condition/treatment. "A repeated measures study uses a single sample, with the same set of individuals measured in all of the different treatment conditions" (Gravetter \& Wallnau, 2004, p. 444). The treatment conditions were job satisfaction, best practices, and job performance. In summary, the work was a single-factor, repeated-measures research design. "The single-factor, repeated-measures design can be used with non-experimental research where the different conditions are not created by manipulating an independent variable. The null hypotheses stated, for the participating population, there are no mean differences among the treatment conditions being compared" (Gravetter \& Wallnau, 2004, p. 444). Null hypotheses for this study were as follows:

(a) Job satisfaction has no effect on best practices.

(b) Job satisfaction has no effect on KECSAC scores.

(c) Best practices have no effect on KECSAC scores.

(d) KECSAC scores have no effect on Job satisfaction.

(e) KECSAC scores have no effect on best practices.

(f) Best practices have no effect on job satisfaction. 
"According to the null hypothesis, on average, all of the treatments had exactly the same effect. As a consequence of the condition, any differences that may exist among the sample means are not caused by the treatments but rather are simply due to chance" (Gravetter \& Wallnau, 2004, p. 445).

The manipulation of the data was to perform a Pearson correlation. Three correlation measures looked at the relationship between two conditions. The measurements searched for the direction of the correspondence to determine if it is positive or negative. A positive relationship showed that the measurements were moving in the same direction; they increased or decreased at the same pace. In a negative correlation, the two variables moved in different directions - as one went up, the other went down for an inverse relationship (Gravetter \& Wallnau, 2004).

Correlations usually follow a linear pattern and produce a straight-line graph. In addition, a correlation explains how well the data fit the condition being considered, with numerical values representing the degree to which the data points are close to a perfect fit (1.00).... The process also shows the level of consistent, predictable relationships among two scores/measurements or, in this research, conditions.... A correlation of +1.00 or -1.00 indicates a perfectly consistent relationship" (Gravetter \& Wallnau, 2004, p. 524-525).

There are four applications for correlations,

(a) Prediction - Two variables/conditions are known to be related in some systematic way, it is possible to use one of the variables to make accurate predictions about the other.

(b) Validity - If a measurement is accurate, it should be related to other measurements of the same condition.

(c) Reliability - The extent that a measurement produces stable, consistent measurements. 
(d) Theory verification - The prediction of the theory can be tested by determining the correlations among the two variables (Gravetter \& Wallnau, 2004, p. 526).

The researcher utilized the most common correlation, the Pearson correlation. This method measured the degree and direction of linear relationship between two variables (Gravetter \& Wallnau, 2004). This work attempted to identify a relationship between job satisfaction and best practices at detention centers in Kentucky. A second relationship explored was whether a relationship existed between best practices and KECSAC program scores. A third relationship was whether a relationship existed between job satisfaction and KECSAC scores. Finally, the researcher explored the possibility that combination of job satisfaction and best practices might have an impact on program performance.

When a perfect linear relationship exists, every change in one condition/treatment is mirrored in the other compared condition, for a perfect linear relationship of \pm 1.00 . At the other extreme, there could be no linear relationship, and the measurement of one of the conditions could not correspond with the measurement of another condition, producing no co-variability. The resulting correlation would be zero (Gravetter \& Wallnau, 2004). Either level of correlation should have been expected, because this was a quantitative research project deductive in nature. 


\section{CHAPTER IV}

\section{RESULTS \\ Introduction}

This chapter presents the data, results of the planned analysis of the data collected, and results of data collected from the survey instruments for the study. The instruments used were the Kentucky Educational Collaborative for State Agency Children (KECSAC) monitoring tool, the Minnesota Satisfaction Questionnaire (MSQ), and the Best Practices Survey (BPS). Findings were explored to explain the correlations among overall program performance, best practice utilization, and job satisfaction for teachers in Kentucky detention centers.

The findings should be representative of expected outcomes from Michigan, Florida, and nationally because Kentucky has revamped its juvenile justice system based on models from each of these states, which were acknowledged by the Office of Juvenile Justice and Delinquency Prevention (OJJDP) as being leaders in the field of juvenile justice (Flores, 2003). In addition, these programs have incorporated the effective national mandates outlined by D. Roush of Michigan State University in his Desktop Guide to Good Juvenile Detention Practice, developed through a grant from the Office of Juvenile Justice and Delinquency Prevention with the U. S. Department of Juvenile Justice. Since Florida and Kentucky are frequently mentioned as model juvenile detention programs (KECSAC, 2007), replication of the study can be expected due to programs being aligned to common, national standards. Thus, a meaningful research 
criterion was met as the current study generated theory about Kentucky juvenile detention center educational patterns (Creswell, 1994).

\section{Demographic Profile}

Collection and analysis of demographics was not a major goal of this study. The participants were purposely selected based on their employment by the detention centers. The entire population, defined as certified educators teaching at the eight juvenile detention centers in Kentucky, was used $(n=31)$. All educators met Kentucky certification requirements, and the respective school boards that placed these personnel in juvenile facilities on a contract basis validated highly skilled educator qualifications. Gender, race, and age were not variables considered in this study.

The following data summaries will present the information that was collected and analyzed. After the presentation of the facts, a discussion of the findings will follow. By presenting the findings and then discussing the analysis, a clearer explanation should occur to those unfamiliar with the juvenile detention educational setting.

\section{Minnesota Satisfaction Questionnaire Data Summary}

The rational for Table 1 was MSQ scores were recorded as individual scores during the pilot study and the detention center study. It was necessary to aggregate the individual subjects' data by site; therefore, the calculated mean per center was used. As seen in Table 1, scores from the Kentucky detention centers were slightly higher than the pilot study. 
Table 1

Detention Center and Pilot Study MSQ Statistics:

\begin{tabular}{lcc}
\hline \multicolumn{1}{c}{ Statistics } & Detention Center & Pilot Study \\
& $n=8$ & $n=16$ \\
\hline Mean & 4.24 & 3.94 \\
Median & 4.45 & 4.03 \\
Mode & 4.65 & 2.23 \\
Standard Deviation & .63 & .71 \\
Variance & .4 & .5 \\
\hline
\end{tabular}

Table 2 contains descriptive statistics for the research findings that were tabulated to find means and standard deviation. The independent variable was the center and the dependent variable was the MSQ scores. The MSQ scores were given as composite scores for each facility. The mean difference at $32 \%$ was accounted for by the differences in facility management and faculty performance among the eight centers. As seen by Table 2, the individual scores were used to calculate center means that ranged from 4.73 to 3.25 and allowed the data to be used for a Pearson correlation of the three instruments. 
Table 2

Detention Center Variable Profile

Dependent Variable, MSQ Total by Centers

\begin{tabular}{lllc}
\hline \multicolumn{1}{c}{ Center } & $\mathrm{n}$ & Mean & Standard Deviation \\
1 & 3 & 4.0500 & .97596 \\
2 & 4 & 4.6000 & .34400 \\
3 & 3 & 4.3000 & .48218 \\
4 & 4 & 3.2500 & .70358 \\
5 & 2 & 4.2250 & .31820 \\
6 & 6 & 4.3750 & .43903 \\
7 & 5 & 4.2500 & .43589 \\
8 & 4 & 4.7375 & .27500 \\
\hline Total & 31 & 4.2371 & .63034 \\
\hline
\end{tabular}

Table 3 summarizes the ANOVA which resulted in $r^{2}=.475, \dot{\eta}=.475$ or $48 \%$. Analysis of variance (ANOVA) showed the significant relationship between average MSQ scores among the sites in terms of the mean level of satisfaction. The measure of effect size was $F(7,23)=2.97, p<.05$. 
Table 3

ANOVA Table: MSQ total.

\begin{tabular}{lcccc}
\hline \multicolumn{1}{c}{ Groups } & Sum of Squares & df & Mean Square & F \\
\hline Between (Combined) & 5.658 & 7 & .808 & $2.97^{*}$ \\
Within & 6.262 & 23 & .272 & \\
& & & & \\
\hline Total & 11.920 & 30 & & \\
\hline
\end{tabular}

${ }^{*} p<.05$.

For the MSQ pilot study, coefficient Alpha was .94. For the Detention Center MSQ, coefficient Alpha reliability was .935 , as compared with the published MSQ reliability of .94. In summary, the reliability for the pilot and the study groups was approximately .94 .

\section{Best Practices Survey Data Summary}

The BPS was developed after a review of the literature and consultation with the statistician to insure standard statistical practices were employed. Through a review of DJJ mandates and KDE Academic Expectations, Learning Goals, and Core Content, 25 components were highlighted as being best practices for detention center educators. The survey measured the presence and importance of 25 essential characteristics. When the results were tabulated, the researcher examined the data and sorted the findings into two areas, BPS facility and BPS education. The BPS was a self-administered measure of best teaching practices. Teachers rated the facilities in two ways, to what degree each item was present and to what degree each item was important. While a divergent number of practices were surveyed, they were considered by current research to be essential components of a good detention program. Because of the diversity of items measured, 
indices were calculated, rather than composite scores, and justified using interrater agreement.

This interrater agreement was defined as the degree to which teachers agree on what they see and explained how the data were related. It was calculated as a justification for using the mean score from each center so a Pearson correlation could be calculated across the three instruments. An acceptable level for an interrater agreement was documented at .7; if lower, they were less representative of teachers' consensus. The interrater agreement showed that the mean was reflective of the centers and the calculation served as a justification for using this score. As can be seen in Table 4, interrater agreement levels exceeded the .7 criteria in all centers except center $1(.67)$ and center $3(.65)$.

Table 4

Inter-rater Agreement Levels

\section{$\begin{array}{ll}\text { Education BPS } & \text { Facility BPS }\end{array}$}

\section{Center 1} .67 .99

Center 2

Center 3

Center 4

Center 5

.86

.98

Center 6

Center 7

Center 8 
After data were collected, an overlapping relationship was found in the 25 best practices surveyed on the BPS tool. In order to control inflation among these items, the researcher conducted an empirical collapse of the items and arrived at 12 BPS education items and 13 BPS facility items. The Internal Consistency Coefficient of .78 was calculated to show the reliability of the overall index with a BPS facility index and education index of .71. To limit the amount of data, only the BPS presence items were tabulated. Importance items were not used in this study. Table 5 shows the BPS items that were used for the facility and education index. 
Table 5

BPS Facility and Education Indices

\begin{tabular}{cc}
\hline Facility Items & Education Items \\
\hline 1 & 6 \\
2 & 7 \\
3 & 9 \\
4 & 10 \\
5 & 12 \\
8 & 13 \\
11 & 16 \\
14 & 18 \\
15 & 19 \\
17 & 23 \\
20 & 24 \\
21 & 25 \\
22 & \\
\hline
\end{tabular}

KECSAC Program Improvement Tool (SIDE) Data Summary

Of the three tools used, the KECSAC was the weakest due to lack of reliability. This evaluation tool rates detention centers based on Standards, Indicators, Descriptors, and Evidence items pulled from the American Correctional Association Policy and Procedure Manual. The evaluation process is based on observation of a facility by a trained KECSAC observer who uses the check sheet to make value judgments as to the 
level at which each item is implemented. These trained observers provide an objective evaluation of the programs and their scores are used to determine the efficacy of the detention center. This objectivity is valued by academia much more than the subjective opinions of the actual educators. While there is no validated research to provide validity and reliability of the KECSAC document, it continues to be accepted as the evaluation tool for educational programming in detention settings.

Dr. Leon Swartz of the Kentucky Department of Education developed the tool with support from the U. S. Department of Justice and Office of Juvenile Justice and Delinquency Prevention. To date, it is the only evaluative document for educational programs at juvenile detention centers in Kentucky. The department explained that they utilized a percentage derived by total points divided by possible points when they needed a numerical representation of a program's effectiveness.

Table 6 tabulates the following scores calculated by using the same formula, Total possible points 308 (which was derived by 77 exemplary possibilities) divided by the number of points a center scored for Exemplary (4), Fully Functional (3), Limited or Partial development (2), Little or No development (1), or NA not applicable (0). There are 77 items to be scored with 12 items that have either yes or no choices. 
Table 6

KECSAC Point totals and Percentages by Center

$\begin{array}{lll}\text { Center Points } & \text { Percentage }\end{array}$

Site 1

$201 / 308$

$65 \%$

Site 2

$263 / 308$

$85 \%$

Site 3

$185 / 308$

$60 \%$

Site 4

$242 / 308$

$79 \%$

Site 5

$233 / 308$

$76 \%$

Site 6

$245 / 308$

$80 \%$

Site 7

$239 / 308$

$78 \%$

Site 8

$215 / 308$

$70 \%$

It is important to note KECSAC scores are recorded as center scores, and have no standard deviation because they represent a unit and not individuals, as with the MSQ and BPS scores. Furthermore, it should be noted that the standards addressed in the KECSAC audit tool are not necessarily educational components but are more in line with the policy and procedure standards that govern the Department of Juvenile Justice. While this tool is not perfect, it is the only source of performance criteria available for educators in detention centers.

\section{Research Question 1}

Was there a relationship between the Minnesota Satisfaction Questionnaire (MSQ) and the Best Practice Survey (BPS)? As indicated in Chapter III, the MSQ short form was used to measure job satisfaction levels of faculties in juvenile detention centers. 
The BPS instrument measured 25 components of best practices and divided them into a Facility and Education index. Each person's MSQ score, BPS education score, and BPS facility score $(n=31)$ were used to calculate correlations. Table 7 shows the Pearson correlations derived from individual scores for the MSQ and the BPS facility and education.

Table 7

Correlation of Individual MSQ and BPS scores

\begin{tabular}{lcc}
\hline \multicolumn{1}{c}{ Variables } & Pearson correlation & Significant (2-tailed) \\
\hline MSQ to BPS Education & .323 & .076 \\
MSQ to BPS Facility & $.394^{*}$ & .028 \\
BPS Education to & $.712^{* *}$ & .000 \\
BPS Facility & \\
\hline$n=31$ & \\
& \\
$* *$ Correlation is significant at the 0.05 level (2-tailed) & \\
$*$ Correlation is significant at the 0.01 level
\end{tabular}

As can been seen in Table 7, there was no significant relationship between MSQ and BPS education. However, there was a significant positive correlations among MSQ and BPS facilities suggesting that job satisfaction has a considerable relationship to the job site. There was an even greater significant positive correlations among BPS education and BPS facility due to each being based on best practices.

Another noteworthy question at this point arose, Was there differences in the mean MSQ scores and the mean BPS scores among the eight centers in the state? In order to explore this question, three one-way analyses of variance (ANOVA), were 
calculated. For each ANOVA, center was the independent variable with eight levels.

Table 8 shows mean, standard deviation, and other statistics on three dependent variables from the eight detention centers.

Table 8

Descriptive Statistics for MSQ, BPS Education Scores, \& BPS Facility Scores

\begin{tabular}{lccccccc}
$\begin{array}{c}\text { Dependent } \\
\text { Variable } \\
\text { (Survey) }\end{array}$ & $\begin{array}{c}\text { Independent } \\
\text { Variable }\end{array}$ & & & & & \multicolumn{2}{c}{$95 \%$ Confidence } \\
(Center) & $\mathrm{n}$ & Mean & $\begin{array}{c}\text { Standard } \\
\text { Deviation }\end{array}$ & $\begin{array}{c}\text { Standard } \\
\text { Error }\end{array}$ & $\begin{array}{c}\text { Upper } \\
\text { Unterval for Mean }\end{array}$ \\
\hline BPS & 1 & 3 & 6.916 & 1.664 & .961 & 2.782 & 11.052 \\
Education & 2 & 4 & 9.416 & .456 & .223 & 8.690 & 10.143 \\
& 3 & 3 & 7.250 & 1.691 & .977 & 3.048 & 11.451 \\
& 4 & 4 & 6.500 & .573 & .287 & 5.588 & 7.412 \\
& 5 & 2 & 6.917 & 1.061 & .750 & -2.613 & 16.446 \\
& 6 & 6 & 7.806 & 1.090 & .445 & 6.662 & 8.950 \\
& 7 & 5 & 7.800 & .419 & .187 & 7.280 & 8.321 \\
& 8 & 4 & 9.104 & .497 & .249 & 8.313 & 9.895 \\
& Total & 31 & 7.815 & 1.294 & .232 & 7.340 & 8.289 \\
\hline BPS & & & & & & & \\
\hline & 1 & 3 & 8.590 & .347 & .200 & 7.728 & 9.451 \\
& 2 & 4 & 9.500 & .437 & .219 & 8.804 & 10.196 \\
& 3 & 3 & 8.103 & 1.244 & .718 & 5.014 & 11.192 \\
& 4 & 4 & 6.673 & .455 & .227 & 5.950 & 7.396 \\
& 5 & 2 & 7.231 & .435 & .308 & 3.321 & 11.140 \\
& 6 & 6 & 8.808 & .853 & .348 & 7.912 & 9.703 \\
& 7 & 5 & 7.369 & .916 & .410 & 6.232 & 8.506 \\
& 8 & 4 & 9.135 & .463 & .232 & 8.398 & 9.872 \\
& Total & 31 & 8.241 & 1.153 & .207 & 7.818 & 8.664 \\
& & & & & & & \\
\hline MSQ & 1 & 3 & 4.050 & .976 & .563 & 1.626 & 6.474 \\
& 2 & 4 & 4.600 & .344 & .172 & 4.053 & 5.147 \\
& 3 & 3 & 4.300 & .482 & .278 & 3.102 & 5.498 \\
& 4 & 4 & 3.250 & .704 & .352 & 2.131 & 4.370 \\
& 5 & 2 & 4.225 & .318 & .225 & 1.366 & 7.084 \\
& 6 & 6 & 4.375 & .439 & .179 & 3.914 & 4.836 \\
& 7 & 5 & 4.250 & .436 & .195 & 3.709 & 4.791 \\
& & 4 & 4.738 & .275 & .138 & 4.300 & 5.175 \\
& & 31 & 4.237 & .630 & .113 & 4.006 & 4.470 \\
& & & & & & & \\
\hline & & & & & & &
\end{tabular}


The preceding descriptive statistics were used for an ANOVA between MSQ,

BPS education and BPS facility. Table 9 provides summaries of the three ANOVA and shows significant differences among the centers on each dependent variable.

Table 9

(ANOVA) for Best Practice Survey Education - BPS education, Best Practice Facility BPS facility, and Minnesota Satisfaction Questionnaire-MSQ

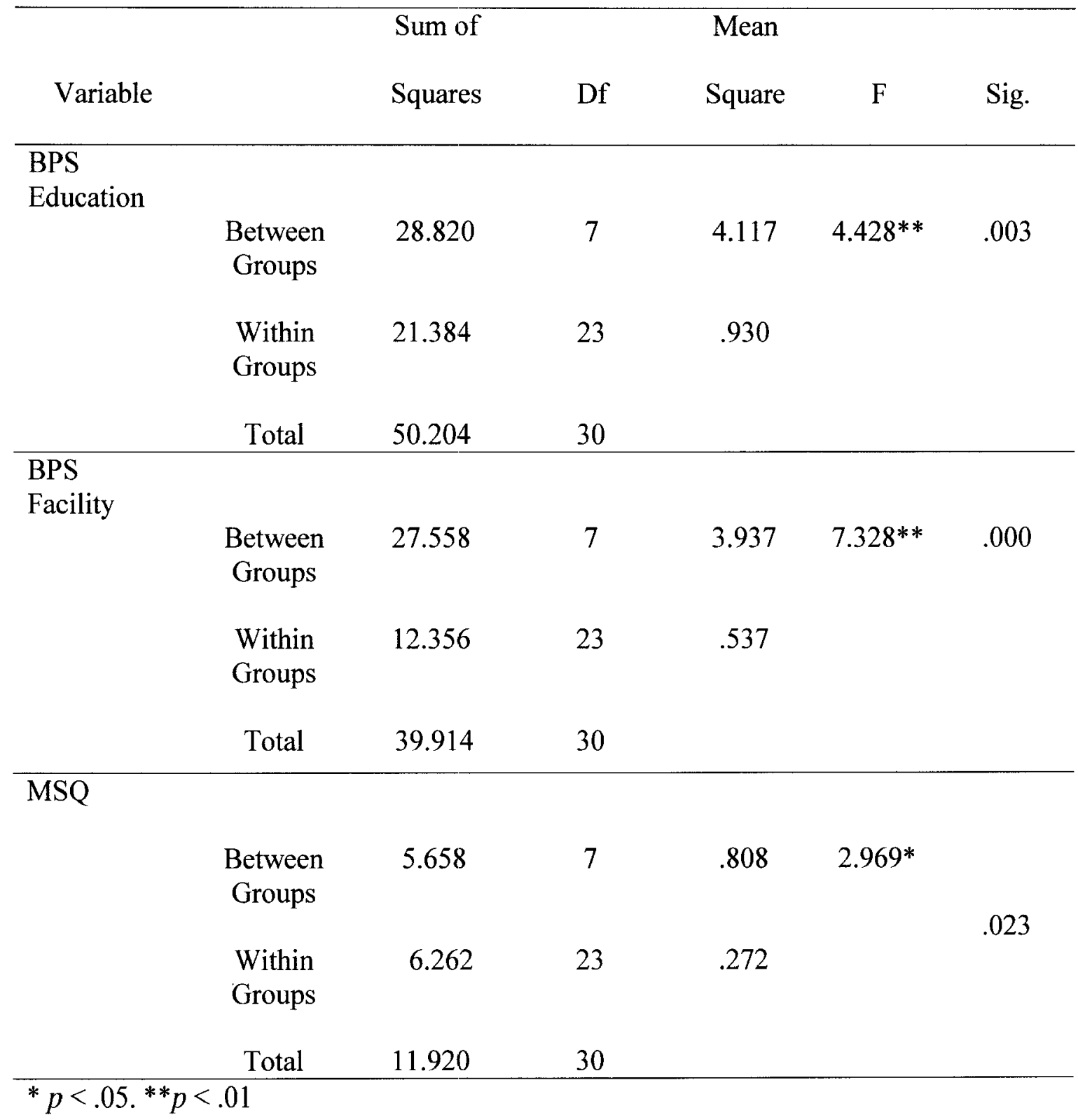


After the analysis of variance was tabulated for the three variables - BPS education, BPS facility, and MSQ - a conclusion could be drawn about the differences in the scores from the eight centers. It was interesting to note that the MSQ scores were significant at the $p<.05$ level; the BPS facility scores and the BPS education scores were significant at the $p<.01$ level.

Multiple comparisons were calculated for each ANOVA. The BPS, MSQ, and KECSAC scores were the dependent variables and the eight individual detention centers were the independent variables. The statistical analysis employed was a Bonferroni comparison because it was more conservative. The data were extensive; therefore, the researcher determined that a discussion of the significant correlations among sites would be of major interest. First, Best Practices Survey for Education was examined. The Bonferroni multiple comparison procedure yielded significant center differences at the $p$ $<.05$ level for two centers: sites $2-4$ (2.92 mean difference) and sites 8 - 4 (2.69 mean difference). Next, Best Practices for Facilities were compared and significant Bonferroni comparison results were tabulated; at $p<.05$ were sites $2-4$ ( 2.83 mean difference), sites $2-5$ (2.27 mean difference), sites $2-7$ (2.13 mean difference), sites 6 - 4 (2.13 mean difference), sites 8 - 4 (2.46 mean difference) and sites 8 - 7 (1.77 mean difference). Next, MSQ was compared using Bonferroni comparisons and results at $p<.05$ were sites $2-4$ (1.35 mean difference) and sites $8-4$ (1.49 mean difference). When these data were explored, it became evident that sites 2 - 4 and 4 - 8 showed significance between MSQ, BPS-E, and BPS-F.

Without a breach in confidentiality, it was difficult to explain the true meaning of this significance. However, site 2 and site 8 were younger centers with a staff selected by 
the facility superintendent. Site 4 was an older center that had a staff placed by the school board. Facility supervision differed on management styles, missions, and goals at all three locations along with extrinsic geographical and cultural differences. According to the educational professionals from each location, sites 2 and 8 tended to be educationally oriented while site 4 tended to be punitive/punishment orientated. The study does not provide data to support or explain these suggestions.

Research Question 2

Was there a relationship between BPS and Kentucky Educational Collaborative for State Agency Children (KECSAC)? Chapter III explained the origin of the BPS and the KECSAC tool. The researcher developed the BPS, and the state of Kentucky supported research that produced the KECSAC audit tool. This tool used standards with multiple indicators, descriptors, and evidence to produce an overall percentage score for institutions. These data were a group statistic $(n=8)$ that required data from the BPS to be averaged for a facility total rather than an individual score. As shown in Table 10, the data were aggregated according to juvenile detention center by finding the average BPS education and facility score for teachers in each center. 
Table 10

Descriptive Statistics for BPS Index per center

\begin{tabular}{cccccc}
\hline & & \multicolumn{2}{c}{ Mean } & \multicolumn{2}{c}{ Standard Deviation } \\
Center & $n$ & Education & Facility & Education & Facility \\
\hline 1 & 3 & 6.917 & 8.590 & 1.665 & .347 \\
2 & 4 & 9.417 & 9.500 & .456 & .437 \\
3 & 3 & 7.250 & 8.103 & 1.691 & 1.244 \\
4 & 4 & 6.500 & 6.673 & .573 & .455 \\
5 & 2 & 6.912 & 7.231 & 1.061 & .435 \\
6 & 6 & 7.806 & 8.808 & 1.090 & .854 \\
7 & 5 & 7.800 & 7.369 & .419 & .916 \\
8 & 4 & 9.104 & 9.135 & .497 & .463 \\
Total & 31 & 7.815 & 8.241 & 1.294 & 1.153 \\
\hline
\end{tabular}

In Table 11, Pearson correlation coefficients were derived from the average BPS score of each center being compared with the KECSAC rating of each detention center. Specifically, each center's BPS average score and KECSAC rating was paired, and then a correlation was calculated $(n=8)$. 
Table 11

Correlations among BPS and KECSAC

\begin{tabular}{lcc}
\hline \multicolumn{1}{c}{ Variables } & Pearson correlation with KECSAC & Sig. (2-tailed) \\
\hline BPS Education & .323 & .435 \\
BPS Facility & -.014 & .974 \\
$n=8$ & & \\
\hline
\end{tabular}

As can be seen in Table 11, these correlations were not statistically significant at $p<.05$. The absence of a relationship between best teaching strategies and overall program efficacy, as scored by KECSAC, was a disturbing find in this study. The study began with the goal of showing the relationships among best teaching strategies and overall program efficacy. The researcher hypothesized that better teaching procedures would lead to a higher KECSAC efficacy score and that poor teaching styles would correlate with a lower KECSAC assessment score. The failure of a significant correlation among collected data was unsettling and perplexing.

\section{Research Question 3}

Was there a relationship between MSQ and KECSAC? Once again, a reference to Chapter III was necessary to understand the methodology used to show this link. The first step was to aggregate data by juvenile detention centers. The average MSQ scores were calculated for each teacher in the centers. A Pearson correlation coefficient was performed with the average MSQ score from each center compared with the KECSAC rating of each center. Each center's MSQ average was paired with the KECSAC rating 
and then a correlation was calculated $(n=8)$. As can be seen in Table 12, the correlations among MSQ and KECSAC scores were not statistically significant.

Table 12

Correlation of MSQ scores to KECSAC

\begin{tabular}{lcc}
\hline Variable & $\begin{array}{c}\text { Pearson correlation with } \\
\text { KECSAC }\end{array}$ & Significant (2-tailed) \\
& & \\
\hline MSQ Total Mean & -.048 & .910 \\
& & \\
\hline
\end{tabular}

Once again, the study showed no significant relationship between a variable and the KECSAC audit tool. In this case, job satisfaction did not appear to have a bond with program efficacy, as measured by this instrument. In summary, job satisfaction was not demonstrated to have a relationship to performance. This was especially true when examining the relationship at the facility level.

\section{Research Question 4}

Does a significant relationship exist between the KECSAC scores and the combined effect of BPS and MSQ scores? The strategy necessary to answer this question would require utilizing aggregated data from the eight juvenile detention centers with the information being treated to a multiple regression analysis with two predictor variables: (a) average MSQ scores from each center, and (b) BPS average score from each center. The dependent variable would be the KECSAC rating $(n=8)$. However, when individual correlations of MSQ to KECSAC and BPS education and BPS facility to KECSAC were calculated, the findings suggested that neither were significant; and a combination of 
MSQ and BPS would not produce any significance when correlated with KECSAC. Both BPS education and BPS facility produced the finding that the zero order correlations were not significant at the institutional level; therefore, it was not necessary to aggregate the data with a multiple regression analysis, as it could not be significant.

Table 13

Individual Correlation of MSQ with BPS education \& BPS facility with KEC'SAC

\begin{tabular}{lccc}
\hline \multicolumn{1}{c}{ Dependent Variables } & $\mathrm{N}$ & Pearson correlation & Sig. (2-tailed) \\
\hline BPS Education with BPS & 8 & $.789^{*}$ & .020 \\
Facility & & & \\
MSQ with BPS Education & 8 & $.799^{*}$ & .017 \\
MSQ with BPS Facility & 8 & $.776^{*}$ & .024 \\
MSQ with KECSAC & 8 & -.048 & .910 \\
BPS Education with KECSAC & 8 & .323 & .435 \\
& & & .974 \\
BPS Facility with KECSAC & 8 & -.014 & \\
\hline
\end{tabular}

Table 13, above, summarizes correlations among the study levels aggregated at the centers. With the aggregated data, the study indicated a significant relationship between Best Practices at the education and facility levels. A significant correlation was found between (a) the education best practices and job satisfaction and (b) the facility best practices and job satisfaction. However, the data documented that no significant 
relationships existed between job satisfaction, best practices, and overall program efficacy as measured by the KECSAC tool. None of the variables had a significant correlation with the KECSAC instrument which led the researcher to question the implication of those results. 


\section{CHAPTER V}

\section{DISCUSSIONS, CONCLUSIONS, AND RECOMMENDATIONS}

\section{Introduction}

In an effort to address ever changing and escalating deficiencies in the federal juvenile justice system, an extensive study was launched in 1992 resulting in the Juvenile Detention Alternatives Initiative. By 1996, the Kentucky General Assembly enacted legislation that established a new Department of Juvenile Justice (DJJ) charged with reforming the program. By 1999, Kentucky was in compliance with the Juvenile Justice Delinquency Prevention Act (JJDPA) mandates and the Office of Juvenile Justice and Delinquency Prevention (OJJDP) released previously frozen federal funding. As a result of this effort, Kentucky has been very systematic in efforts to provide a detention system that meets federal guidelines and is proactive in rehabilitating the delinquent juvenile population.

Kentucky's overhaul of juvenile justice mirrored national efforts to address the growing juvenile delinquency problem. The general consensus was that due to a variety of social ills (i.e., rise in divorce rates, out of wedlock births, economic challenges, and a lack of alternative placement for juvenile delinquents) a better structure needed to be developed to assume the parens patriae role. Since the government had historically been expected to assume the role of caretaker of delinquent juveniles, it was logical for them to officially and legally accept this overwhelming challenge. 
An important component of this problem relates to the state attempting to provide care and education for the increasing number of juvenile delinquents that society is being forced to incarcerate due to their criminal actions. There were approximately 18,000 juvenile cases opened in the fiscal year of 2004 and subsequently referred to the Kentucky Department of Juvenile Justice (Lewis, 2004). The magnitude of associated costs, short and long-term, is of major concern to taxpayers who pay the bills, legislators who develop the budgetary allotments, the clients (juveniles) themselves, and society in general. In order to provide a report card to all stakeholders and practitioners, the efficacy of detention centers is evaluated annually with an audit instrument administered by the Kentucky Educational Collaborative for State Agency Children (KECSAC). This document reviews standards, indicators, descriptors, and evidence to provide an accountability score for facilities and faculties.

The national statistic of $26 \%$ of at-risk juveniles being placed in juvenile detention settings substantiates the importance of this study (Lewis, 2004). This statistic represents too many children to be allowed to slip through the cracks of state and federal bureaucracy. Furthermore, recidivism rates, on a national average, are $50 \%$ to $80 \%$ meaning that for many of these at-risk children, there is a revolving door of failure. In contrast, recidivism rates vary in the eight detention centers across Kentucky from $40 \%$ to $80 \%$. The best-case scenario is that the Kentucky centers are doing something right. The worse case scenario is that the centers are perpetuating the problem.

The purpose of this study was to examine the perceptions, attitudes, and levels of job satisfaction among the teaching staff at each of the eight Juvenile Detention Centers in the Commonwealth of Kentucky. The Minnesota Satisfaction Questionnaire (MSQ) 
was used to evaluate the level of job satisfaction among the professional teaching staff. Another survey focused on best teaching practices was administered to the faculties. This survey, BPS, was developed from a review of literature related to best teaching strategies for at-risk populations. The results of these surveys were compared to the annual KECSAC evaluation report for each juvenile detention center.

The Minnesota Satisfaction Questionnaire (MSQ)-short form- consisted of 20 items, which referred to a reinforcer in the work environment. The respondent indicated how satisfied he/she were with the reinforcer on his/her present job. Five response alternatives were presented for each item, "Very Dissatisfied; Dissatisfied; Neither (dissatisfied nor satisfied); Satisfied; Very Satisfied.” The short-form MSQ consisted of three scales, Intrinsic Satisfaction, Extrinsic Satisfaction, and General Satisfaction. This tool was developed as a result of the Work Adjustment Project (Minnesota Studies in Vocational Rehabilitation supported in part by a Research Grant RD-1613-G from the Vocational Rehabilitation Administration, Department of Health, Education, and Welfare, Washington, DC 20201) and measured job satisfaction with several specific aspects of work and work environments.

The Best Practices Survey (BPS) was designed to evaluate the effectiveness of a juvenile detention educational program. This survey was developed to reflect the suggestions found in the Desktop Guide to Good Juvenile Detention Practice. This is a research report compiled by David W. Roush of the National Juvenile Detention Association Center for Research and Professional Development at Michigan State University. Physical, intellectual, social, and emotional areas were addressed along with activity, competence, identity, social skills, structure, and involvement (Heward, 2003). 
Based on research, 25 areas were explored on the BPS survey. Structure, safety, security, fairness, consistency, education, community involvement, careers/vocational planning, learning styles, physical training, life skills, computer skills, nutrition, celebrations, and facility involvement were highlighted points of exploration.

The Best Practices Survey (BPS) used S. Zemelman, H. Daniels, and A. Hyde's 1993 work as a reference point. Their objective was to compile a national consensus about "best educational practice." With that aim, a group of professionals worked in a Best Practice Network and in the Illinois Writing Project to validate their work. Key points included that educational programs should be child-centered; experiential; reflective; authentic; holistic; social; collaborative; democratic; cognitive; developmental; constructivist; psycholinguistic; and challenging.

The third tool used was the KECSAC program improvement tool - Standards, Indicators, Descriptors and Evidence (SIDE). Swartz, of the Kentucky Department of Education, applied research from the Alternative Education Programs for At-Risk Youth, Issues, Best Practice, and Recommendations and the following areas were designated as pertinent concerns, low ratio of students to teachers, structured classrooms with behavioral management practices that support safety and security facility policies, positive rather than punitive emphasis, adult mentors, individualized behavioral interventions based on functional behavioral assessment, social skills instruction, and high-quality academic instruction.

The men and women who attempt the reclamation of this adjudicated population, must be strong individuals committed to the long haul. They must research and implement best practices, they must find satisfaction in this high stress job, and they must 
be willing to accept evaluation with constructive criticism in order to meet the ever changing needs of the juvenile detention center resident. The goal of this study was to highlight three key factors relevant to an educator practicing in one of the eight detention centers across the Commonwealth.

\section{The Study in Brief}

This study focused on 31 educators employed by Kentucky school boards to work at the eight juvenile detention centers across the Commonwealth. The researcher used a quantitative research approach for a non-experimental, descriptive study. Descriptive data were collected through the use of surveys and the state KECSAC tool with numerical scores assigned to tabulate the findings of this non-experimental study. The independent variable for the study was the centers and the dependent variables were the surveys, Minnesota Satisfaction Questionnaire (MSQ), the Best Practices Survey (BPS), and the Kentucky Education Collaborative for State Agency Children (KECSAC) audit document.

Statistical procedures included mean, median, mode, standard deviation, and variance to tabulate MSQ results per center. An ANOVA was used to indicate the significant relationship between sites in terms of mean level of satisfaction. Inter-rater agreement levels were used to explain the BPS findings after an empirical collapse of the surveyed dimensions. KECSAC findings were reported as percentages. SPSS version 15 was used to run a multiple comparison across the centers by Bonferroni comparisons. After the preceding manipulations were completed, Pearson correlations were calculated for MSQ, BPS, and KECSAC scores. 
According to Pearson correlations, there was no relationship at the facility level for MSQ to KECSAC. There was a significant relationship between Best Practices at the facility level (BPS-F) and the total MSQ scores. There was a significant relationship between Best Practices at the educational level (BPS-E) and MSQ scores. Best Practices at the facility level (BPS-F) and educational level (BPS-E) were also significantly related. None of the categories were significantly related to the KECSAC evaluation tool. Based on these findings, it would appear that the state's Kentucky Educational Collaborate for State Agency Children's Standards Indicators, Descriptors, and Evidence tool was not an adequate measurement for Commonwealth juvenile detention centers program efficacy.

\section{Best Practices and Job Performance}

This section provided a summary discussion of Chapter IV results. The data collected were framed by the five explored juvenile delinquent sections, Definition, Education, Self Concept, Teachers, Pilot Study and the research questions that structured the study found in Chapter II. From the literature review, three areas were highlighted as being significant in the education of juvenile delinquents: teacher job satisfaction, best teaching strategies, and program efficacy. To measure teacher job satisfaction the MSQ was used and to measure best teaching strategies the BPS was used. Data from the KECSAC audit tool were used to measure program efficacy. ANOVAs were conducted to analyze findings while Pearson correlations were completed to establish the relationship among three education components, Job Satisfaction, Best Practices, and Program Efficacy.

A stable environment with consistent key players is a novel concept for many juvenile delinquents. Juveniles experience too much instability and variability over the 
course of their short life (i.e., dysfunctional homes, foster care, treatment facilities, alternate schools, and alternate learning centers (ALC), suspension, expulsion, and detention centers). By the time they reach the level of DJJ detention, they are disillusioned: emotionally, socially, and educationally. When they enter a facility which provides a consistent educational staff, they are more likely to be rehabilitated.

The professionally mature staff at the detention center has many pluses to offer these children. They are familiar with the facility rules and philosophy and can present these "secrets" in a non-threatening manner to new residents. These types of teachers are secure in their job requirements and know how to handle bureaucracy in order to meet the needs of their new students. Teachers are able to stay focused on students' needs rather than personal needs. They are comfortable in their position, they understand the culture, and they facilitate the climate. With personal matters stabilized, they are able to concentrate on applying best practices to their students' situations. The implementation of best practices hinges on a stable/secure faculty that focuses energies on the kids rather than on the adults - even individuals who are not happy are still competent when they have a strong administrator. Theoretically, best practices develop because of consistent staffing, administration expectations, and mandated practices (Cropanzano \& Wright, 2001).

Kentucky Educational Collaborative for State Agency Children (KECSAC)

At the present time, the KECSAC audit tool is the only state tool available to measure the performance of the educational programs at detention centers across the Commonwealth. This document consists of Standards, Indicators, Descriptors, and Evidence, which a trained observer uses as a checklist to evaluate the educational 
programs at juvenile detention centers. While juvenile justice professionals developed this tool, it has not undergone statistical reliability and validity test.

School systems are hampered in efforts to evaluate the performance of their detention center educational staff because of the rapid changeover of students. The average stay in detention centers is 7 days. This average is calculated by looking at longterm residents that may be in a program for 2 years and by looking at residents that are sentenced to spending the weekend. The rapid transitioning of this population invalidates the usual state assessment test scores because accountability cannot be designated. State tests (i.e., CATS and CTBS) are given to residents that are in a facility on the date that the testing roster is set. If students are moved, the tests are mailed to the appropriate facility. If students enter a detention center from a public school, then the state obtains the testing materials from the school system and administers the test in the facility.

Currently, KECSAC is researching ways to assess the actual accountability level of juvenile detention center's educational performance. The goal is to find a way to assess the educational level of a resident when they enter the facility and then assess the educational level at their time of exiting the program. With these data, the actual performance of programming could be documented. The Brigance Test, which is a commercial test of basic skills in reading, writing, and math, along with the Test of Adult Basic Education (TABE), is currently used to pinpoint grade levels. Testing is completed after a 7 day window of residence has been documented. Unfortunately, the time limit for the TABE to be re-administered is often too long and charges for using the test become prohibitive. This timeframe overlaps release time and the cost factor becomes 
unmanageable with the revolving door residency. The Brigance test does not align with TABE results so comparisons are invalid.

From the previous discussion, it becomes evident that there is no true evaluation instrument for juvenile detention centers. When the KECSAC tool was used, in this study, to measure program efficacy, it was found to be ineffective. When Pearson correlations were used to find relationships among Best Practices (BPS), Job Satisfaction (MSQ), and Program Efficacy (KECSAC), they were found to be statistically nonexistent. Therefore, it can be summarized that since there exists no evaluation tool, the accountability issue for juvenile detention centers is unmeasured. Without assessment, the educational programming of these centers suffers due to lack of direction and accountability.

\section{Summary}

Research Question Number 1. Was there a significant relationship between MSQ scores and BPS scores? In order to answer this question, some steps were necessary to process the data accurately. First, the center scores were averaged to produce one score allowing correlation calculations between sites. The standard deviation was calculated to show that the scores were truly representative of the overall facility job satisfaction level. Sites 1 and 4 had the greatest deviation among scores. This was explained by the fact that each faculty had members on both ends of the satisfaction and best practices spectrum. There was a highly motivated proactive member and then there was a disgruntled individual who used policy and procedures as justification for handing out packets.

After the MSQ scores were averaged by center (Table 2), the researcher employed an ANOVA to look for commonalities. There were some significant relationships 
highlighted in the MSQ scores from the eight detention centers around Kentucky. Significantly different means defined the extent of faculty differences with respect to job satisfaction. These means indicated the degree of satisfaction; a high mean portrayed satisfaction and a low mean portrayed dissatisfaction. The larger the standard deviation, the greater the amount of variability found in the data.

There are several factors that may explain job satisfaction levels among detention center educators. The usual reasons for staying in a position are acquisition of tenure, time invested towards retirement, lack of training, and finally a need to stay due to a restricted employment market. Some centers are in populous school districts that allow teachers to relocate. Other centers are located in a small district with no room for relocation. Self-selected teachers who choose to remain at a particular center indicate higher levels of job satisfaction. Employment options in small districts are limited and a professional move may be impractical, thus locking in employees with lower levels of job satisfaction. Unfortunately, the students are then served by unhappy teachers because neither have an option of relocating.

The third step consisted of a correlation of individual MSQ and BPS scores and produced two significant relationships to be explored. It was obvious that the individualized Best Practices Survey results found no relationship between BPS-E (educational factors) and individualized MSQ (job satisfaction of teachers). However, the aggregated data showed that individual BPS-E was strongly related to individual BPS-F (facility factors). This was understandable because the educational program is housed within the juvenile justice facility and must abide by two sets of guiding principles, school district guidelines and DJJ guidelines. If the facility administration was pro- 
education, then the educational program was supported and tended to drive the facility programming. As a result of this type of teamwork, the third correlation was not surprising.

The BPS-F score was significantly related to the MSQ total. It was obvious that teachers were more satisfied working in an appreciative environment that valued their expertise. With this correlation, the aggregated data showed a $15 \%$ variance, which was shared by BPS facilities and MSQ. This significant relationship was explained by the fact that teachers can only implement programming that is approved and supported by the facility administration. When an administration supported innovative and proactive teaching strategies, then the teachers were able to implement best practices that truly made a difference for this at-risk population. In addition, when facility administration acknowledged the professional accomplishments of the educational staff, a higher level of job satisfaction was documented and led to better teaching practices (Chapman \& Lowther, 1982). The significant relationship between BPS-E and BPS-F, $r=.712, p<.01$ and the significant relationship between BPS-F and MSQ, $r=.394, p<.05$ reinforced the above discussion of these findings.

Another area of exploration sought to determine if differences in the mean MSQ scores and the mean BPS scores existed among the eight centers. An attempt was made to address this question by using the center as the independent variable and average MSQ score as the dependent variable. A second one-way analysis of variance (ANOVA) with center as the independent variable at eight levels and BPS education and facility scores as the dependent variables were also tabulated. It was determined that an ANOVA per dependent variable would be a better procedure than an alternative analysis of a 
multivariate analysis of variance (MANOVA) using both dependent variables simultaneously in the same analysis. After a review of the aggregated data, it was determined there was insufficient power for a (MANOVA) because of too few subjects. There were not enough data entries to produce significance.

Due to the size limitation, the researcher employed the Bonferroni comparison method. Employing this statistical procedure allowed for many comparisons, similar to an ANOVA (NIST, 2008). "The Bonferroni comparison is a statistical adjustment for multiple comparisons to avoid false positives" (NIST, 2008) and, as such, produced the following results. Best Practices at the educational level were significant at sites two/ four and four/eight on both comparison levels. This was an interesting finding, as these three facilities are very different culturally, geographically, and professionally. Data suggest that a rural culture gives rise to a controllable group of juveniles who can be motivated to conform (Heward, 2003). Traditionally, urban detention centers have a more violent clientele, due to the more populous setting, and require stronger security measures. It was interesting to note that the faculties at all three locations had common educational policies as determined by the state of Kentucky yet they deal with a very diverse at-risk population.

Best Practices BPS-F comparisons appear to be similar across the detention centers. This was a logical result when one considered the policy and procedure manuals that governed these locations. Consistent and stringent checks and balances govern each institution. There was very little room for policy digression within the facility realm.

Finally, due to the small sample size, job satisfaction levels of teachers were compared across the eight centers using the Bonferroni comparison method. The findings 
were surprising. Site two/four and site four/eight were again related within the pair-wise comparisons. This data seemed contradictory when listening to DJJ's educational branch professional development training sessions. Site two and eight were relative newcomers while Site four was a more mature center. New and old teachers were continuously struggling to perform and find their niche at each program while the state educational branch quickly offered undocumented explanations for program efficacy based on public opinions. Program specifics cannot be discussed as a way to explain these Bonferroni comparisons because they would compromise confidentiality of the study. Therefore, while educational opinions tended to be accepted by lay-persons, it should be noted that there was no statistical validation for any relationship between program efficacy as measured by KECSAC and the other two explored areas.

Research Question 2. Was there a significant relationship between BPS scores and KECSAC scores? Once again it was necessary to average the individual scores for the BPS instrument in order to produce a facility score. The mean was reported as an index that was justified by an interrater agreement statistic. $A$ review of the descriptive statistics for the Best Practices Survey indices substantiated the averaging strategy of the researcher. A look at the standard deviations of each index revealed that the interrater agreement levels were accurate in their reflection of accord between faculty members at each facility. With the conventional rate established at 0.7 , all BPS-E were above or within five hundredths of a point. The BPS-F findings were within two tenths of a point. Thus, the deviations of opinions were not extreme and mean averages were justified.

After the BPS-E and BPS-F scores per center were generated, an ANOVA was used to search for the relationship between BPS scores and KECSAC scores. The 
correlations were not found to be significant at the 0.05 level (2-tailed). The absence of a relationship between best teaching strategies and overall program efficacy, as scored by KECSAC, was a disturbing finding in this study. A possible explanation for the lack of relationship might be found in the fact that while the KECSAC audit tool continues to be used to evaluate centers and programs, the instrument has not established reliability or validity for that purpose. With the emphasis on accountability for Juvenile Detention centers found in Kentucky, it is essential that a better measurement for educational performance at detention centers be explored.

Research Question 3. Was there a significant relationship between MSQ scores and KECSAC scores? Descriptive Statistics for MSQ averages per center were used to look for this correlation. There was a significant difference among the facilities mean scores. The MSQ total between combined groups was $F(7,23)=2.97, p<.05$. The level of cooperation between teaching staff, peers, facility co-workers, and facility administration may explain this difference. Many levels of personalities come into play when two separate entities are housed under one roof. Without a common goal, the two units develop a stressful coexistence sometimes detrimental to the education of the students due to internal conflict among educators, line staff, and administration.

When MSQ, teacher job satisfaction scores, were correlated with the state evaluation scores on KECSAC, there was no significant relationship found. This finding was supported by the literature review. Theoretically, it has been determined that longevity has a stronger relationship with performance than satisfaction. However, it became obvious that this longevity factor could not be obtained, in normal settings, unless the educator was satisfied. For the most part, unhappy employees tended to change 
jobs frequently. This was especially true of teachers unless they were in a restricted job market. Furthermore, it was suggested that teachers with low job satisfaction frequently implement best strategies when in the company of a forceful curriculum leader and an established program based on a strong publisher created curriculum that gives step by step procedures to be implemented (i.e., Success for All and SRA Reading Programs) (Zemelman, Daniels, \& Hyde, 1993).

Research Question 4. Does a significant relationship exist between the KECSAC scores and the combined effect of BPS and MSQ scores? In order to complete Pearson correlations to find relationships among data from these three instruments, MSQ means had to be computed for each site, interrater agreements calculated to justify means of BPS, and point scores converted to percentages for state data. After these manipulations of data, correlations were explored. Unfortunately, there was no significant relationship found between KECSAC with any other measures. The only correlation found was between KECSAC raw points and KECSAC percentages $(r=.999, p>.01)$.

\section{CONCLUSIONS}

The implications of these findings indicated a need for implementation of best teaching strategies, strong curriculum leadership, collaborative educational and facility programs, execution of individual education plans for at-risk youth, identification and accommodations for diverse learning styles and a strong multi-talented faculty (Tobin \& Sprague, 1999). Obviously, KECSAC did not adequately measure the implementation of best teaching practices, and it did not have a relationship with teacher job satisfaction as reported by the educators. It appeared that, KECSAC's 2008 mission statement, "committed to the belief that all children can learn and have a right to quality education 
and children who do not receive an education of quality cannot realize their greatest potential, "did not have any impact or relevance on providing a quality educational program. While the KECSAC, 2008 stated goal to, "provide a comprehensive evaluation of the delivery of educational services to State Agency Children including the administrative process, service delivery, program monitoring, and outcomes," identified a commitment to accountability, this study found no significant correlations among the employment of the BPS-F, BPS-E, and KECSAC's audit tool. KECSAC's objective to provide a complete evaluation of the delivery of educational services to state agency children did not appear to be met when evaluated under that stated audit tool purpose. Job satisfaction and KECSAC did not have a significant correlation.

Caution should be practiced when making a blanket statement concerning the accuracy of the KECSAC audit tool. The lack of correlation could be due to inaccurate measurements by the BPS and the MSQ. However, the MSQ instrument has undergone extensive research and stringent reliability measures (Weiss et al., 1967), and should be viewed as an authentic assessment tool. The BPS survey was tested for reliability and had a Cronbach's Alpha based on standardized items of .849 for BPS-F and .790 for BPS-E. Since the acceptable level was .7, the survey appeared to be reliable by statistical standards. By comparison, the KECSAC audit tool has not undergone reliability and validity testing. Nonetheless, the researcher can only conclude that data analysis did not find correlations among the KECSAC document and the Best Practices Survey or the Minnesota Satisfaction Questionnaire.

The purpose of this study was not to discredit the KECSAC audit tool which came about as a result of the 1990 Kentucky Education Reform Act (KERA), by which Eastern 
Kentucky University's College of Education was delegated "responsibility for the management and operation of this statewide collaborative" (KECSAC, 2008). Since it was established, KECSAC has "significantly improved services to the historically under served population of at-risk youth in Kentucky. Among these important improvements are, Greatly enhanced coordination and the simplification of the distribution of funds to serve at-risk youth; and the establishment of a statewide monitoring process designed to support programs in their efforts to serve the needs of Kentucky's at-risk youth" (KECSAC, 2008).

\section{RECOMMENDATIONS}

Through the deductive nature of this study, it became apparent that the current audit tool (KECSAC) was not adequate to explore two essential areas necessary for a good educational program: best teaching strategies and job satisfaction as reported by the practitioners. One suggestion may be that the audit tool be reworked with a greater focus on specific educational issues rather than on vague overall transformational plans meant to evaluate the district rather than a specific school's performance. Another suggestion to explain the lack of correlation of KECSAC to MSQ and BPS might be the reporting method. The MSQ and BPS data were provided by individual teacher opinions that were processed to provide one score per site. An impartial person auditing programs and recording observations might conduct a more objective investigation and provide data that would align more consistently with an improved KECSAC audit tool. Unfortunately, scores by outside observers would lose the personal aspect that makes these reports, MSQ and BPS, insightful reflections and would nullify the self-reporting analysis that these instruments were meant to produce. 
In conclusion, the study did not find significant relationships among the Kentucky Educational Collaborative for State Agency Children audit tool (KECSAC), the Minnesota Satisfaction Questionnaire (MSQ), and the Best Practices Survey (BPS). On the other hand, the MSQ, BPS-E, and BPS-F had significant relationships. The study offered some explanations; however, there was no substantiated evidence to support these conclusions. Therefore, the importance of this study remains with its addition to the knowledge base pertaining to the detention centers operating in the Commonwealth of Kentucky, and will help perpetuate the momentum of juvenile justice reform. 


\section{REFERENCES}

Allen-Hagen, B. (1993). Conditions of confinement in juvenile detention and correctional facilities. Juvenile Justice Bulletin, 1-5.

Allen-Hagen, B. (1991). Children in custody 1989, Public juvenile facilities. Juvenile Justice Bulletin, OJJDP Update on Statistics.

Arends, R. (2000). Learning to teach. New York, McGraw-Hill.

Aries, P. (1962). Centuries of childhood, trans. Robert Baldick. New York, Alfred A. Knopf.

Babbie, E. (1990). Survey research methods. Belmont, CA, Wadsworth, Inc.

Baker, B.K. (1999). Cognitive distortions among juvenile delinquents and nondelinquents. (Department of Psychology, Missouri Western State College). Abstract retrieved May 26, 2004, from http://clearinghouse.mwsc.edu/manuscripts/144.asp

Baumeister, R., Campbell, J., Krueger, J., \& Vohs, K. (2005, January). Exploding the self-esteem myth. Scientific American, 292, 84-91.

Beebe, M., \& Mueller, F. (1993). Categorical offenses of juvenile delinquents and the relationship to achievement. Journal of Correctional Education, 44, 193-198.

Beech, M., \& Platt, J. (1994). The effectiveness of learning strategies in improving performance and increasing the independence of juvenile offenders with learning problems. Journal of Correctional Education, 45, 8-25. 
Blankenship, V (2005). Coalition for juvenile justice (CJJ). Retrieved 9/29/05 from CJJ eMonitor at blank@acsalaska.net

Bloomberg, T., \& Waldo G. (December, 2001). Implementing research-based best practices in juvenile justice education. Corrections Today. 63, 144-148.

Blunt, A., \& Dickinson, G. (2005). Changing Approaches. 50-62.

Retrieved January 2, 2007 from http://www-distance.syr.edu/cach4.html

Bogdan, R., \& Biklen, S. (1998). Qualitative research in education, An introduction to theory and methods. Needham Heights, MA, Allyn \& Bacon.

Bonny, A., Britto, M., Klostermann, B., Hornug, R., \& Slap, G. (2000, November). School disconnectedness, Identifying adolescents at-risk. Pediatrics, 106(5), $1017-1022$.

Boxler, H. N. (2004). Grounded practice: Exploring criticalities in a job re-education setting. Adult Education Quarterly, 54, 210-223.

Brooks, K., Brown, B., Lester, P., Soler, M., Walson, J., \& Williamson, D. (March, 2001). A practitioner's guide to juvenile detention in Kentucky. The Children's LawCenter, Inc. Kentucky Department of Juvenile Justice.

Brooks, K., Kinsman, A., Griller-Clark, H., Leone, P., \& Ordover, E. (June, 2001). The special needs of youth in the juvenile justice system, Implications for effective practice. The Children's Law Center, Inc. Kentucky Department of Juvenile Justice.

Brown, M. (1983). Juvenile detention, Professional development program series monograph. Austin, Texas Juvenile Probation Commission. 
Brunetti, G., Courtney, V., \& Marston, S. (2005). Elementary and high school teachers, Birds of a feather? Education, 125, 469-495.

Bullis, M., Walker, H., \& Sprague, J. (2001). A promise unfulfilled, Social skills training with at-risk and antisocial children and youth. Exceptionality, 9, 67-91.

Byrd, K., O'Connor, K., Thackrey, M., \& Sacks, J. (1992). The utility of self-concept as a predictor of recidivism among juvenile offenders. The Journal of Psychology, 127(2), 195-201.

Cancio, E., West, R., \& Young, R. (2004). Improving mathematics homework completion and accuracy of students with EBD through self-management and parent participation. Journal of Emotional \& Behavioral Disorders, 12, 9-22.

CARET, Definition of Study Types. Retrieved January 2, 2002 from http://caret.iste.org/RatingStudy.html

Cavan, R. (1969). Juvenile delinquency, Development, treatment, control $2 \mathrm{~d}$ ed.). Philadelphia, Lippincott Co.

Chapman, D., \& Lowther, M. (1982, March/April). Teacher's satisfaction with teaching. Journal of Educational Research, 75, 241-247.

Chassin, L., Presson, C., Young, R., \& Light, R. (1981). Self-concept of institutionalized adolescents, A framework for conceptualizing labeling effects. Journal of Abnormal Psychology, 90, 143-151.

Cheng, S. (1997, Fall). Psychological determinants of idolatry. Adolescence, 32, 687-690.

Cole, G. (1989). The American system of criminal justice (5 $5^{\text {th }}$ ed.). Pacific Grove, CA, Brooks/Cole Publishing. 
Creswell, J. (1994). Research design: Qualitative and quantitative approaches. Thousand Oaks, CA, Sage Publications, Inc.

Cropanzano, R., \& Wright, T. (2001). When a "Happy" worker is really a "Productive" worker. Consulting Psychology Journal, Practice and Research, 53, 182-199.

Cusick, P. (1992). The educational system, Its nature and logic. New York, McGraw-Hill, Inc.

Day, R. (2003). Each child, every child, The story of the council for better education, equity and adequacy in Kentucky's schools. Unpublished doctoral dissertation, University of Kentucky, Lexington, KY.

Dembo, R., \& Williams, L. (1994). Development and assessment of a classification of high risk youths. Journal of Drug Issues, 24, 25-54.

Dieruf, K. (2004). Ethical decision-making by students in physical and occupational therapy. Journal of Allied Health, 33, 24-30.

Dobbie, A., Passmore, C., Parchman, M., \& Tysinger, J. (2002). Guidelines for constructing a survey. Family Medicine, 34, 281-286.

Drakeford, W. (2002). The impact of an intensive program to increase the literacy skills of youth confined to juvenile corrections. Journal of Contemporary Ethnography, $53,139-144$.

Eitzen, D. (1976). The self-concept of delinquents in a behavior modification treatment program. The Journal of Social Psychology, 99, 203-206.

Eyo, I. (1981). British delinquents and non-delinquents on seven domains of the selfconcept. The Journal of Psychology, 109, 137-145. 
Federal Bureau of Investigation (2006). Crime in the United States 2004. Table 5.

Washington, DC. Retrieved November 15, 2007 from

www.cdc.gov/nchs/about/major/dvs/popbridge/popbridge.htm

Flores, J. (2003). Latest resources from OJJDP. Washington, D.C. Office of Juvenile Justice and Delinquency Prevention. U.S. Department of Justice.

Fowler, F. (1993). Survey research methods. Newbury Park, CA, Sage Publications, Inc.

Fox, S. (1970). Juvenile justice reform, An historical perspective. Stanford Law Review, $22,1187-1239$.

Gluck, S. (1997). Wayward youth, super predator. Corrections Today, 59, 62-66.

Gravetter, F., \& Wallnau, L. (2004). Statistics for the behavioral sciences. Belmont, CA, Wadsworth/Thomson Learning.

Griffin, M., Janice K., \& Smith L. (2002). Conversations with delinquents: The mingling of meager dialogues. Journal of Contemporary Ethnography, 53, 127-130.

Glasser, W. (1990). The quality school. New York, Harper \& Row Publishing.

Hamilton, S., Seibert, M., Gardner, R., \& Talbert-Johnson, C. (2000). Using guided notes to improve the academic achievement of incarcerated adolescents with learning and behavior problems. Remedial and Special Education, 21, 133-141.

Harvey, R., \& Hollander, E. (2004). Benchmarking $r_{\mathrm{wg}}$ interrater agreement indices:

Let's drop the .70 rule-of thumb. Paper presented at the Annual conference of the Society for Industrial and Organizational Psychology, Chicago.

Hellriegel, K., \& Yates, J. (1999, February). Collaboration between correctional and public school systems serving juvenile offenders, A case study. Education and Treatment of Children, 22, 55-84. 
Heward, W. (2003). Exceptional children. Upper Saddle River, NJ, Pearson Educational.

Holcomb, E. (1996). Asking the right question. Thousand Oaks, CA, Corwin Press.

Howard, M. (2001). Painting in the treatment of a middle class juvenile delinquent. American Journal of Art Therapy, 40, 40-46.

Hunter, J. (1991). Culture wars. New York, Harper Collins.

In re Gault et al. 387 U.S. 1 (1967).

Inman, D., \& Marlow, L. (2004, Summer). Teacher retention, Why do beginning teachers remain in the profession? Education, 124, 605-614.

Jordan, J. (1968). The responsibility of the superintendent to maintain the function of detention. A National Institute for Juvenile Detention Home Administrators, Final Report.

Joronen, J., Graham, S., \& Schuster, M. (2003). Bullying among young adolescents: The strong, the weak, and the troubled. Pediatrics, 112(6), 1231-1237.

Juvenile Offenders and Victims, 1999 National Report, 185 - 213.

Kamps, D., Willis, H., Greenwood, C., Thorne, S., Lazo, J., Crockett, J., Akers, J., \& Swaggart, B. (2003). Curriculum influences on growth early reading fluency for students with academic and behavior risks: A descriptive study. Journal of Emotional and Behavioral Disorders, 11, 211-225.

Katsiyannis, A., Zhang, D., Barrett, D., \& Flaska, T. (2004). Background and psychosocial variables associated with recidivism among adolescent males, A three year investigation. Journal of Emotional and Behavior Disorders, 12, 23-29. 
Kelly, R., Roush, D., \& Smith, J. (1990). Public correctional policy on juvenile services, Juvenile detention. Laurel, MD, Unpublished manuscript, Juvenile Detention Committee, American Correctional Association.

Kentucky Educational Collaborative for State Agency Children (KECSAC) Online. (n.d.) 2007-2008 KECSAC Brochure. Retrieved February 14, 2008, from http://www.kecsac.edu.edu/about.php

Kentucky Revised Statues $\S \S 600-645$ (Lexis 1999 \& Supp. 2007).

Kentucky Youth Advocates, Inc. (1987). A resource manual to the new Kentucky unified juvenile code at 4 p. 4-6.

Klopovic, J., Vasue, M., \& Yearwood, D. (2003). Effective program practices for at-risk Youth. Kingston, NJ, Civic Research Institute, Inc.

Koerner, P. (2000). Profile of a juvenile delinquent. Washington, National School Improvement Project.

Kopecky, F. (1989). Introduction to juvenile justice, Detention basic training workbook. Springfield, IL, Center for Legal Studies, Sangamon State University.

Leone, P. (1994, Spring). Education services for youth with disabilities in a state operated juvenile correctional system. Journal of Special Education, 28(1), 43-59.

Leone, P., \& Malmgren, K. (2000). Effects of a short-term auxiliary reading program on the reading skills of incarcerated youth. Education and Treatment of Children, 23, 239-248.

Levy, K. (1997, June). Multifactorial self-concept and delinquency in Australian adolescents. Journal of Social Psychology, 137, 277-284. 
Levy, K. (1997, Fall). The contribution of self-concept in the etiology of adolescent delinquency. Adolescence, 32, 671-684.

Levy, K. (2001, Summer). The relationship between adolescent attitudes toward authority, self-concept, and delinquency. Adolescence, 36, 333-347.

Lewis, E. (2004). Defender caseload report. Kentucky department of public advocacy.

Lynam, D. (1996). Early identification of chronic offenders, Who is the fledgling psychopath? Psychological Bulletin, 120, 209-234.

Ma, X.; \& MacMillan, R. (1999, September/October). Influences of workplace conditions on teachers' job satisfaction. Journal of Educational Research, 93, 39-48.

Manski, C., \& Nagin, D. (1998, January). Bounding disagreements about treatment effects, A case study of sentencing and recidivism. Sociological Methodology, 28(1), 99-138.

Marshall, C., \& Rossman, G. (1995). Designing qualitative research. Thousand Oaks, CA, Sage Publications, Inc.

Marzano, R., Pickering, D., \& Pollock, J. (2001) Classroom instruction that works. Alexandria, VA, Association for Supervision and Curriculum Development. Maslow, A. (1954). Motivation and personality. New York, Harper \& Row. Mayse, J. (July 24, 2005). Paying for Prisoners. Messenger-Inquirer. Owensboro, KY. Retrieved October 20, 2005 from www.messenger-inquirer.com.

Moody, E. (1997, October). Lessons from pair counseling with incarcerated juvenile delinquents. Journal of Addictions and Offender Counseling, 18(1), 10-26.

Moreland, D. (1941). History and prophecy, John Augustus and his successors. National Probation Association Yearbook, 5. 
Moroz, K. (2000, Summer). Progressive relaxation with young offenders, A beginning counselor gathers confidence. Guidance and Counseling, 15(4), 27-31.

Murray, J. (2001). Clay, J. Maconchie's experiment. London, John Murray, 256-259.

Munson, W., \& Strauss, C. (1993, March). Career salience of institutionalized adolescent offenders. Career Development Quarterly, 41, 246-257.

Newman, D. (1986). Introduction to criminal justice ( $3^{\text {rd }}$ ed.). New York, Random House.

NIST/SEMATECH. (2008). e-Handbook of Statistical Methods. Retrieved March 10, 2008 from www.itl.nist.gov/div898/handbook/prc/section4/prc473

Norman, S. (1957). Juvenile detention. NPPA journal, 3, 392-403.

Nunn, G., \& Miller, M. (2000, December). At-risk adolescents' perceptions of learning temperaments, Implications for educational interventions. Journal of Instructional Psychology, 27, 266-272.

Ornstein, A., \& Hunkins, F. (1993) Curriculum. Boston, MA, Allyn and Bacon.

Osborne, D., \& Gaebler, T. (1992). Reinventing government. New York, NY, Penguin Books.

PA 1839, The seminal case. Ex Parte Crouse 4 Wharton Reports. (E. D. Pa 1839).

Painter, R. (2007). Job satisfaction levels of juvenile detention education faculties and the implementation of best teaching practices compared to overall program efficacy. Pilot study, Unpublished doctoral dissertation, University of Louisville/Western Kentucky University, Kentucky. 
Pappenfort, D., \& Young, T. (1980). Use of secure detention for juveniles and alternatives to its use, National study of juvenile detention. Washington, DC: Office Juvenile Justice and Delinquency Prevention, U. S. Department of Justice. Patten, M. (2005). Understanding research methods, An overview of the essentials. Glendale, CA, Pyrczah Publishing.

Payne, R. (1998). A framework for understanding poverty. Highlands, TX, RFT Publishing.

Payne, R. (1998). Learning structures. Highlands, TX, RFT Publishing.

Pearson, L., \& Moomaw, W. (2005, September). The relationship between teacher autonomy and stress, work satisfaction, empowerment, and professionalism. Educational Research Quarterly, 29, 37-53.

Pennsylvania Juvenile Justice Task Force. (1991). Toward the year 2000, A blueprint for excellence. Harrisburg, PA, Author.

People ex rel. Wayburn v. Schupf, 39 N.Y. 2 d pp. $687-688,350$ N.E. 2 d, pp. $906-910$ (1976).

Phillips, G., \& Gibbons, M. (2000). 63 ways of teaching or learning anything. Issaquah, WA, National School Improvement Project.

Platt, A. (1969). The child savers. Chicago, University of Chicago Press.

Prior, M., Smart, D., Sanson, A., \& Oberklaid, F. (2001). Longitudinal predictors of behavioral adjustment in pre-adolescent children. Australian and New Zealand Journal of Psychiatry, 35, 297-307.

Pollock, J., \& Vierra, A. (1992). Reading Educational Research. Arizona, Gorsuch Scarisbrick, Publishers. 
Powell, N. (2003 - 2004). Kentucky educational collaborative for state agency

children annual report. Eastern Kentucky University, Department of Education.

Quist , R., \& Matshazi, D. (2000). The child and adolescent functional assessment scale (CAFAS): A dynamic predictor of juvenile recidivism. Adolescences, 35, 181193.

Rauck, J. (1999). Redefining the good life, A new focus in the social sciences. The chronicles of higher education, 13-15.

Rief, L. (1992). Seeking diversity. Portsmouth, NH, Reed Publishing.

Roberts, T., \& Ryan, S. (2002). Tattooing and high risk behavior in adolescents. Pediatrics, 110(6), 1058-1063.

Roush, D. (April, 1996). Juvenile detention training needs assessment, Research report. Washington, DC, Office of Juvenile Justice and Delinquency Prevention, U.S. Department of Justice.

Roush, D. (October, 1996). Desktop guide to good juvenile detention practice. Michigan State University, Center for Research and Professional Development. OJJDP grant \# 92-JN-CX-006.

Roy, Sudipto (1995). Juvenile restitution and recidivism in a midwestern county. Federal Probation, 59, 55-63.

Rubin, T. (2003). Juvenile justice policies, practices, and programs. Kingston, New Jersey, Civic Research Institute, Inc. 
Sabol, W., Minton, T., \& Harrison, P. (2007) Prison and Jail Inmates at Midyear 2006.

U.S. Department of Justice, Office of Justice Programs Bureau of Justice

Statistics Bulletin. Retrieved October 14, 2007 from

http://www.ojp.usdoj.gov/bjs/pubalp2.htm\#pjmidyear

Schroeder, C. (May 16, 1998). Juvenile center construction starts, Newport site to be third in Kentucky. The Cincinnati enquirer. Cincinnati, Ohio. Retrieved August 26, 2005 from http:/www.enquirer.com/editions/1998/05/16/7394.html

Schultz, L. (1973). The cycle of juvenile court history. Crime and Delinquency, 457.

Sizemore v. Commonwealth, Ky. 450 S.W.2d 494 (1970).

Schall v. Martin, 467 U. S. 253 (1994).

Silver, M. (1996). An Introduction to the office of juvenile justice and delinquency prevention. Retrieved December 30, 2007 from http://www.ncjrs.gov/txtfiles/91453.txt

Slocumb, P., \& Payne, R. (2000). Removing the mask, Giftedness in poverty. Highlands, TX, RFT Publishing.

Smith, L. (1998). Behavioral \& Emotional Characteristics of Children in Detention. Journal of Correctional Education, 49, 63-67.

Sprague, J., Walker, H., Stieber, S., Simonsen, B., Nishioka, V., \& Wagner, L. (2001). Exploring the relationship between school discipline referrals and delinquency. Psychology in the Schools, 38, 197-207.

Stahl, A., Puzzachera, C., Livsey, S., Sladky, A., Finnegan, T., Tierney, N., \& Snyder, H. (2007). Juvenile court statistics 2003-2004. Pittsburgh, PA, National Center for Juvenile Justice. 
Steinhart, D., (2000). Pathways to juvenile detention reform, A structured approach. Annie E. Casey Foundation, I, pp. 6, 7-9, 71.

Studer, Q., (2004). The art of catching and keeping a great work force. Retrieved May 14, 2007 from https://search.ebscohost.com/<The Art of Catching-and Keeping-a Great Work Force. $\langle/ \mathrm{A}>$

Sussman, F., \& Baum, F. (1969). Law of juvenile delinquency (3d ed.). New York, Oceana Publications.

Svensson, O., Lundberg, I., Jacobson, C. (2001). The prevalence of reading and spelling difficulties among inmates of institutions for compulsory care of juvenile delinquents. Dyslexia, 7, 62-76.

Tappan, P. (1949). Juvenile delinquency. New York, McGraw-Hill.

Teplin, L., (2001). Assessing alcohol, drug, and mental disorders in juvenile detainees. Juvenile Justice Bulletin, 1-2.

Thomas, R. (2000). Kentucky disproportionate minority confinement initiative, Interim Report 3(3), 21-25.

Tobin, T., \& Sprague, J. (1999). Alternative education programs for at-risk youth, Issues, best practice, and recommendations. University of Oregon, Oregon school study council. OJJDP grant \#97-S22.

Trochim, W. (2006). Social research methods. Retrieved October 25, 2006 from http://www.socialresearchmethods.net/kb/qualdeb.htm 
Tucker, J. (2004). Another mothers' movement, 1890 to 1920, The role of women's voluntary organizations in Progressive Era social reform. Retrieved December 11, 2007 from http://www.mothersmovement.org

U.S. Department of Education. (June, 1995). Teachers \& goals 2000, leading the journey toward high standards for all students.

University of Iowa Labor Center. (2000). Child Labor Public Education Project.

Retrieved October 14, 2007 from

http:/www.continuetolearn.uiowa.edu/laborctr/child_labor/about/us_history.html

Waldie, K., \& Spreen, O. (1993). The relationship between learning disabilities and persisting delinquency. Journal of Learning Disabilities, 26, 417-423.

Warner, F. (1933). Juvenile detention in the United States. Chicago, IL, University of Chicago Press.

Wayburn v. Schupf. (1976). 39 N. Y. 2d, $687-688,350$ N. E. 2d, 908-909.

Weaver, R. (2007). Every coin has two sides, Uncovering the model minority myth. NEA Today, 26, 3- 9.

Webb, L., Montello, P., \& Norton, S. (1994). Human resources administration. New York, NY, Macmillian College Publishing Company.

Weiss, D., Dawis, R., England, G., \& Lofquist, L. (1967). Manual for the Minnesota satisfaction questionnaire. Minneapolis, MN, University of Minnesota.

Wilgus, A., \& Epstein, I. (1978). Group homes for adolescents, A comparative case study. Social Work, 23, 486-492. 
Williamson, D. (2000). An analysis of juvenile waiver in the Commonwealth of Kentucky,

10-11. Unpublished Ph.D. dissertation, University of Kentucky, Lexington, KY.

Whiteley, S. (2001). Why don't they just enroll in a tertiary course or get a job? Youth Studies Australia, 20, 23-29.

Wolfgang, C. (2001). Solving discipline and classroom management problems. New York, NY, John Wiley and Sons, Inc.

Zemelman, S., Daniels, H., \& Hyde, A. (1993). Best practices. Portsmouth, NH: Heinemann. 
APPENDIX A

STANDARDS AND INDICATORS FOR DETENTION CENTER

PERFORMANCE 


\section{Appendix A}

Standards and Indicators for Detention Center Performance

The Kentucky Educational Collaborative for State Agency Children (KECSAC) was established in 1992 by the Kentucky General Assembly. They were conceived to address the educational needs of state agency children in response to the 1990's KERA movement. Their primary goal is to assist local school boards in providing education to youth who are mandated to the Kentucky Cabinets for Justice, Health and Family Services, Mental Health, and Mental Retardation Services. Over 16, 000 children are defined as State Agency Children (SAC).

Under the leadership of Eastern Kentucky University, the department has responsibility for the management and operation of educational components for at-risk and delinquent youth in the Commonwealth. In order to address the differential levels of required services needed in detention center settings, KECSAC funded the development of an audit tool known as SIDE derived from its use of Standards, Indicators, Descriptors, and Evidence as a way to evaluate the performance of secure facilities. There are nine standards reviewed by this document through the observation of trained KECSAC evaluators.

- Standard One evaluates Curriculum. It states, "The program develops and implements a curriculum that is rigorous, intentional, and aligned to state and local standards." There are nine indicators with a descriptor of each, along with a column to record the evidence that reflects a high or low score in that area.

- Standard Two evaluates Assessment with eleven indicators. The focus is, "The program uses multiple evaluation and assessment strategies to continuously monitor and modify instruction to meet student needs and support proficient student work." 
- Standard Three evaluates Instruction with eleven indicators - "The instructional program actively engages all students by using effective, varied, and researchbased practices to improve student academic performance."

- Standard Four evaluates Culture with nine indicators - "The district, schools, and program function as an effective learning community and support a climate conducive to performance excellence."

- Standard Five looks at Support - "The district, schools, and program work with families and community groups to remove barriers to learning in an effort to meet the intellectual, social, career, and developmental needs of students and has six indicators."

- Standard Six looks at Professional Development - "The district, schools, and program provide research-based, results-driven professional development opportunities for staff and implement performance evaluation procedures in order to improve teaching and learning," with nine indicators.

- Standard Seven examines leadership - "District, school, and program instructional decisions focus on support for teaching and learning, organizational direction, high performance expectations, creating a learning culture and developing leadership capacity," with eight indicators.

- Standard Eight surveys Resources/Organization - "The program is organized to maximize the use of all available resources to support high student and staff performance," with ten indicators.

- Standard Nine looks at Planning - "The district, schools, and program develop, implement, and evaluate a comprehensive and effective plan that communicates a clear purpose, direction, and action plan focused on teaching and learning," with sixteen indicators.

A cumulative performance score is generated by the assignment of points derived from scores for Exemplary, Fully Functioning, Limited or Partial Development, Little or No Development, and Not Applicable. 
APPENDIX B

RESEARCH INSTRUMENT: BEST PRACTICES SURVEY 
Research Instrument, Best Practices Survey

This instrument was designed to explore research validated components of a successful detention center. There were two areas explored with a two part question under each heading. The survey asked the educators to make value judgments concerning the presence and importance of twenty-five highlighted areas.

\section{Best Practices Survey}

Best Practices Facility Dimensions:

Structure

Safety

Security

Fairness

Consistency

Community Involvement

Physical Training

Conflict Resolution

Nutrition

Treats/Rewards

Management Involvement

Counseling

Health Services

Best Practices Education Dimensions:

Education

Reading \& Math Levels

Career Majors

Learning Styles

Life Skills

Computer Skills

Teachers/Education

Accelerated Reader Program

Special Events, Plays, etc.

Drug/Sex Education

Violence Prevention Education

Career Planning 
Appendix B

\section{BEST PRACTICES, Survey}

Presence and Importance:

Subjects:

1. Structure

13. Computer Skills

2. Safety

14. Conflict Resolution

3. Security

15. Nutrition

4. Fairness

16. Teachers/Education

5. Consistency

17. Treats/Rewards

6. Education

18. Accelerated Reader Program

7. Reading Levels

8. Math Levels

9. Career Majors

10. Learning Styles

19. Special Events, plays, assemblies, etc.

20. Management Involvement

21. Counseling

22. Health Services

11. Physical Training

23. Drug/Sex Education

12. Life Skills

24. Violence Prevention Education

25. Career Planning

Dissertation Data Collection

Survey of Detention Center Programming

1. Is structure present at your facility?

$\begin{array}{lrlllllll}1 & 2 & 3 & 4 & 5 & 6 & 7 & 8 & 9 \\ \text { Never } & & \text { Sometimes } & & & \text { Almost Always }\end{array}$

Is structure important at your facility?

$\begin{array}{llllllllll}1 & 2 & 3 & 4 & 5 & 6 & 7 & 8 & 9 & 10\end{array}$

Not at all important Somewhat Important Highly Important 
2. Is safety present at your facility?

$\begin{array}{lrlllllll}1 & 2 & 3 & 4 & 5 & 6 & 7 & 8 & 9 \\ \text { Never } & & \text { Sometimes } & & & \text { Almost Always }\end{array}$

Is safety important at your facility?

$\begin{array}{llllllllll}1 & 2 & 3 & 4 & 5 & 6 & 7 & 8 & 9 & 10\end{array}$

Not at all important Somewhat Important Highly Important

3. Is security present at your facility?

$\begin{array}{lrlllllll}1 & 2 & 3 & 4 & 5 & 6 & 7 & 8 & 9 \\ \text { Never } & & \text { Sometimes } & & & \text { Almost Always }\end{array}$

Is security important at your facility?

$\begin{array}{llllllllll}1 & 2 & 3 & 4 & 5 & 6 & 7 & 8 & 9 & 10\end{array}$

Not at all important Somewhat Important Highly Important

4. Is fairness practiced at your facility?

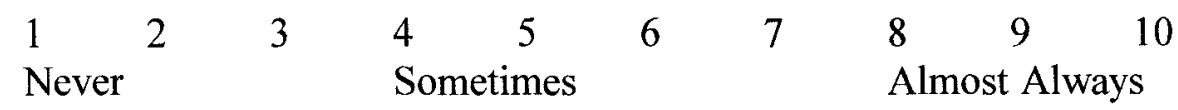

Is fairness important at your facility?

$\begin{array}{llllllllll}1 & 2 & 3 & 4 & 5 & 6 & 7 & 8 & 9 & 10\end{array}$

Not at all important Somewhat Important Highly Important 
5. Is consistency practiced at your facility?

$\begin{array}{lrlllllll}1 & 2 & 3 & 4 & 5 & 6 & 7 & 8 & 9 \\ \text { Never } & & \text { Sometimes } & & & \text { Almost Always }\end{array}$

Is consistency important at your facility?

$\begin{array}{llllllllll}1 & 2 & 3 & 4 & 5 & 6 & 7 & 8 & 9 & 10\end{array}$

Not at all important Somewhat Important Highly Important

6. Is an educational program present at your facility?

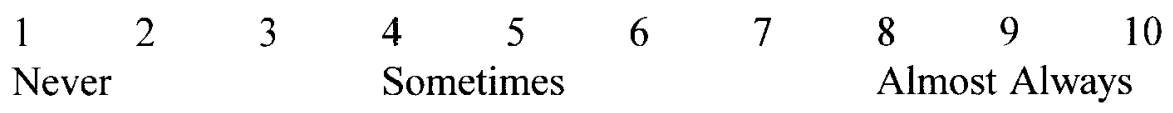

Is the educational program important at your facility?

$\begin{array}{llllllllll}1 & 2 & 3 & 4 & 5 & 6 & 7 & 8 & 9 & 10\end{array}$ Not at all important Somewhat Important Highly Important

7. Are Reading Levels tested at your facility?

$\begin{array}{lllllllll}1 & 2 & 3 & 4 & 5 & 6 & 7 & 8 & 9 \\ \text { Never } & & & \text { Sometimes } & & & \text { Almost Always }\end{array}$

Are Reading Levels important at your facility?

$\begin{array}{llllllllll}1 & 2 & 3 & 4 & 5 & 6 & 7 & 8 & 9 & 10\end{array}$

Not at all important Somewhat Important Highly Important 
8. Are Math Levels tested at your facility?

$\begin{array}{lllllllll}1 & 2 & 3 & 4 & 5 & 6 & 7 & 8 & 9 \\ \text { Never } & & \text { Sometimes } & & & \text { Almost Always }\end{array}$

Are Math Levels important at your facility?

$\begin{array}{llllllllll}1 & 2 & 3 & 4 & 5 & 6 & 7 & 8 & 9 & 10\end{array}$

Not at all important Somewhat Important Highly Important

9. Is the Work Adjustment Model/Career Majors present at your facility?

$\begin{array}{lllllllll}1 & 2 & 3 & 4 & 5 & 6 & 7 & 8 & 9 \\ \text { Never } & & \text { Sometimes } & & & \text { Almost Always }\end{array}$

Is Career Majors/Work Adjustment Model important at your facility?

$\begin{array}{llllllllll}1 & 2 & 3 & 4 & 5 & 6 & 7 & 8 & 9 & 10\end{array}$

Not at all important Somewhat Important Highly Important

10. Are Learning Styles posted at your facility?

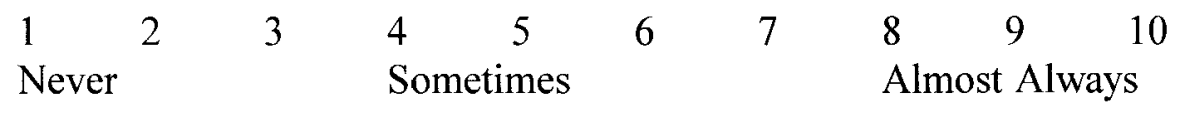

Are Learning Styles important at your facility?

$\begin{array}{llllllllll}1 & 2 & 3 & 4 & 5 & 6 & 7 & 8 & 9 & 10\end{array}$

Not at all important Somewhat Important Highly Important 
11. Is Physical Training present at your facility?

$\begin{array}{lrlllllll}1 & 2 & 3 & 4 & 5 & 6 & 7 & 8 & 9 \\ \text { Never } & & \text { Sometimes } & & & \text { Almost Always }\end{array}$

Is Physical Training important at your facility?

$\begin{array}{llllllllll}1 & 2 & 3 & 4 & 5 & 6 & 7 & 8 & 9 & 10\end{array}$

Not at all important Somewhat Important Highly Important

12. Are Life Skills taught at your facility?

$\begin{array}{lrlllllll}1 & 2 & 3 & 4 & 5 & 6 & 7 & 8 & 9 \\ \text { Never } & & \text { Sometimes } & & & \text { Almost Always }\end{array}$

Are Life Skills important at your facility?

$\begin{array}{llllllllll}1 & 2 & 3 & 4 & 5 & 6 & 7 & 8 & 9 & 10\end{array}$

Not at all important Somewhat Important Highly Important

13. Are Computer Skills taught at your facility?

$\begin{array}{lrlllllll}1 & 2 & 3 & 4 & 5 & 6 & 7 & 8 & 9 \\ \text { Never } & & \text { Sometimes } & & & \text { Almost Always }\end{array}$

Are Computer Skills important at your facility?

$\begin{array}{llllllllll}1 & 2 & 3 & 4 & 5 & 6 & 7 & 8 & 9 & 10\end{array}$

Not at all important Somewhat Important Highly Important 
14. Is Conflict Resolution taught at your facility?

$\begin{array}{lllllllll}1 & 2 & 3 & 4 & 5 & 6 & 7 & 8 & 9 \\ \text { Never } & & \text { Sometimes } & & & \text { Almost Always }\end{array}$

Is Conflict Resolution important at your facility?

$\begin{array}{llllllllll}1 & 2 & 3 & 4 & 5 & 6 & 7 & 8 & 9 & 10\end{array}$

Not at all important Somewhat Important Highly Important

15. Is Good Nutrition practiced at your facility?

$\begin{array}{lrlllllll}1 & 2 & 3 & 4 & 5 & 6 & 7 & 8 & 9 \\ \text { Never } & & \text { Sometimes } & & & \text { Almost Always }\end{array}$

Is Good Nutrition important at your facility?

$\begin{array}{llllllllll}1 & 2 & 3 & 4 & 5 & 6 & 7 & 8 & 9 & 10\end{array}$

Not at all important Somewhat Important Highly Important

16. Are Teachers present at your facility?

$\begin{array}{lllllllll}1 & 2 & 3 & 4 & 5 & 6 & 7 & 8 & 9 \\ \text { Never } & & \text { Sometimes } & & & \text { Almost Always }\end{array}$

Are Teachers important at your facility?

$\begin{array}{llllllllll}1 & 2 & 3 & 4 & 5 & 6 & 7 & 8 & 9 & 10\end{array}$

Not at all important Somewhat Important Highly Important 
20. Is Management involved with residents at your facility?

$\begin{array}{lrlllllll}1 & 2 & 3 & 4 & 5 & 6 & 7 & 8 & 9 \\ \text { Never } & & \text { Sometimes } & & & \text { Almost Always }\end{array}$

Is the involvement of Management with residents important at your facility?

$\begin{array}{llllllllll}1 & 2 & 3 & 4 & 5 & 6 & 7 & 8 & 9 & 10\end{array}$

Not at all important Somewhat Important Highly Important

21. Is Counseling present at your facility?

$\begin{array}{lrllllllr}1 & 2 & 3 & 4 & 5 & 6 & 7 & 8 & 9 \\ \text { Never } & & \text { Sometimes } & & & \text { Almost Always }\end{array}$

Is Counseling important at your facility?

$\begin{array}{llllllllll}1 & 2 & 3 & 4 & 5 & 6 & 7 & 8 & 9 & 10\end{array}$

Not at all important Somewhat Important Highly Important

22. Are Health Services available at your facility?

$\begin{array}{lrlllllll}1 & 2 & 3 & 4 & 5 & 6 & 7 & 8 & 9 \\ \text { Never } & & \text { Sometimes } & & & \text { Almost Always }\end{array}$

Are Health Services important at your facility?

$\begin{array}{llllllllll}1 & 2 & 3 & 4 & 5 & 6 & 7 & 8 & 9 & 10\end{array}$

Not at all important Somewhat Important Highly Important 
23. Is Drug/Sex Education present at your facility?

$\begin{array}{lrlllllll}1 & 2 & 3 & 4 & 5 & 6 & 7 & 8 & 9 \\ \text { Never } & & \text { Sometimes } & & & \text { Almost Always }\end{array}$

Is Drug/Sex Education important at your facility?

$\begin{array}{llllllllll}1 & 2 & 3 & 4 & 5 & 6 & 7 & 8 & 9 & 10\end{array}$

Not at all important Somewhat Important Highly Important

24. Is Violence Prevention education present at your facility?

$\begin{array}{lrlllllll}1 & 2 & 3 & 4 & 5 & 6 & 7 & 8 & 9 \\ \text { Never } & & & \text { Sometimes } & & & \text { Almost Always }\end{array}$

Is Violence Prevention education important at your facility?

$\begin{array}{llllllllll}1 & 2 & 3 & 4 & 5 & 6 & 7 & 8 & 9 & 10\end{array}$

Not at all important Somewhat Important Highly Important

25. Is Career Planning (i.e., GED test, College Correspondence Courses, Vocational Counseling) present at your facility?

$\begin{array}{llllllllll}1 & 2 & 3 & 4 & 5 & 6 & 7 & 8 & 9 & 10 \\ \text { Never } & & \text { Sometimes } & & & \text { Almost Always }\end{array}$

Is Career Planning (i.e., GED test, College Correspondence Courses, Vocational Counseling) important at your facility?

$\begin{array}{llllllllll}1 & 2 & 3 & 4 & 5 & 6 & 7 & 8 & 9 & 10\end{array}$

Not at all important Somewhat Important Highly Important

Copyright, Rebecca M. Painter [September 5, 2005] 
APPENDIX C

RESEARCH INSTRUMENT, MINNESOTA SATISFACTION QUESTIONNAIRE 


\section{Appendix C}

II. Minnesota Satisfaction Questionnaire (short form)

Vocational Psychology Research, University of Minnesota Copyright 1977

Ask yourself, How satisfied am I with this aspect of my job?

Very Sat. means I am very satisfied with this aspect of my job.

Sat. means I am satisfied with this aspect of my job.

$\mathbf{N}$ means I can't decide whether I am satisfied or not with this aspect of my job.

Dissat. Means I am dissatisfied with this aspect of my job.

Very Dissat. Means I am very dissatisfied with this aspect of my job.

On my present job, this is how I feel about ...

Very

Very

1. Being able to keep busy all the time

Dissat. Dissat. N Sat. Sat.

2. The chance to work alone on the job

3. The chance to do different things from time to time

4. The chance to be "somebody" in the community

5. The way my boss handles his/her workers

6. The competence of my supervisor in making decisions

7. Being able to do things that don't go against my conscience

8. The way my job provides for steady employment

9. The chance to do things for other people

10. The chance to tell people what to do

11. The chance to do something that makes use of my abilities

12. The way company policies are put into practice

13. My pay and the amount of work I do

14. The chances for advancement on this job

15. The freedom to use my own judgment

16. The chance to try my own methods of doing the job

17. The working conditions

18. The way my co-workers get along with each other

19. The praise I get for doing a good job

20. The feeling of accomplishment I get from the job 

1. Check one:
Male
Female

2. When were you born? 20

3. Circle the number of years of schooling you completed:

45678

9101112

Grade School
13141516

College
17181920

Graduate/Prof. School

4. What is your present job called?

5. What do you do on your present job?

6. How long have you been on your present job? years month

7. What would you call your occupation, your usual line of work?

8. How long have you been in this line of work? years month 
APPENDIX D

RESEARCH INSTRUMENT, KENTUCKY EDUCATIONAL COLLABORATIVE FOR STATE AGENCY CHILDREN AUDIT TOOL - PILOT AND CENTERS. 


\section{Appendix D}

\section{Summary of KECSAC Audit Tool used for Pilot}

Program Improvement Tool

Standards, Indicators, Descriptors, and Evidence

(SIDE)

Rubric: $\quad$ Circle the best answer...............

- EX Exemplary level of development and implementation

- FF Fully Functioning and Operational level of development and implementation

- LP Limited or Partial development and implementation

- LN Little or No development and implementation

- NA Not Applicable

1. Your curriculum is rigorous, intentional, and aligned to state and local standards.
EX
FF
LP
LN
NA

2. Program uses multiple evaluation and assessment strategies to continuously monitor and modify instruction to meet student needs and support proficient student work.
EX
FF
LP
LN
NA

3. The instructional program actively engages all students by using effective, varied, and research-based practices to improve student academics.
EX
FF
LP
LN
NA

4. The district, schools, and program function as an effective learning community and support a climate conductive to performance excellence.
EX
FF
LP
LN
NA

5. The district, schools, and program work with families and community groups to remove barriers to learning in an effort to meet the intellectual, social, and career, and developmental needs of students.
EX
FF
LP
LN
NA

6. The district, schools, and program provide research-based, results-driven professional development opportunities for staff and implement performance evaluation procedures in order to improve teaching and learning.
EX
FF
LP
LN
NA 
7. District, schools, and program instructional decisions focus on support for teaching/learning, organizational direction, high performance, learning culture, and developing leadership capacity.
EX
FF
LP
LN
NA

8. The program is organized to maximize the use of all available resources to support high student and staff performance.
EX
FF
LP
LN
NA

9. The district, schools, and program develop, implement, and evaluate a comprehensive and effective plan that communicates a clear purpose, direction and action plan focused on teaching and learning.
EX
FF
LP
$\mathbf{L N}$
NA

10. The district, schools, and program are focused on education rather than punishment. Their goal is to provide the tools necessary to rehabilitate, educate, and motivate the juvenile delinquents in the program.
EX
FF
LP
LN
NA 


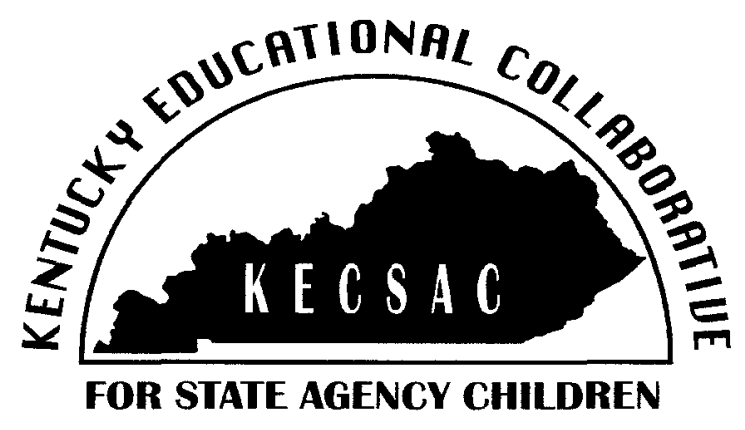




\section{ACADEMIC PERFORMANCE}

\section{Standard 1 - Curriculum}

The program develops and implements a curriculum that is rigorous, intentional, and aligned to state and local standards.

\begin{tabular}{|c|c|c|}
\hline Indicators & Descriptors & Evidence \\
\hline $\begin{array}{l}\text { 1.1a Curriculum is aligned with } \\
\text { state and local district } \\
\text { documents. }\end{array}$ & $\begin{array}{l}\text { The curriculum defines what } \\
\text { students should know and be } \\
\text { able to do based on standards } \\
\text { documents; promotes in- } \\
\text { depth study; connects with } \\
\text { different content areas; and } \\
\text { addresses age and } \\
\text { developmental levels. }\end{array}$ & $\begin{array}{ll}\text { - } & \text { Kentucky's Core Content for } \\
& \text { Assessment } \\
\text { - } & \text { Program of Studies } \\
\text { - } & \text { District Aligned Curriculum } \\
\text { - } & \text { Unit/Lesson Plans } \\
\text { - } & \text { Core Content for Assessment } \\
& \text { Categories/Sub-Categories }\end{array}$ \\
\hline $\begin{array}{l}\text { 1.1b Discussions take place } \\
\text { among education and } \\
\text { treatment staffs regarding } \\
\text { curriculum standards. }\end{array}$ & $\begin{array}{l}\text { The district, schools, and } \\
\text { program initiate and facilitate } \\
\text { discussions about curriculum } \\
\text { across grades levels } \\
\text { (vertically) and content areas } \\
\text { (horizontally). }\end{array}$ & $\begin{array}{ll}\text { - } & \text { Content Integration } \\
\text { - } & \text { Mapping } \\
\text { - } & \text { Departmentalization/Grouping } \\
\text { - } & \text { Observation/Interview } \\
\text { - } & \text { Minutes from Meetings } \\
\end{array}$ \\
\hline $\begin{array}{l}\text { 1.1c Discussions occur among } \\
\text { teachers and other educational } \\
\text { staff to reduce curriculum } \\
\text { gaps. }\end{array}$ & $\begin{array}{l}\text { The district, schools, and } \\
\text { program initiate and facilitate } \\
\text { discussions to reduce } \\
\text { overlapping curriculum; } \\
\text { address and eliminate } \\
\text { curriculum gaps and } \\
\text { redundancy of content. }\end{array}$ & $\begin{array}{ll}- & \text { Mapping } \\
- & \text { Unit/Lesson Plans } \\
\text { - } & \text { Faculty Meetings } \\
\text { - } & \text { Meeting Minutes/Reports } \\
\text { - Interviews }\end{array}$ \\
\hline $\begin{array}{l}\text { 1.1d Communication exists } \\
\text { among teachers and other } \\
\text { educational staff to focus on } \\
\text { key curriculum transition points } \\
\text { among grade levels and } \\
\text { content areas. }\end{array}$ & $\begin{array}{l}\text { The program identifies and } \\
\text { documents transition points } \\
\text { among grade levels and core } \\
\text { and non-core content areas. }\end{array}$ & $\begin{array}{ll}- & \text { Common Planning Time } \\
\text { - } & \text { Mapping } \\
\text { - } & \text { Interdisciplinary Units } \\
\text { - } & \text { Core Content for Assessment } \\
& \text { Categories/Sub-Categories } \\
\text { - } \quad \text { Unit/Lesson Plans with Re-teaching } \\
\text { and Enrichment }\end{array}$ \\
\hline
\end{tabular}




\begin{tabular}{|c|c|c|}
\hline $\begin{array}{l}\text { 1.1e Curriculum is linked to } \\
\text { specific continuing } \\
\text { education, life, and career } \\
\text { options. }\end{array}$ & $\begin{array}{l}\text { The curriculum includes a } \\
\text { variety of options for } \\
\text { continuing education; } \\
\text { experiences for career } \\
\text { options; preparation to be } \\
\text { useful citizens; and } \\
\text { development of an Individual } \\
\text { Graduation Plan (IGP). }\end{array}$ & $\begin{array}{ll}\text { - } & \text { Master Schedule } \\
\text { - } & \text { Student Schedules/IGP } \\
\text { - } \quad \text { Nore/Non-Core Content } \\
\quad \text { graduadion, transition to adult life) } \\
\text { - Career Assessment }\end{array}$ \\
\hline $\begin{array}{l}\text { 1.1f } \mathrm{A} \text { process is in place } \\
\text { and used to monitor, } \\
\text { evaluate, and review } \\
\text { curriculum. }\end{array}$ & $\begin{array}{l}\text { The program has a } \\
\text { systematic on-going process } \\
\text { in place to monitor, review, } \\
\text { and evaluate curriculum at } \\
\text { least annually. }\end{array}$ & $\begin{array}{ll} & \text { Needs Assessment Data } \\
\text { - } & \text { Results Documents } \\
\text { - } & \text { Meeting Schedule/Minutes } \\
\text { - Interviews }\end{array}$ \\
\hline $\begin{array}{l}1.1 \mathrm{~g} \mathrm{~A} \text { common academic } \\
\text { core and non-core content } \\
\text { curriculum is available for } \\
\text { all students. }\end{array}$ & $\begin{array}{l}\text { The curriculum demonstrates } \\
\text { high expectations, higher } \\
\text { order thinking, and problem } \\
\text { solving; addresses the } \\
\text { learning needs of all; and } \\
\text { communicates standards and } \\
\text { expectations to all students. }\end{array}$ & $\begin{array}{ll} & \text { Master Schedule } \\
\text { - } & \text { Teacher Certification/Assignments } \\
\text { - } & \text { Student Class Schedules } \\
\text { - } & \text { Init/Lesson Plans } \\
\text { Interviews }\end{array}$ \\
\hline $\begin{array}{l}\text { * 1.a Curriculum selection is } \\
\text { dependent on student grade } \\
\text { levels, performance levels, } \\
\text { learning styles, multiple } \\
\text { intelligences, emotional } \\
\text { intelligences, behavior } \\
\text { management needs; and } \\
\text { includes control for } \\
\text { individual and small group } \\
\text { instruction. }\end{array}$ & $\begin{array}{l}\text { Needs assessment data is } \\
\text { used to identify individual } \\
\text { student academic; behavior, } \\
\text { social, emotional, } \\
\text { attitude/relationship; and } \\
\text { career/vocational } \\
\text { instructional levels. }\end{array}$ & $\begin{array}{ll}\text { - } & \text { State Tests (i.e., KCCT, CTBS), } \\
\text { - Other Academic Standardized Tests } \\
\text { (i.e., behavior rating scales, social } \\
\text { maturity surveys, learning } \\
\text { styles/multiple intelligence } \\
\text { assessments, career interest } \\
\text { inventories). } \\
\text { - Classroom/Treatment Assessments } \\
\text { - Collaboration Between Education and } \\
\text { Treatment Staff }\end{array}$ \\
\hline $\begin{array}{l}\text { *1.b Character education, } \\
\text { social skills, life skills, and } \\
\text { behavior competence } \\
\text { curricula are integrated with } \\
\text { the education and treatment } \\
\text { program components. }\end{array}$ & $\begin{array}{l}\text { Curricula are integrated } \\
\text { within academic content } \\
\text { areas; taught as a stand } \\
\text { alone course or team-taught; } \\
\text { or addressed during } \\
\text { individual/group treatment } \\
\text { sessions. }\end{array}$ & $\begin{array}{ll}\text { - } & \text { Treatment/Educational Staff Meeting } \\
\text { - Schedule/Minutes } \\
\text { - } \\
\text { - } \quad \text { Mnit/Lesson Plans } \\
\text { - Interviews/Observation }\end{array}$ \\
\hline
\end{tabular}

* Alternative Education Research-Based Strategies 


\section{Standard 2 - Assessment}

The program uses multiple evaluation and assessment strategies to continuously monitor and modify instruction to meet student needs and support proficient student work.

\begin{tabular}{|c|c|c|}
\hline Indicators & Descriptors & Evidence \\
\hline $\begin{array}{l}\text { 2.1a Classroom assessments } \\
\text { are frequent, rigorous, and } \\
\text { aligned to Kentucky's Core } \\
\text { Content for Assessment. }\end{array}$ & $\begin{array}{l}\text { Assessments are aligned } \\
\text { with the curriculum, } \\
\text { frequent, and provide a } \\
\text { variety of opportunities to } \\
\text { measure learning; are } \\
\text { rigorous, authentic, and } \\
\text { based on multiple sources of } \\
\text { assessment data. }\end{array}$ & $\begin{array}{ll}\text { - } & \text { Student Performance Reports } \\
\text { - } & \text { Unit/Chapter Test Results } \\
\text { - } & \text { Student Work Samples } \\
\text { Writing Portfolios }\end{array}$ \\
\hline $\begin{array}{l}\text { 2.1b Teachers and other } \\
\text { educational staff collaborate } \\
\text { on authentic assessment } \\
\text { tasks that are aligned with } \\
\text { Kentucky's Core Content for } \\
\text { Assessment. }\end{array}$ & $\begin{array}{l}\text { Assessments are valid, } \\
\text { appropriate, and reflect } \\
\text { authentic assessment tasks. }\end{array}$ & $\begin{array}{ll}\text { - } & \text { Test Item Analysis } \\
\text { - } & \text { Release Items/Scrimmage Tests } \\
\text { - } & \text { Test Results, Projects, Models } \\
\text { - Unit/Lesson Plans }\end{array}$ \\
\hline $\begin{array}{l}\text { 2.1c Students can articulate } \\
\text { academic expectations and } \\
\text { know requirements to be } \\
\text { proficient. }\end{array}$ & $\begin{array}{l}\text { Students articulate what } \\
\text { they know and communicate } \\
\text { strengths; teachers } \\
\text { collaborate and use scoring } \\
\text { guides (rubrics). }\end{array}$ & $\begin{array}{ll}\text { - } & \text { Student Work Samples } \\
\text { - } & \text { Classroom Test Results } \\
\text { - } & \text { Meeting Schedule/Minutes } \\
\text { - } & \text { Scoring Guide (Rubric) } \\
\text { - Interviews and Observation }\end{array}$ \\
\hline $\begin{array}{l}\text { 2.1d Formal and informal } \\
\text { assessments are used to } \\
\text { identify individual student } \\
\text { curriculum gaps. }\end{array}$ & $\begin{array}{l}\text { School staff analyzes } \\
\text { assessment results and } \\
\text { disaggregates data to } \\
\text { identify curriculum gaps to } \\
\text { determine what students } \\
\text { know and are able to do. }\end{array}$ & $\begin{array}{l}\text { - Individual Student Performance (i.e., } \\
\text { Core Content for Assessment/sub- } \\
\text { categories and other diagnostic } \\
\text { assessments) } \\
\text { - Teacher-Made Tests } \\
\text { - Standardized Achievement Tests }\end{array}$ \\
\hline $\begin{array}{l}\text { 2.1e Multiple assessments } \\
\text { provide feedback on student } \\
\text { learning. }\end{array}$ & $\begin{array}{l}\text { Multiple opportunities and } \\
\text { forms of classroom } \\
\text { assessments provide } \\
\text { meaningful feedback for } \\
\text { students. }\end{array}$ & $\begin{array}{ll}\text { - } & \text { Multiple Choice Test-Taking Results } \\
\text { - } & \text { Open-Response Test-Taking Results } \\
\text { - } & \text { Writing Portfolio Samples } \\
& \text { Portfolios, Projects, Research }\end{array}$ \\
\hline $\begin{array}{l}\text { 2.1f Teachers use } \\
\text { performance standards and } \\
\text { performance level } \\
\text { descriptions to develop } \\
\text { scoring guides that are } \\
\text { shared with students. }\end{array}$ & $\begin{array}{l}\text { Performance standards and } \\
\text { performance level } \\
\text { descriptions are used to } \\
\text { develop scoring guides } \\
\text { (rubrics), to create student } \\
\text { work models, and to ensure } \\
\text { that assessment tasks are } \\
\text { age appropriate. }\end{array}$ & $\begin{array}{ll}\text { - } & \text { Observation } \\
\text { - } & \text { Displays } \\
\text { - } & \text { examples/Modelems/Benchmarks/Releas } \\
\text { - Unit/Lesson Plans }\end{array}$ \\
\hline $\begin{array}{l}\text { 2.1g CATS coordination } \\
\text { exists between the district, } \\
\text { schools, and this program - } \\
\text { results are available, and } \\
\text { reported (includes alternate } \\
\text { portfolios when applicable). }\end{array}$ & $\begin{array}{l}\text { The district, schools, and } \\
\text { program provide } \\
\text { disaggregated results, } \\
\text { purposes of assessment; } \\
\text { training, test-taking practice, } \\
\text { sequenced approaches to } \\
\text { writing portfolios } \\
\text { development, and } \\
\text { monitoring of the } \\
\text { development of scoring } \\
\text { guides. }\end{array}$ & $\begin{array}{ll}\text { - } & \text { District/School/Program Disaggregated } \\
& \text { Sub-Group Data } \\
\text { - } & \text { Student Cumulative Folder Information } \\
\text { - } & \text { Due Process Folder Information } \\
\text { - } & \text { IEP, IPI, ILP/IGP }\end{array}$ \\
\hline $\begin{array}{l}\text { 2.1h Student work is } \\
\text { analyzed to inform instruction, } \\
\text { revise curriculum, and obtain } \\
\text { information about teaching }\end{array}$ & $\begin{array}{l}\text { Teachers and other } \\
\text { educational staff collaborate } \\
\text { and regularly analyze } \\
\text { classroom assessments. }\end{array}$ & $\begin{array}{ll}\text { - } & \text { Meeting Schedule/Minutes } \\
\text { - } & \text { Result Documents } \\
\text { - } & \text { Observation } \\
& \text { Student Work Samples } \\
\end{array}$ \\
\hline
\end{tabular}




\begin{tabular}{|c|c|c|}
\hline $\begin{array}{l}\text { *2.a Formal and informal } \\
\text { assessments are used to } \\
\text { identify causes of behavior, } \\
\text { reasons for the behaviors, } \\
\text { replacement behaviors, } \\
\text { student } \\
\text { interview/involvement, and } \\
\text { use of multi-component } \\
\text { interventions that influence } \\
\text { students. }\end{array}$ & $\begin{array}{l}\text { Universal, targeted, and } \\
\text { intensive intervention } \\
\text { strategies are used } \\
\text { throughout the school, within } \\
\text { classrooms, and for } \\
\text { individual students, } \\
\text { respectively. }\end{array}$ & $\begin{array}{ll}\text { - } & \text { Safe School Plan } \\
\text { - } & \text { Instructional Discipline Plan } \\
\text { - } & \text { Functional Behavior Assessments } \\
\text { - } & \text { Individual Student Assessment Results } \\
\text { - } & \text { Point/Level Systems } \\
\text { - } & \text { Modeling }\end{array}$ \\
\hline $\begin{array}{l}\text { *2.b Education and treatment } \\
\text { staff collaborates, use } \\
\text { behavior, social rating, } \\
\text { learning styles, and career } \\
\text { interest assessments to } \\
\text { improve student learning. }\end{array}$ & $\begin{array}{l}\text { The program and classroom } \\
\text { learning environment is safe } \\
\text { and orderly, highly } \\
\text { structured, and positive } \\
\text { rather than punitive. }\end{array}$ & $\begin{array}{ll} & \text { Safe School Plan } \\
\text { - } & \text { Code of Conduct } \\
\text { - } & \text { Staff, Family, Student Handbooks } \\
\text { - } & \text { Program Defined (i.e., purpose, type) } \\
\text { - } \quad \text { Classion, and Belief Statements } \\
\text { - } \quad \text { Meeting Schedule/Minutes } \\
\text { - Program and Student Assessment } \\
\quad \text { Results } \\
\end{array}$ \\
\hline $\begin{array}{l}{ }^{* \star 2} 2 . c \text { Youth are assessed } \\
\text { formally and/or informally } \\
\text { within } 30 \text { days of enrollment } \\
\text { to determine educational } \\
\text { needs. }\end{array}$ & Yes/No & $\begin{array}{ll}\text { - } & \text { Student Assessments } \\
\text { - } & \text { Cumulative Folders } \\
\text { - } & \text { Passpocess Folders } \\
\text { - } & \text { IEP, IPI, ILP/IGP (SSTS) }\end{array}$ \\
\hline
\end{tabular}

* Alternative Education Research-Based Strategies

** KECSAC (documentation required) 


\section{Standard 3-Instruction}

The instructional program actively engages all students by using effective, varied, and research-based practices to improve student academic performance.

\begin{tabular}{|c|c|c|}
\hline Indicators & Descriptors & Evidence \\
\hline $\begin{array}{l}\text { 3.1a Varied instructional } \\
\text { strategies are used in all } \\
\text { classrooms. }\end{array}$ & $\begin{array}{l}\text { Teachers use a variety of } \\
\text { student-centered } \\
\text { instructional strategies; } \\
\text { address various learning } \\
\text { styles and multiple } \\
\text { intelligences; require higher } \\
\text { order thinking; and integrate } \\
\text { content. }\end{array}$ & $\begin{array}{l}\text { - } \quad \text { Lesson Plans (i.e., goals, objectives, } \\
\text { - } \quad \text { Equivities, materials, assessment) } \\
\text { - } \quad \text { Appropriate Physical Space } \\
\text { - } \quad \text { Strategies (i.e., direct, indirect, student } \\
\text { centered, peer, collaborative) }\end{array}$ \\
\hline $\begin{array}{l}\text { 3.1b Instructional strategies } \\
\text { and learning activities are } \\
\text { aligned with district and state } \\
\text { learning goals and } \\
\text { assessment expectations. }\end{array}$ & $\begin{array}{l}\text { Instruction is aligned with } \\
\text { the state and district, } \\
\text { curriculum, and learning } \\
\text { activities require students to } \\
\text { complete assessment tasks } \\
\text { similar to those on state } \\
\text { assessments. }\end{array}$ & $\begin{array}{ll}\text { - } & \text { Unit/Lesson Plans } \\
\text { - } & \text { Assessments (i.e., KCCT, CTBS, } \\
\text { - } & \text { Writing Porttolios } \\
\text { - } & \text { Open Response/On-Demand Writing }\end{array}$ \\
\hline $\begin{array}{l}\text { 3.1c Strategies are } \\
\text { monitored/aligned to address } \\
\text { behavior management needs, } \\
\text { individual student } \\
\text { intelligences, learning styles, } \\
\text { and social skills needs. An } \\
\text { Individual Plan of Instruction } \\
\text { (IPI) and/or Individual } \\
\text { Education Plan (IEP) is } \\
\text { developed for each student. }\end{array}$ & $\begin{array}{l}\text { Leadership monitors } \\
\text { unit/lesson plans and } \\
\text { instruction; ensures that } \\
\text { learning needs and styles } \\
\text { are addressed; and supports } \\
\text { instruction that is connected } \\
\text { to real-life experiences. }\end{array}$ & 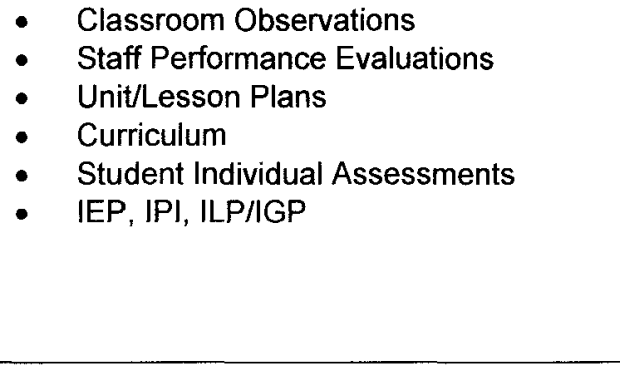 \\
\hline $\begin{array}{l}\text { 3.1d Teachers demonstrate } \\
\text { the content knowledge } \\
\text { needed to motivate students } \\
\text { to high levels of learning. }\end{array}$ & $\begin{array}{l}\text { Certified teachers in specific } \\
\text { content areas are recruited } \\
\text { and assigned to certified } \\
\text { areas; participate in PD; } \\
\text { demonstrate content } \\
\text { knowledge and } \\
\text { communication skills. }\end{array}$ & $\begin{array}{ll}\text { - } & \text { Certificates, Diplomas, References } \\
\text { - } & \text { Teacher Interview Results } \\
\text { - } & \text { Individual Growth Plans } \\
\text { - } & \text { Observation } \\
\text { - } & \text { Evaluation } \\
\text { - } & \text { PDMorkshop Attendance and Collegial } \\
& \text { Collaboration } \\
\end{array}$ \\
\hline $\begin{array}{l}\text { 3.1e Teachers } \\
\text { incorporate technology } \\
\text { in the classroom. }\end{array}$ & $\begin{array}{l}\text { Technology is an } \\
\text { integral part of } \\
\text { instruction; used } \\
\text { regularly; and is } \\
\text { available and } \\
\text { accessible to all } \\
\text { students. }\end{array}$ & $\begin{array}{l}\text { - } \quad \text { Unit/Lesson Plans } \\
\text { - } \text { Observation } \\
\text { - } \quad \text { Hardware, Software, Internet } \\
\text { Laboratories and Learning } \\
\text { Centers }\end{array}$ \\
\hline $\begin{array}{l}\text { 3.1f Instructional } \\
\text { resources are sufficient } \\
\text { to effectively deliver the } \\
\text { curriculum. }\end{array}$ & $\begin{array}{l}\text { A variety of print and } \\
\text { electronic resources } \\
\text { are available that } \\
\text { reflect diversity, } \\
\text { multiculturalism, and } \\
\text { are developmentally } \\
\text { appropriate. }\end{array}$ & $\begin{array}{l}\text { - Equipment, Supplies, Materials } \\
\text { - } \quad \text { Curriculum } \\
\text { - } \text { Textbooks, Media Center } \\
\text { - Availability } \\
\text { - Unit/Lesson Plans }\end{array}$ \\
\hline
\end{tabular}




\begin{tabular}{|c|c|c|}
\hline $\begin{array}{l}\text { 3.1g Teachers review student } \\
\text { work for curriculum, } \\
\text { instructional, and assessment } \\
\text { implications. }\end{array}$ & $\begin{array}{l}\text { Teachers meet regularly to } \\
\text { analyze student work, } \\
\text { writing samples, and } \\
\text { released items: and apply a } \\
\text { process to examine student } \\
\text { work. }\end{array}$ & $\begin{array}{ll}\text { - } & \text { Schedule/Meeting Minutes } \\
\text { - } & \text { Portfolios, On-Demand Writing } \\
\text { Samples } \\
\text { - } \quad \text { KCCT Released Items } \\
\text { - Open Response/Multiple Choice Test } \\
\text { Results } \\
\text { - Program of Studies/Core Content for } \\
\text { Assessment Categories and Sub- } \\
\text { Category Analysis Results }\end{array}$ \\
\hline $\begin{array}{l}\text { *3.a High-quality academic } \\
\text { instruction that is aligned with } \\
\text { individual student learning } \\
\text { needs is evident. }\end{array}$ & $\begin{array}{l}\text { Teachers use direct } \\
\text { instruction and learning } \\
\text { strategies; control for } \\
\text { difficulty of instruction; use } \\
\text { small, interactive groups; } \\
\text { and employ directed } \\
\text { response and questioning of } \\
\text { students. }\end{array}$ & $\begin{array}{ll}\text { - } & \text { Observation } \\
\text { - } & \text { Unit/Lesson Plans } \\
\text { - } & \text { IEP, IPI, ILP/IGP } \\
\text { - } & \text { Supplemental and Extended } \\
& \text { Curriculum }\end{array}$ \\
\hline $\begin{array}{l}\text { *3.b Highly structured } \\
\text { classrooms include behavior } \\
\text { management and student } \\
\text { self-management skill } \\
\text { instruction. }\end{array}$ & $\begin{array}{l}\text { Teachers use point level } \\
\text { systems for structure; self- } \\
\text { management skills are } \\
\text { taught; high rates of positive } \\
\text { reinforcement are observed; } \\
\text { high academic expectations } \\
\text { are stressed; and transition } \\
\text { strategies are used. }\end{array}$ & $\begin{array}{ll}\text { - } & \text { Observation } \\
\text { - } & \text { Rules, Routines } \\
\text { - } & \text { Consistency, Fairness } \\
\text { - } & \text { Level/Point Systems } \\
\text { - } & \text { Social Skills Curriculum } \\
\text { - } & \text { IEP, IPI, ILP/IGP }\end{array}$ \\
\hline $\begin{array}{l}\text { *3.c High-quality diagnostic } \\
\text { instruction has value, } \\
\text { meaning, and relevance for } \\
\text { students. }\end{array}$ & $\begin{array}{l}\text { Teachers use diagnostic } \\
\text { instruction to monitor } \\
\text { student learning that are } \\
\text { correlated with the } \\
\text { curriculum. }\end{array}$ & $\begin{array}{ll}\text { - } & \text { Observation/Evaluation } \\
\text { - } & \text { Student Achievement Results } \\
\text { - } & \text { Lesson Plans } \\
\text { - } & \text { Curriculum } \\
\end{array}$ \\
\hline $\begin{array}{l}\text { **3.d All educators meet state } \\
\text { certification requirements. }\end{array}$ & - Yes/No & - $\quad$ Certificates \\
\hline
\end{tabular}

* Alternative Education Research-Based Strategies

** KECSAC (documentation required) 


\section{LEARNING ENVIRONMENT}

\section{Standard 4 - Culture}

The district, schools, and program function as an effective learning community and support a climate conducive to performance excellence.

\begin{tabular}{|c|c|c|}
\hline Indicators & Descriptors & Evidence \\
\hline $\begin{array}{l}\text { 4.1a leadership supports a } \\
\text { safe, orderly, and equitable } \\
\text { learning environment. }\end{array}$ & $\begin{array}{l}\text { Physical structures of the } \\
\text { school are safe; policies and } \\
\text { practices are consistently } \\
\text { enforced; academic and } \\
\text { behavior standards are } \\
\text { defined; and the learning } \\
\text { environment is evaluated } \\
\text { regularly. }\end{array}$ & $\begin{array}{ll}\text { - } & \text { Safe School Data } \\
\text { - } & \text { Code of Conduct } \\
\text { - } & \text { Misfi, Family, Student Handbook and Belief Statements } \\
\text { - } & \text { Office Referrals } \\
\text { - } & \text { Physical Plant } \\
\text { - } & \text { Safe School Assessment (Kentucky } \\
& \text { Center for School Safety) } \\
\text { - } & \text { District Comprehensive School } \\
& \text { Improvement Plan } \\
\end{array}$ \\
\hline $\begin{array}{l}\text { 4.1b leadership, teachers, } \\
\text { treatment, and other support } \\
\text { staff believe and strive for } \\
\text { high achievement. }\end{array}$ & $\begin{array}{l}\text { Leadership supports mission } \\
\text { and belief statements; } \\
\text { promotes programs for } \\
\text { families and communities; } \\
\text { shares successes; focuses } \\
\text { on academic achievement } \\
\text { for all students; and creates } \\
\text { a schedule for teacher } \\
\text { collaboration. }\end{array}$ & $\begin{array}{ll}\text { - } & \text { Mission Statement, Belief System, } \\
& \text { Rules, Routines } \\
\text { - } \quad \text { Family/Guardian Involvement Activities } \\
\text { - } \quad \text { Community Involvement Activities } \\
\text { - } \quad \text { Master Schedule }\end{array}$ \\
\hline $\begin{array}{l}\text { 4.1d leadership, teachers, } \\
\text { treatment, and other support } \\
\text { staff are involved in a } \\
\text { collaborative decision-making } \\
\text { process. }\end{array}$ & $\begin{array}{l}\text { Staff (teaching and non- } \\
\text { teaching) is guided by } \\
\text { mission and belief } \\
\text { statements and practice } \\
\text { effective decision-making } \\
\text { skills; a committee structure } \\
\text { exists; and the climate } \\
\text { encourages support and } \\
\text { growth. }\end{array}$ & $\begin{array}{l}\text { - } \quad \text { Committee and Work Group Meetings } \\
\text { Schedule and Minutes of Meetings } \\
\text { - } \quad \text { Observation } \\
\text { - Interviews } \\
\text { - Professional Development }\end{array}$ \\
\hline $\begin{array}{l}\text { 4.1g Teachers communicate } \\
\text { student progress. }\end{array}$ & $\begin{array}{l}\text { Parents/guardians are } \\
\text { contacted on a regular basis } \\
\text { and progress reports are } \\
\text { sent home or to DJJ/DCBS } \\
\text { staff. }\end{array}$ & $\begin{array}{l}\text { - Progress Reports, Conferences, E-Mail, } \\
\text { Telephone } \\
\text { - Interviews }\end{array}$ \\
\hline
\end{tabular}




\begin{tabular}{|c|c|c|}
\hline $\begin{array}{l}\text { 4.1h Teachers demonstrate a } \\
\text { concern for students and inspire their } \\
\text { best efforts. }\end{array}$ & $\begin{array}{l}\text { Teachers have high } \\
\text { academic and behavioral } \\
\text { expectations for all } \\
\text { children; use motivating } \\
\text { and engaging } \\
\text { instructional strategies; } \\
\text { and access support } \\
\text { when needed. }\end{array}$ & $\begin{array}{l}\text { - } \text { Academic Guidelines } \\
\text { - } \quad \text { Discipline Guidelines } \\
\text { Universal School-Wide, Targeted, } \\
\text { and Intensive } \\
\text { Prevention/Intervention Strategies } \\
\text { - } \quad \text { Lesson Plans } \\
\text { IEP, IPI, ILP/IGP } \\
\text { Modeling }\end{array}$ \\
\hline $\begin{array}{l}\text { * } 4 . \text { Equity and diversity are valued. } \\
\text { All aspects of the program reflect } \\
\text { consistency, uniformity, fairness, and } \\
\text { support by all staff. }\end{array}$ & $\begin{array}{l}\text { Physical, cultural, socio- } \\
\text { economic, racial/ethnic, } \\
\text { disability, and gender } \\
\text { differences among all } \\
\text { staff and students are } \\
\text { considered before } \\
\text { program and service } \\
\text { decisions are made. } \\
\text { Equipment, supplies, and } \\
\text { materials are distributed } \\
\text { equitably among all staff } \\
\text { for each student. }\end{array}$ & $\begin{array}{ll}- & \text { Program Improvement Plan } \\
\text { - } & \text { Budget } \\
\text { - } & \text { Equipment, Supplies, Material } \\
& \text { Availability } \\
\text { - } & \text { Rules and Routines } \\
\text { - Observation of Dignity and } \\
& \text { Respect for One Another }\end{array}$ \\
\hline $\begin{array}{l}\text { *4.b Highly structured classrooms } \\
\text { include } \\
\text { behavior management and provide } \\
\text { opportunities for high rates of positive } \\
\text { reinforcement. }\end{array}$ & $\begin{array}{l}\text { Teachers use a } \\
\text { behavioral management } \\
\text { plan, provide positive } \\
\text { reinforcement, stress } \\
\text { high expectations, and } \\
\text { encourage transitions. }\end{array}$ & $\begin{array}{ll}\text { - } & \text { Observation } \\
\text { - } & \text { Rules, Routines } \\
\text { - } & \text { Consistency, Fairness } \\
\text { - } & \text { Level/Point Systems } \\
\text { - } & \text { Social Skills Curriculum } \\
\text { - } & \text { IEP, IPI, ILP/IGP } \\
\end{array}$ \\
\hline $\begin{array}{l}\text { *4.c Positive rather than punitive } \\
\text { emphasis on behavior management } \\
\text { offers rewards for acceptable } \\
\text { behavior. }\end{array}$ & $\begin{array}{l}\text { Rewards are given for } \\
\text { acceptable behavior; } \\
\text { classroom rules are clear } \\
\text { and directly taught; and } \\
\text { initial rich reinforcement } \\
\text { fades to normal levels as } \\
\text { behaviors improve. }\end{array}$ & $\begin{array}{ll}\text { - } & \text { Rewards System (i.e. } \\
& \text { Assemblies, Certificates, Field } \\
& \text { Trips, Tangible and Verbal } \\
& \text { Reinforcement) } \\
\text { - } & \text { Point/Level Systems } \\
\text { - } & \text { Behavior Modification Plans } \\
\text { - } & \text { Code of Conduct } \\
\text { - Universal, Targeted, Intensive } \\
\text { - Intervention Strategies } \\
\text { - IEP IPI, ILP/IGP } \\
\end{array}$ \\
\hline $\begin{array}{l}* * 4 . d \text { The teacher pupil ratio for on- } \\
\text { site state agency school programs } \\
\text { shall average, based on annual } \\
\text { average daily attendance, no more } \\
\text { than ten (10) students to (1) teacher } \\
\text { without a classroom aid and fifteen } \\
\text { (15) students to one (1) teacher with } \\
\text { a classroom aid. }\end{array}$ & - Yes/No & $\begin{array}{ll}\text { - } & \text { Program Reports } \\
\text { - } & \text { KECSAC Census Data } \\
\text { - } & \text { Average Daily Attendance }\end{array}$ \\
\hline $\begin{array}{l}\text { Alternative Education Researo } \\
\text { KECSAC (documentation requir }\end{array}$ & 5 & \\
\hline
\end{tabular}




\section{Standard 5 - Support}

The district, schools, and program work with families and community groups to remove barriers to learning in an effort to meet the intellectual, social, career, and developmental needs of students.

\begin{tabular}{|c|c|c|}
\hline Indicators & Descriptors & Evidence \\
\hline $\begin{array}{l}\text { 5.1a Families and communities } \\
\text { are active partners in the } \\
\text { educational process and work } \\
\text { with internal school/district and } \\
\text { external community partners to } \\
\text { promote programs and services } \\
\text { for all students. }\end{array}$ & $\begin{array}{l}\text { Family programs are available; } \\
\text { partnerships between the } \\
\text { program and the community } \\
\text { exist; and students have an } \\
\text { opportunity to be involved in the } \\
\text { community. }\end{array}$ & $\begin{array}{ll}\text { - } & \text { Family/Parent and } \\
& \text { Community Involvement } \\
& \text { Activities } \\
\text { - } & \text { Meeting Schedule and } \\
& \text { Minutes } \\
\text { - } & \text { Service Learning } \\
\text { - } & \text { School-To-Work } \\
\text { - } & \text { Advisory Council } \\
\end{array}$ \\
\hline $\begin{array}{l}5.1 \mathrm{~b} \text { Structures are in place to } \\
\text { ensure that all students have } \\
\text { access to all curricula. }\end{array}$ & $\begin{array}{l}\text { Participation in ESS programs is } \\
\text { monitored and designed to } \\
\text { support and promote individual } \\
\text { student achievement. Targeted } \\
\text { students receive support } \\
\text { services from ESS, FRYSC, Title } \\
\text { I, and guidance counselors. }\end{array}$ & $\begin{array}{ll}\text { - } & \text { Master Schedule } \\
\text { - } & \text { Individual Student } \\
& \text { Schedules } \\
\text { - } & \text { Full Service Commitment } \\
\text { - } & \text { ESS/FRYSC/Title 1 Student } \\
& \text { Roster }\end{array}$ \\
\hline $\begin{array}{l}5.1 \mathrm{c} \text { Organizational structures } \\
\text { and supports are in place to } \\
\text { reduce barriers to learning. }\end{array}$ & $\begin{array}{l}\text { A variety of instructional } \\
\text { resources and materials are } \\
\text { available; written policy exists to } \\
\text { refer students for all health } \\
\text { needs; strategies are developed } \\
\text { for students with learning } \\
\text { problems; all teachers receive } \\
\text { PD to support individual } \\
\text { professional growth; instructional } \\
\text { grouping is used; and adequate } \\
\text { financial resources are allocated. }\end{array}$ & $\begin{array}{ll} & \text { Educational and Treatment } \\
& \text { Staff Collaboration (i.e., } \\
& \text { Title I, FRYSC, DJJ, DCBS, } \\
& \text { IDEA, KETS, Grants) } \\
\text { - } & \text { PD Calendar } \\
\text { - } & \text { Individual Growth Plans } \\
\text { - } & \text { Unit/Lesson Plans } \\
-\quad & \text { Written Policies } \\
\text { - } & \text { Budget }\end{array}$ \\
\hline $\begin{array}{l}\text { 5.1d Students are given } \\
\text { instructional support beyond the } \\
\text { school day and outside of the } \\
\text { classroom. }\end{array}$ & $\begin{array}{l}\text { Communication exists among } \\
\text { classroom teachers, ESS, and } \\
\text { FRYSC staff. ESS is used to } \\
\text { promote student achievement; } \\
\text { assessment strategies are used } \\
\text { to identify individual needs; co- } \\
\text { curricular programs exist; } \\
\text { students have opportunities for } \\
\text { citizenship and service learning; } \\
\text { and practices are monitored } \\
\text { regularly. }\end{array}$ & $\begin{array}{ll} & \text { Meeting Schedule/Minutes } \\
\text { - } & \text { Student Assessments } \\
\text { - } & \text { Mnitt/Les Schedule } \\
\text { - } & \text { Curriculum Plans } \\
\text { - } & \text { ESS/FRYSC/Title 1 Student } \\
& \text { Roster } \\
\text { - } & \text { Mentoring } \\
\text { - } & \text { Tutoring }\end{array}$ \\
\hline
\end{tabular}




\begin{tabular}{|l|l|l|}
\hline $\begin{array}{l}\text { 5.1e An accurate student } \\
\text { record system is in place to } \\
\text { provide timely information } \\
\text { about student academic and } \\
\text { non-academic results. }\end{array}$ & $\begin{array}{l}\text { A student profile of } \\
\text { academic development is } \\
\text { maintained; multiple sources } \\
\text { of data are reflected; and } \\
\text { technology is used. }\end{array}$ & $\bullet \begin{array}{l}\text { STI/SSTS } \\
\text { Cumulative/Due Process Folder } \\
\text { IEP, IPI, ILP/IGP }\end{array}$ \\
$\begin{array}{l}\text { *5.a Adult mentors provide } \\
\text { positive reinforcement. }\end{array}$ & $\begin{array}{l}\text { The mentoring plan includes } \\
\text { training for positive } \\
\text { reinforcement, building } \\
\text { relationships to establish } \\
\text { trust; and tracking and } \\
\text { support for achievement, } \\
\text { behavior, attendance, and } \\
\text { attitude improvement. }\end{array}$ & $\bullet \begin{array}{l}\text { Mentoring Plan } \\
\text { Schedule/Meeting Minutes }\end{array}$ \\
\hline
\end{tabular}

* Alternative Education Research-Based Strategies 


\section{Standard 6 - Professional Development}

The district, schools, and program provide research-based, results-driven professional development opportunities for staff and implement performance evaluation procedures in order to improve teaching and learning.

\begin{tabular}{|c|c|c|}
\hline Indicators & Descriptors & Evidence \\
\hline $\begin{array}{l}\text { 6.1a Long-term } \\
\text { professional growth needs } \\
\text { are met for all staff. }\end{array}$ & $\begin{array}{l}\text { A long-term plan exists to enhance } \\
\text { leadership abilities; develop a change } \\
\text { process over time; and support } \\
\text { professional growth needs. }\end{array}$ & $\begin{array}{l}\text { - Needs Assessment Data } \\
\text { - } \quad \text { Program Improvement Plan } \\
\text { - } \quad \text { Individual Growth Plans } \\
\text { - } \quad \text { PD Schedule } \\
\text { - } \quad \text { Intaff/Faculty Handbook } \\
\text { - Interviews }\end{array}$ \\
\hline $\begin{array}{l}\text { 6.1b Staff capacity is built } \\
\text { for administrators, } \\
\text { teachers, treatment, and } \\
\text { other support staff with on- } \\
\text { going PD. }\end{array}$ & $\begin{array}{l}\text { The district, schools, and program } \\
\text { have identified the instructional needs } \\
\text { of all staff; individual and program- } \\
\text { wide needs are addressed and } \\
\text { identified through a formal process. }\end{array}$ & $\begin{array}{ll}\text { - } & \text { Staff Needs Assessment } \\
& \text { Survey } \\
\text { - } & \text { New Educator Training } \\
& \text { Attendance } \\
\text { - } & \text { Conferences and Workshop } \\
& \text { Schedule } \\
\text { - } & \text { Performance Evaluations } \\
\text { - } & \text { Individual Growth Plans } \\
\text { - } & \text { Progran Improvement Plan } \\
\end{array}$ \\
\hline $\begin{array}{l}\text { 6.1c Staff development is } \\
\text { aligned with student } \\
\text { performance goals. }\end{array}$ & $\begin{array}{l}\text { PD has a direct connection to student } \\
\text { learning goals; identified through an } \\
\text { evaluation process; and is on-going } \\
\text { and job-embedded. }\end{array}$ & $\begin{array}{ll} & \text { Needs Assessment } \\
& \text { Data/Disaggregated Data } \\
\text { - } & \text { Program Improvement Plan } \\
\text { - } & \text { PD Plan } \\
\text { - } & \text { IEP, IPI }\end{array}$ \\
\hline $\begin{array}{l}\text { 6.1e PD is on-going, and } \\
\text { job-embedded. }\end{array}$ & $\begin{array}{l}\text { PD emphasizes sustained and } \\
\text { continuous growth through traditional } \\
\text { and non-traditional avenues; provides } \\
\text { time for collaboration; encourages } \\
\text { mentorship models and follow-up } \\
\text { skills; and reinforces new learning. }\end{array}$ & $\begin{array}{ll}\text { - } & \text { PD Plan/Schedule } \\
\text { - } & \text { Mnit/lesson Plans } \\
\text { - } & \text { Menter Schedule Plan } \\
\text { - } & \text { Evaluation Plan } \\
\end{array}$ \\
\hline
\end{tabular}




\begin{tabular}{|c|c|c|}
\hline $\begin{array}{l}\text { 6.2b leadership provides } \\
\text { sufficient PD resources. }\end{array}$ & $\begin{array}{l}\text { Adequate financial resources are } \\
\text { provided, and a process to evaluate } \\
\text { appropriateness exists. }\end{array}$ & $\begin{array}{ll}\text { - } & \text { Budget } \\
\text { - } & \text { Program Improvement Plan } \\
\text { - } & \text { PD Plan } \\
\text { - } & \text { Staff/Faculty Handbook } \\
\text { - } & \text { Individual Growth Plan } \\
\end{array}$ \\
\hline $\begin{array}{l}6.2 e \text { Instructional } \\
\text { leadership needs are } \\
\text { addressed in the } \\
\text { comprehensive } \\
\text { district/school/program } \\
\text { improvement plan. }\end{array}$ & $\begin{array}{l}\text { The District/Program Improvement } \\
\text { Plan is based on multiple forms of } \\
\text { data; leadership regularly reviews } \\
\text { components of the plan; and PD is } \\
\text { addressed in individual growth plans. }\end{array}$ & $\begin{array}{ll}\text { - } & \text { Student, Staff, and Program } \\
\text { Needs Assessment Data } \\
\text { - } \quad \text { Faculty Meeting } \\
\text { Schedule/Minutes } \\
\text { - Individual Growth } \\
\text { Plans } \\
\text { - } \quad \text { PD Plan } \\
\end{array}$ \\
\hline $\begin{array}{l}\text { 6.2f leadership provides } \\
\text { evaluation and follow-up } \\
\text { support in line with district } \\
\text { procedures, and the } \\
\text { program has a clearly } \\
\text { defined staff evaluation } \\
\text { process. }\end{array}$ & $\begin{array}{l}\text { PD growth plans are based on formal } \\
\text { evaluations; leadership provides } \\
\text { assistance with meaningful feedback; } \\
\text { growth plans are aligned with the } \\
\text { Program Improvement Plan; and } \\
\text { resources and avenues of support are } \\
\text { available. }\end{array}$ & $\begin{array}{ll}\text { - } & \text { Individual Growth Plans } \\
\text { - } & \text { Program Improvement Plan } \\
\text { - } & \text { Performance Evaluations } \\
\text { - } & \text { Clinical Supervision } \\
\text { - } & \text { Master Schedule } \\
\text { - } \quad \text { Interviews } \\
\end{array}$ \\
\hline $\begin{array}{l}{ }^{*} 6 . \text { E Education and } \\
\text { treatment staffs use PD } \\
\text { and student needs } \\
\text { assessment data to } \\
\text { identify interventions and } \\
\text { measure specific; student } \\
\text { outcomes. }\end{array}$ & $\begin{array}{l}\text { Meetings take place to determine } \\
\text { individual, classroom, and treatment } \\
\text { PD needs that provide individual } \\
\text { students with academic, emotional, } \\
\text { social, and behavioral support. }\end{array}$ & $\begin{array}{ll}\text { - } & \text { Student Needs } \\
& \text { Assessment Data } \\
\text { - } & \text { Staff Needs Survey } \\
\text { - Individual Growth } \\
\text { Plans } \\
\text { - } \quad \text { Program Improvement Plan }\end{array}$ \\
\hline $\begin{array}{l}{ }^{* *} 6 . b \text { An individual growth } \\
\text { plan is available and is } \\
\text { supported by an individual } \\
\text { professional development } \\
\text { plan for all education staff. }\end{array}$ & $\begin{array}{l}\text { Teachers review student needs } \\
\text { assessment data to determine their } \\
\text { individual PD needs. }\end{array}$ & $\begin{array}{ll} & \text { Individual Growth Plans } \\
\text { - } & \text { Staff Surveys } \\
\text { - } & \text { Needs Assessment Data } \\
\text { - } & \text { Performance } \\
& \text { Evaluation Report } \\
\text { - } & \text { PD Plan } \\
\text { - } & \text { Administrators and Teachers } \\
\end{array}$ \\
\hline
\end{tabular}

* Alternative Education Research-Based Strategies

** KECSAC (documentation required) 


\section{EFFICIENCY}

\section{Standard 7 - leadership}

District, schools, and program instructional decisions focus on support for teaching and learning, organizational direction, high performance expectations, creating a learning culture and developing leadership capacity.

\begin{tabular}{|c|c|c|}
\hline Indicators & Descriptors & Evidence \\
\hline $\begin{array}{l}\text { 7.1b leadership decisions } \\
\text { are collaborative and data- } \\
\text { driven. }\end{array}$ & $\begin{array}{l}\text { State assessment data is analyzed to } \\
\text { make decisions focused on academic } \\
\text { performance, and a variety of data } \\
\text { sources is used. }\end{array}$ & $\begin{array}{l}\text { - } \quad \text { Program Improvement Plan } \\
\text { - } \quad \text { Meeting Schedule/Minutes } \\
\text { - } \quad \text { Formal and Informal } \\
\text { Assessment Data }\end{array}$ \\
\hline $\begin{array}{l}\text { 7.1d leadership } \\
\text { disaggregates data and } \\
\text { decisions are based on } \\
\text { this data. }\end{array}$ & $\begin{array}{l}\text { Academic achievement data is } \\
\text { analyzed to inform decision-making for } \\
\text { diverse populations, including income } \\
\text { level, race/ethnicity, disability, and } \\
\text { gender. }\end{array}$ & $\begin{array}{l}\text { - } \quad \text { CATS Achievement Data } \\
\text { Sub-Group Population CATS } \\
\text { Data (i.e., gender, } \\
\text { race/ethnicity, disability, } \\
\text { poverty) }\end{array}$ \\
\hline $\begin{array}{l}\text { 7.1k leadership } \\
\text { demonstrates academic } \\
\text { performance, learning } \\
\text { environment, and } \\
\text { efficiency skills. }\end{array}$ & $\begin{array}{l}\text { The program leader is viewed as the } \\
\text { instructional leader and engages staff } \\
\text { in discussions about student } \\
\text { performance. Academic issues are } \\
\text { addressed at faculty meetings; } \\
\text { curriculum is reviewed; formal and } \\
\text { informal observations are conducted; } \\
\text { and meaningful feedback is provided } \\
\text { to create a positive learning } \\
\text { environment. }\end{array}$ & $\begin{array}{l}\text { - } \quad \text { Individual Growth Plan } \\
\text { - } \quad \text { Needs Assessment Data } \\
\text { - } \quad \text { Meeting Schedule/Minutes } \\
\text { - } \quad \text { Staff Performance Evaluations } \\
\text { - } \quad \text { Program Improvement Plan }\end{array}$ \\
\hline $\begin{array}{l}* \star 7 . \text { a leadership works } \\
\text { collaboratively with staff, } \\
\text { students, } \\
\text { parents/guardians, } \\
\text { families, and communities } \\
\text { for involvement and } \\
\text { effectiveness. }\end{array}$ & $\begin{array}{l}\text { Parent/family and community activities } \\
\text { exist and are used to identify program, } \\
\text { staff, and student needs. }\end{array}$ & $\begin{array}{l}\text { - } \quad \text { Parent Improvement Activities } \\
\text { - } \quad \text { Activities } \\
\text { - } \quad \text { Program Improvement Plans }\end{array}$ \\
\hline $\begin{array}{l}\text { *7.b leadership } \\
\text { interviews perspective } \\
\text { new teachers and } \\
\text { provides the local school } \\
\text { district with interview } \\
\text { results. }\end{array}$ & $\begin{array}{l}\text { Procedures and practices are in place } \\
\text { to identify new teachers; interviews are } \\
\text { conducted; certification is considered; } \\
\text { and program selection is based on } \\
\text { student needs. }\end{array}$ & $\begin{array}{ll}- & \text { Student Needs Assessment } \\
& \text { Data } \\
\text { - Interview Schedule } \\
\text { - Interview Recommendations } \\
\text { - } \quad \text { Program Improvement Plan }\end{array}$ \\
\hline $\begin{array}{l}\text { **.c leadership } \\
\text { designates a school } \\
\text { administrator who is the } \\
\text { instructional leader for the } \\
\text { educational program. }\end{array}$ & Yes/No & \\
\hline
\end{tabular}




\begin{tabular}{|l|l|l|}
\hline $\begin{array}{l}\text { **7.d Designated School } \\
\text { Administrator attends } \\
\text { required State Agency } \\
\begin{array}{l}\text { Children School } \\
\text { Administrator Association } \\
\text { (SACSAA) meetings. }\end{array}\end{array}$ & Yes/No & $\begin{array}{l}\text { Register } \\
\text { Sign-In Sheet } \\
\text { Complete Evaluation Form }\end{array}$ \\
\hline $\begin{array}{l}\text { **7.e leadership reinforces } \\
\text { the program mission, } \\
\text { beliefs, and goals. }\end{array}$ & $\begin{array}{l}\text { The program uses a collaborative } \\
\text { decision-making process that includes } \\
\text { all stakeholders to develop mission } \\
\text { and belief statements. These } \\
\text { statements are honored within the } \\
\text { program, classrooms, and among } \\
\text { students. }\end{array}$ & $\bullet \begin{array}{l}\text { Parent/Family and Student } \\
\text { Handbook } \\
\text { Staff Handbook } \\
\text { Sharing of SACSAA Information }\end{array}$ \\
\hline $\begin{array}{l}\text { **7.f leadership regulates } \\
\text { policies, establishes } \\
\text { procedures, and reinforces } \\
\text { practices to create a } \\
\text { positive climate. }\end{array}$ & $\begin{array}{l}\text { A positive learning environment exists } \\
\text { and is reflected in the program's } \\
\text { culture and climate. }\end{array}$ & $\bullet \begin{array}{l}\text { Observation/Interviews } \\
\text { Safe School Data }\end{array}$ \\
\hline
\end{tabular}

*Alternative Education Research-Based Strategies

* KECSAC (documentation required) 


\section{Standard 8 - Resources/Organization}

The program is organized to maximize the use of all available resources to support high student and staff performance.

\begin{tabular}{|c|c|c|}
\hline Indicators & Descriptors & Evidence \\
\hline $\begin{array}{l}\text { 8.1a Program is organized } \\
\text { to maximize use of all } \\
\text { available resources to } \\
\text { support high student and } \\
\text { staff expectations }\end{array}$ & $\begin{array}{l}\text { Resources are allocated equitably; } \\
\text { expansion of resources outside the } \\
\text { school exists; the budgeting process } \\
\text { involves staff; policies exist regarding } \\
\text { resource management; the master } \\
\text { schedule allows for teacher } \\
\text { collaboration; and committees are } \\
\text { used when appropriate. }\end{array}$ & $\begin{array}{ll}\text { - } & \text { Budget } \\
\text { - } & \text { Master Schedule } \\
\text { - } & \text { Scculty Meeting } \\
\text { - } & \text { Committee Representation } \\
\text { - } & \text { Average Daily Attendance }\end{array}$ \\
\hline $\begin{array}{l}\text { 8.1b Master and student } \\
\text { schedules reflect that all } \\
\text { students have access to } \\
\text { all curricula. }\end{array}$ & $\begin{array}{l}\text { The schedule offers flexibility to all } \\
\text { students; students have equal access } \\
\text { to all classes; and student course } \\
\text { offerings are aligned with state } \\
\text { documents. }\end{array}$ & $\begin{array}{ll}\text { - } & \text { Master Schedule } \\
\text { - } & \text { School Calendar } \\
\text { - } & \text { Individual Student Schedules } \\
\text { - } & \text { Student Transcripts } \\
& \text { ILP/IGP } \\
\end{array}$ \\
\hline $\begin{array}{l}\text { 8.1c Staff is allocated and } \\
\text { organized according to the } \\
\text { learning needs of } \\
\text { students. }\end{array}$ & $\begin{array}{l}\text { Staff is assigned based on student } \\
\text { performance; all teachers are certified; } \\
\text { student/teacher ratios are maintained; } \\
\text { room assignments are made for } \\
\text { opportunities to share resources; and } \\
\text { a sufficient number of instructional } \\
\text { assistants is assigned to each } \\
\text { classroom. }\end{array}$ & $\begin{array}{ll} & \text { Needs Assessment Data } \\
\text { - } & \text { Program Improvement Plan } \\
\text { - } & \text { Master Schedus Data } \\
\text { - } & \text { Average Daily Attendance }\end{array}$ \\
\hline $\begin{array}{l}\text { 8.1d Staff makes efficient } \\
\text { use of instructional time to } \\
\text { maximize student learning. }\end{array}$ & $\begin{array}{l}\text { Policies and procedures exist to } \\
\text { protect instructional time; the schedule } \\
\text { is adjusted to accommodate } \\
\text { instructional needs; other programs } \\
\text { that occur during instructional time are } \\
\text { connected to learning goals; and } \\
\text { classroom management and } \\
\text { organizational structure assure that } \\
\text { time is available for instruction. }\end{array}$ & $\begin{array}{ll}\text { - } & \text { Master Schedule } \\
\text { - } & \text { Teacher Assignments } \\
& \text { Scheduly/Other Activity } \\
\text { - School Board Policies } \\
\text { - }\end{array}$ \\
\hline
\end{tabular}




\begin{tabular}{|c|c|c|}
\hline $\begin{array}{l}8.2 \mathrm{a} \\
\text { District/school/program } \\
\text { resources are equitable. }\end{array}$ & $\begin{array}{l}\text { The district, schools, and program } \\
\text { have clearly defined policies and } \\
\text { budgetary procedures; support for } \\
\text { external funding sources exists; } \\
\text { financial records are available; funding } \\
\text { is provided in a timely manner; and } \\
\text { teachers have access to equal fiscal } \\
\text { resources. }\end{array}$ & $\begin{array}{ll}\text { - } & \text { Budget Policy } \\
\text { - } & \text { Munis Reports } \\
\text { - } & \text { Equipment, Supplies, Materials } \\
\text { - } & \text { Allocation Procedures } \\
& \text { Program Improvement Plan }\end{array}$ \\
\hline $\begin{array}{l}8.2 \mathrm{~b} \text { The allocation of } \\
\text { discretionary funds and } \\
\text { resources are data-driven. }\end{array}$ & $\begin{array}{l}\text { Policies and operational procedures } \\
\text { exist for expenditures to support the } \\
\text { mission and belief statements that are } \\
\text { related directly to program needs. }\end{array}$ & $\begin{array}{ll}\text { - } & \text { Budget } \\
\text { - } & \text { Program Improvement Plan } \\
\text { - } & \text { Grant Assessment Data } \\
& \text { Documentation } \\
\end{array}$ \\
\hline $\begin{array}{l}\text { **8.1g Normal accounting } \\
\text { procedures are followed } \\
\text { and records are available. }\end{array}$ & $\begin{array}{l}\text { The district provides the program with } \\
\text { a record system and technical support. }\end{array}$ & $\begin{array}{ll}\text { - } & \text { Record Sheets } \\
\text { - } & \text { Munis System } \\
\text { - } & \text { District Personnel Support } \\
\text { - } & \text { Average Daily Membership } \\
\end{array}$ \\
\hline $\begin{array}{l}* * 8.1 \mathrm{~h} \text { Students are } \\
\text { included in the district } \\
\text { count for the allocation of } \\
\text { technology funds and } \\
\text { have access to KETS } \\
\text { support. }\end{array}$ & $\begin{array}{l}\text { The district ensures that students } \\
\text { receive KETS funding and provides } \\
\text { technical support. }\end{array}$ & $\begin{array}{ll}\text { - } & \text { Hardware, Software, Internet } \\
& \text { access } \\
\text { - } & \text { Records } \\
\text { - } & \text { District/School Staff Support }\end{array}$ \\
\hline $\begin{array}{l}\text { matei Instructional } \\
\text { materials are comparable } \\
\text { (quality/quantity) to those } \\
\text { provided to regular school } \\
\text { students. }\end{array}$ & $\begin{array}{l}\text { Current classroom materials are } \\
\text { appropriate for students enrolled in the } \\
\text { program. }\end{array}$ & $\begin{array}{ll}\text { - } & \text { Per-Pupil Expenditure } \\
\text { - } & \text { Individualized Print and } \\
& \text { Electronic } \\
\text { - } & \text { Textbooks, Audio Visual } \\
& \text { Equipment } \\
\text { - } & \text { Interview } \\
\end{array}$ \\
\hline $\begin{array}{l}* \star 8.1 \mathrm{j} \text { Adequate space is } \\
\text { provided for education and } \\
\text { treatment services that } \\
\text { meet state regulations. }\end{array}$ & $\begin{array}{l}\text { The program is housed in a facility that } \\
\text { is safe, maintained at high standards, } \\
\text { and includes classrooms that are large } \\
\text { enough to accommodate all students. }\end{array}$ & $\begin{array}{ll}\text { - } & \text { Operation \& Maintenance } \\
& \text { Support } \\
\text { - } & \text { Facility Plan } \\
\text { - } & \text { Safe School Plan } \\
\text { - } & \text { Floor Plan } \\
\end{array}$ \\
\hline
\end{tabular}




\section{Standard 9 - Planning}

The district, schools, and program develop, implement, and evaluate a comprehensive and effective plan that communicates a clear purpose, direction, and action plan focused on teaching and learning.

\begin{tabular}{|c|c|c|}
\hline Indicators & Descriptors & Evidence \\
\hline $\begin{array}{l}\text { 9.1 a A collaborative } \\
\text { process is used to define } \\
\text { the program's vision, } \\
\text { mission, belief, and goal } \\
\text { statements. }\end{array}$ & $\begin{array}{l}\text { Collaboration exists in the } \\
\text { development of mission and belief } \\
\text { statements that are data-driven and } \\
\text { finalized through consensus. }\end{array}$ & $\begin{array}{ll}\text { - } & \text { Family/Community Involvement } \\
& \text { Activities } \\
\text { - } & \text { Meeting Schedule/Minutes } \\
\text { - } & \text { Program Improvement Plan } \\
\text { - Staff/Faculty Handbook }\end{array}$ \\
\hline $\begin{array}{l}\text { 9.2a The planning process } \\
\text { includes collecting, } \\
\text { managing and analyzing } \\
\text { academic and non- } \\
\text { academic data. }\end{array}$ & $\begin{array}{l}\text { A systematic process exists for the } \\
\text { collection and analysis of data that } \\
\text { provides an accurate reflection of } \\
\text { program performance; data is } \\
\text { disaggregated, and analyzed to gain } \\
\text { an overall understanding of needs. }\end{array}$ & $\begin{array}{ll} & \text { District Support (District } \\
& \text { Assessment Coordinator) } \\
\text { - } & \text { Program Improvement Plan } \\
\text { - } & \text { Needs Assessment Data } \\
& \text { Analysis } \\
\text { - } & \text { Meeting Schedule/Minutes }\end{array}$ \\
\hline $\begin{array}{l}9.2 b \text { Data is used to } \\
\text { identify priority needs for } \\
\text { program improvement. }\end{array}$ & $\begin{array}{l}\text { Data is used to guide the program } \\
\text { improvement plan, and data } \\
\text { summaries are analyzed and used for } \\
\text { prioritizing improvement needs. }\end{array}$ & $\begin{array}{ll}- & \text { Program Improvement Plan } \\
-\quad & \text { KECSAC Program Improvement } \\
& \text { Report }\end{array}$ \\
\hline $\begin{array}{l}\text { 9.3c Desired results for } \\
\text { student learning are } \\
\text { defined by the program } \\
\text { improvement plan. }\end{array}$ & $\begin{array}{l}\text { A planning team is used to review } \\
\text { data, set meaningful goals, and ensure } \\
\text { that student-learning results are clear } \\
\text { and concise. The planning team } \\
\text { includes internal and external partners. }\end{array}$ & $\begin{array}{l}\text { - } \quad \text { Program Improvement Plan } \\
\text { Implementation and Impact } \\
\text { Checks }\end{array}$ \\
\hline $\begin{array}{l}\text { 9.5a An improvement plan } \\
\text { with goals, objectives, } \\
\text { strategies, activities, } \\
\text { resources, timelines and } \\
\text { person(s) responsible is } \\
\text { developed collaboratively. }\end{array}$ & $\begin{array}{l}\text { The Program Improvement Plan } \\
\text { includes action steps aligned with } \\
\text { goals and objectives that are validated } \\
\text { and research-based. }\end{array}$ & $\begin{array}{l}\text { - Program Improvement Plan } \\
\text { - Needs Assessment Data }\end{array}$ \\
\hline $\begin{array}{l}\text { 9.6d Continuous program } \\
\text { improvement is } \\
\text { demonstrated by } \\
\text { implementation and } \\
\text { impact checks. }\end{array}$ & $\begin{array}{l}\text { The Program Improvement Plan is } \\
\text { monitored and reviewed for progress; } \\
\text { adjustments are made; feedback is } \\
\text { obtained; and new and emerging } \\
\text { targets are identified. }\end{array}$ & $\begin{array}{ll}\text { - } & \text { Annual Program Improvement } \\
\text { Plan Monitoring/Evaluation } \\
\text { - KECSAC Program Improvement } \\
\text { Report } \\
\text { Implementation and Impact } \\
\text { Checks } \\
\end{array}$ \\
\hline $\begin{array}{l}{ }^{* *} 9 . a \text { Student writing } \\
\text { portfolios and/or working } \\
\text { folders are forwarded to } \\
\text { the receiving school as } \\
\text { part of the educational } \\
\text { records when a youth } \\
\text { transitions from a } \\
\text { program. }\end{array}$ & Yes/No & $\begin{array}{ll}\text { - } & \text { Student Records } \\
\text { - } & \text { Educational Passports } \\
\text { - } & \text { Due Process Folder/Cumulative } \\
& \text { Folder } \\
\text { - } & \text { STI/STSS }\end{array}$ \\
\hline
\end{tabular}




\begin{tabular}{|c|c|c|}
\hline $\begin{array}{l}{ }^{*} 9 . b \text { Educational records } \\
\text { are requested from the } \\
\text { sending school. }\end{array}$ & Yes/No & - Communication Records \\
\hline $\begin{array}{l}\text { *9.c Educational records } \\
\text { are forwarded to the } \\
\text { receiving school within } \\
\text { five days following the } \\
\text { release of the student } \\
\text { from the school/program. }\end{array}$ & Yes/No & $\begin{array}{l}\text { - } \quad \text { Communication Records } \\
\text { - } \quad \text { Teacher Record Book }\end{array}$ \\
\hline $\begin{array}{l}{ }^{\star \star} 9 . \mathbf{d} \text { An educational } \\
\text { passport is prepared. }\end{array}$ & Yes/No & $\begin{array}{ll}- & \text { Educational Passport } \\
\text { - } & \text { STI/STSS } \\
\text { - } & \text { Cumulative Folder } \\
& \text { Due Process Folder } \\
\end{array}$ \\
\hline $\begin{array}{l}{ }^{*} 9 . e \text { The Kentucky } \\
\text { Department of Education } \\
\text { mandated number of } \\
\text { instructional days (175) } \\
\text { with 6-hours instructional } \\
\text { time are provided. }\end{array}$ & Yes/No & $\begin{array}{ll}\text { - } & \text { KDE Approved School Calendar } \\
\text { - } & \text { Master Schedule } \\
\text { - } & \text { KECSAnt Schedules } \\
& \text { KECSC Reports }\end{array}$ \\
\hline $\begin{array}{l}\text { **.f An annual } \\
\text { interagency agreement } \\
\text { between the local school } \\
\text { district and the treatment } \\
\text { program exists. }\end{array}$ & Yes/No & - Interagency Agreement \\
\hline $\begin{array}{l}{ }^{*} 9 . \mathrm{g} \text { School personnel } \\
\text { participate in the } \\
\text { treatment planning } \\
\text { meetings. }\end{array}$ & $\begin{array}{l}\text { School administrator, program } \\
\text { administrator, teachers, and support } \\
\text { staff collaborate with treatment staff to } \\
\text { provide academic and non-academic } \\
\text { information regarding students. }\end{array}$ & $\begin{array}{ll}\text { - } & \text { Meeting Schedule/Minutes } \\
\text { - } & \text { ITP } \\
\text { Interviews }\end{array}$ \\
\hline $\begin{array}{l}* * 9 . h \text { Time sheets for } \\
\text { educational and treatment } \\
\text { staff are maintained. }\end{array}$ & Yes/No & - Records \\
\hline $\begin{array}{l}* * . i \text { Personnel who are } \\
\text { assigned to the program } \\
\text { are afforded all the } \\
\text { amenities of school district } \\
\text { faculty and/or staff. }\end{array}$ & $\begin{array}{l}\text { School administrator, teachers and } \\
\text { support staff receive compensation, } \\
\text { benefits, and other employee } \\
\text { amenities that are equitable with } \\
\text { regular school personnel. }\end{array}$ & $\begin{array}{ll}\text { - } & \text { Human Resource Support } \\
\text { - } & \text { Technology } \\
\text { - } & \text { Planning Time } \\
& \text { Materials, Equipment, Supplies }\end{array}$ \\
\hline $\begin{array}{l}\star \star 9 . j \text { The KECSAC } \\
\text { mandated extended } \\
\text { school calendar includes } \\
35 \text { additional days, each } \\
\text { with a minimum of } 4 \text { hours } \\
\text { of direct instruction. }\end{array}$ & Yes/No & $\begin{array}{l}\text { Approved KECSAC and District } \\
\text { Calendar }\end{array}$ \\
\hline $\begin{array}{l}\text { **9.k School personnel } \\
\text { support and participate in } \\
\text { activities to promote } \\
\text { positive student transitions } \\
\text { between schools and } \\
\text { programs. }\end{array}$ & Yes/No & $\begin{array}{ll}\text { - } & \text { Student Transition Plan } \\
\text { - } & \text { Student Transition Folder } \\
\text { - } & \text { Transition Meetings } \\
\text { - } & \text { Transition Counselor }\end{array}$ \\
\hline
\end{tabular}

* Alternative Education Research-Based Strategies

${ }^{* *}$ KECSAC (documentation required) 


\section{KECSAC REFERENCES}

Barr, R. \& Parrett, W. H. (2001). Hope fulfilled for at-risk and violent youth: K-12 programs that work. Needham Heights, MA: Ally and Bacon.

Fitzpatrick, K. A. (1998). Indicators of school of quality. National Study of School Evaluation (NSSE). Schaumburg, IL.

Kentucky Department of Education. (2000). Standards and indicators for school improvement. Frankfort, KY: Author.

Kentucky Department of Education. (2002). Discussion of accountability for A2A6 schools. Frankfort, KY: Author.

Schargel, F. P. \& Smink, J. (2001). Strategies to help solve our school dropout problem. Larchmont, NY: Eye On Education.

Swarts, L. (2001). The influence of research-based systems/strategies on alternative education program safety. Louisville, KY: Unpublished dissertation, University of Louisville.

Swarts, L (2002). Alternative education accountability. Louisville, KY: Sapphire Publishing.

Sprague, J., Walker, H., Nishioka, V., \& Stieber, S. (2000). Skills for success: An empirical evaluation of alternative education interventions for predelinquent and delinquent middle school students. Unpublished manuscript, University of Oregon.

Tobin, T. \& Sprague, J. (1999). Alternative education programs for at-risk youth: Issues, best practices, and recommendations. Oregon School Study Council, University of Oregon. 


\section{CURRICULUM VITAE}

NAME:

ADDRESS:

DOB:

EDUCATION \& TRAINING:

AWARDS:

NATIONAL MEETING PRESENTATIONS:
Rebecca Minton Painter

750 Richardsville $\mathrm{Rd}$.

Bowling Green, KY 42101

Warren County, Kentucky - May 15, 1958

B.S., Elementary Education

Western Kentucky University

$1976-1980$

M.A.E. Educational Administration

Western Kentucky University

$1983-1987$

Rank I Educational Administration

Western Kentucky University

$1997-1998$

Bowling Green School District Teacher of the Year, 2007

Junior Achievement Teacher of the Year, 2005

Cable in the Classroom, Pushing the Envelope, 2005

KECSAC Teacher of the Year, 2003

Women of Achievement Award, 2000

Kentucky Dept. of Ed. Distinguished Educator, 1999

Murray State Teacher Recognition, 1998

Campbellsville Award for Excellence, 1997

B. G. Schools Elementary Teacher of the Year, 1997

Commonwealth Institute for Teachers, 1996 \& 1997

Outstanding Young Educator, 1992

KECSAC, 11-20-02

Educating At-risk Youth Conference

New Educators Training for KECSAC, 9-26-05

Violence Prevention Conference, 5-3-04

Indianapolis National Partnership for Juvenile Services

6-2-03; 6-14-04; 6-7-05; 6-12-07

NPJS presentation for Arkansas, 3-20-07 